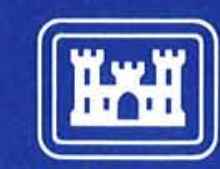

US Army Corps

of Engineers
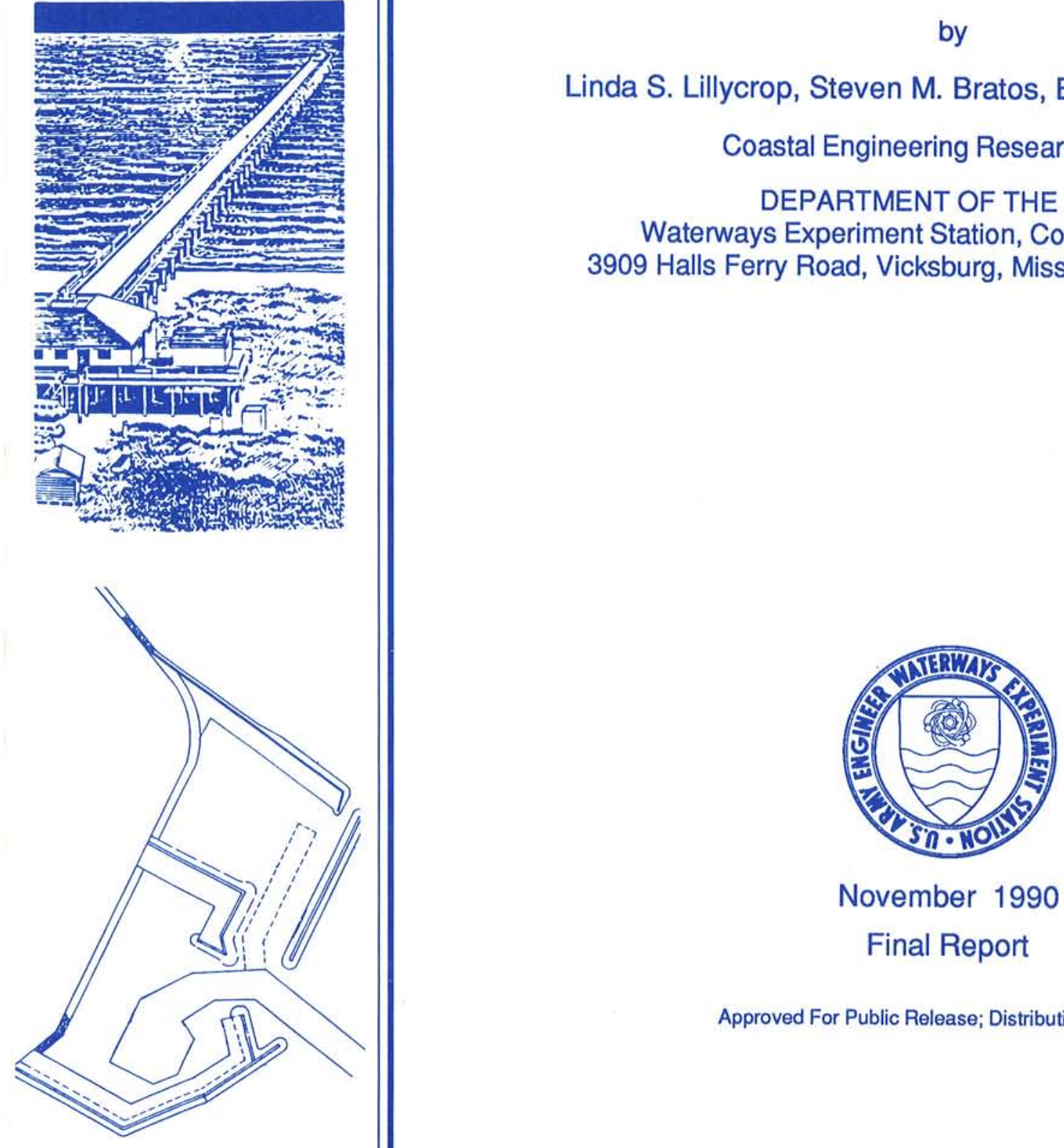

November 1990

Final Report

Approved For Public Release; Distribution Unlimited

Prepared for US Army Engineer Division, Pacific Ocean Honolulu, Hawaii 96858-5400 
Destroy this report when no longer needed. Do not return it to the originator.

The findings in this report are not to be construed as an official Department of the Army position unless so designated by other authorized documents.

The contents of this report are not to be used for advertising, publication, or promotional purposes.

Citation of trade names does not constitute an

official endorsement or approval of the use of such commercial products. 
Unclassified

SECUAIP CLASSIFICA TION OF THIS PAGE

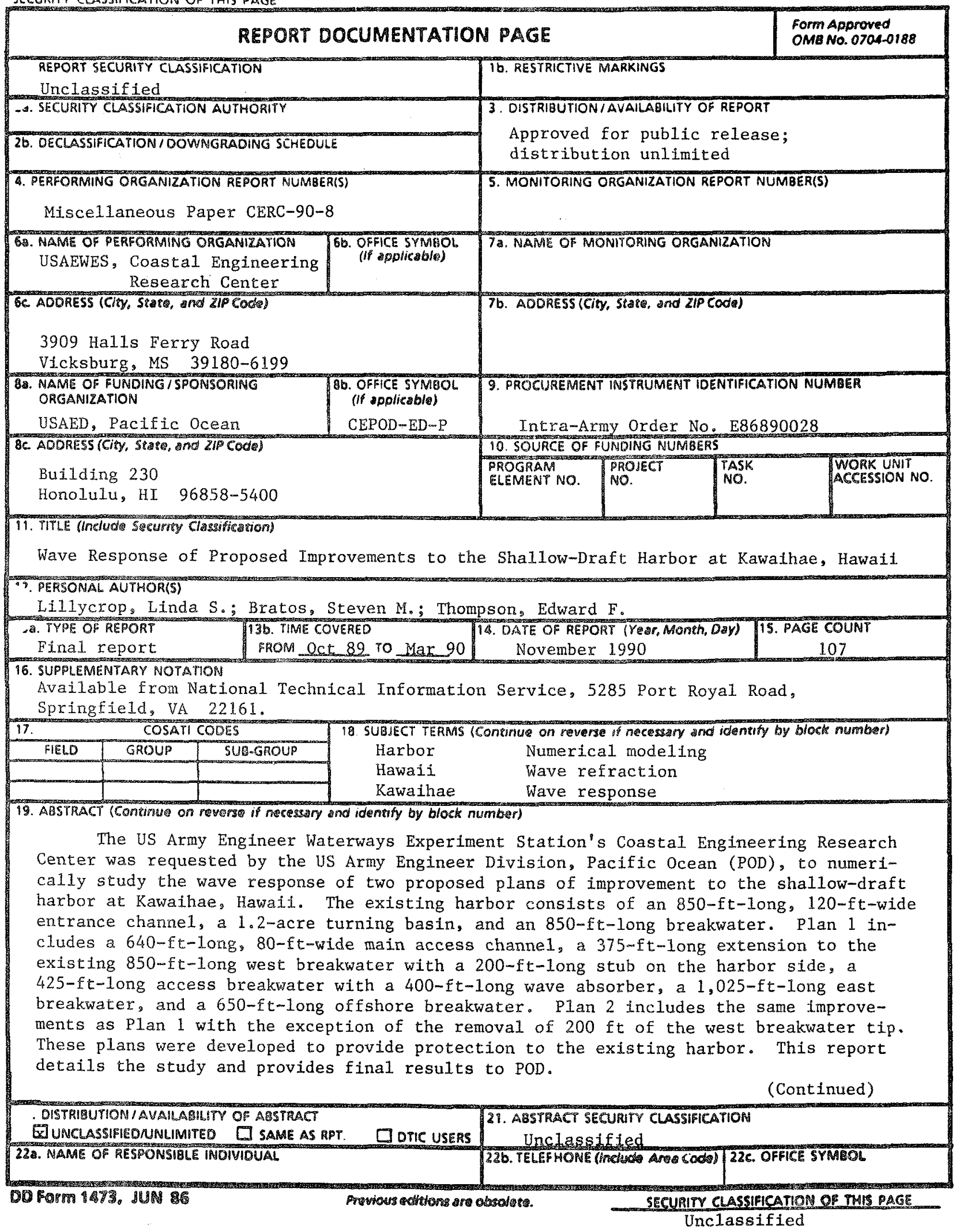


Unclassified

SECURITY CLASSIFICATION OF THIS PAGE

\section{ABSTRACT (Contined)}

Significant wave heights, periods, and directions taken from the Wave Information Studies' hindcast data base were combined with nondirectional wave measurements from the Coastal Field Data Collection Program buoy at Barbers Point, Oahu. The resulting climatological data were input into the Regional Coastal Processes Wave finite differences model and transformed to the Kawaihae Harbor vicinity.

The transformed wave conditions were then input to the Harbor Wave Response finite element model to determine the wave climate inside the harbor. The harbor plans were tested with waves ranging in period from 7 to $20 \mathrm{sec}$ and with westerly approach directions ranging from $202.5 \mathrm{deg}$ (from SSW) to $337.5 \mathrm{deg}$ (from NNW): - A-5:5-ft above mean lower low water storm surge was used.

The results of this study found that Plan 1 met the requirements to adequately protect the harbor from the incident wave climate. It was determined that this plan wi11 keep the wave helght in the harbor berthing areas at $1 \mathrm{ft}$ or lower and in the harbor channels and turning basin at $2 \mathrm{ft}$ or lower approximately 90 percent of the time per year.

Unclassified 


\section{PREFACE}

This study was authorized by the US Army Engineer Division, Pacific Ocean (POD), and was conducted during the period October 1989 through March 1990 by the personnel of the Coastal Oceanography Branch (COB), Research Division (RD), Coastal Engineering Research Center (CERC), of the US Army Engineer Waterways Experiment Station (WES). Mr. John H. Lockhart, Jr., Headquarters, US Army Corps of Engineers (HQUSACE), provided project oversight on behalf of HQUSACE. Messrs. Stanley Boc, POD, and Lockhart also visited CERC to oversee progress of the study.

This report was prepared by Ms. Linda S. Lillycrop, Hydraulic Engineer, COB; Mr. Steven M. Bratos, Hydraulic Engineer, COB; and Dr. Edward F. Thompson, Research Hydraulic Engineer, RD. Ms. Panola Rivers, Civil Engineering Technician, $C O B$, assisted in preparing various files and tables for this study. Ms. Lillycrop, Mr. Bratos, and Ms. Rivers were under the direct supervision of Dr. Martin C. Miller, Chief, COB, and Mr. H. Lee Butler, Chief, RD, and under the general supervision of Mr. Charles C. Calhoun, Jr., Assistant Chief, CERC, and Dr. James R. Houston, Chief, CERC.

The assistance of Mr. Paul D. Farrar, Research Oceanographer, COB, is deeply appreciated. Dr. H. S. Chen, Marine Products Branch, Development Division, National Meteorological Center, National Oceanic and Atmospheric Administration, provided valuable suggestions for implementing the harbor model used in this study. Ms. Lori Copland, US Army Engineer District, Sacramento, and Mr. Steve Hatton, Information Technology Laboratory, WES, developed the initial finite element grid for the harbor model.

Commander and Director of WES during publication of this report was COL Larry B. Fulton, EN. Technical Director was Dr. Robert W. Whalin. 


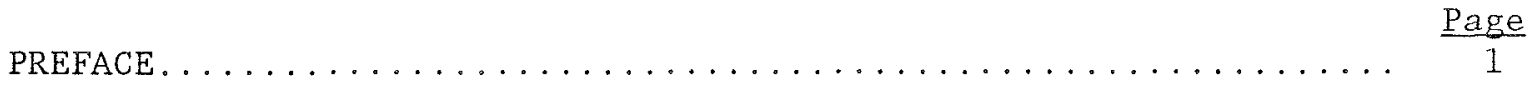

CONVERSION FACTORS, NON-SI TO SI (METRIC)

UNITS OF MEASUREMENT ........................ 3

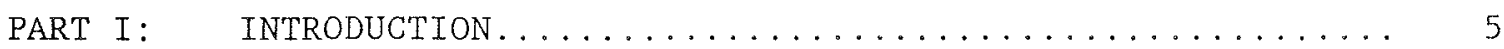

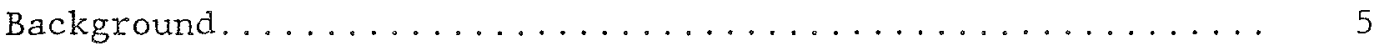

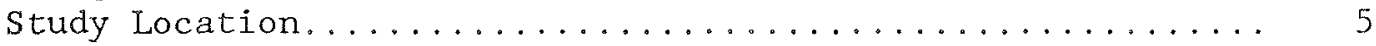

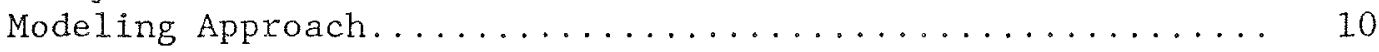

PART II: DEEPWATER WAVE CONDITIONS................. 12

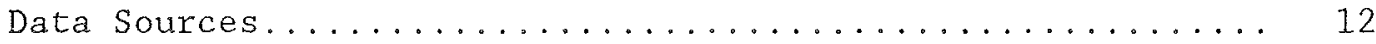

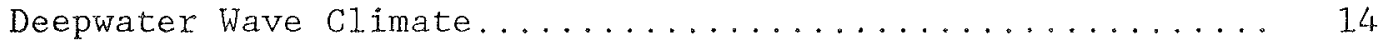

PART III: WAVE TRANSFORMATION MODELING............... 17

Wave Transformation Model....................... 17

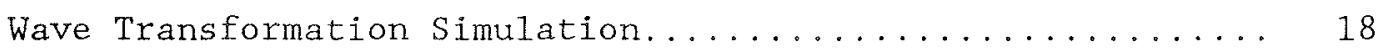

PART IV: HARBOR WAVE RESPONSE MODELING.............. 26

Harbor Wave Response Mode1.................... 26

Finite Element Grids for Plan 1 and Plan 2............ 29

Harbor Wave Response Simulation.................. 31

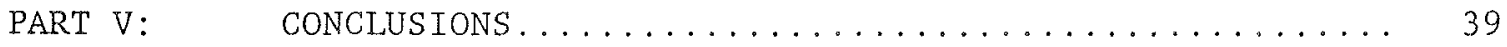

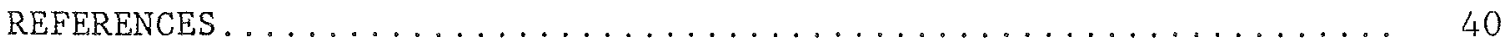

TABLES 1-21

PLATES $1-39$

APPENDIX A: OFFSHORE WAVE CLIMATE PERCENT OCCURENCE TABLES...... AI

APPENDIX $B:$ NOTATION. . . . . . . . . . . . . . . . . . . 


\section{CONVERSION FACTORS, NON-SI TO SI (METRIC) \\ UNITS OF MEASUREMENT}

Non-SI units of measurement used in this report can be converted to SI (metric) units as follows:

Multiply

degrees (angle)

feet

nautical mile

nautical mile/hour
By

0.01745329

0.3048

1.852

1.852
To Obtain

radian

meters

kilometers

kilometers/hour 


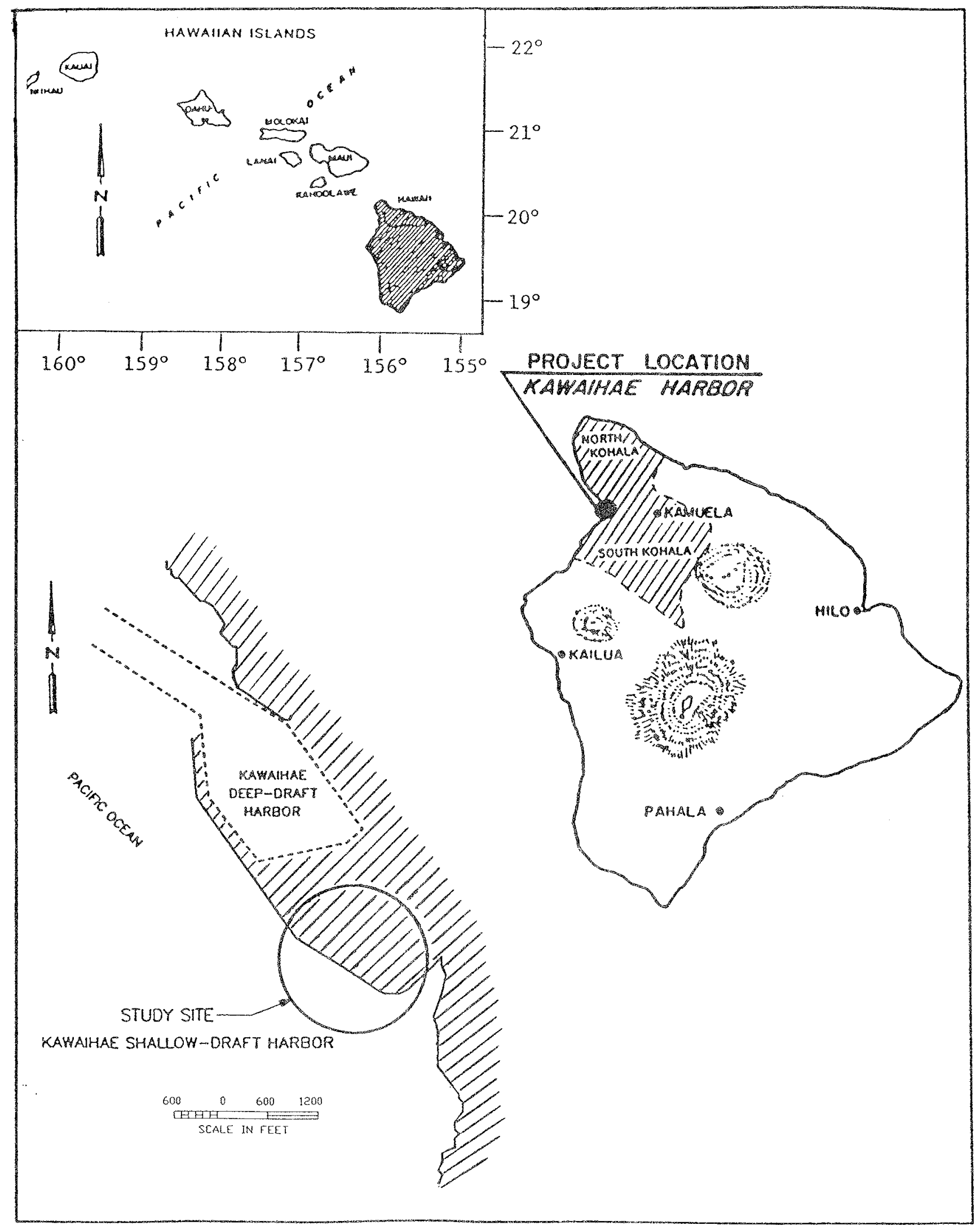

Figure 1. Study Locotion 


\section{WAVE RESPONSE OF PROPOSED IMPROVEMENTS TO THE \\ SHALLOW-DRAFT HARBOR AT KAWAIHAE, HAWAII}

\section{PART I: INTRODUCTION}

\section{Background}

1. At the request of the US Army Engineer Division, Pacific Ocean (POD), a numerical model study of wave response of the proposed improvements to Kawaihae shallow-draft harbor was conducted by the U.S. Army Engineer Waterways Experiment Station's (USAEWES) Coastal Engineering Research Center (CERC). The study was conducted to determine if proposed improvements (Plan 1) would provide the shallow-draft harbor with adequate protection from the incident wave climate. The shallow-draft harbor is part of a harbor complex plan consisting of an existing deep-draft harbor and proposed ferry terminal. The shallow-draft harbor includes an entrance channel, turning basin, and breakwater to provide limited shelter for small craft until harbor improvements are completed. Following the evaluation of Plan 1, a second plan (Plan 2) consisting of a breakwater modification was tested to determine if the cost-saving changes would provide adequate protection.

\section{Study Location}

2. The Kawaihae harbor complex is located on the northwest coast of the island of Hawaii, the largest and most southerly island in the Hawailan Island chain. The shallow-draft harbor site is immediately south of the existing Kawaihae deep-draft harbor. The tributary area for the harbor complex includes the North and South Kohala Judicial Districts (Figure 1).

3. Selection of the harbor site was based on a wide bordering coral 
reef which provides natural protection from storm waves approaching the area, excellent navigation conditions, adequate area for development of shoreside facilities, and compatibility with the existing and proposed uses of the harbor complex.

4. During the project formulation phase of the harbor complex design, the shallow-draft harbor site went under extensive investigation by the US Army Engineex Nuclear Cratering Group (USAENCG). The site was a potential test area for the USAENCG research and development project (Project Tugboat), a study to test excavations using a high explosive row charge cratering technique. Due to favorable test conditions such as an extensive coral reef, the remoteness of the area from large developments, and accessibility to the test site from land, the shallow-draft harbor site was selected for the study. The objectives of Project Tugboat were to collect technical data on high explosive cratering techniques and their applicability to harbor excavation work. In addition, the explosive excavations would provide a useful portion of the shallow-draft harbor. Results of the Project Tugboat explosions yielded construction of an $850 \mathrm{ft}^{*}$ long, $120 \mathrm{ft}$ wide, and approximate $12 \mathrm{ft}$ deep entrance channel and a 1.2 acre $12 \mathrm{ft}$ deep turning basin. An 850 ft long breakwater was also constructed under Project Tugboat and was incorporated into the design plan of the shallow-draft harbor. The breakwater and excavated axea would provide limited shelter for small craft until the proposed shallow-draft harbor improvements were completed. The General Design Memorandum (GDM) for Kawaihae Harbor for Light-Draft Vessels (US Army Engineer District, Honolulu 1971) contains a record of the research and planning which led to the proposed design improvements, Plan 1 (Figure 2).

* A table of factors for converting non-SI units of measurement to SI (metric) units is presented on page 3. 


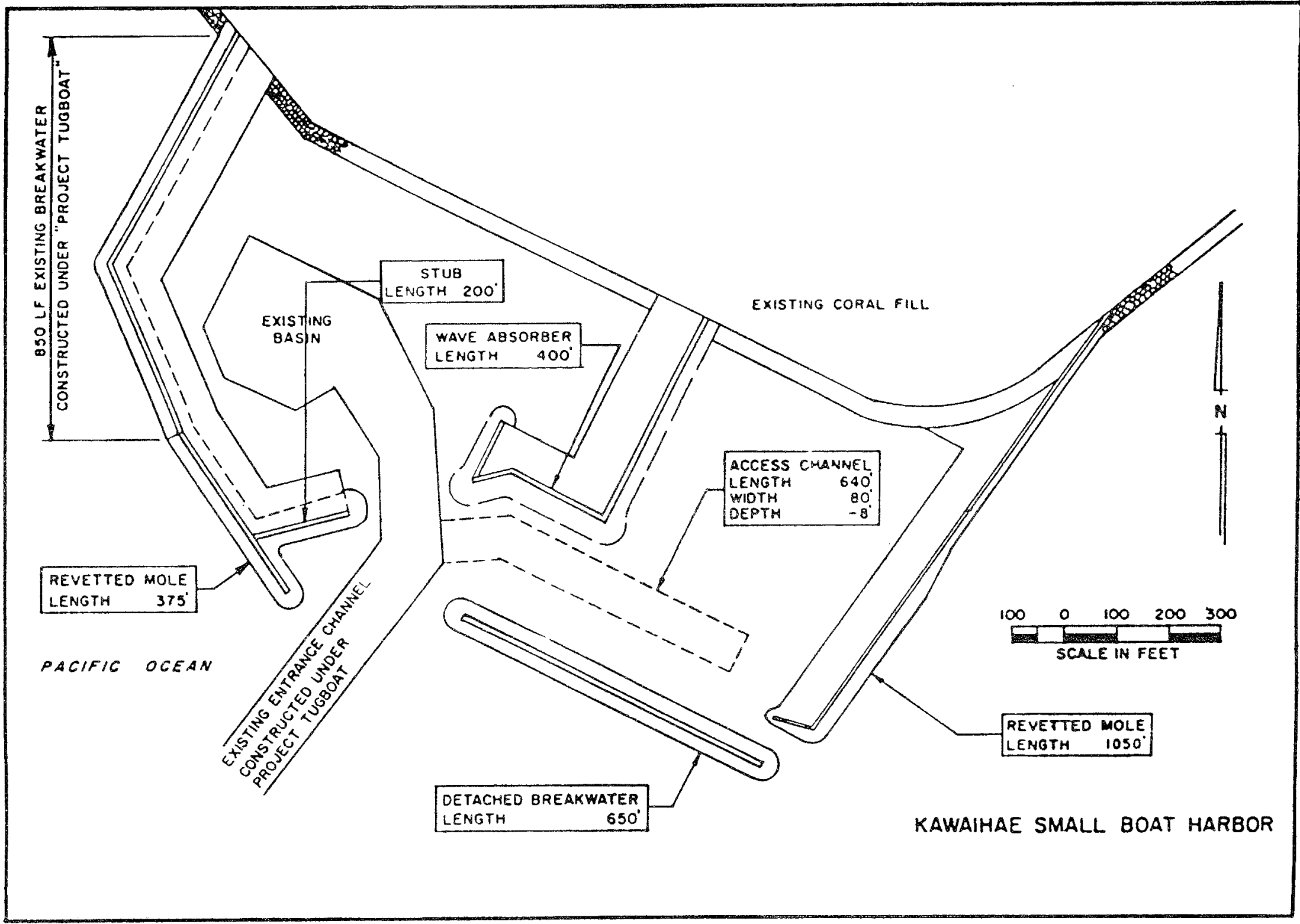

Figure 2. Plon 1 
5. Plan 1 will provide berthing facilities for approximately 300 small craft, and includes the following improvements:

a. A $640 \mathrm{ft}$ long, $80 \mathrm{ft}$ wide, $8 \mathrm{ft}$ deep main access channel to provide access from the entrance channel to an approximate 5.8 acre east basin.

b. A $375 \mathrm{ft}$ long revetted mole breakwater extension of the existing $850 \mathrm{ft}$ west breakwater, with a $200 \mathrm{ft}$ long stub mole on the harbor side of the extension.

c. A $400 \mathrm{ft}$ long wave absorber on the seaward end of a $425 \mathrm{ft}$ long access mole.

d. A $1,050 \mathrm{ft}$ long east revetted mole.

e. A $650 \mathrm{ft}$ long, $12 \mathrm{ft}$ wide offshore breakwater located adjacent to the entrance channel.

6. Plan 2 (Figure 3) includes the same improvements as Plan 1 with the exception of a modification to the west revetted mole breakwater extension of the existing breakwater. The breakwater extension will be reduced from $375 \mathrm{ft}$ to $175 \mathrm{ft}$ to reduce construction costs.

7. Study objectives of the Headquarters, US Army Corps of Engineers (HQUSACE) and POD were to verify that the proposed harbor design improvements meet the criteria that the wave heights not exceed 1 ft in the berthing areas and $2 \mathrm{ft}$ in the entrance channel and turning basin more than approximately 10 percent of the time. To accomplish this objective, Plan I was tested using the HARBD numerical harbor response model (Chen and Houston 1987) developed at CERC. Modifications to Plan 1 would then be considered and tested if (a) Plan 1 did not meet the HQUSACE criteria or (b) Plan 1 could then be modified to lower construction costs. 


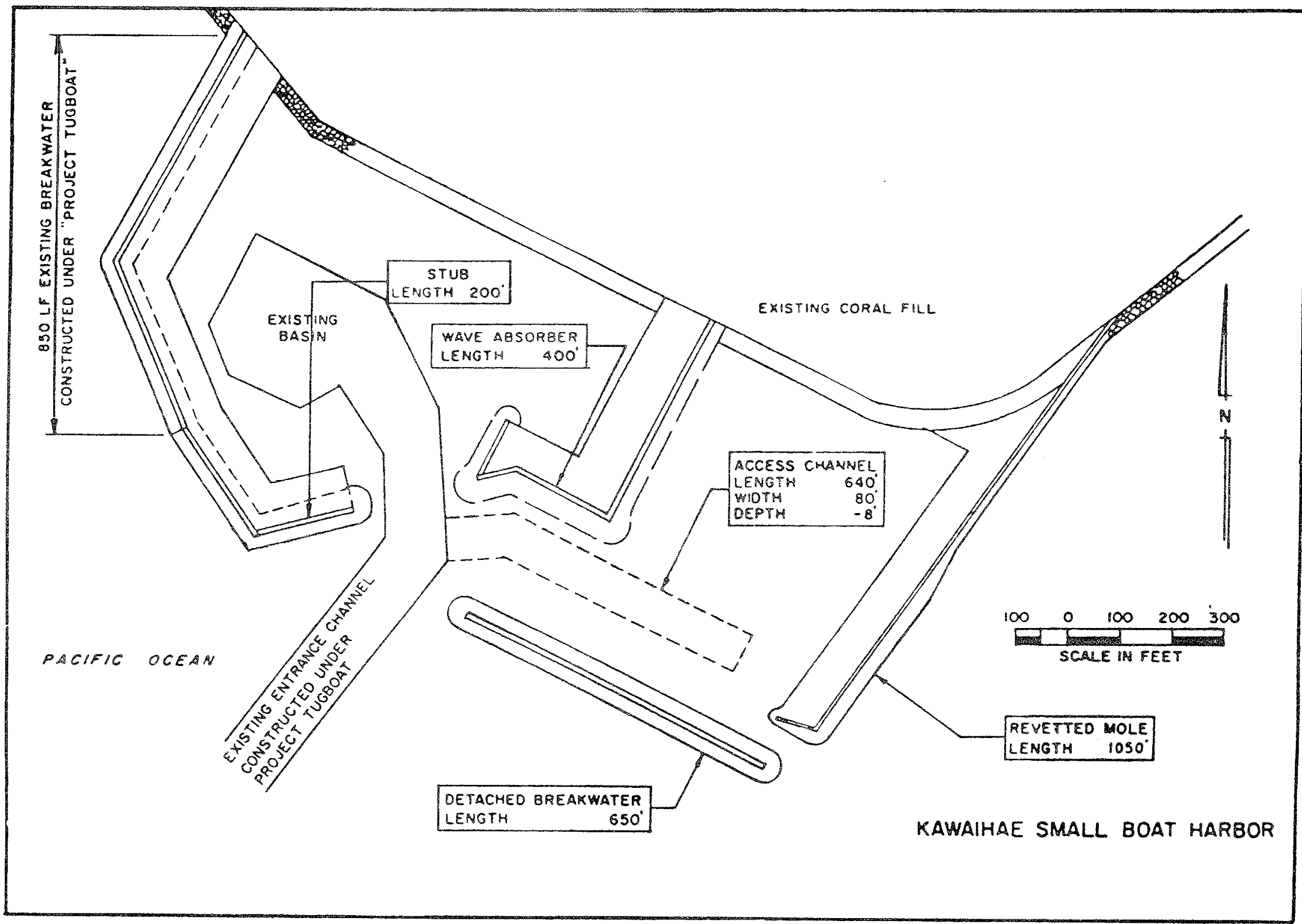

Figure 3. Plan 2 
Modeling_Approach

8. Both numerical and physical modeling alternatives were considered for this study. Physical modeling would have the advantages of providing more complete, reliable results for this particular study and would allow more comprehensive optimization of the project design. However, the physical model probably would cost significantly more and take longer to complete than the numerical model. The assumptions inherent in the numerical modeling approach are as follows:

- no wave transmission through the breakwater,

- no wave overtopping of structures,

- structure crest elevations will not be tested or optimized,

- wave current interaction in the channel through the reef will not be evaluated,

- wave breaking effects in the entrance channel will not be considered,

- diffraction around the structure ends will be represented by diffraction around a blunt vertical wall with specified reflection coefficient.

Within the limits of the assumptions, the numerical modeling approach can be expected to give a reasonable assessment of the proposed plan. The numerical modeling approach was selected because POD's allowable time, study funds, and design modification alternatives for this particular project were extremely limited. The procedure of this study is described in the following paragraphs.

9. The deepwater wave conditions for the northwest side of the island of Hawaii were established from available sources such as the Wave Information Study (WIS) deepwater hindcasts for the Pacific Coast (Corson, et al 1986), the National Oceanic and Atmospheric Administration's National Data Buoy Center (NDBC) measurements (Gilhousen, et a1 1986), the Coastal Field Data Collection Program (CFDCP) (US Army Corps of Engineers (USACE) 1987), and the Summary of Synoptic Meteorological Observations (SSMO) (US Naval Weather Service Command 1976). The percent occurrences of the deepwater conditions 
were calculated to later determine the percent occurrence of the wave heights inside the harbor. The method to establish the deepwater conditions is presented in PART II of this report: Deepwater Wave Conditions.

10. The offshore waves were input to the Regional Coastal Processes WAVE Propagation Model, RCPWAVE, (Ebersole, Cialone, and Prater 1986). The model was used to transform and refract the offshore waves to the Kawaihae vicinity. The RCPWAVE Model is presented in PART III of this report: Wave Transformation Modeling.

11. The resulting wave conditions of RCPWAVE were then used as input to HARBD to determine the wave response inside the harbor. The resulting wave heights in the harbor channels, turning basin, and berthing areas were determined and the percent occurrence of those conditions were calculated using the results of both the RCPWAVE and HARBD models. The HARBD Mode1 and the details and results of the procedures are presented in PART IV of this report: Wave Response Modeling. 


\section{PART II: DEEPWATER WAVE CONDITIONS}

\section{Data Sources}

12. The coastline in the vicinity of Kawaihae shallow-draft harbor is exposed to waves coming from westerly directions ranging from about northnorthwest to south-southwest. Several relevant sources of wave information are available though none are ideally suited for use at Kawaihae.

13. The Wave Information Studies (WIS) deepwater hindcasts for the Pacific coast include seven stations around the Hawaiian Islands (Corson, et al 1986). Two of the stations are on the west side of the island of Hawaii and have exposures somewhat representative of Kawaihae (Figure 4). Station 34 lies about 250 nautical miles $(\mathrm{nm})$ due west of Kawaihae. Station 35 is approximately $150 \mathrm{~nm}$ southwest of Kawaihae. The WIS 20-year wave climate is very similar for both stations. The wIS stations show that well over 90 percent of the wave conditions come from a northerly direction, between northwest and northeast.

14. The WIS information has some important limitations relative to the project site. The stations are relatively distant from the site; they are subject to somewhat different exposures than the project site; they represent deep water rather than the very shallow conditions at the site; the. WIS hindcasting grid did not extend south of the equator; and, the grid omitted the southwestern part of the north Pacific basin in order to ease computational requirements (Corson, et al 1986). Thus waves from the quadrant between west and south, including some important exposure directions for the project site, may be under represented in the WIS information.

15. Another data source is the deepwater buoys operated by the National Oceanic and Atmospheric Administration's National Data Buoy Center (NDBC). 


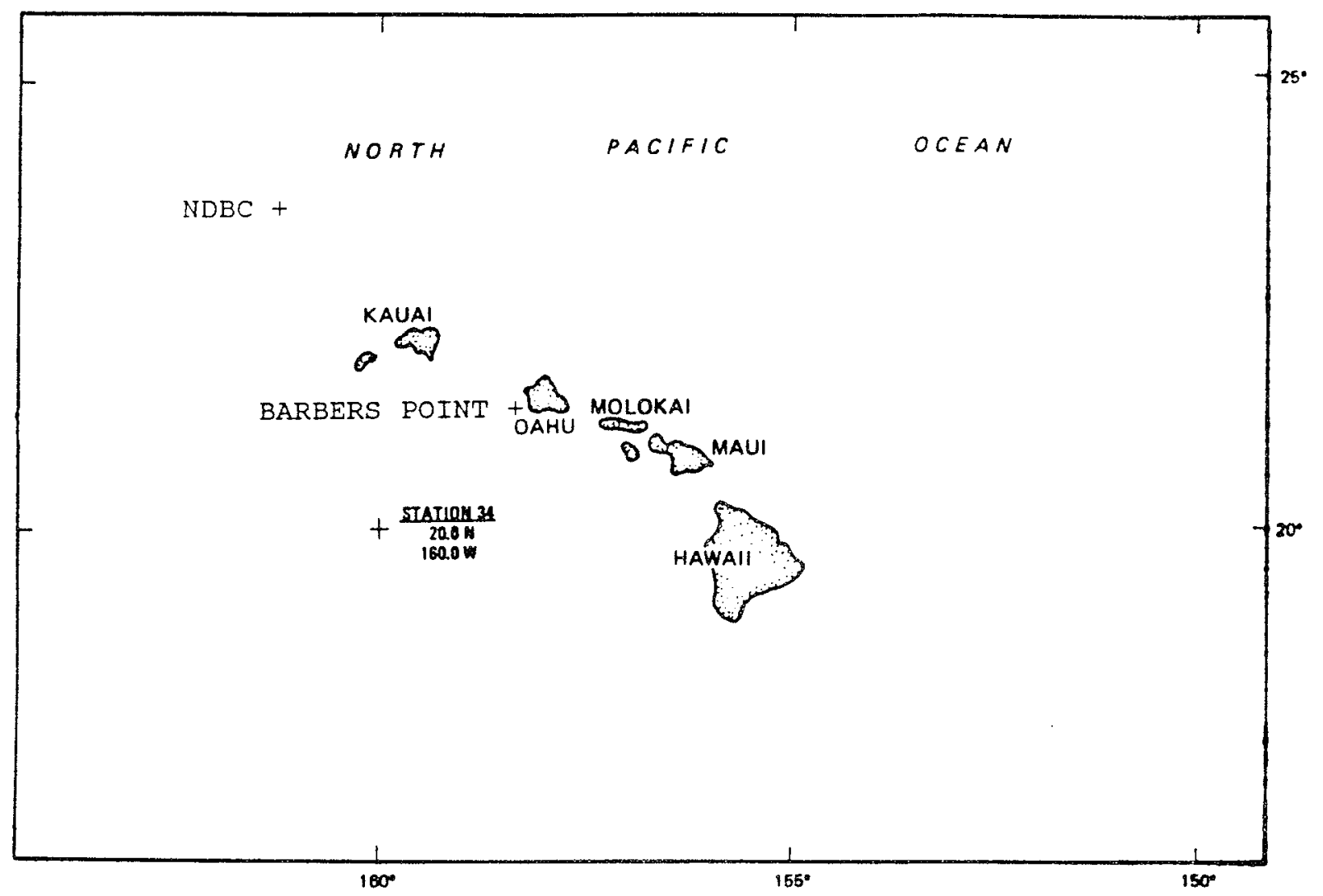

Figure 4. Sources of wave information for the Kowaihae area.

Climatological information in the vicinity of the Hawailan Islands is readily available from only one buoy, Station 51001. (Gilhousen, et al 1986).

Measurements include wind speed and direction and wave height and period over the years 1981-84. However, wave direction measurements are not available from this station. The station is not representative of the project site since it is fully exposed to the important north and east approach directions, Figure 4.

16. Nondirectional wave measurements are available from a nearshore buoy at Barbers Point, Oahu, Figure 4. Water depth at the buoy is $600 \mathrm{ft}$. The buoy, funded through the Monitoring Completed Coastal Projects (MCCP) Program of the US Army Corps of Engineers (USACE 1987), has been in operation since June 1986, a long enough time period to provide general climatological data. Although Barbers Point is on a different island than Kawaihae, the 
local coastline orientation and exposure are remarkably similar at the two sites. The main difference is that Barbers Point is more open to the south than Kawaihae.

17. A final data source examined is the Summary of Synoptic Meteorological Observations (US Naval Weather Service Command 1976). These climatological summaries of shipboard wave observations were considered to be of lower quality due to poor comparisons with the other available sources and they were not used.

\section{Deepwater Wave Climate}

18. Offshore wave climate at the Kawaihae shallow-draft harbor site was estimated using information from WIS Station 34, NDBC Station 51001, and MCCP Barbers Point buoy. Each of the 3 sources has strengths and limitations relative to the others. The percent occurrence of significant wave height and peak spectral period from WIS (for all directions) and NDBC were compared and the results were very similar. Since the NDBC buoy is exposed to all directions, it appears that major elements of the offshore wave climate are adequately represented in the WIS information despite limitations on the grid coverage. Further validation of the WIS data became available in the final stages of this study. Gilhousen et al (1990) provide a climatological summary for a NDBC buoy located very near the WIS station 34 and results are comparable.

19. The Kawaihae shallow-draft harbor site is exposed to a sector from about $202.5 \mathrm{deg}$ to $337.5 \mathrm{deg}$ azimuth. WIS information within this sector was taken as part of the deepwater climate at Kawaihae. WIS information outside this sector was not used because Kawaihae is sheltered by land from those directions.

20. The WIS percent occurrence for the exposed sector show 
significantly higher wave events than at Barbers Point. It appears that Barbers Point summaries represent a general wave climate for a southwestfacing coast and are not distorted by unusual high-energy events. Therefore the joint height-period distribution table from a relatively complete year at Barbers Point (USACE 1987) was used to augment the WIS estimates. The Barbers Point data, weighted to represent the rejected sectors of WIS, was added to the WIS percent occurrence from each direction in the exposed sector. The relative frequency of occurrence of each direction in the exposed sector was maintained throughout the addition of the Barbers Point data. The resulting percent occurrence, given in Appendix A and summarized by direction in Table 1 at the end of the text of this report, is considered as the best possible representation of the deep water wave climate at Kawaihae shallow-draft harbor. The percent occurrence of waves corresponding to Table 1 is shown in Figure 5 . 


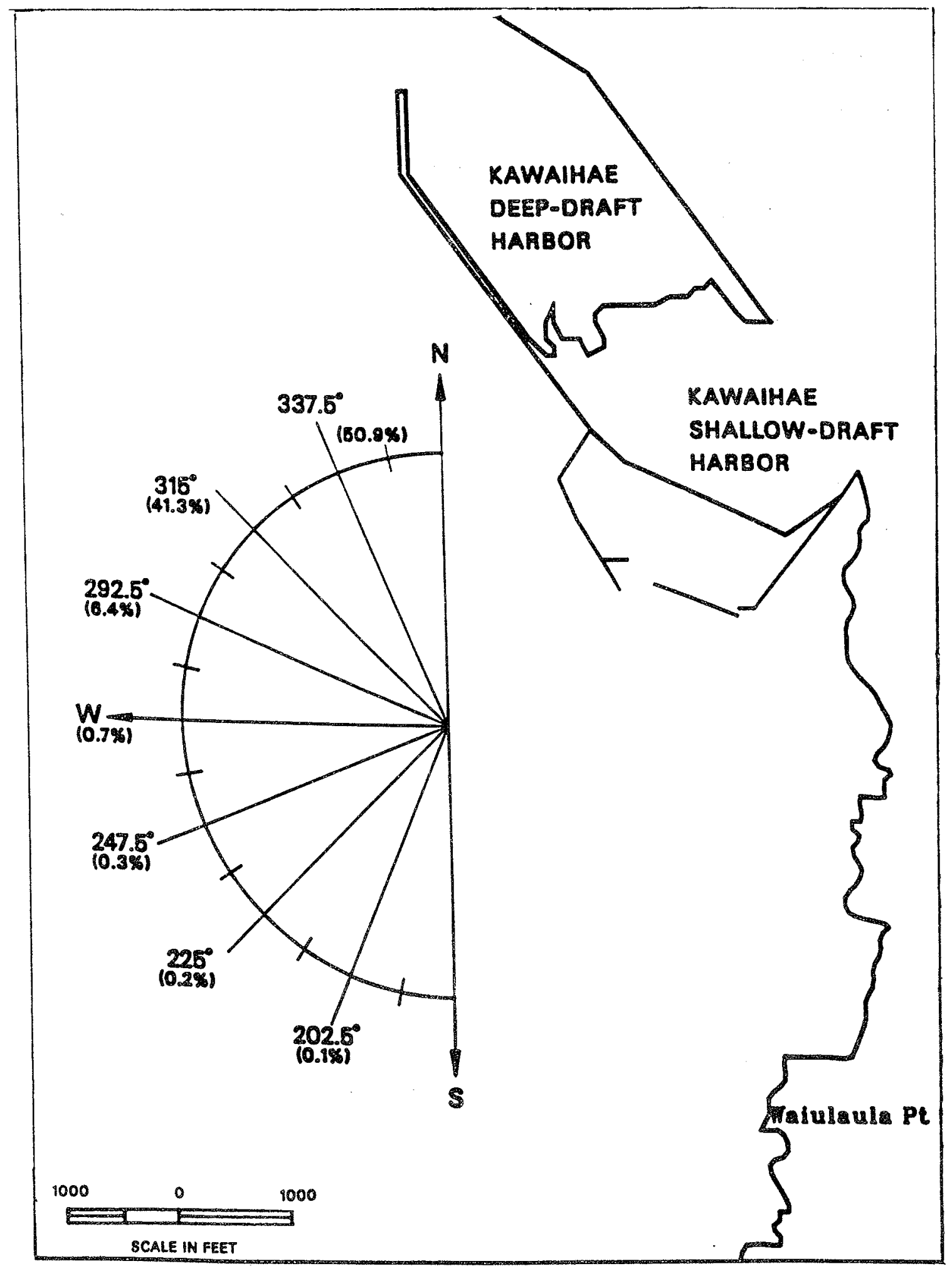

Figure 5. Percent occurrence of deepwater wove conditions by direction 


\section{Wave Transformation Mode1}

21. Once the deepwater wave conditions were established, it was necessary to transform the waves shoreward to the Kawaihae vicinity. This was accomplished using the wave refraction-diffraction numerical model RCPWAVE (Ebersole, Cialone and Prater 1986). RCPWAVE is a finite difference wave propagation model based on the mild slope equation (Berkhoff 1972), which approximates monochromatic, unidirectional wave transformation over smooth bathymetry, including refraction and diffraction. The mild slope equation is given by:

where:

$$
\frac{\partial}{\partial x} \operatorname{cc}_{\mathrm{g}} \frac{\partial \phi}{\partial x}+\frac{\partial}{\partial y} \operatorname{cc}_{\mathrm{g}} \frac{\partial \phi}{\partial y}+\frac{\omega^{2} c_{\mathrm{g}}}{\mathrm{c}} \phi=0
$$

$$
\begin{aligned}
\mathrm{x}, \mathrm{y} & =\text { orthogonal horizontal coordinates } \\
\mathrm{c} & =\text { wave celerity } \\
\mathrm{c}_{\mathrm{g}} & =\text { group velocity } \\
\omega & =\text { radian wave frequency } \\
\phi & =\text { complex velocity potential }
\end{aligned}
$$

By neglecting wave reflections the velocity potential function can be expressed as :

$$
\phi=a e^{i s}
$$

where:

$$
\begin{aligned}
a(x, y) & =\text { wave amplitude function } \\
e & =2.71828, \text { the base of the natural logarithm } \\
i & =(-1)^{1 / 2} \\
\mathrm{~s}(\mathrm{x}, \mathrm{y}) & =\text { wave phase function }
\end{aligned}
$$

Substituting the expression for velocity potential into Equation 1 and solving 
for the real and imaginary parts separately yields (Berkhoff 1976):

$$
\begin{gathered}
\frac{1}{a}\left\{\frac{\partial^{2} a}{\partial x^{2}}+\frac{\partial^{2} a}{\partial y^{2}}+\frac{1}{c c_{g}}\left[\nabla a * \nabla\left(c c_{g}\right)\right]\right\}+k^{2}-|\nabla s|^{2}=0 \\
\nabla *\left(a^{2} c c_{g} \nabla s\right)=0
\end{gathered}
$$

where:

$$
\nabla=(\partial / \partial x+\partial / \partial y) \text {, the gradient operator }
$$

22. Expressing the irrotationality of the wave phase function gradient in the vector form yields an expression which can be solved for local wave angles once the magnitude of the wave phase function gradient is known. The vector forms can be substituted into Equation 4 to give the following expression for energy:

$$
\frac{\partial}{\partial x}\left[a^{2} c c_{g}|\nabla s| \cos \theta\right]+\frac{\partial}{\partial y}\left[a^{2} c c_{g}|\nabla s| \sin \theta\right]=0
$$

Once the wave phase characteristics $\nabla$ s and $\theta$ are determined this equation can be solved for the wave amplitude function. Since the wave frequency is constant, the wave height which is proportional to the amplitude function can be determined.

23. Equations 3 and 5 , along with the local wave angle expression and the dispersion relation, describe the combined refraction and diffraction process for linear waves with the assumption that the bottom slopes are smal1, wave reflections are negligible, and energy losses due to bottom friction or wave breaking outside the surf zone can be neglected. For the purpose of determining input wave conditions at the Kawaihae vicinity (outer boundary of the HARBD model) these assumptions are reasonable.

\section{Wave Transformation Simulation}

24. RCPWAVE transformation estimates were performed from a depth of approximately $180 \mathrm{ft}$ offshore to $22 \mathrm{ft}$ at the HARBD outer boundary (Kawaihae vicinity). Representative period-direction combinations with a unit wave 
height were selected from the modified WIS percent occurrence tables, summarized by direction in Table 1, for input into RCPWAVE. Each deepwater wave input to RCPWAVE was refracted using Snell's law and assuming straight parallel contours up to the seaward boundary of the RCPWAVE grid.

25. The RCPWAVE model uses a rectangular uniformly spaced finite difference grid. The grid used in this study, Figure 6, had 35 cells alongshore (positive $\mathrm{y}$-axis directed south) and 45 cells across-shore (positive $\mathrm{x}$-axis directed offshore or west). Each cell is $200 \mathrm{ft}$ alongshore and $100 \mathrm{ft}$ offshore. The grid spacing is somewhat fine for this application so that transformations over the sometimes complex and rapidly varying bathymetry can be resolved. The grid is situated so that the maximum amount of waves incident on the harbor are accounted for. Since the greatest exposure is to the west and south the majority of the grid extends south of the harbor area.

26. Input requirements for RCPWAVE are deepwater wave height, period and direction. As stated earlier a unit wave height was selected for all RCPWAVE runs to produce a normalized amplification factor based on the ratio of wave height to incident wave height. The amplification factors obtained from the deepwater period-direction combination can be used to calculate the transformed wave height. This greatly reduces the number of RCPWAVE runs required. Wave period-direction combinations selected from the modified wIS data range from 7 to $20 \mathrm{sec}$ and 202 to $337 \mathrm{deg}$ azimuth respectively. The limits in which RCPWAVE remains stable are generally up to $60 \mathrm{deg}$ angle of approach. Upon testing, the model became unstable for waves with periods longer than $7 \mathrm{sec}$ from $337 \mathrm{deg}$. For waves approaching from $337 \mathrm{deg}$, there is a 40-50 nm fetch between Kawaihae harbor and the nearest island, Maui. Based on the fetch and average wind speed for the area of 30 knots (NDBC station 


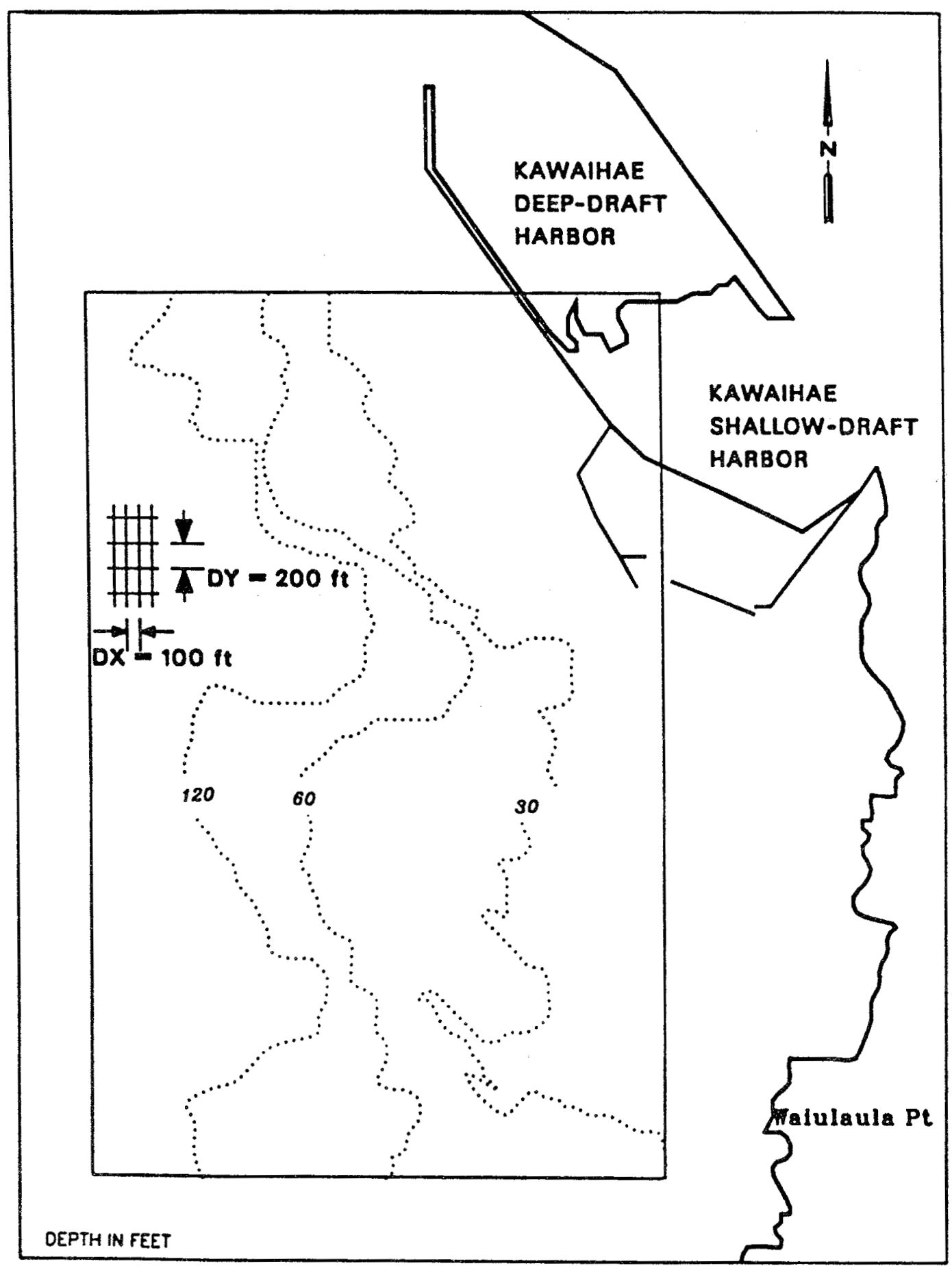

Figure 6. Extent of RCPWAVE finite difference grid 
51001) wave periods generated within this fetch are limited to $7 \mathrm{sec}$ and shorter (SPM Fig. 3-24, p 3-50). Assuming that waves from 337 deg generated outside this fetch area are sufficiently attenuated by the sheltering islands north-northwest of the harbor, waves with periods longer than 7 sec from this direction can be neglected.

27. Output from RCPWAVE, for each period-direction combination, consists of resulting local wave angles and amplification factors for each grid cell. For each input wave condition the average local wave angle (ALWA) and average amplification factor of the cells directed toward the harbor which coincided with the HARBD outer boundary were computed. The input deepwater wave periods and directions, and the corresponding transformed ALWA's and average amplification factors are given in Table 2. The table shows that the ALWA's at the HARBD boundary range from 245 to 240 deg for deepwater wave conditions from 247, 270, and $292 \mathrm{deg}$ with the exception of the $7 \mathrm{sec}$ wave in the 292 deg deepwater wave direction. The ALWA in this case is 250 deg. The average amplification factors for these deepwater wave directions also have little variation, ranging from 0.60 to 0.70 with the exception of the 17 and $20 \mathrm{sec}$ waves in the 292 deg deepwater wave direction. ALWA's show more sensitivity to change in wave period for the 225 and 315 deg deepwater wave directions. Deepwater waves approaching from $225 \mathrm{deg}$ and ranging from 7 to 20 sec have transformed ALWA's ranging from 234 to 244 deg, while deepwater waves from 315 deg have ALWA's ranging from 255 to $238 \mathrm{deg}$. The average amplification factors for 225 and 315 deg deepwater wave directions ranges from 0.70 to 0.80 and 0.55 to 0.70 respectively.

28. Figures 7,8 , and 9 are wave refraction diagrams for the 7,13 , and $20 \mathrm{sec}$ deepwater periods from 225, 247, 292, and $315 \mathrm{deg}$. Table 2 and the wave refraction diagrams show that with the exception of some of the shorter 

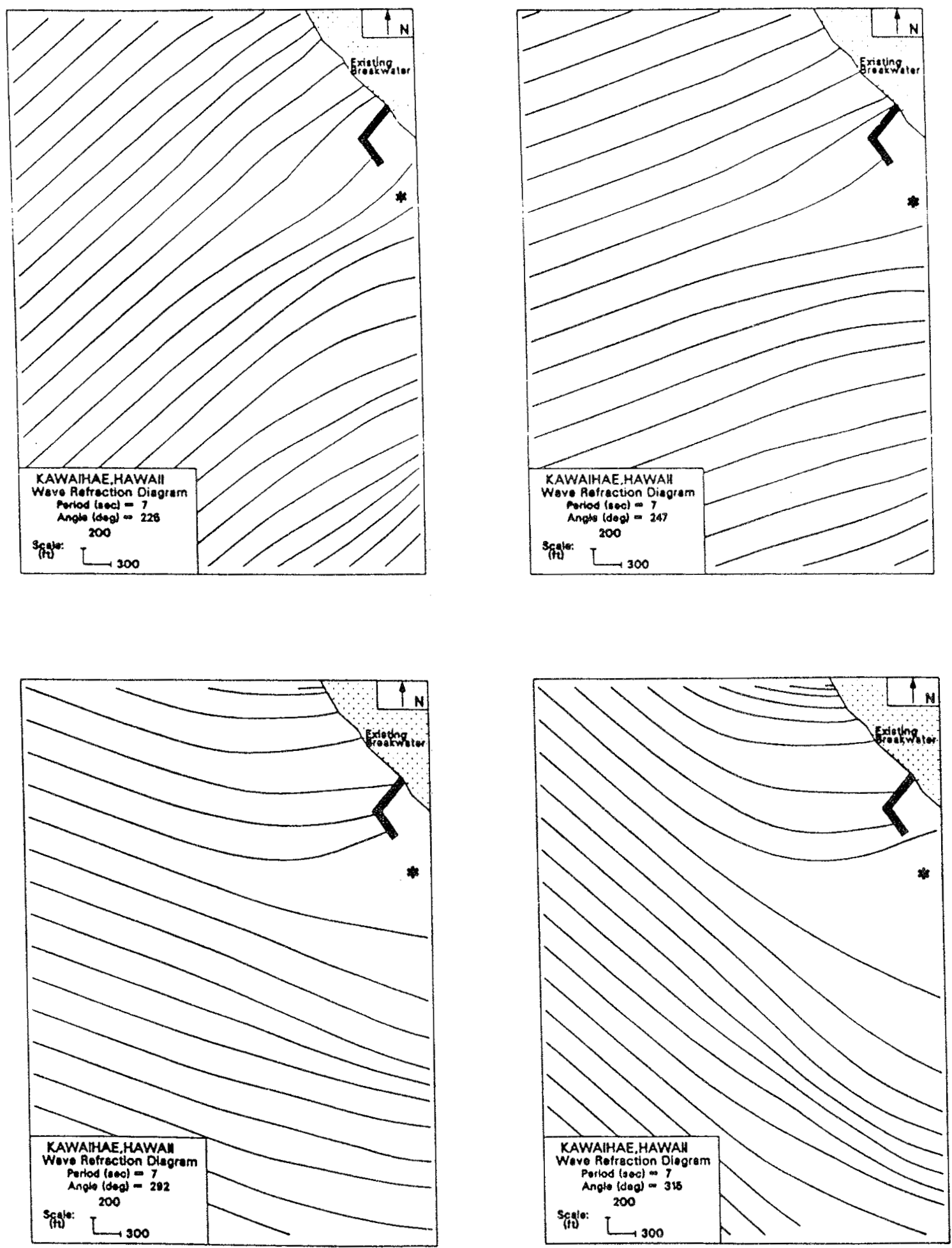

Figure 7. RCPWAVE wove refraction diogroms, 7 sec woves

( $*$ location of harbor entrance) 

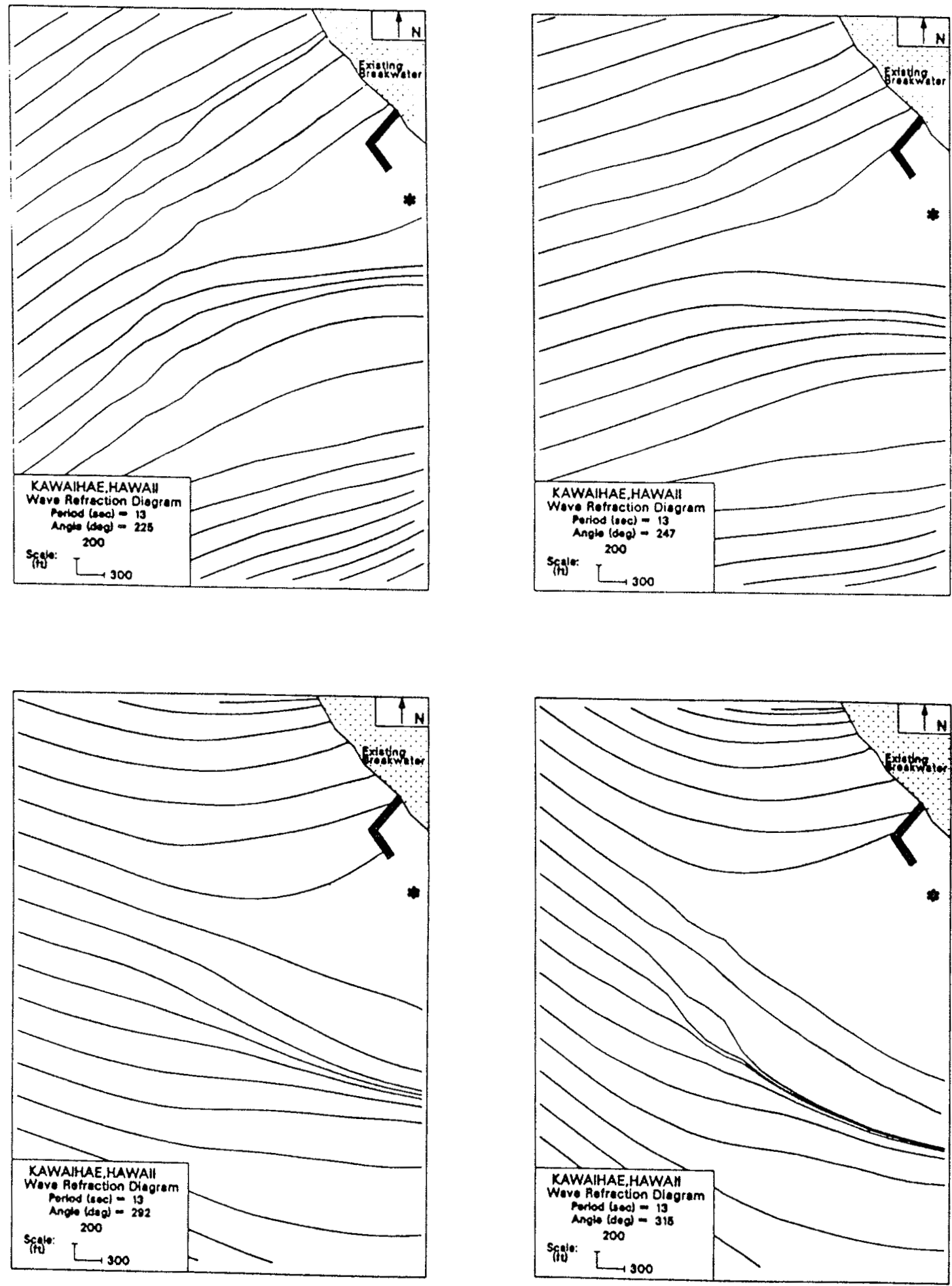

Figure 8. RCPWAVE wove refroction diagrams, $13 \mathrm{sec}$ waves

( $*=$ location of harbor entrance) 

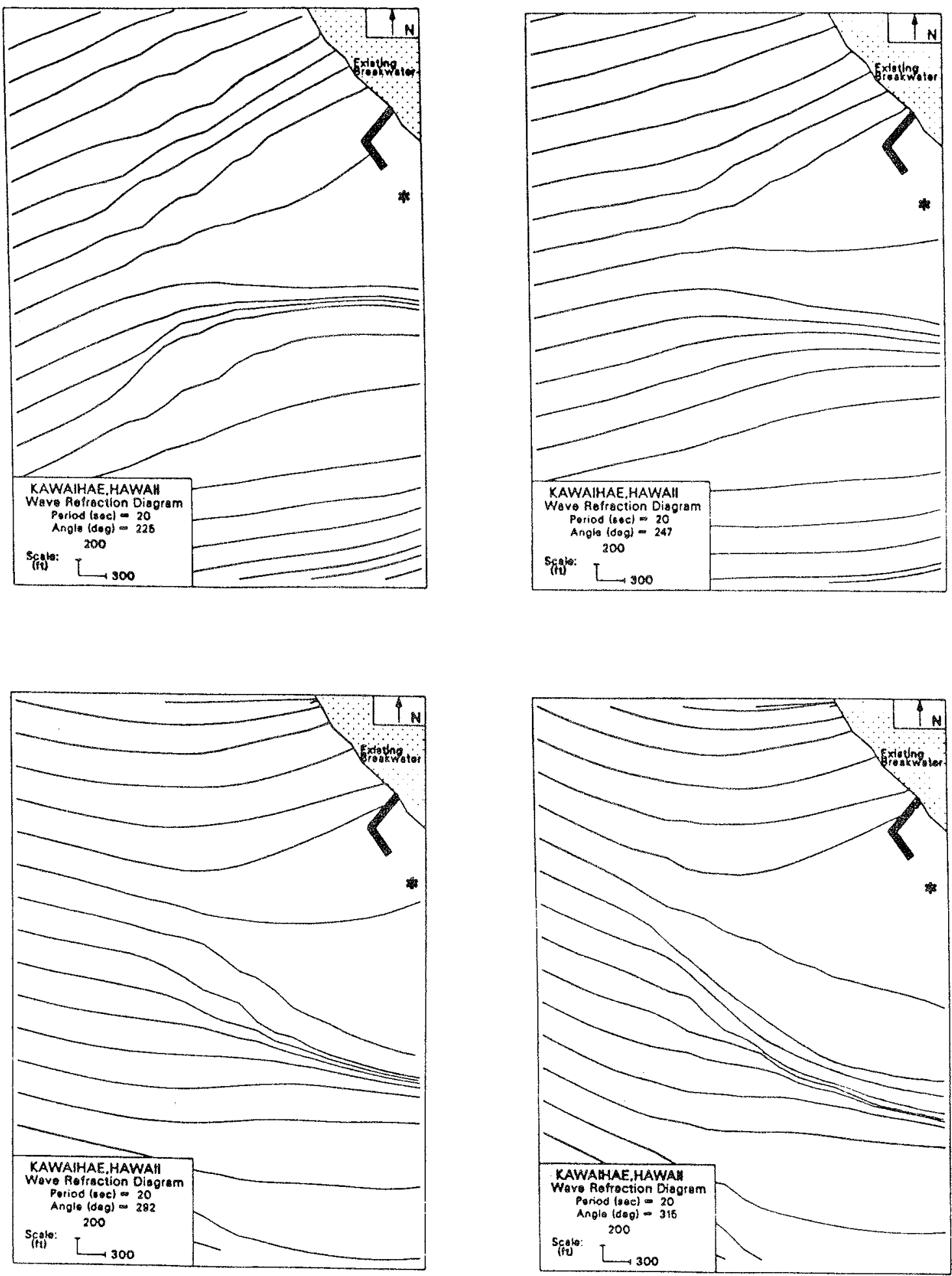

Figure 9. RCPWAVE wave refraction diograms, 20 sec woves

( $*=$ location of harbor entrance) 
wave periods the majority of deepwater waves from different direction bands are refracted to an average angle within 2 or 3 degrees of $240 \mathrm{deg}$ at the HARBD boundary.

29. The wave refraction diagrams also show spreading of energy near the harbor area caused by a canyon like feature in the bathymetry. This spreading of energy results in significantly reduced wave heights at the harbor. 


\section{Harbor Wave Response Model}

30. The numerical model HARBD (Chen and Houston 1987) was used to model the harbor wave response at Kawaihae shallow-draft harbor, Hawaii. HARBD is a steady state hybrid finite element model which calculates linear wave oscillations in harbors of arbitrary configuration and variable water depth. The model is advantageous over other numerical harbor models since bottom friction and boundary absorption are included. The bottom friction is assumed to be proportional to flow velocity with a phase difference. The boundary absorption is based on a formulation similar to that in the impedance condition in acoustics and is expressed in terms of wave number $(2 \pi / L$ where $L$ is the wavelength) and reflection coefficient of the boundary. The result is that HARBD predicts wave amplitudes which are more realistic than those from previous models (Chen and Houston 1987). HARBD was originally developed for harbor oscillations (long period waves), and the general formulation was adapted for wind waves (short period waves) by Houston (1981).

31. The model has been tested and compared with excellent results for a number of cases for which analytic solutions are known (Chen 1984 and Chen and Houston 1987). It has been applied in the design of Agat Harbor, Guam (Farrar and Chen 1987), studying the effects of entrance channel dredging at Morro Bay Harbor, California (Kaihatu, Lillycrop, and Thompson, 1989), and analyzing harbor resonance at Los Angeles-Long Beach Harbor California (Sargent 1989). The model was used to plan wave protection at Fisherman's Wharf, San Francisco, California (Bottin, Sargent, and Mize, 1985), Green Harbor, Massachusetts (Weishar 1986), Los Angeles-Long Beach Harbor, California (Houston 1976), and to estimate the wave conditions in Indiana Harbor, Indiana 
during a study of sediment disposal alternatives (Clausner and Abe1 1986). HARBD was compared to laboratory data collected from the physical model study of Barcelona Harbor, Buffalo, New York (Crawford and Chen 1988) with encouraging results.

32. In the HARBD solution formulation, the water domain is divided into near and far regions. The near region is bounded by an artificial semicircular ring outside the harbor and includes the harbor and all marine structures and bathymetry of interest. The far region is an infinite semicircular ring bounded by the near region and extends to infinity in all horizontal directions. The infinite far region is assumed to have straight coastlines, a constant water depth, and no bottom friction. The finite near region, which contains the area of interest, is subdivided into a mesh of triangular shaped finite elements. The length of the sides of each element is determined from the desired grid resolution and design wave parameters. The water depth and bottom friction coefficient are specified for each element, and a reflection coefficient is assigned to each element on the solid boundaries. The model requires a wave period and direction as input. The solution consists of an amplification factor (i.e. the ratio of the wave height to the incident wave height) and a corresponding phase angle for the entire near region. The phase angle is of little importance to the present study.

33. The model solves the following governing equation:

$$
\frac{\partial}{\partial x} \lambda c c_{g} \frac{\partial \phi}{\partial x}+\frac{\partial}{\partial y} \lambda c c_{g} \frac{\partial \phi}{\partial y}+\frac{\omega^{2} c_{g}}{c} \phi=0
$$

where

$$
\begin{aligned}
c & =\text { wave phase velocity } \\
c_{\mathrm{g}} & =\text { wave group velocity } \\
\phi & =\text { spatial flow potential }
\end{aligned}
$$




$$
\omega=\text { radian wave frequency }
$$

The complex bottom friction factor $\lambda$ is assumed proportional to the maximum velocity at the bottom of the flow field and is defined as

$$
\lambda=1 /\left(1+\left(i \beta a_{0} / h \sinh k h\right) e^{i \gamma}\right)
$$

where

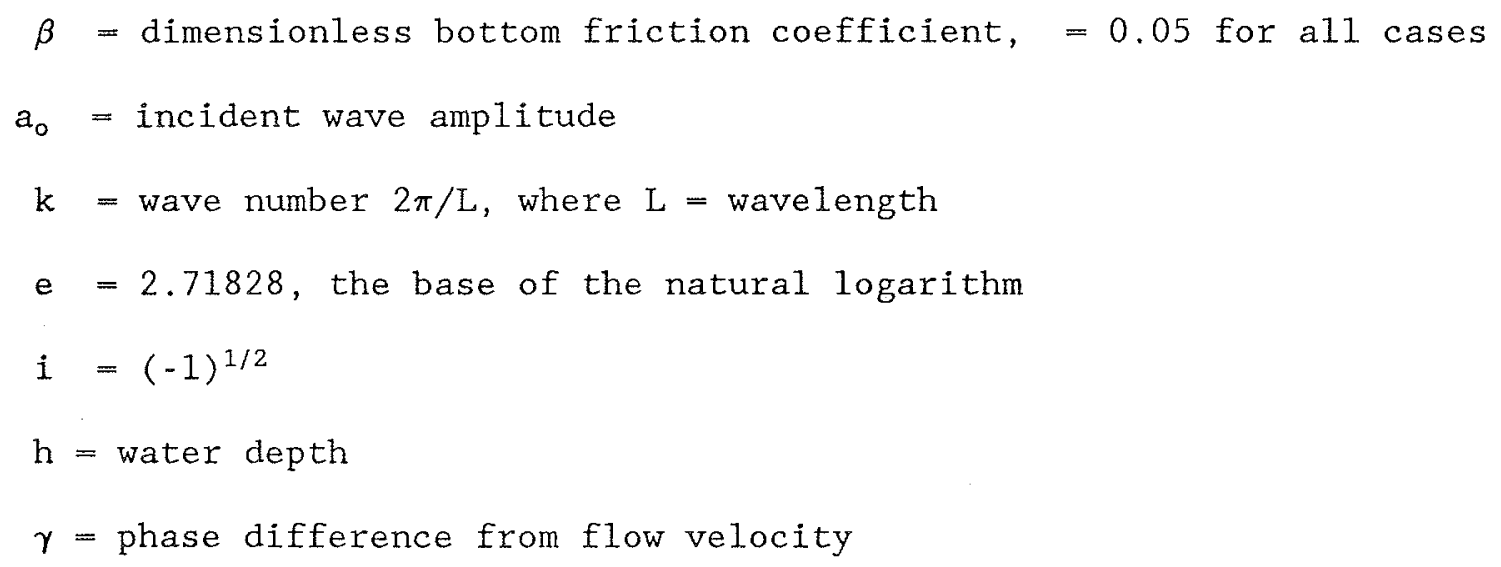

An absorbing boundary condition is applied along the solid boundaries inside the harbor and is expressed as

$$
\partial \phi / \partial \mathrm{n}-\alpha \phi=0
$$

and

$$
\alpha=i k\left(1-K_{r} / 1+K_{r}\right)
$$

where

$\mathrm{n}=$ independent variable in the direction of the unit-normal vector. $\mathrm{K}_{\mathrm{r}}=$ the reflection coefficient of the boundary.

34. A conventional finite element approximation is used in the near region, and an analytical solution with unknown coefficients is used to describe the far region. The conditions in the near and far regions must be matched along the artificial semicircle boundary. This requirement is met by HARBD routines which automatically match the solutions using the stationarity of a functional, to a series of Hankel Functions which give the solution for 
the infinite region (Farrar and Chen 1987). The hybrid element numerical techniques used in the formulation are discussed in greater detail in Chen and Mei (1974).

35. The HARBD model is intended to simulate waves which can be adequately described by the mild slope equation (Equation 6). Model accuracy decreases as wave conditions approach those outside the validity of this governing equation. HARBD does not simulate nonlinear processes such as wave breaking, wave transformation and overtopping of structures, and wave current interaction, however, the model predicts wave heights accurately if these processes are not dominant.

\section{Finite Element Grids for Plan 1 and Plan 2}

36. The finite element grids used to model Plan 1 and Plan 2 are shown in Figures 10 and 11. Both grids cover the same offshore and harbor areas with the exception of the modified west mole breakwater tip of Plan 2 . The total number of elements (triangles), nodes (triangular corners), and boundary elements are 8674, 4561, and 348, respectively, for P1an 1 and 8703, 4571, and 339, respectively, for Plan 2. An approximate 6 elements per wavelength resolution is obtained for each grid. The wavelength is determined from linear wave theory using the design wave period of 8 seconds and a water depth of 8 feet.

37. The orientation and seaward extension of the artificial semicircular boundary is sufficient to adequately model the incident wave climate from pertinent directions into the study area. The semicircle diameter is approximately $1600 \mathrm{ft}$ and is designed to be approximately twice the distance between the east and west breakwater tips. The entire seaward sides of the breakwaters were not enclosed since these areas would not affect the response inside the harbor. 


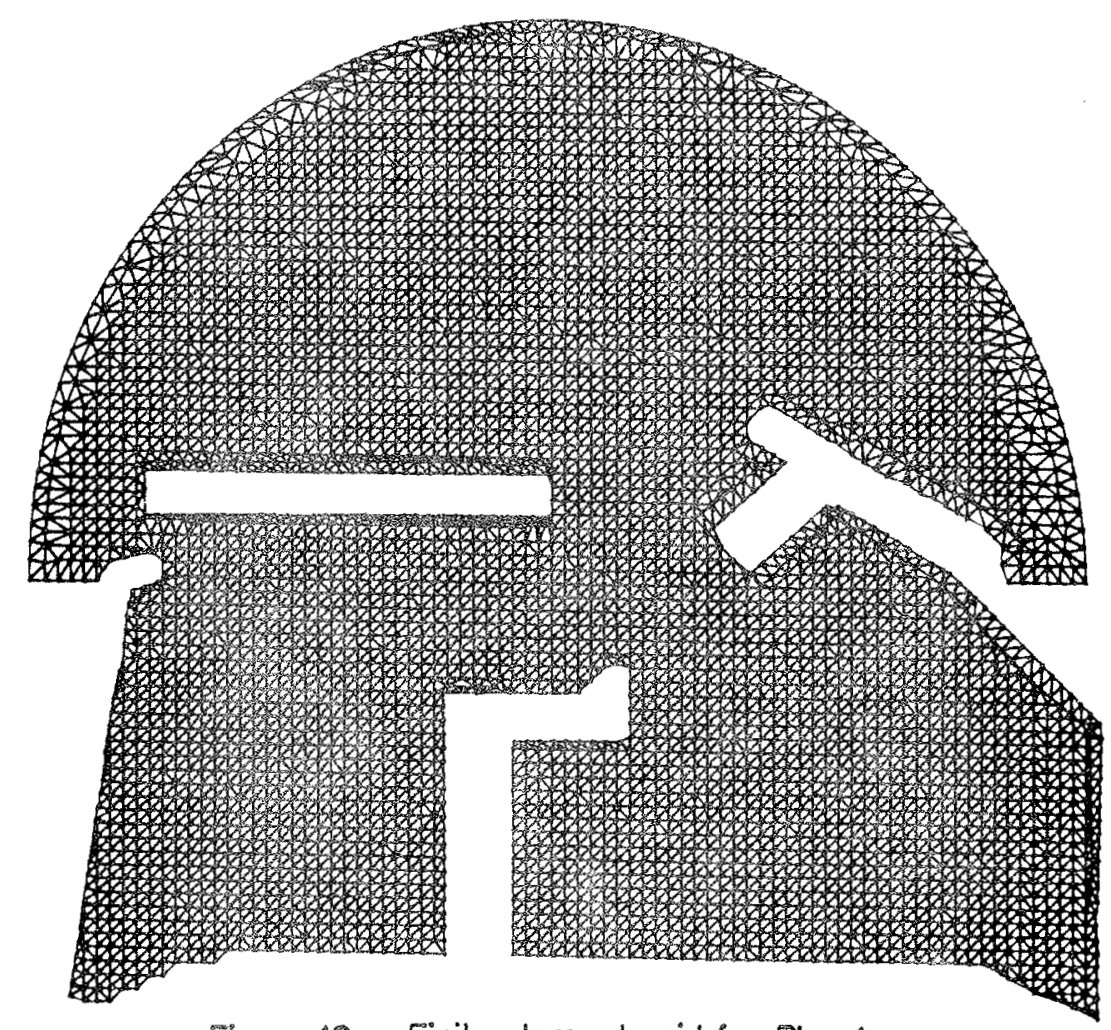

Figure 10. Finite element grid for Plan 1

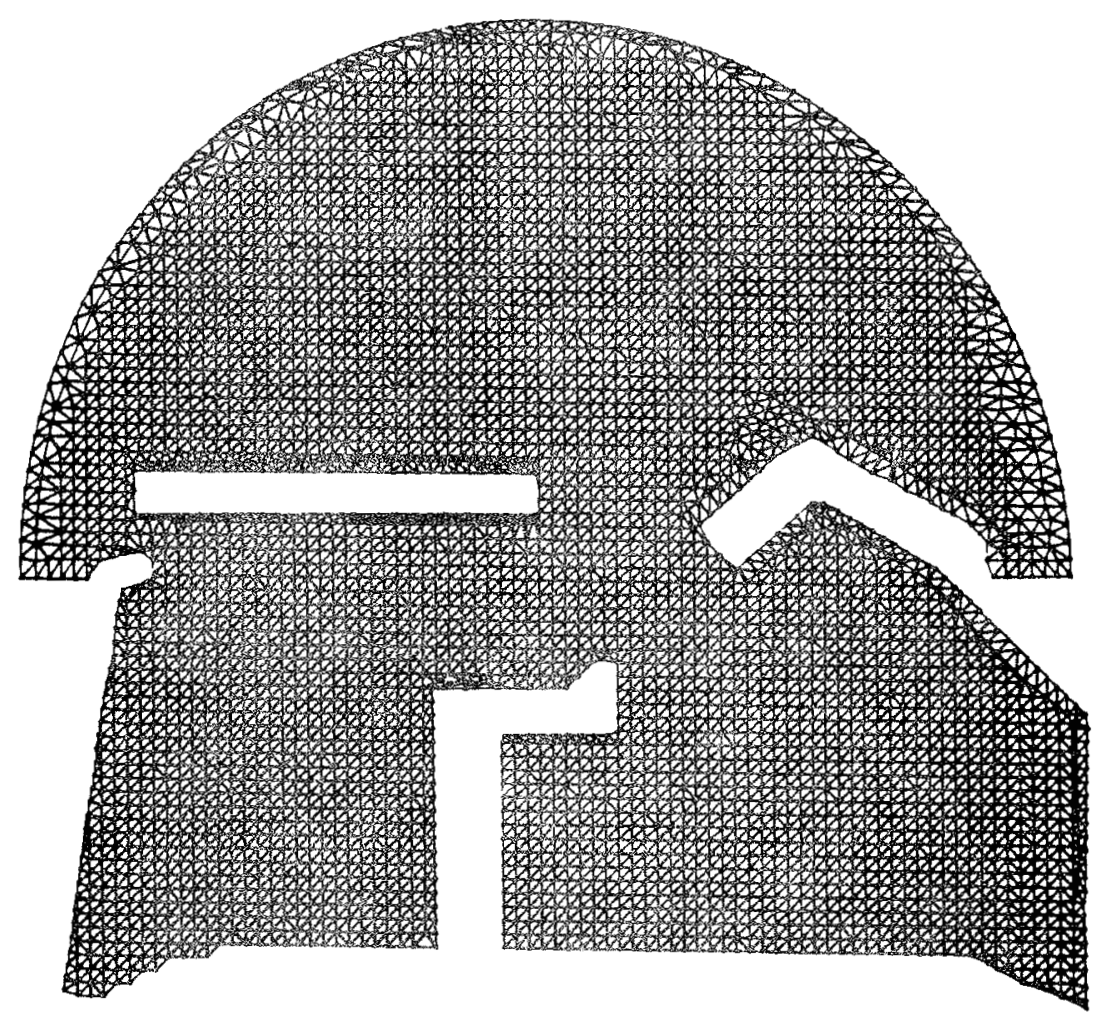

Figure 1\% Finite element grid for Plan 2 
38. The grid bathymetry was obtained from District hydrographic surveys of the study area based on conditions determined in 1989. A portion of the reef located south of the west mole breakwater was included in the bathymetry. A tide level of $5.5 \mathrm{ft}$ (POD recommendation) was added to the Mean Lower Low Water Level (MLLW) of the hydrographic survey for all tests. The reflection coefficients were calculated using methods in the Shore Protection Manual (SPM 1984), and were refined upon recommendation from POD. The assigned reflection coefficients were 0.25 for the $1: 2$ sloped detached breakwater and $1: 2$ sloped seaward sides of the east and west mole breakwaters, 0.35 for the $1: 1.5$ sloped harbor sides of the east and west mole breakwaters, 0.30 for the wave absorber and interior mole, and 0.1 for the beach. The boundaries along the diameter of the semicircle were fully transmissive. The bottom friction factor ( $\beta$ ) was set at 0.05 for all elements.

39. The grid for this study was initially developed at WES' Information Technology Laboratory (ITL). The grid was massaged and refined by CERC for application to HARBD. This procedure for HARBD grid generation was an original WES application.

\section{Harbor Wave Response Simulation}

40. Since 14 of the 39 deepwater wave period and direction combinations input to RCPWAVE refracted to duplicate angles at the HARBD boundary (Table 2 ), only 25 input wave period and direction combinations were necessary to establish the 39 refracted deepwater wave conditions at the harbor. The RCPWAVE-HARBD grid interface and the location of the selected RCPWAVE output cells are shown in Figure 12. The output cells selected were coincident with the HARBD outer boundary and were directed toward the harbor. A normalized unit wave height was used for all input combinations to establish a wave height to incident wave height amplification factor. The RCPWAVE 


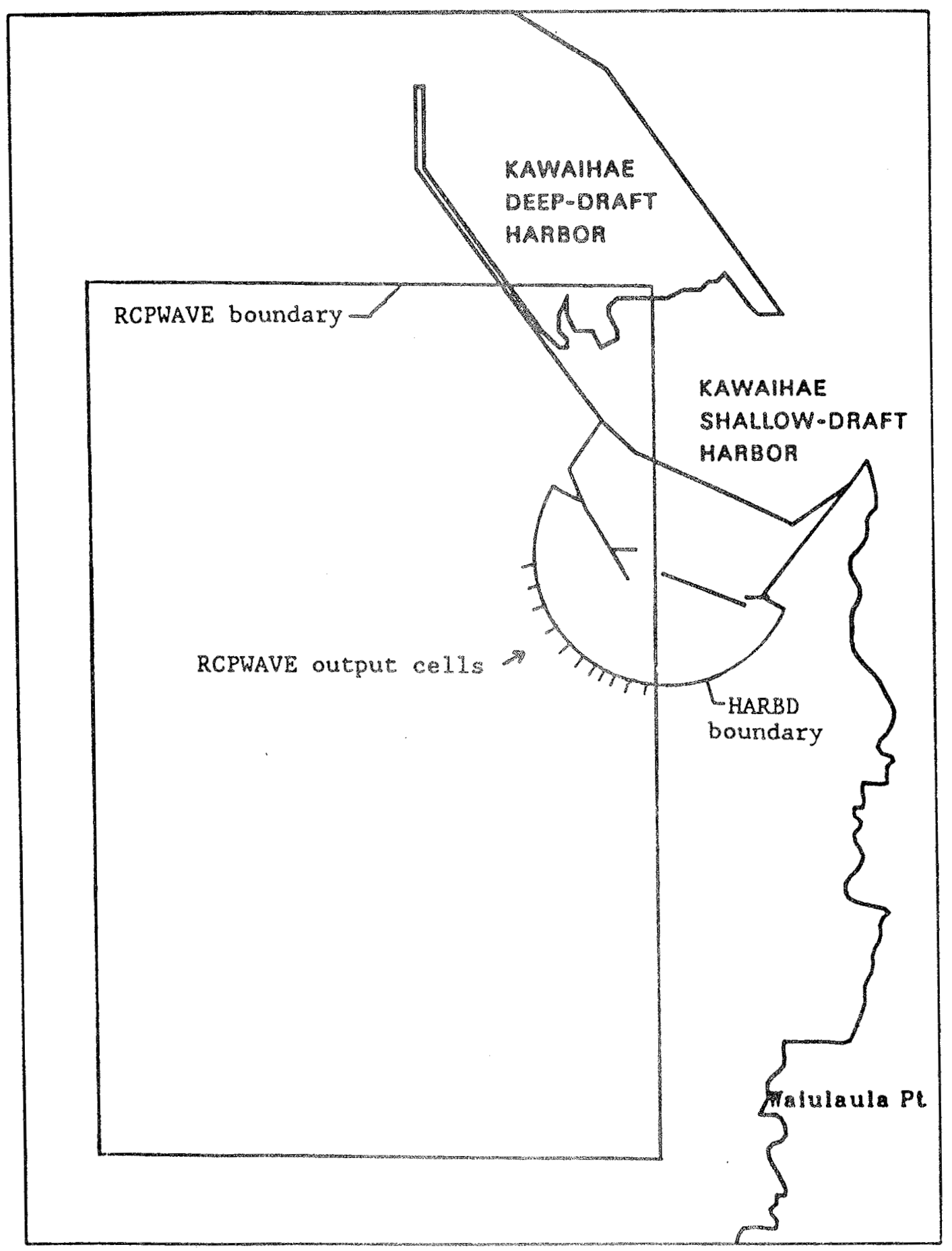

Figure 12. RCWWAVE-HARBD grid interface 
amplification factors were multiplied with the HARBD amplification factors corresponding to each deepwater condition. The 25 wave period and direction combinations were tested for both Plans 1 and 2. All simulations were run on the WES CRAY Y-MP supercomputer facilities.

41. Nineteen output "basins" were selected to determine the wave response throughout the harbor. A basin is an area consisting of a specified number of elements from which the mean value of the results of those elements is calculated. The basin locations were the same for Plans 1 and 2 and selected by CERC, POD, and HQUSACE. They are shown in Figure 13. Basins 1 through 12 are located in the harbor berthing areas with a $1 \mathrm{ft}$ maximum wave height criterion, and basins 13 through 19 are located throughout the harbor channels and turning basin with a $2 \mathrm{ft}$ maximum wave height criterion. The resulting HARBD amplification factors at these basins for each deepwater wave condition were saved and tabulated for Plans 1 and 2 (Tables 3 through 16).

42. The percent occurrence of wave heights exceeding $1 \mathrm{ft}$ in the berthing areas and $2 \mathrm{ft}$ in the channel and turning basin were calculated for Plans 1 and 2. The procedure to calculate the percent occurrence of wave heights exceeding the $1 \mathrm{ft}$ maximum criterion is as follows. The largest HARBD amplification factor of basins 1 through 12, was selected for each deepwater wave condition. The selected HARBD amplification factors were then multiplied by the RCPWAVE amplification factors corresponding to each deepwater wave condition. The wave conditions resulting in the largest wave heights were then calculated by multiplying the HARBD-RCPWAVE amplification factor for each deepwater condition by the wave height intervals of the corresponding percent occurrence table. The percent occurrence of those resulting wave heights which exceeded $1 \mathrm{ft}$ were then tabulated. The same procedure was used to calculate the percent occurrence of wave heights exceeding the $2 \mathrm{ft}$ criterion 


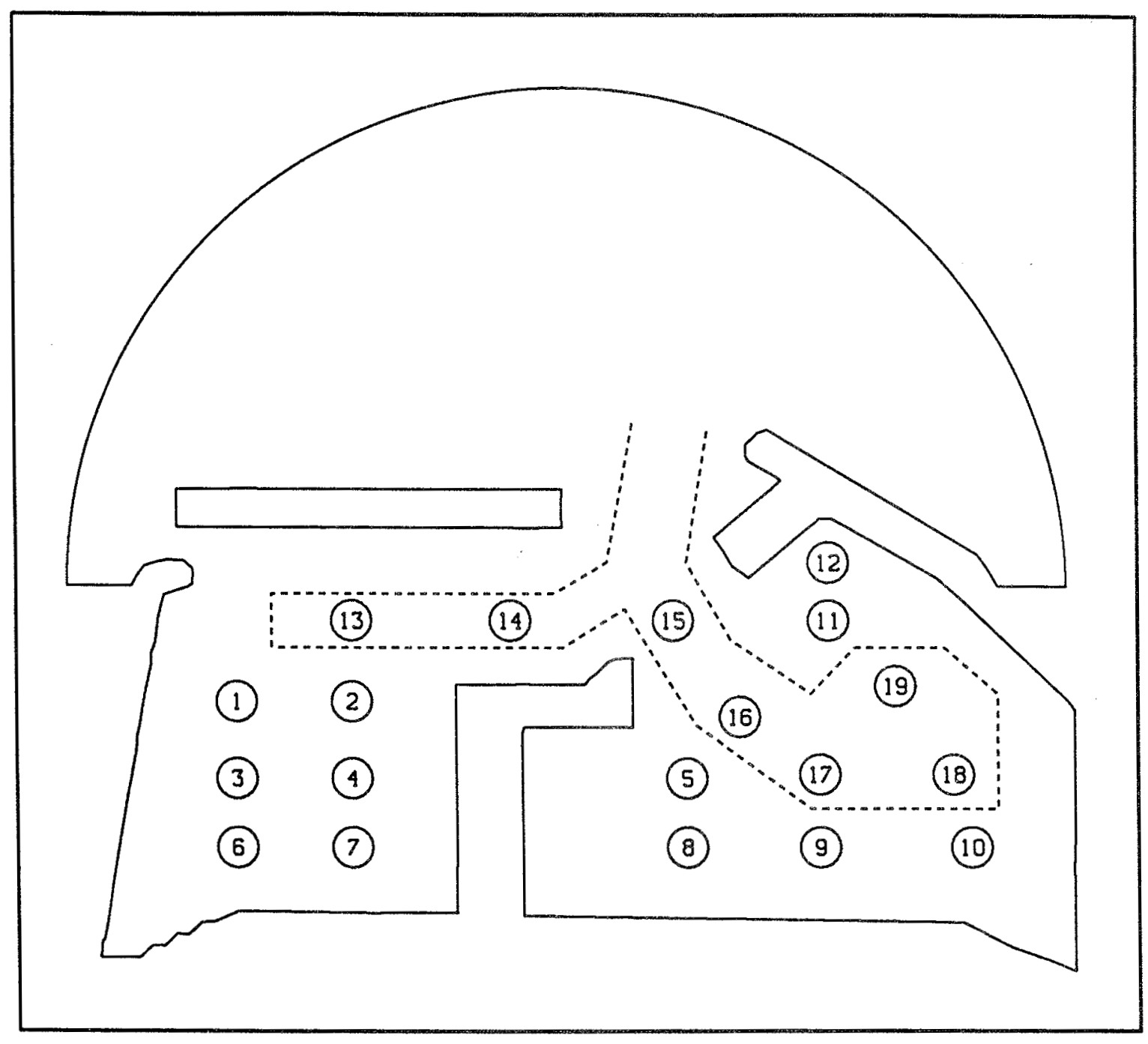

Figure 13. Output basin locations for Plans 1 and 2 
in basins 13 through 19 .

43. The resulting HARBD-RCPWAVE basin amplification factors of Plans 1 and 2 for each deepwater wave condition are plotted in Plates 1-39. The plots show that the amplification factors from Plan 2 exceed those of Plan 1 for 90 percent of the deepwater conditions.

44. Table 17 is a tabulation of the largest resulting HARBD-RCPWAVE amplification factors from each deepwater wave direction, the corresponding deepwater wave period, and the basin in which they occurred for the 1 and $2 \mathrm{ft}$ maximum criteria of Plans 1 and 2. Table 17 shows that the largest wave amplification factors and thus largest wave heights occurring in the $1 \mathrm{ft}$ maximum criterion berthing areas (basins 1 through 12) were caused by the 11 sec wave from directions of 202.5, 225.0, 247.5, and $292.5 \mathrm{deg}$, and the $7 \mathrm{sec}$ wave from directions of $270.0,315.0$, and 337.5 deg. The largest wave heights from directions of $202.5,225.0,247.5,270.0$, and $292.5 \mathrm{deg}$ occurred in basin 5 and those from 315.0 and $337.5 \mathrm{deg}$ occurred in basin 2. Referring to Figure 13, basins 2 and 5 are located on the east and west sides of the wave absorber. The largest wave heights occurring in the $2 \mathrm{ft}$ maximum criterion turning basin and channels (basins 13 through 19) resulted from the 11 sec wave from directions of 202.5, 225.0, and $247.5 \mathrm{deg}$, and the $7 \mathrm{sec}$ wave from directions of $270.9,292.5,315.0$, and $337.5 \mathrm{deg}$. The largest wave heights from $202.5,225.0,247.5$, and $270.0 \mathrm{deg}$ occurred in basin 15 and those from $292.5,315.0$ and 337.5 deg occurred in basin 14. Basin 14 is located in the access channel and basin 15 in the entrance channel. The worst case wave condition for both the maximum 1 and 2 ft criteria areas was the $7 \mathrm{sec}$ wave from $315 \mathrm{deg}$.

45. In evaluating Table 17 for Plan 2, the largest amplification factors and thus largest wave heights occurring in the berthing areas (basins 
1 through 12) are caused by the $11 \mathrm{sec}$ wave from all directions with the exception of the $7 \mathrm{sec}$ fetch limited wave from $337.5 \mathrm{deg}$. The $11 \mathrm{sec}$ wave from 270.0 deg occurred in basin 8 and the remaining waves occurred in basin 5. Basin 8 is located at the back of the harbor, on the west side of the wave absorber, and below basin 5 . The largest wave heights occurring in the turning basin and channels (basins 13 through 19) result from the 11 sec wave from directions of $202.5,225.0,247.5,270.0$, and $292.5 \mathrm{deg}$, and the $7 \mathrm{sec}$ wave from 315.0 and $337.5 \mathrm{deg}$. The $11 \mathrm{sec}$ waves occurred in basin 15 and the $7 \mathrm{sec}$ waves occurred in basin 14. The worst case wave conditions for Plan 2 were the $11 \mathrm{sec} 225.0 \mathrm{deg}$ wave for the maximum $1 \mathrm{ft}$ criterion and the $7 \mathrm{sec}$ 315.0 deg wave for the maximum $2 \mathrm{ft}$ criterion.

46. The percent occurrence of wave heights exceeding the maximum 1 and 2 ft criteria more than approximately 10 percent of the time were calculated using the percent occurrence tables of deepwater conditions and the largest HARBD-RCPWAVE amplifications factors for Plans 1 and 2. These results are given in Tables 18 through 21 and illustrated in Figures 14 and 15 . Although wave breaking was not taken into account in Tables 18 through 20, the higher wave heights would most likely have broken over the reef, thus reducing the wave heights in the harbor. With a controlling water depth of 8 feet and a water level of $5.5 \mathrm{ft}$, those waves breaking over the reef may still result in sizable waves which exceed the design criteria.

47. In evaluating the resulting percent occurrences tables, Tables 18 through 21, and Figures 14 and 15, it is apparent that the waves approaching from the west southwest (202.5 to 270.0 deg) directions are insignificant in comparison to the waves approaching from the northwest (292.5 to $337.5 \mathrm{deg}$ ) directions. The percentage of wave heights exceeding the maximum $1 \mathrm{ft}$ criterion for Plan 1 and 2 is 10.9 percent and 21.4 percent, respectively, and 


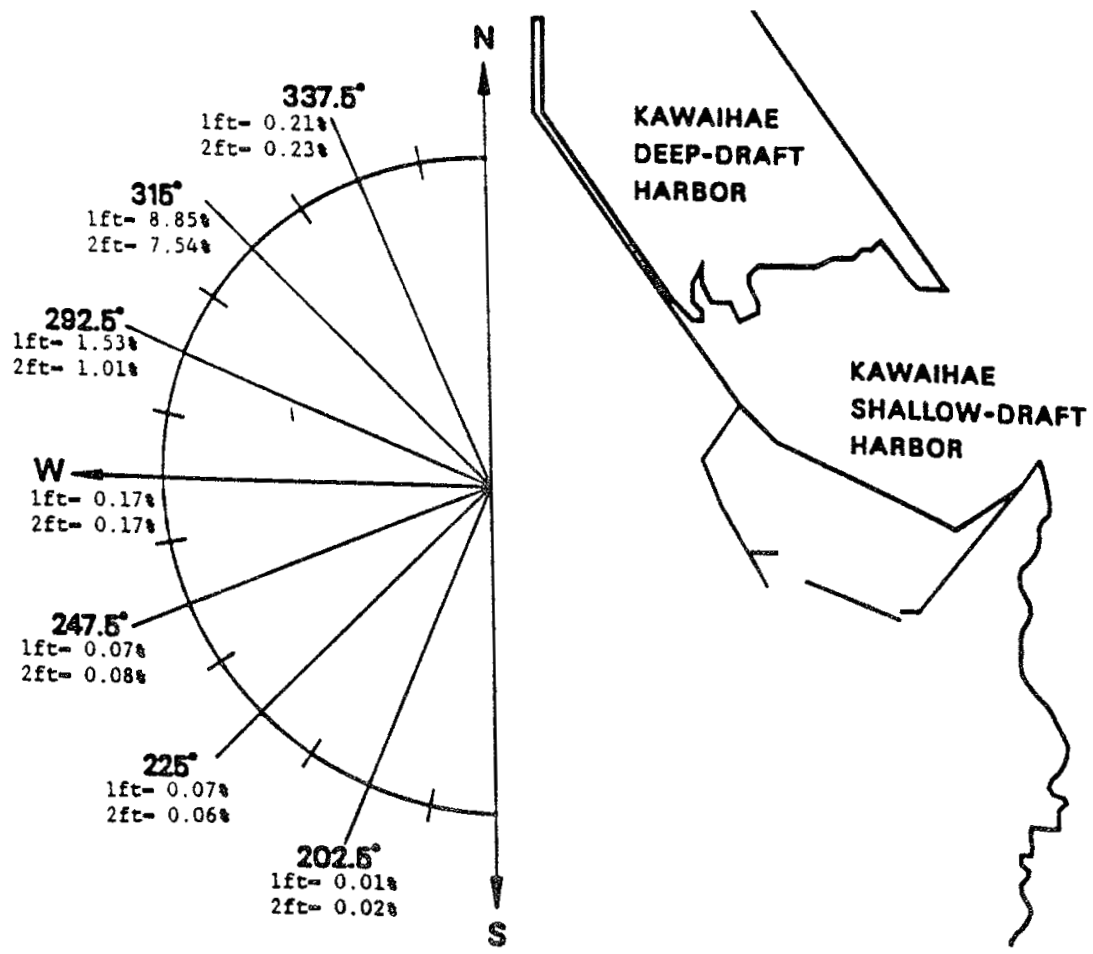

Figure 14. Plan 1 - Percent occurrence of wave heights exceeding 1 and $2 \mathrm{ft}$ criteria

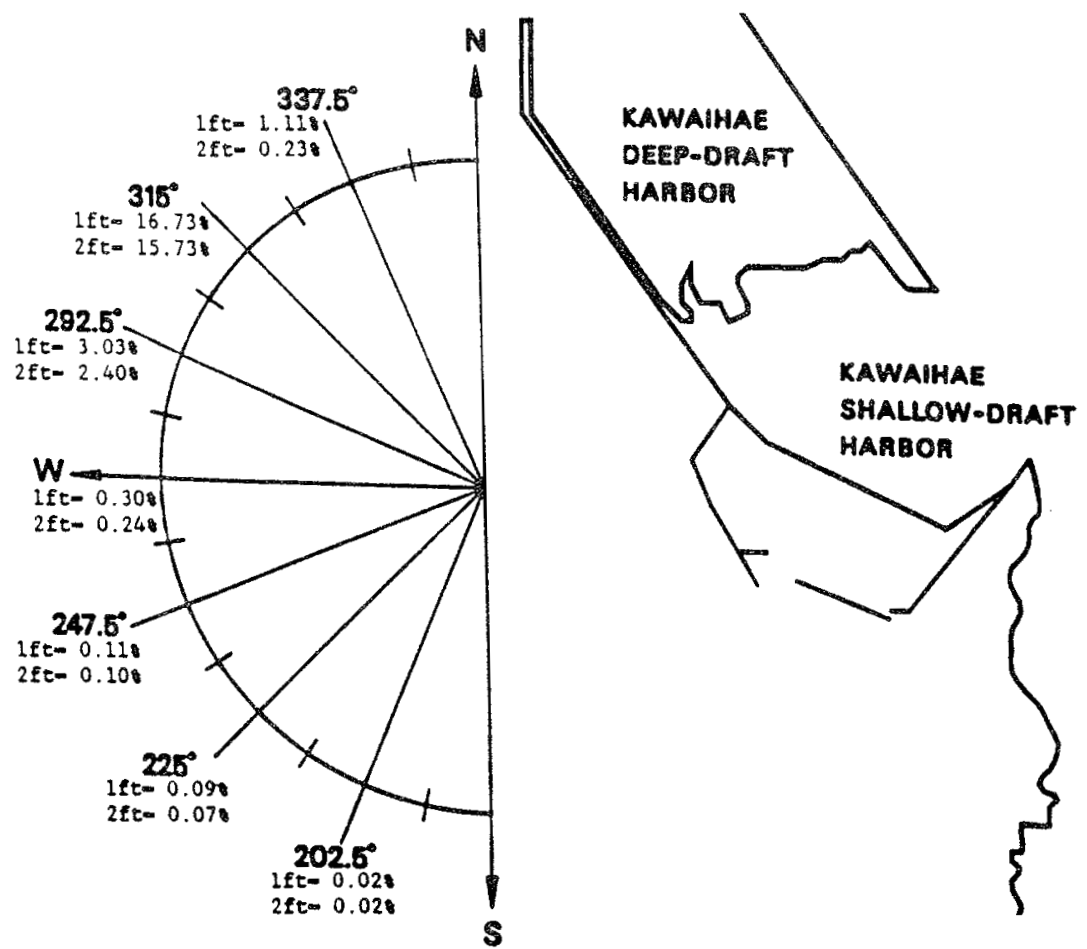

Figure 15. Plan 2 - Percent occurrence of wave heights exceeding 1 and 2 ft criteria 
the percentage of wave heights exceeding the maximum 2 ft criterion for Plan 1 and 2 is 9.1 percent and 18.8 percent, respectively. These values are conservative since they represent the basins with the largest wave heights in the harbor. When one considers the uncertainties in augmenting the WIS deepwater data, approximating values in the RCPWAVE modeling, and estimating the harbor reflection coefficients, confidence can be held in the Plan 1 tolerance limits meeting the HQUSACE criteria of not exceeding 1 and 2 ft more than approximately 10 percent of the time. The plan 2 values however, do exceed the HQUSACE criteria. The removal of the west breakwater tip reduces protection from a large percentage of waves occurring fxom the northwest and thus significantly increased wave heights inside the harbor. 
PART V: CONCLUSIONS

48. The numerical model studies and results described in this report should be seen in light of the following considerations:

a. The deepwater waves were based on estimates from WIS and MCCP data. Generation of more accurate incident wave data would improve the validity of the overall results.

b. The input water level and revised SPM reflection coefficients were based on estimates from POD and were not re-evaluated. Research in this area continues at CERC for better guidance.

c. The following assumptions were made in the implementation of the HARBD numerical model used in this study. The model does not consider wave transmission through the breakwater, overtopping of structures, and wave breaking effects in the entrance channe1; structure crest elevations were not tested or optimized; currents in the channel through the reef and nonlinear effects were neglected as well as other than depthlimited wave breaking over the reef; and diffraction around the structure ends was represented by diffraction around a blunt vertical wall with specified reflection coefficients. If wave transmission through the breakwater and overtopping of structures did occur in the harbor, the increased energy would result in larger wave heights than predicted. The presence of wave currents and breaking would increase hazardous navigation, however wave breaking would reduce the energy in the harbor and result in lower wave heights than predicted. The primary effects which must be considered within a harbor such as Kawaihae are wave refraction, diffraction, and dissipation effects for which the model has been well verified.

d. The HARBD model uses monochromatic waves only.

49. Based on the results of this study, the following conclusions were

reached:

a. The POD plan based on the GDM ( $P$ lan 1) is satisfactory relative to the design criteria of the project for protecting the harbor from the incident wave climate. Plan 1 is recommended.

b. Plan 2, which is identical to Plan 1 with the exception of the reduced west mole breakwater tip, will not protect the harbor adequately from the deepwater waves which refract to incident angles from the northwest. 


\section{REFERENCES}

Berkhoff, J.C.W. 1972. "Computation of Combined Refraction-Diffraction," " Proceedings of the 13th Internal Conference on Coastal Engineering, American Society of Civil Engineers, Vol. 1, pp 471-490.

Berkhoff, J.C.W. 1976. "Mathematical Models for Simple Harmonic Linear Water Waves, Wave Diffraction and Refraction," Publication No. 1963, Delft Hydraulics Laboratory, Delft, The Netherlands.

Berkhoff, J.C.W., Booij, N., and Radder, A.C. 1982. "Verification of Numerical Wave Propagation Models for Simple Harmonic Linear Water Waves, "Coastal Engineering, Vol. 6, pp 255-279.

Bottin, R.R., Jx., Sargent, F.E., and Mize, M.G. 1985. "Fisherman's Wharf Area, San Francisco Bay, California, Design for Wave Protection: Physical and Numerical Model Investigation," Technical Report CERC-86-7, US Army Engineer Waterways Experiment Station, Vicksburg, Miss.

Chen, H.S., and Houston, J.R. 1987. "Calculation of Water Oscillation in Coastal Harbors: HARBS and HARBD User's Manual, "Instruction Report CERC-87-2, US Army Engineer Waterways Experiment Station, Vicksburg, Miss.

Chen, H.S., and Mei, C.C. 1974. "Oscillations and Wave Forces in an Offshore Harbor," Report No. 190, Department of Civil Engineering, Massachusetts Institute of Technology, Cambridge, MA.

Clausner, J.E., and Abe1, C.E. 1986. "Contained Aquatic Disposal: Site Location and Cap Material Investigations for Outer Indiana Harbor, IN. and Southern Lake Michigan," Technical Report, US Army Engineer Waterways Experiment Station, Vicksburg, Miss.

Corson, W.D., Abel, C.E., Brooks, R.M., Farrar, P.D., Groves, B.J., Jensen, R.E., Payne, J.B., Ragsdale, D.S., and Tracy, B.A. 1986. "Pacific Coast Hindcast Deepwater Wave Information," WTS Report 14, US Army Engineer Waterways Experiment Station, Vicksburg, Miss.

Crawford, P.L., and Chen, H.S. 1988. "Comparison of Numerical and Physical Models of Wave Response in a Harbor, "Miscellaneous Paper CERC-88-11, US Army Engineer Waterways Experiment Station, Vicksburg, Miss.

Ebersole, B.A., Cialone, M.A., and Pratex, M.D. 1986. "Regional Coastal Processes Numerical Modeling System Report 1: RCPWAVE - A Linear Wave Propagation Model for Engineering Use, "Technical Report CERC-86-4, US Army Engineer Waterways Experiment Station, Vicksburg, Miss.

Farrar, P.D., and Chen, H.S. 1986. "Wave Response of the Proposed Harbor at Agat, Guam: Numerical Model Investigation," Technical Report CERC-87-4, US Army Engineer Waterways Experiment Station, Vicksburg, Miss. 
Gilhousen, D.B., Changery, M.J., Baldwin, R.G., Karl, T.R., and Burgin, M.G. 1986. "Climatic Summaries for NDBC Data Buoys," National Data Buoy Center, NSTL, Miss.

Houston, J.R 1976. "Long Beach Harbor Numerical Analysis of Harbor Oscillation; Existing Conditions and Proposed Improvements," Miscellaneous Paper H-76-20, Report 1, US Army Engineer Waterways Experiment Station, Vicksburg, Miss.

Houston, J.R. 1981. "Combined Refraction and Diffraction of Short Waves Using the Finite Element Method," Applied Ocean Research, Vol. 3, No. 4, pp. 163170 .

Kaihatu, J.M., Lillycrop, L.S., and Thompson, E.F. 1989. "Effects of Entrance Channel Dredging at Morro Bay, California," Miscellaneous Paper CERC-89-3, US Army Engineer Waterways Experiment Station, Vicksburg, Miss.

Shore Protection Manual 1984. 2 vo1. US Army Engineer Waterways Experiment Station, Vicksburg, Miss.

US Army Corps of Engineers. 1987. "Coastal Data Information Program Annual Report 1986," IMR Reference no. 87-1, California Department of Boating and Waterways, La Jolla, CA.

US Army Engineer Division, Pacific Ocean. 1971. "General Design Memorandum for Kawaihae Harbor for Light-Draft Vessels," Honolulu, Hawaii.

US Naval Weather Service Command. 1976. "Summary of Synoptic Meteorologica1 Observations," prepared by the National Climatic Data Center, Asheville, N.C.

Weishar, L.L. and Aubrey, D.G. 1986. "A study of Inlet Hydraukics at Green Harbor, Marshfield, Mass.," Miscellaneous Report CERC 88-10, US Army Engineer Waterways Experiment Station, Vicksburg, Miss. 
Table 1

Percent Occurrence of Wave Heights Versus Direction ${ }^{* *}$

\begin{tabular}{|c|c|c|c|c|c|c|c|c|}
\hline Wave Height & Wave & cecti & 2, deg & from & iich we & jes ap & (oach) & \\
\hline $\mathrm{ft}$ & 202.5 & 225 & 247.5 & 270 & $\underline{292.5}$ & 315 & 337.5 & Total \\
\hline $0-3$ & 0.04 & 0.10 & 0.13 & 0.31 & 2.75 & 16.86 & 20.88 & 41.03 \\
\hline $3-6$ & 0.02 & 0.07 & 0.09 & 0.20 & 1.82 & 11.74 & 16.05 & 29.97 \\
\hline $6-9$ & 0.02 & 0.02 & 0.05 & 0.11 & 0.34 & 4.61 & 7.52 & 12.65 \\
\hline $9-12$ & $*$ & 0.02 & 0.04 & 0.09 & 1.02 & 5.56 & 5.30 & 12.12 \\
\hline $12-15$ & $*$ & 0.01 & 0.01 & 0.01 & 0.47 & 2.02 & 1.10 & 3.63 \\
\hline$>15$ & $\underline{0.00}$ & 0.02 & 0.01 & $\underline{0.02}$ & $\underline{0.06}$ & 0.45 & $*$ & 0.56 \\
\hline TOTAL & 0.08 & 0.24 & 0.33 & 0.74 & 6.46 & 41.31 & 50.85 & 100.0 \\
\hline
\end{tabular}

** Percent occurrence is below table resolution 
Table 2

RCPWAVE Offshore and Refracted Wave Conditions

\begin{tabular}{|c|c|c|c|}
\hline $\begin{array}{l}\text { Period } \\
(\text { sec })\end{array}$ & $\begin{array}{l}\text { Offishore } \\
\text { Direction } \\
\quad \text { (deg) }\end{array}$ & $\begin{array}{l}\text { Refracted } \\
\text { Direction } \\
\quad(\text { deg })\end{array}$ & $\begin{array}{c}\text { Amplification } \\
\text { Factor }\end{array}$ \\
\hline 7 & 202.5 & 230.0 & 0.60 \\
\hline 9 & 202.5 & 234.0 & 0.69 \\
\hline 11 & 202.5 & 240.0 & 0.70 \\
\hline 7 & 225.0 & 234.0 & 0.80 \\
\hline 9 & 225.0 & 237.0 & 0.75 \\
\hline 11 & 225.0 & 240.0 & 0.75 \\
\hline 13 & 225.0 & 242.0 & 0.70 \\
\hline 15 & 225.0 & 242.0 & 0.75 \\
\hline 17 & 225.0 & 243.0 & 0.75 \\
\hline 20 & 225.0 & 244.0 & 0.70 \\
\hline 7 & 247.5 & 240.0 & 0.70 \\
\hline 9 & 247.5 & 240.0 & 0.70 \\
\hline 11 & 247.5 & 240.0 & 0.70 \\
\hline 13 & 247.5 & 240.0 & 0.70 \\
\hline 15 & 247.5 & 240.0 & 0.70 \\
\hline 17 & 247.5 & 240.0 & 0.70 \\
\hline 20 & 247.5 & 240.0 & 0.70 \\
\hline 7 & 270.0 & 245.0 & 0.65 \\
\hline 9 & 270.0 & 240.0 & 0.60 \\
\hline 11 & 270.0 & 240.0 & 0.65 \\
\hline 13 & 270.0 & 240.0 & 0.65 \\
\hline 15 & 270.0 & 240.0 & 0.65 \\
\hline 17 & 270.0 & 240.0 & 0.65 \\
\hline 20 & 270.0 & 240.0 & 0.65 \\
\hline 7 & 292.5 & 250.0 & 0.70 \\
\hline 9 & 292.5 & 245.0 & 0.70 \\
\hline 11 & 292.5 & 245.0 & 0.73 \\
\hline 13 & 292.5 & 240.0 & 0.70 \\
\hline 15 & 292.5 & 240.0 & 0.70 \\
\hline 17 & 292.5 & 240.0 & 0.80 \\
\hline 20 & 292.5 & 240.0 & 0.90 \\
\hline 7 & 315.0 & 255.0 & 0.70 \\
\hline 9 & 315.0 & 246.0 & 0.70 \\
\hline 11 & 315.0 & 243.0 & 0.60 \\
\hline 13 & 315.0 & 240.0 & 0.55 \\
\hline 15 & 315.0 & 240.0 & 0.60 \\
\hline 17 & 315.0 & 237.0 & 0.65 \\
\hline 20 & $315: 0$ & 238.0 & 0.63 \\
\hline 7 & 337.5 & 260.0 & 0.53 \\
\hline
\end{tabular}


Table 3

HARBD Wave Amplification Factors for Proposed Improvements Plan 1. Wave Angle $=202.5 \mathrm{deg}$

\begin{tabular}{|c|c|c|c|c|c|c|c|}
\hline \multicolumn{8}{|c|}{ Wave Period, sec } \\
\hline Basin & 7 & 9 & 11 & 13 & 15 & 17 & 20 \\
\hline 1 & 0.08 & 0.18 & 0.12 & $*$ & $*$ & $*$ & * \\
\hline 2 & 0.09 & 0.22 & 0.11 & & & & \\
\hline 3 & 0.06 & 0.13 & 0.05 & & & & \\
\hline 4 & 0.08 & 0.17 & 0.07 & & & & \\
\hline 5 & 0.30 & 0.11 & 0.37 & & & & \\
\hline 6 & 0.06 & 0.12 & 0.08 & & & & \\
\hline 7 & 0.07 & 0.12 & 0.03 & & & & \\
\hline 8 & 0.22 & 0.09 & 0.29 & & & & \\
\hline 9 & 0.27 & 0.18 & 0.27 & & & & \\
\hline 10 & 0.19 & 0.13 & 0.22 & & & & \\
\hline 11 & 0.20 & 0.12 & 0.23 & & & & \\
\hline 12 & 0.10 & 0.07 & 0.11 & & & & \\
\hline 13 & 0.08 & 0.17 & 0.10 & & & & \\
\hline 14 & 0.21 & 0.49 & 0.27 & & & & \\
\hline 15 & 0.52 & 0.16 & 0.53 & & & & \\
\hline 16 & 0.38 & 0.20 & 0.32 & & & & \\
\hline 17 & 0.31 & 0.17 & 0.24 & & & & \\
\hline 18 & 0.17 & 0.13 & 0.13 & & & & \\
\hline 19 & 0.18 & 0.12 & 0.16 & & & & \\
\hline
\end{tabular}

* No data for these wave periods 
Table 4

HARBD Wave Amplification Factors for Proposed Improvements

$\underline{P l a n} 1$. Wave Angle $=225 \mathrm{deg}$

\begin{tabular}{|c|c|c|c|c|c|c|c|}
\hline \multicolumn{8}{|c|}{ Wave Period, sec } \\
\hline Basin & 7 & 9 & 11 & 13 & 15 & 17 & 20 \\
\hline 1 & 0.22 & 0.14 & 0.12 & 0.11 & 0.19 & 0.13 & 0.08 \\
\hline 2 & 0.23 & 0.18 & 0.11 & 0.11 & 0.20 & 0.14 & 0.10 \\
\hline 3 & 0.15 & 0.16 & 0.05 & 0.07 & 0.15 & 0.11 & 0.14 \\
\hline 4 & 0.22 & 0.09 & 0.07 & 0.08 & 0.11 & 0.09 & 0.05 \\
\hline 5 & 0.10 & 0.04 & 0.30 & 0.12 & 0.18 & 0.11 & 0.14 \\
\hline 6 & 0.12 & 0.08 & 0.08 & 0.04 & 0.06 & 0.06 & 0.09 \\
\hline 7 & 0.18 & 0.05 & 0.03 & 0.04 & 0.10 & 0.07 & 0.02 \\
\hline 8 & 0.08 & 0.05 & 0.28 & 0.13 & 0.16 & 0.07 & 0.08 \\
\hline 9 & 0.13 & 0.12 & 0.26 & 0.11 & 0.14 & 0.06 & 0.07 \\
\hline 10 & 0.14 & 0.11 & 0.22 & 0.07 & 0.07 & 0.04 & 0.04 \\
\hline 11 & 0.21 & 0.11 & 0.23 & 0.10 & 0.08 & 0.06 & 0.05 \\
\hline 12 & 0.13 & 0.06 & 0.11 & 0.09 & 0.06 & 0.04 & 0.05 \\
\hline 13 & 0.19 & 0.16 & 0.10 & 0.09 & 0.21 & 0.14 & 0.12 \\
\hline 14 & 0.30 & 0.46 & 0.27 & 0.25 & 0.32 & 0.23 & 0.25 \\
\hline 15 & 0.29 & 0.18 & 0.53 & 0.25 & 0.31 & 0.16 & 0.22 \\
\hline 16 & 0.12 & 0.13 & 0.32 & 0.16 & 0.22 & 0.10 & 0.14 \\
\hline 17 & 0.17 & 0.13 & 0.24 & 0.08 & 0.15 & 0.09 & 0.12 \\
\hline 18 & 0.16 & 0.12 & 0.13 & 0.04 & 0.09 & 0.06 & 0.05 \\
\hline 19 & 0.18 & 0.12 & 0.16 & 0.08 & 0.07 & 0.03 & 0.07 \\
\hline
\end{tabular}


Table 5

HARBD Wave Amplification Factors for Proposed Improvements

Plan 1, Wave Angle $=247.5 \mathrm{deg}$

\begin{tabular}{|c|c|c|c|c|c|c|c|}
\hline \multicolumn{8}{|c|}{ Wave Period, sec } \\
\hline Basin & 7 & 9 & 11 & 13 & 15 & 17 & 20 \\
\hline 1 & 0.15 & 0.16 & 0.12 & 0.11 & 0.19 & 0.12 & 0.08 \\
\hline 2 & 0.19 & 0.22 & 0.11 & 0.13 & 0.20 & 0.14 & 0.10 \\
\hline 3 & 0.13 & 0.21 & 0.05 & 0.08 & 0.15 & 0.13 & 0.12 \\
\hline 4 & 0.14 & 0.13 & 0.07 & 0.09 & 0.11 & 0.09 & 0.05 \\
\hline 5 & 0.14 & 0.13 & 0.29 & 0.06 & 0.18 & 0.16 & 0.12 \\
\hline 6 & 0.12 & 0.10 & 0.08 & 0.04 & 0.07 & 0.09 & 0.09 \\
\hline 7 & 0.06 & 0.08 & 0.03 & 0.05 & 0.10 & 0.07 & 0.02 \\
\hline 8 & 0.12 & 0.14 & 0.27 & 0.07 & 0.16 & 0.11 & 0.08 \\
\hline 9 & 0.16 & 0.15 & 0.26 & 0.07 & 0.15 & 0.10 & 0.07 \\
\hline 10 & 0.14 & 0.15 & 0.21 & 0.06 & 0.07 & 0.06 & 0.04 \\
\hline 11 & 0.13 & 0.19 & 0.23 & 0.09 & 0.09 & 0.10 & 0.06 \\
\hline 12 & 0.09 & 0.10 & 0.11 & 0.07 & 0.07 & 0.07 & 0.06 \\
\hline 13 & 0.14 & 0.20 & 0.10 & 0.11 & 0.22 & 0.15 & 0.12 \\
\hline 14 & 0.35 & 0.43 & 0.27 & 0.26 & 0.31 & 0.30 & 0.25 \\
\hline 15 & 0.33 & 0.32 & 0.53 & 0.16 & 0.33 & 0.25 & 0.22 \\
\hline 16 & 0.21 & 0.20 & 0.32 & 0.09 & 0.22 & 0.16 & 0.14 \\
\hline 17 & 0.22 & 0.16 & 0.24 & 0.06 & 0.15 & 0.15 & 0.12 \\
\hline 18 & 0.12 & 0.17 & 0.13 & 0.03 & 0.10 & 0.09 & 0.05 \\
\hline 19 & 0.14 & 0.18 & 0.16 & 0.07 & 0.07 & 0.05 & 0.07 \\
\hline
\end{tabular}


Table 6

HARBD Wave Amplification Factors for Proposed Improvements

Plan 1. Wave Angle $=270 \mathrm{deg}$

\begin{tabular}{|c|c|c|c|c|c|c|c|}
\hline \multicolumn{8}{|c|}{ Wave Period, sec } \\
\hline Basin & 7 & 9 & 11 & 13 & 15 & 17 & 20 \\
\hline 1 & 0.16 & 0.16 & 0.12 & 0.11 & 0.19 & 0.12 & 0.08 \\
\hline 2 & 0.25 & 0.22 & 0.11 & 0.13 & 0.20 & 0.14 & 0.10 \\
\hline 3 & 0.15 & 0.21 & 0.05 & 0.08 & 0.15 & 0.13 & 0.14 \\
\hline 4 & 0.15 & 0.13 & 0.07 & 0.09 & 0.11 & 0.09 & 0.05 \\
\hline 5 & 0.34 & 0.13 & 0.37 & 0.06 & 0.18 & 0.16 & 0.14 \\
\hline 6 & 0.17 & 0.10 & 0.08 & 0.04 & 0.07 & 0.09 & 0.09 \\
\hline 7 & 0.10 & 0.08 & 0.03 & 0.05 & 0.10 & 0.07 & 0.02 \\
\hline 8 & 0.27 & 0.14 & 0.29 & 0.07 & 0.16 & 0.11 & 0.08 \\
\hline 9 & 0.27 & 0.15 & 0.27 & 0.07 & 0.15 & 0.10 & 0.07 \\
\hline 10 & 0.21 & 0.15 & 0.22 & 0.06 & 0.07 & 0.06 & 0.04 \\
\hline 11 & 0.22 & 0.19 & 0.23 & 0.09 & 0.09 & 0.10 & 0.06 \\
\hline 12 & 0.12 & 0.10 & 0.11 & 0.07 & 0.07 & 0.07 & 0.06 \\
\hline 13 & 0.18 & 0.20 & 0.10 & 0.11 & 0.22 & 0.15 & 0.12 \\
\hline 14 & 0.42 & 0.43 & 0.27 & 0.26 & 0.31 & 0.30 & 0.25 \\
\hline 15 & 0.63 & 0.32 & 0.53 & 0.16 & 0.33 & 0.25 & 0.22 \\
\hline 16 & 0.42 & 0.20 & 0.32 & 0.09 & 0.22 & 0.16 & 0.14 \\
\hline 17 & 0.36 & 0.16 & 0.24 & 0.06 & 0.15 & 0.15 & 0.12 \\
\hline 18 & 0.19 & 0.17 & 0.13 & 0.03 & 0.10 & 0.09 & 0.05 \\
\hline 19 & 0.23 & 0.18 & 0.16 & 0.07 & 0.07 & 0.05 & 0.07 \\
\hline
\end{tabular}


Table 7

HARBD Wave Amplification Factors for Proposed Improvements

Plan 1. Wave Angle $=292.5 \mathrm{deg}$

\begin{tabular}{|c|c|c|c|c|c|c|c|}
\hline \multicolumn{8}{|c|}{ Wave Period, sec } \\
\hline Basin & 7 & 9 & 11 & 13 & 15 & 17 & 20 \\
\hline 1 & 0.19 & 0.18 & 0.08 & 0.11 & 0.19 & 0.12 & 0.08 \\
\hline 2 & 0.32 & 0.24 & 0.13 & 0.13 & 0.20 & 0.14 & 0.10 \\
\hline 3 & 0.23 & 0.23 & 0.08 & 0.08 & 0.15 & 0.13 & 0.14 \\
\hline 4 & 0.22 & 0.13 & 0.08 & 0.09 & 0.11 & 0.09 & 0.05 \\
\hline 5 & 0.32 & 0.27 & 0.32 & 0.06 & 0.18 & 0.16 & 0.14 \\
\hline 6 & 0.15 & 0.10 & 0.08 & 0.04 & 0.07 & 0.09 & 0.09 \\
\hline 7 & 0.17 & 0.08 & 0.06 & 0.05 & 0.10 & 0.07 & 0.02 \\
\hline 8 & 0.25 & 0.26 & 0.26 & 0.07 & 0.16 & 0.11 & 0.08 \\
\hline 9 & 0.28 & 0.28 & 0.24 & 0.07 & 0.15 & 0.10 & 0.07 \\
\hline 10 & 0.19 & 0.22 & 0.18 & 0.06 & 0.07 & 0.06 & 0.04 \\
\hline 11 & 0.20 & 0.27 & 0.18 & 0.09 & 0.09 & 0.10 & 0.06 \\
\hline 12 & 0.13 & 0.14 & 0.08 & 0.07 & 0.07 & 0.07 & 0.06 \\
\hline 13 & 0.23 & 0.21 & 0.08 & 0.11 & 0.22 & 0.15 & 0.12 \\
\hline 14 & 0.60 & 0.40 & 0.27 & 0.26 & 0.31 & 0.30 & 0.25 \\
\hline 15 & 0.57 & 0.53 & 0.44 & 0.16 & 0.33 & 0.25 & 0.22 \\
\hline 16 & 0.42 & 0.37 & 0.28 & 0.09 & 0.22 & 0.16 & 0.14 \\
\hline 17 & 0.34 & 0.26 & 0.20 & 0.06 & 0.15 & 0.15 & 0.12 \\
\hline 18 & 0.17 & 0.25 & 0.10 & 0.03 & 0.10 & 0.09 & 0.05 \\
\hline 19 & 0.19 & 0.26 & 0.12 & 0.07 & 0.07 & 0.05 & 0.07 \\
\hline
\end{tabular}


Table 8

HARBD Wave Amplification Factors for Proposed Improvements

Plan 1. Wave Angle $=315 \mathrm{deg}$

\begin{tabular}{|c|c|c|c|c|c|c|c|}
\hline \multicolumn{8}{|c|}{ Wave Period, sec } \\
\hline Basin & 7 & 9 & 11 & 13 & 15 & 17 & 20 \\
\hline 1 & 0.22 & 0.17 & 0.09 & 0.11 & 0.19 & 0.12 & 0.08 \\
\hline 2 & 0.39 & 0.21 & 0.11 & 0.13 & 0.20 & 0.14 & 0.10 \\
\hline 3 & 0.27 & 0.20 & 0.06 & 0.08 & 0.15 & 0.13 & 0.14 \\
\hline 4 & 0.24 & 0.10 & 0.06 & 0.09 & 0.11 & 0.09 & 0.05 \\
\hline 5 & 0.15 & 0.30 & 0.35 & 0.06 & 0.18 & 0.16 & 0.14 \\
\hline 6 & 0.22 & 0.09 & 0.08 & 0.04 & 0.07 & 0.09 & 0.09 \\
\hline 7 & 0.15 & 0.05 & 0.03 & 0.05 & 0.10 & 0.07 & 0.02 \\
\hline 8 & 0.12 & 0.29 & 0.28 & 0.07 & 0.16 & 0.11 & 0.08 \\
\hline 9 & 0.10 & 0.33 & 0.26 & 0.07 & 0.15 & 0.10 & 0.07 \\
\hline 10 & 0.09 & 0.24 & 0.20 & 0.06 & 0.07 & 0.06 & 0.04 \\
\hline 11 & 0.08 & 0.28 & 0.20 & 0.09 & 0.09 & 0.10 & 0.06 \\
\hline 12 & 0.05 & 0.14 & 0.09 & 0.07 & 0.07 & 0.07 & 0.06 \\
\hline 13 & 0.29 & 0.19 & 0.08 & 0.11 & 0.22 & 0.15 & 0.12 \\
\hline 14 & 0.79 & 0.38 & 0.27 & 0.26 & 0.31 & 0.30 & 0.25 \\
\hline 15 & 0.29 & 0.59 & 0.49 & 0.16 & 0.33 & 0.25 & 0.22 \\
\hline 16 & 0.17 & 0.42 & 0.30 & 0.09 & 0.22 & 0.16 & 0.14 \\
\hline 17 & 0.15 & 0.30 & 0.22 & 0.06 & 0.15 & 0.15 & 0.12 \\
\hline 18 & 0.08 & 0.28 & 0.12 & 0.03 & 0.10 & 0.09 & 0.05 \\
\hline 19 & 0.09 & 0.28 & 0.14 & 0.07 & 0.07 & 0.05 & 0.07 \\
\hline
\end{tabular}


Table 9

HARBD Wave Amplification Factors for Proposed Improvements Plan 1. Wave Angle $=337 \mathrm{deg}$

\begin{tabular}{|c|c|c|c|c|c|c|c|}
\hline \multicolumn{8}{|c|}{ Wave Period, sec } \\
\hline Basin & 7 & 9 & 11 & 13 & 15 & 17 & 20 \\
\hline 1 & 0.19 & $*$ & $*$ & $*$ & $*$ & $*$ & $*$ \\
\hline 2 & 0.31 & & & & & & \\
\hline 3 & 0.20 & & & & & & \\
\hline 4 & 0.18 & & & & & & \\
\hline 5 & 0.24 & & & & & & \\
\hline 6 & 0.19 & & & & & & \\
\hline 7 & 0.10 & & & & & & \\
\hline 8 & 0.19 & & & & & & \\
\hline 9 & 0.15 & & & & & & \\
\hline 10 & 0.10 & & & & & & \\
\hline 11 & 0.13 & & & & & & \\
\hline 12 & 0.06 & & & & & & \\
\hline 13 & 0.24 & & & & & & \\
\hline 14 & 0.52 & & & & & & \\
\hline 15 & 0.39 & & & & & & \\
\hline 16 & 0.25 & & & & & & \\
\hline 17 & 0.18 & & & & & & \\
\hline 18 & 0.09 & & & & & & \\
\hline 19 & 0.11 & & & & & & \\
\hline
\end{tabular}

* No data for these wave periods 
Table 10

HARBD Wave Amplification Factors for Proposed Improvements Plan 2, Wave Angle $=202.5 \mathrm{deg}$

\begin{tabular}{|c|c|c|c|c|c|c|c|}
\hline \multicolumn{8}{|c|}{ Wave Period, sec } \\
\hline Basin & 7 & 9 & 11 & 13 & 15 & 17 & 20 \\
\hline 1 & 0.13 & 0.15 & 0.12 & $*$ & $*$ & * & $*$ \\
\hline 2 & 0.16 & 0.18 & 0.12 & & & & \\
\hline 3 & 0.09 & 0.10 & 0.08 & & & & \\
\hline 4 & 0.11 & 0.15 & 0.10 & & & & \\
\hline 5 & 0.37 & 0.18 & 0.51 & & & & \\
\hline 6 & 0.11 & 0.09 & 0.05 & & & & \\
\hline 7 & 0.07 & 0.11 & 0.09 & & & & \\
\hline 8 & 0.28 & 0.15 & 0.41 & & & & \\
\hline 9 & 0.33 & 0.21 & 0.39 & & & & \\
\hline 10 & 0.23 & 0.13 & 0.32 & & & & \\
\hline 11 & 0.22 & 0.11 & 0.34 & & & & \\
\hline 12 & 0.11 & 0.07 & 0.16 & & & & \\
\hline 13 & 0.12 & 0.15 & 0.10 & & & & \\
\hline 14 & 0.29 & 0.39 & 0.17 & & & & \\
\hline 15 & 0.65 & 0.21 & 0.76 & & & & \\
\hline 16 & 0.48 & 0.25 & 0.45 & & & & \\
\hline 17 & 0.38 & 0.18 & 0.34 & & & & \\
\hline 18 & 0.19 & 0.12 & 0.20 & & & & \\
\hline 19 & 0.21 & 0.10 & 0.23 & & & & \\
\hline
\end{tabular}

* No data for these wave periods 
Table 11

HARBD Wave Amplification Factors for Proposed Improvements

Plan 2. Wave Angle $=225 \mathrm{deg}$

\begin{tabular}{|c|c|c|c|c|c|c|c|}
\hline \multicolumn{8}{|c|}{ Wave Period, sec } \\
\hline Basin & 7 & 9 & 11 & 13 & 15 & 17 & 20 \\
\hline 1 & 0.25 & 0.11 & 0.12 & 0.18 & 0.24 & 0.19 & 0.13 \\
\hline 2 & 0.29 & 0.13 & 0.12 & 0.19 & 0.26 & 0.20 & 0.20 \\
\hline 3 & 0.17 & 0.14 & 0.08 & 0.13 & 0.21 & 0.18 & 0.24 \\
\hline 4 & 0.24 & 0.07 & 0.10 & 0.14 & 0.14 & 0.13 & 0.11 \\
\hline 5 & 0.15 & 0.04 & 0.51 & 0.17 & 0.21 & 0.20 & 0.25 \\
\hline 6 & 0.18 & 0.05 & 0.05 & 0.06 & 0.10 & 0.11 & 0.15 \\
\hline 7 & 0.19 & 0.04 & 0.09 & 0.07 & 0.14 & 0.10 & 0.05 \\
\hline 8 & 0.11 & 0.03 & 0.41 & 0.18 & 0.19 & 0.14 & 0.14 \\
\hline 9 & 0.13 & 0.09 & 0.39 & 0.16 & 0.18 & 0.12 & 0.13 \\
\hline 10 & 0.13 & 0.11 & 0.32 & 0.10 & 0.09 & 0.07 & 0.07 \\
\hline 11 & 0.21 & 0.11 & 0.34 & 0.15 & 0.11 & 0.11 & 0.09 \\
\hline 12 & 0.13 & 0.06 & 0.16 & 0.13 & 0.08 & 0.08 & 0.10 \\
\hline 13 & 0.22 & 0.13 & 0.10 & 0.17 & 0.28 & 0.20 & 0.21 \\
\hline 14 & 0.34 & 0.41 & 0.17 & 0.39 & 0.36 & 0.33 & 0.40 \\
\hline 15 & 0.34 & 0.15 & 0.76 & 0.36 & 0.38 & 0.30 & 0.40 \\
\hline 16 & 0.15 & 0.09 & 0.45 & 0.24 & 0.26 & 0.19 & 0.24 \\
\hline 17 & 0.16 & 0.11 & 0.34 & 0.11 & 0.18 & 0.17 & 0.21 \\
\hline 18 & 0.15 & 0.11 & 0.20 & 0.05 & 0.12 & 0.11 & 0.09 \\
\hline 19 & 0.17 & 0.12 & 0.23 & 0.12 & 0.08 & 0.06 & 0.13 \\
\hline
\end{tabular}


Table 12

HARBD Wave Amplification Factors for Proposed Improvements Plan 2, Wave Angle $=247.5 \mathrm{deg}$

\begin{tabular}{|c|c|c|c|c|c|c|c|}
\hline \multicolumn{8}{|c|}{ Wave Period, sec } \\
\hline Basin & 7 & 9 & 11 & 13 & 15 & 17 & 20 \\
\hline 1 & 0.13 & 0.15 & 0.12 & 0.18 & 0.24 & 0.16 & 0.11 \\
\hline 2 & 0.14 & 0.21 & 0.12 & 0.22 & 0.26 & 0.19 & 0.19 \\
\hline 3 & 0.11 & 0.19 & 0.08 & 0.15 & 0.21 & 0.19 & 0.23 \\
\hline 4 & 0.12 & 0.15 & 0.10 & 0.16 & 0.14 & 0.13 & 0.10 \\
\hline 5 & 0.18 & 0.16 & 0.51 & 0.07 & 0.22 & 0.26 & 0.25 \\
\hline 6 & 0.09 & 0.10 & 0.05 & 0.07 & 0.11 & 0.13 & 0.15 \\
\hline 7 & 0.07 & 0.11 & 0.09 & 0.08 & 0.13 & 0.09 & 0.04 \\
\hline 8 & 0.15 & 0.17 & 0.41 & 0.07 & 0.19 & 0.18 & 0.14 \\
\hline 9 & 0.17 & 0.16 & 0.39 & 0.07 & 0.19 & 0.15 & 0.13 \\
\hline 10 & 0.16 & 0.17 & 0.32 & 0.06 & 0.09 & 0.10 & 0.07 \\
\hline 11 & 0.15 & 0.22 & 0.34 & 0.11 & 0.12 & 0.15 & 0.10 \\
\hline 12 & 0.11 & 0.12 & 0.16 & 0.08 & 0.09 & 0.11 & 0.10 \\
\hline 13 & 0.13 & 0.18 & 0.10 & 0.19 & 0.30 & 0.20 & 0.19 \\
\hline 14 & 0.25 & 0.40 & 0.17 & 0.44 & 0.36 & 0.38 & 0.37 \\
\hline 15 & 0.38 & 0.35 & 0.76 & 0.18 & 0.40 & 0.39 & 0.40 \\
\hline 16 & 0.23 & 0.21 & 0.45 & 0.09 & 0.27 & 0.25 & 0.25 \\
\hline 17 & 0.25 & 0.17 & 0.34 & 0.05 & 0.19 & 0.23 & 0.22 \\
\hline 18 & 0.14 & 0.19 & 0.20 & 0.03 & 0.13 & 0.14 & 0.09 \\
\hline 19 & 0.16 & 0.21 & 0.23 & 0.08 & 0.09 & 0.08 & 0.14 \\
\hline
\end{tabular}


Table 13

HARBD Wave Amplification Factors for Proposed Improvements P1an 2, Wave Angle $=270$ deg

\begin{tabular}{|c|c|c|c|c|c|c|c|}
\hline \multicolumn{8}{|c|}{ Wave Period, sec } \\
\hline Basin & 7 & 9 & 11 & 13 & 15 & 17 & 20 \\
\hline 1 & 0.14 & 0.15 & 0.12 & 0.18 & 0.24 & 0.16 & 0.11 \\
\hline 2 & 0.15 & 0.21 & 0.12 & 0.22 & 0.26 & 0.19 & 0.19 \\
\hline 3 & 0.10 & 0.19 & 0.08 & 0.15 & 0.21 & 0.19 & 0.23 \\
\hline 4 & 0.12 & 0.15 & 0.10 & 0.16 & 0.14 & 0.13 & 0.10 \\
\hline 5 & 0.35 & 0.16 & 0.51 & 0.07 & 0.22 & 0.26 & 0.25 \\
\hline 6 & 0.12 & 0.10 & 0.05 & 0.07 & 0.11 & 0.13 & 0.15 \\
\hline 7 & 0.08 & 0.11 & 0.09 & 0.08 & 0.13 & 0.09 & 0.04 \\
\hline 8 & 0.27 & 0.17 & 0.41 & 0.07 & 0.19 & 0.18 & 0.14 \\
\hline 9 & 0.32 & 0.16 & 0.39 & 0.07 & 0.19 & 0.15 & 0.13 \\
\hline 10 & 0.26 & 0.17 & 0.32 & 0.06 & 0.09 & 0.10 & 0.07 \\
\hline 11 & 0.28 & 0.22 & 0.34 & 0.11 & 0.12 & 0.15 & 0.10 \\
\hline 12 & 0.16 & 0.12 & 0.16 & 0.08 & 0.09 & 0.11 & 0.10 \\
\hline 13 & 0.14 & 0.18 & 0.10 & 0.19 & 0.30 & 0.20 & 0.19 \\
\hline 14 & 0.27 & 0.40 & 0.17 & 0.44 & 0.36 & 0.38 & 0.37 \\
\hline 15 & 0.68 & 0.35 & 0.76 & 0.18 & 0.40 & 0.39 & 0.40 \\
\hline 16 & 0.47 & 0.21 & 0.45 & 0.09 & 0.27 & 0.25 & 0.25 \\
\hline 17 & 0.42 & 0.17 & 0.34 & 0.05 & 0.19 & 0.23 & 0.22 \\
\hline 18 & 0.24 & 0.19 & 0.20 & 0.03 & 0.13 & 0.14 & 0.09 \\
\hline 19 & 0.28 & 0.21 & 0.23 & 0.08 & 0.09 & 0.08 & 0.14 \\
\hline
\end{tabular}


Table 14

HARBD Wave Amplification Factors for Proposed Improvements

Plan 2, Wave Angle $=292.5 \mathrm{deg}$

\begin{tabular}{|c|c|c|c|c|c|c|c|}
\hline \multicolumn{8}{|c|}{ Wave Period, sec } \\
\hline Basin & 7 & 9 & 11 & 13 & 15 & 17 & 20 \\
\hline 1 & 0.14 & 0.14 & 0.15 & 0.18 & 0.24 & 0.16 & 0.11 \\
\hline 2 & 0.24 & 0.21 & 0.18 & 0.22 & 0.26 & 0.19 & 0.19 \\
\hline 3 & 0.18 & 0.18 & 0.12 & 0.15 & 0.21 & 0.19 & 0.23 \\
\hline 4 & 0.20 & 0.15 & 0.10 & 0.16 & 0.14 & 0.13 & 0.10 \\
\hline 5 & 0.35 & 0.31 & 0.49 & 0.07 & 0.22 & 0.26 & 0.25 \\
\hline 6 & 0.11 & 0.10 & 0.10 & 0.07 & 0.11 & 0.13 & 0.15 \\
\hline 7 & 0.15 & 0.12 & 0.08 & 0.08 & 0.13 & 0.09 & 0.04 \\
\hline 8 & 0.28 & 0.30 & 0.40 & 0.07 & 0.19 & 0.18 & 0.14 \\
\hline 9 & 0.32 & 0.32 & 0.36 & 0.07 & 0.19 & 0.15 & 0.13 \\
\hline 10 & 0.24 & 0.26 & 0.27 & 0.06 & 0.09 & 0.10 & 0.07 \\
\hline 11 & 0.25 & 0.33 & 0.29 & 0.11 & 0.12 & 0.15 & 0.10 \\
\hline 12 & 0.16 & 0.17 & 0.13 & 0.08 & 0.09 & 0.11 & 0.10 \\
\hline 13 & 0.17 & 0.16 & 0.13 & 0.19 & 0.30 & 0.20 & 0.19 \\
\hline 14 & 0.56 & 0.33 & 0.36 & 0.44 & 0.36 & 0.38 & 0.37 \\
\hline 15 & 0.66 & 0.59 & 0.69 & 0.18 & 0.40 & 0.39 & 0.40 \\
\hline 16 & 0.48 & 0.42 & 0.42 & 0.09 & 0.27 & 0.25 & 0.25 \\
\hline 17 & 0.41 & 0.30 & 0.30 & 0.05 & 0.19 & 0.23 & 0.22 \\
\hline 18 & 0.21 & 0.30 & 0.16 & 0.03 & 0.13 & 0.14 & 0.09 \\
\hline 19 & 0.24 & 0.32 & 0.19 & 0.08 & 0.09 & 0.08 & 0.14 \\
\hline
\end{tabular}


Table 15

HARBD Wave Amplification Factors for Proposed Improvements Plan 2. Wave Angle $=315 \mathrm{deg}$

\begin{tabular}{|c|c|c|c|c|c|c|c|}
\hline \multicolumn{8}{|c|}{ Wave Period, sec } \\
\hline Basin & 7 & 9 & 11 & 13 & 15 & 17 & 20 \\
\hline 1 & 0.20 & 0.11 & 0.13 & 0.18 & 0.24 & 0.16 & 0.11 \\
\hline 2 & 0.39 & 0.16 & 0.13 & 0.22 & 0.26 & 0.19 & 0.19 \\
\hline 3 & 0.27 & 0.15 & 0.09 & 0.15 & 0.21 & 0.19 & 0.23 \\
\hline 4 & 0.25 & 0.09 & 0.07 & 0.16 & 0.14 & 0.13 & 0.10 \\
\hline 5 & 0.21 & 0.33 & 0.52 & 0.07 & 0.22 & 0.26 & 0.25 \\
\hline 6 & 0.23 & 0.08 & 0.06 & 0.07 & 0.11 & 0.13 & 0.15 \\
\hline 7 & 0.17 & 0.06 & 0.07 & 0.08 & 0.13 & 0.09 & 0.04 \\
\hline 8 & 0.17 & 0.33 & 0.42 & 0.07 & 0.19 & 0.18 & 0.14 \\
\hline 9 & 0.12 & 0.38 & 0.39 & 0.07 & 0.19 & 0.15 & 0.13 \\
\hline 10 & 0.11 & 0.29 & 0.31 & 0.06 & 0.09 & 0.10 & 0.07 \\
\hline 11 & 0.08 & 0.34 & 0.32 & 0.11 & 0.12 & 0.15 & 0.10 \\
\hline 12 & 0.06 & 0.17 & 0.15 & 0.08 & 0.09 & 0.11 & 0.10 \\
\hline 13 & 0.26 & 0.12 & 0.10 & 0.19 & 0.30 & 0.20 & 0.19 \\
\hline 14 & 0.86 & 0.35 & 0.27 & 0.44 & 0.36 & 0.38 & 0.37 \\
\hline 15 & 0.39 & 0.67 & 0.75 & 0.18 & 0.40 & 0.39 & 0.40 \\
\hline 16 & 0.21 & 0.48 & 0.45 & 0.09 & 0.27 & 0.25 & 0.25 \\
\hline 17 & 0.17 & 0.35 & 0.33 & 0.05 & 0.19 & 0.23 & 0.22 \\
\hline 18 & 0.09 & 0.33 & 0.19 & 0.03 & 0.13 & 0.14 & 0.09 \\
\hline 19 & 0.10 & 0.34 & 0.22 & 0.08 & 0.09 & 0.08 & 0.14 \\
\hline
\end{tabular}


Table 16

HARBD Wave Amplification Factors for Proposed Improvements

Plan 2, Wave Angle $=337 \mathrm{deg}$

\begin{tabular}{|c|c|c|c|c|c|c|c|}
\hline \multicolumn{8}{|c|}{ Wave Period, sec } \\
\hline Basin & 7 & 9 & 11 & 13 & 15 & 17 & 20 \\
\hline 1 & 0.19 & $*$ & $*$ & $*$ & $*$ & * & $*$ \\
\hline 2 & 0.33 & & & & & & \\
\hline 3 & 0.21 & & & & & & \\
\hline 4 & 0.20 & & & & & & \\
\hline 5 & 0.36 & & & & & & \\
\hline 6 & 0.20 & & & & & & \\
\hline 7 & 0.13 & & & & & & \\
\hline 8 & 0.28 & & & & & & \\
\hline 9 & 0.18 & & & & & & \\
\hline 10 & 0.11 & & & & & & \\
\hline 11 & 0.12 & & & & & & \\
\hline 12 & 0.05 & & & & & & \\
\hline 13 & 0.22 & & & & & & \\
\hline 14 & 0.60 & & & & & & \\
\hline 15 & 0.55 & & & & & & \\
\hline 16 & 0.32 & & & & & & \\
\hline 17 & 0.20 & & & & & & \\
\hline 18 & 0.10 & & & & & & \\
\hline 19 & 0.11 & & & & & & \\
\hline
\end{tabular}

* No data for these wave periods 
Table 17

Largest Resulting HARBD-RCPWAVE Amplification Factors

(Deepwater Wave Conditions)

\begin{tabular}{|c|c|c|c|c|c|c|c|c|c|c|c|c|}
\hline \multirow[b]{3}{*}{$\begin{array}{r}\text { Dir. } \\
(\operatorname{deg}) \\
\end{array}$} & \multicolumn{6}{|c|}{ Plan 1} & \multicolumn{6}{|c|}{$\underline{\operatorname{Plan} 2}$} \\
\hline & \multicolumn{3}{|c|}{$1 \mathrm{ft}$ criteria } & \multicolumn{3}{|c|}{$2 \mathrm{ft}$ criteria } & \multicolumn{3}{|c|}{$1 \mathrm{ft}$ criteria } & \multicolumn{3}{|c|}{2 ftcriteria } \\
\hline & $\begin{array}{r}\text { Per. } \\
(\sec )\end{array}$ & $\begin{array}{l}\text { Amp. } \\
\text { Fac. }\end{array}$ & $\begin{array}{c}\text { Basin } \\
\#\end{array}$ & $\begin{array}{r}\text { Per } \\
(\text { sec })\end{array}$ & $\begin{array}{l}\text { Amp. } \\
\text { Fac. }\end{array}$ & $\begin{array}{c}\text { Basin } \\
\#\end{array}$ & $\begin{array}{r}\text { Per } \\
(\mathrm{sec})\end{array}$ & $\begin{array}{l}\text { Amp. } \\
\text { Fac. }\end{array}$ & $\begin{array}{c}\text { Basin } \\
\#\end{array}$ & $\begin{array}{r}\text { Per } \\
(\mathrm{sec}) \\
\end{array}$ & $\begin{array}{l}\text { Amp. } \\
\text { Fac. }\end{array}$ & $\begin{array}{c}\text { Basin } \\
\#\end{array}$ \\
\hline 202.5 & 11 & 0.26 & 5 & 11 & 0.37 & 15 & 11 & 0.36 & 5 & 11 & 0.53 & 15 \\
\hline 225.0 & 11 & 0.23 & 5 & 11 & 0.40 & 15 & 11 & 0.38 & 5 & 11 & 0.57 & 15 \\
\hline 247.5 & 11 & 0.20 & 5 & 11 & 0.37 & 15 & 11 & 0.36 & 5 & 11 & 0.53 & 15 \\
\hline 270.0 & 7 & 0.22 & 5 & 7 & 0.41 & 15 & 11 & 0.27 & 8 & 11 & 0.49 & 15 \\
\hline 292.5 & 11 & 0.23 & 5 & 7 & 0.42 & 14 & 11 & 0.36 & 5 & 11 & 0.50 & 15 \\
\hline 315.0 & 7 & 0.27 & 2 & 7 & 0.55 & 14 & 11 & 0.31 & 5 & 7 & 0.60 & 14 \\
\hline 337.5 & 7 & 0.16 & 2 & 7 & 0.28 & 14 & 7 & 0.19 & 5 & 7 & 0.31 & 14 \\
\hline
\end{tabular}


Table 18

Percent Occurrence of Wave Heights Versus Direction*

Plan 1 - Wave Heights Exceeding 1 ft

\begin{tabular}{|c|c|c|c|c|c|c|c|c|}
\hline \multirow{2}{*}{$\begin{array}{c}\text { Wave Height } \\
\mathrm{ft}\end{array}$} & \multicolumn{8}{|c|}{ Wave Direction, deg (from which waves approach) } \\
\hline & 202.5 & 225 & 247.5 & 270 & 292.5 & 315 & 337.5 & $\underline{\text { Total }}$ \\
\hline $0-3$ & 0.00 & 0.00 & 0.00 & 0.00 & 0.00 & 0.00 & 0.00 & 0.00 \\
\hline $3-6$ & $*$ & $*$ & * & 0.03 & 0.36 & 3.27 & 0.00 & 3.66 \\
\hline $6-9$ & 0.01 & 0.02 & 0.03 & 0.07 & 0.18 & 2.69 & 0.20 & 3.20 \\
\hline $9-12$ & $\star$ & 0.02 & 0.03 & 0.05 & 0.47 & 1.46 & 0.01 & 2.04 \\
\hline $12-15$ & $*$ & 0.01 & 0.01 & 0.01 & 0.46 & 1.09 & 0.00 & 1.58 \\
\hline$>15$ & 0.00 & 0.02 & $*$ & 0.01 & 0.06 & 0.34 & $*$ & 0.43 \\
\hline TOTAL & 0.01 & 0.07 & 0.07 & 0.17 & 1.53 & 8.85 & 0.21 & 10.91 \\
\hline \multicolumn{9}{|c|}{ Table 19} \\
\hline \multicolumn{9}{|c|}{ Percent Occurrence of } \\
\hline \multicolumn{9}{|c|}{ Plan 1 - Wave Heights Exceeding $2 \mathrm{ft}$} \\
\hline $\begin{array}{l}\text { ave Height } \\
f t\end{array}$ & \multirow{2}{*}{\multicolumn{7}{|c|}{ 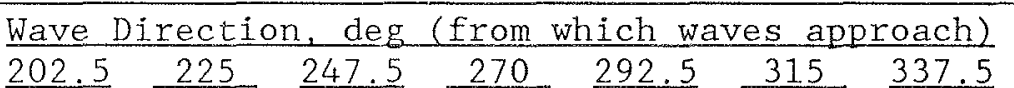 }} & \\
\hline & & & & & & & & Total \\
\hline $0-3$ & 0.00 & 0.00 & 0.00 & 0.00 & 0.00 & 0.00 & 0.00 & 0.00 \\
\hline $3-6$ & 0.02 & 0.00 & $*$ & 0.00 & 0.00 & 2.05 & 0.22 & 2.29 \\
\hline $6-9$ & $\dot{x}$ & 0.01 & 0.02 & 0.08 & 0.16 & 2.64 & 0.01 & 2.92 \\
\hline $9-12$ & $\stackrel{\star}{*}$ & 0.02 & 0.04 & 0.06 & 0.32 & 1.51 & 0.00 & 1.95 \\
\hline $12-15$ & $\ddot{*}$ & 0.01 & 0.02 & 0.02 & 0.47 & 0.89 & 0.00 & 1.41 \\
\hline$>15$ & 0.00 & 0.02 & $\dot{x}$ & 0.01 & 0.06 & 0.45 & 0.00 & 0.54 \\
\hline TOTAL & 0.02 & 0.06 & 0.08 & 0.17 & 1.01 & 7.54 & 0.23 & 9.10 \\
\hline
\end{tabular}

* Percent occurrence is below significance for tabulation 
Table 20

Percent Occurrence of Wave Heights Versus Direction ${ }^{*}$

Plan 2 - Wave Heights Exceeding $1 \mathrm{ft}$

\begin{tabular}{|c|c|c|c|c|c|c|c|c|}
\hline \multirow{2}{*}{$\begin{array}{c}\text { Wave Height } \\
\mathrm{ft}\end{array}$} & \multicolumn{8}{|c|}{ Wave Direction, deg (from which waves approach) } \\
\hline & $\underline{202} \underline{2.5}$ & 225 & 247.5 & 270 & 292.5 & 315 & $\underline{337.5}$ & Total \\
\hline $0-3$ & * & 0.00 & 0.00 & 0.00 & 0.04 & 0.00 & 0.00 & 0.04 \\
\hline $3-6$ & 0.01 & 0.02 & 0.03 & 0.06 & 1.12 & 5.15 & 0.88 & 7.27 \\
\hline $6-9$ & 0.01 & 0.02 & 0.03 & 0.12 & 0.32 & 3.64 & 0.22 & 4.36 \\
\hline $9-12$ & * & 0.02 & 0.04 & 0.09 & 1.02 & 5.47 & 0.01 & 6.64 \\
\hline $12-15$ & $*$ & 0.01 & 0.01 & 0.02 & 0.47 & 2.02 & 0.00 & 2.53 \\
\hline$>15$ & 0.02 & 0.02 & $*$ & 0.01 & 0.06 & 0.45 & 0.00 & 0.54 \\
\hline TOTAL & 0.02 & 0.09 & 0.11 & 0.30 & 3.03 & 16.73 & 1.10 & 21.39 \\
\hline
\end{tabular}

Table 21

Percent Occurrence of Wave Heights Versus Direction ${ }^{*}$

Plan 2 - Wave Heights Exceeding $2 \mathrm{ft}$

\begin{tabular}{|c|c|c|c|c|c|c|c|c|}
\hline \multirow{2}{*}{$\begin{array}{l}\text { Wave Height } \\
\mathrm{ft}\end{array}$} & \multicolumn{8}{|c|}{ Wave Direction, deg (from which waves approach) } \\
\hline & $\underline{202.5}$ & 225 & $\underline{247.5}$ & 270 & $\underline{292.5}$ & 315 & $\underline{337.5}$ & Total \\
\hline $0-3$ & 0.00 & 0.00 & * & 0.00 & 0.00 & 0.00 & 0.00 & * \\
\hline $3-6$ & * & $*$ & 0.01 & 0.04 & 0.54 & 4.36 & 0.00 & 4.95 \\
\hline $6-9$ & 0.01 & 0.02 & 0.04 & 0.08 & 0.32 & 3.43 & 0.22 & 4.12 \\
\hline $9-12$ & $*$ & 0.02 & 0.04 & 0.09 & 1.02 & 5.47 & 0.01 & 6.66 \\
\hline $12-15$ & * & 0.01 & 0.01 & 0.02 & 0.46 & 2.02 & 0.00 & 2.52 \\
\hline$>15$ & 0.00 & 0.02 & $*$ & 0.01 & 0.06 & 0.45 & 0.00 & 0.54 \\
\hline TOTAL & 0.02 & 0.07 & 0.10 & 0.24 & 2.40 & 15.73 & 0.23 & 18.79 \\
\hline
\end{tabular}

* Percent occurrence is below significance for tabularion 
HARBOR BERTHING AREAS

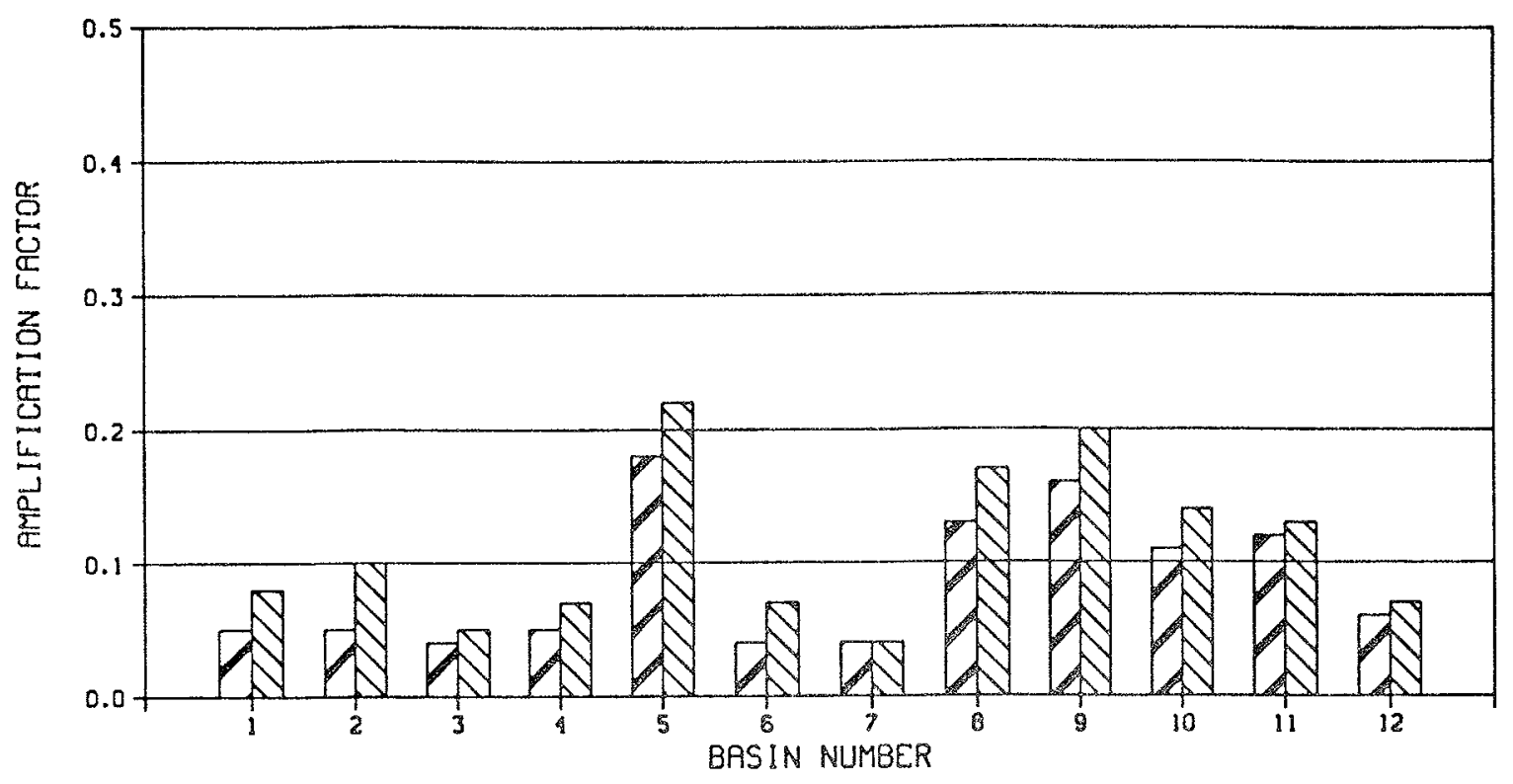

HARBOR ENTRRNCE CHANNEL AND TURNING BASIN

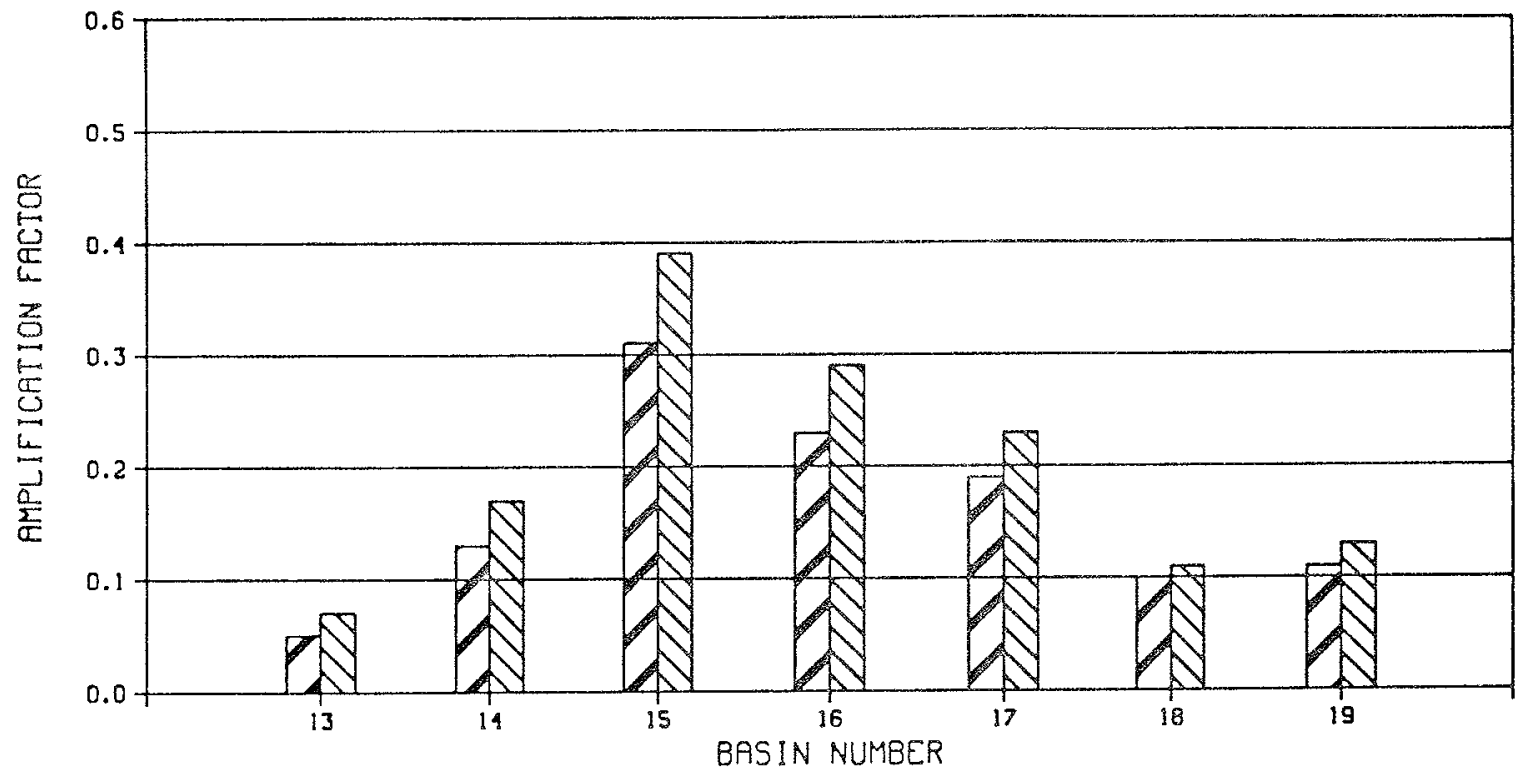

LEGEND

$\square$ PLAN 1

$\triangle$ PLAN 2
WAVE RMPLIFICRTION FACTOR

KAWAIHAE SHRLLOW-DRAFT HARBOR, $\mathrm{HI}$ HAVE PERIOD - 7 seC

WAVE DIRECTION $=202.5 \mathrm{deg}$ 
HARBOR BERTHING RREAS

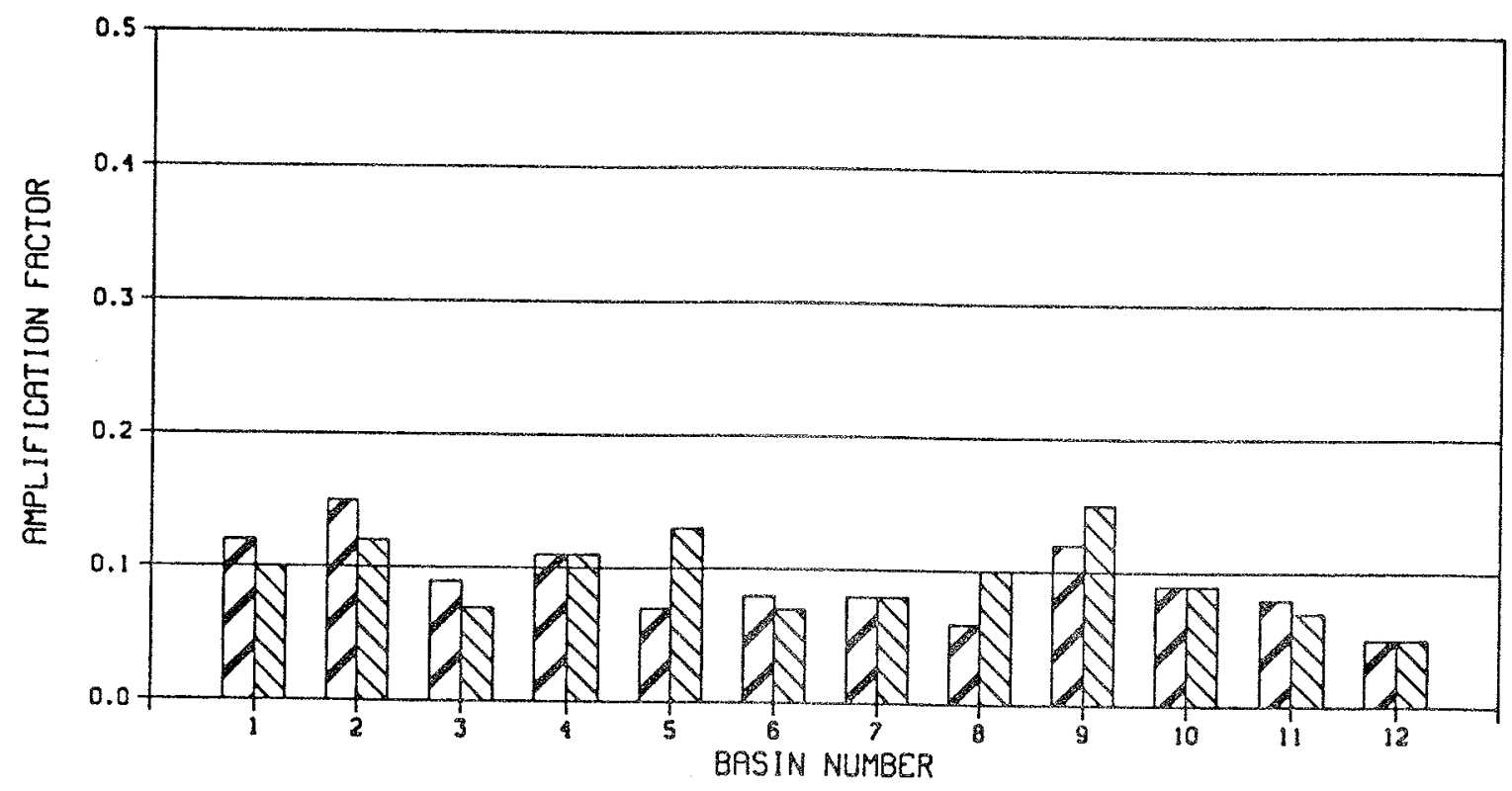

HRRBOR ENTRANCE CHANNEL AND TURNING BASIN

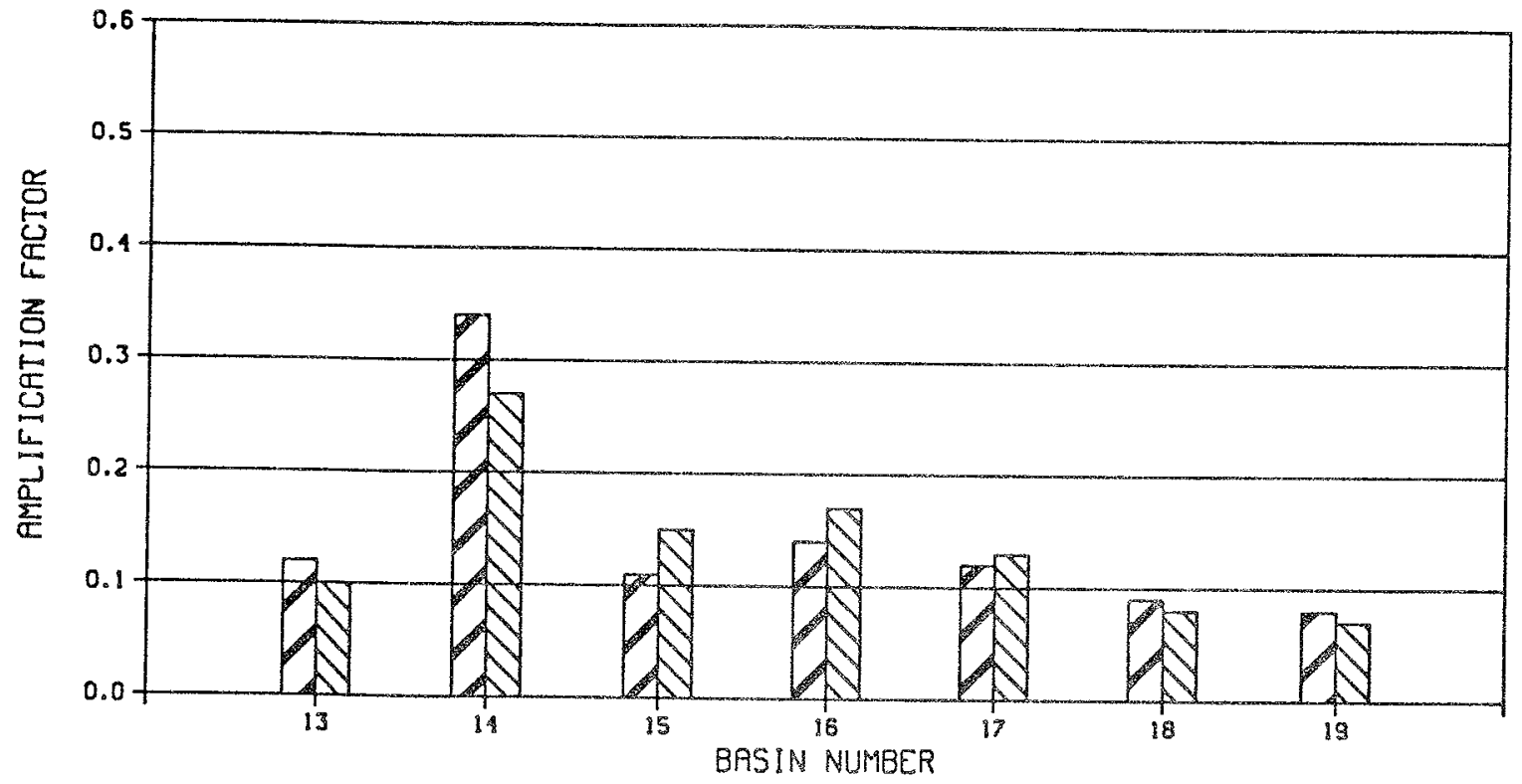

LEGEND

[D PLAN !

$\triangle \triangle$ PLRN 2

WAVE AMPLIFICATION FACTOR

KAWAIHRE SHALLOW-DRAFT HRRBOR, $\mathrm{Hl}$

WAVE PERIOD $=9$ gEC

WRVE DIRECTION $=202.5 \mathrm{deg}$

PLATE 2 
HARBOR BERTHING AREAS

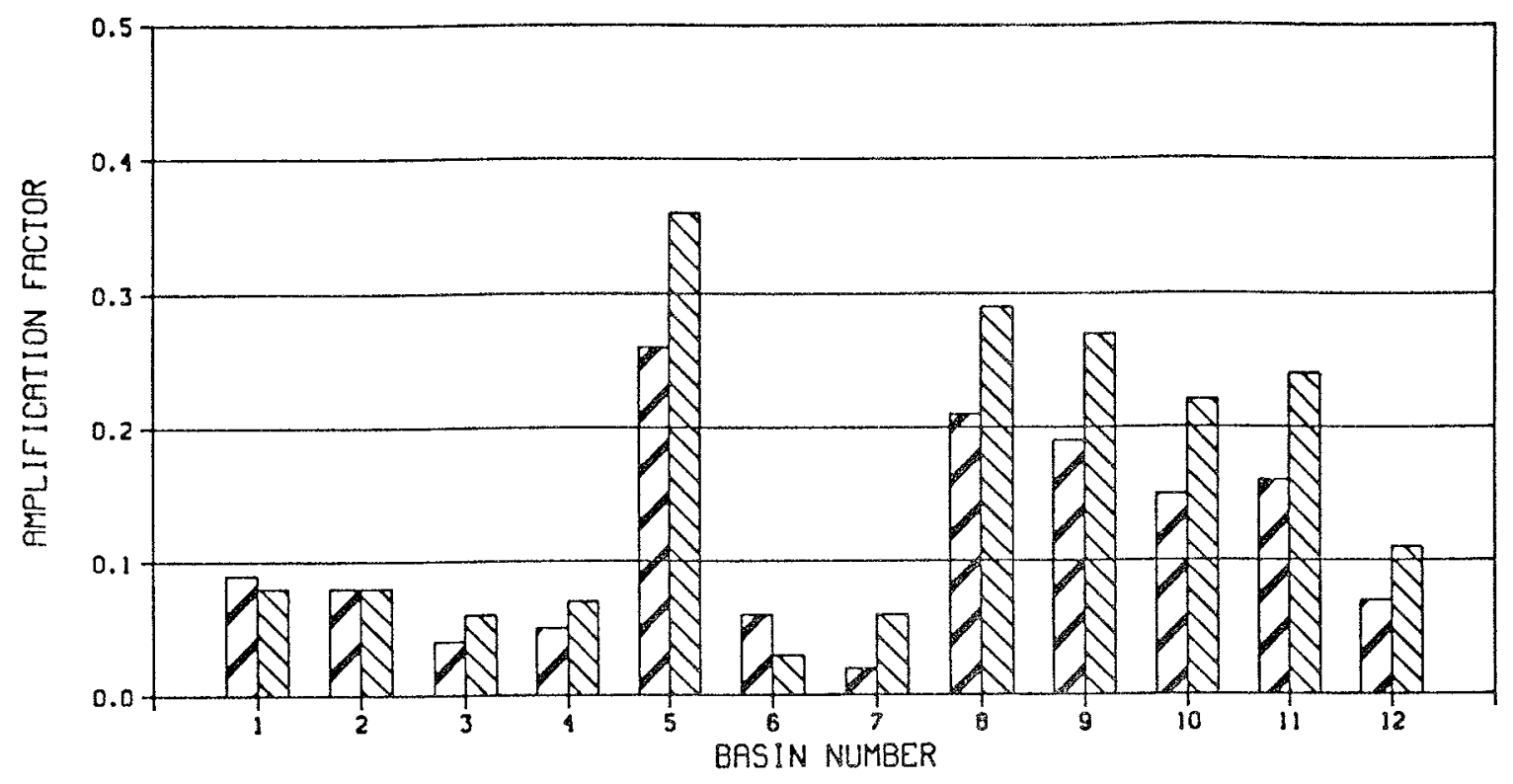

HARBOR ENTRANCE CHANNEL AND TURNING BASIN

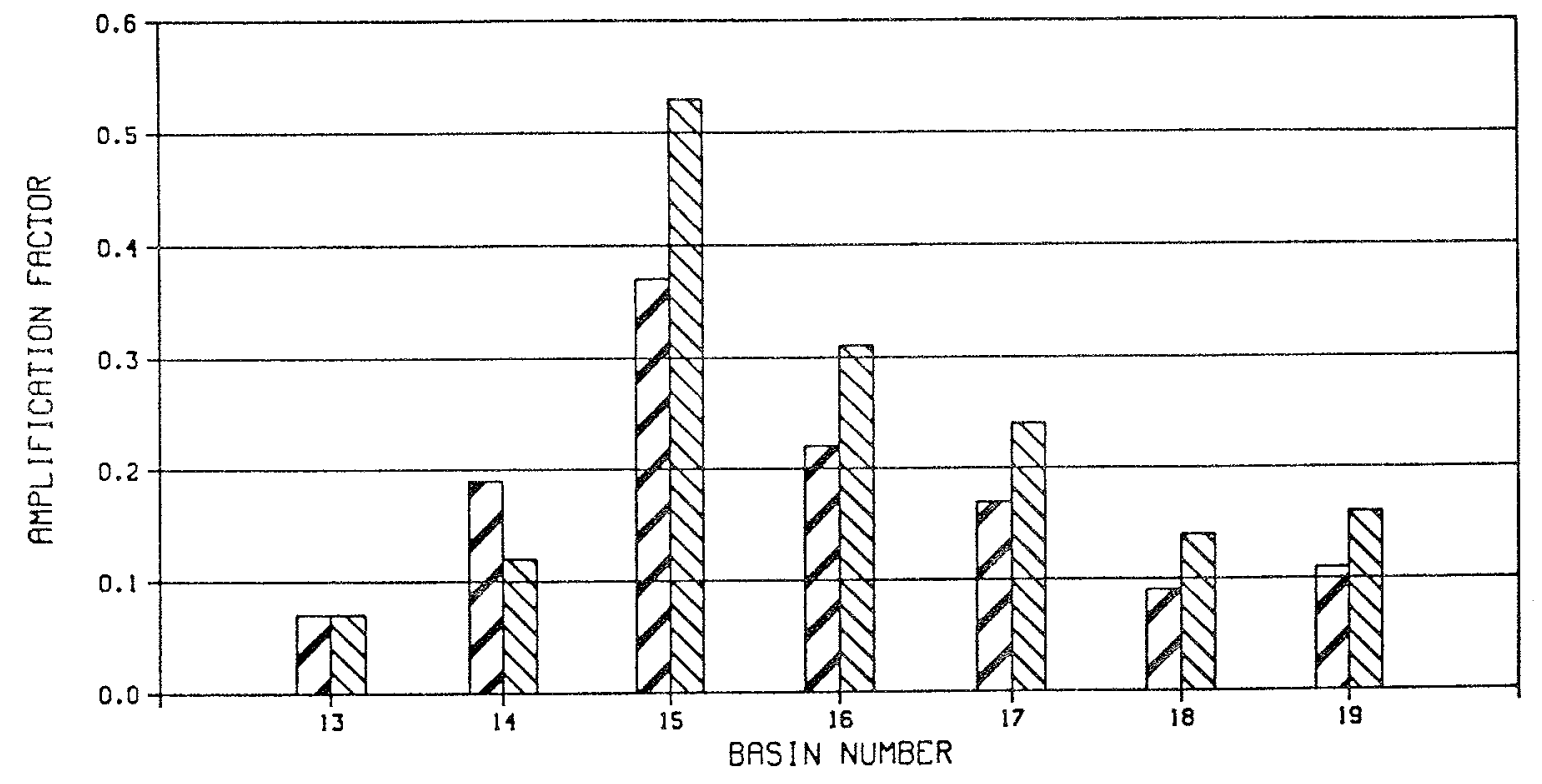

LEGEND

$\square$ PLAN 1

$\triangle$ PLRN 2
WAVE AMPLIFICATION FACTOR

KAWAIHAE SHALLOW-DRAFT HARBOR, HI WAVE PERIOD - $11 \mathrm{sec}$

WRVE DIRECTION - $202.5 \mathrm{deg}$ 
HRRBOR BERTHING RREAS

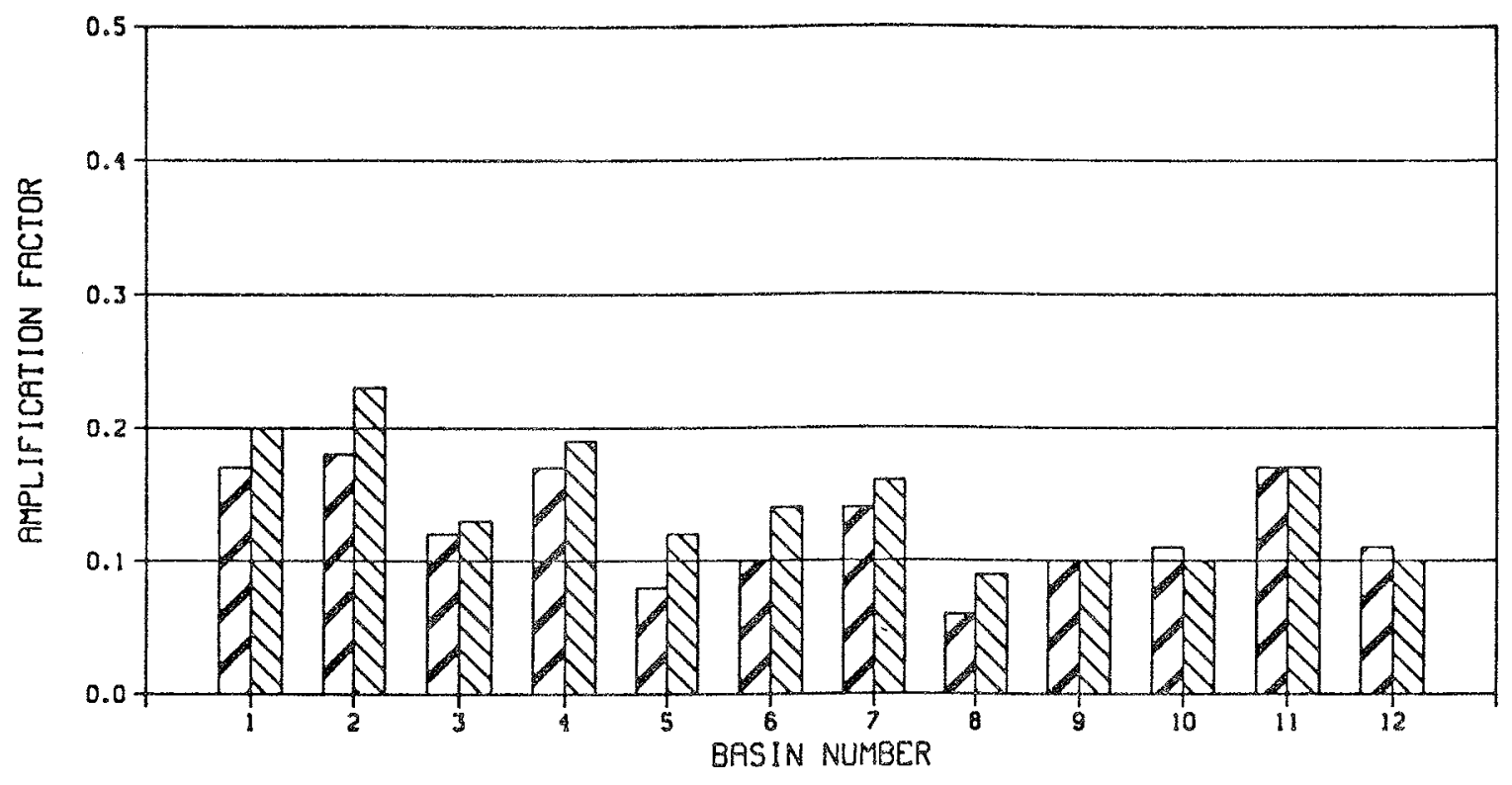

HARBOR ENTRANCE CHANNEL AND TURNING BASIN

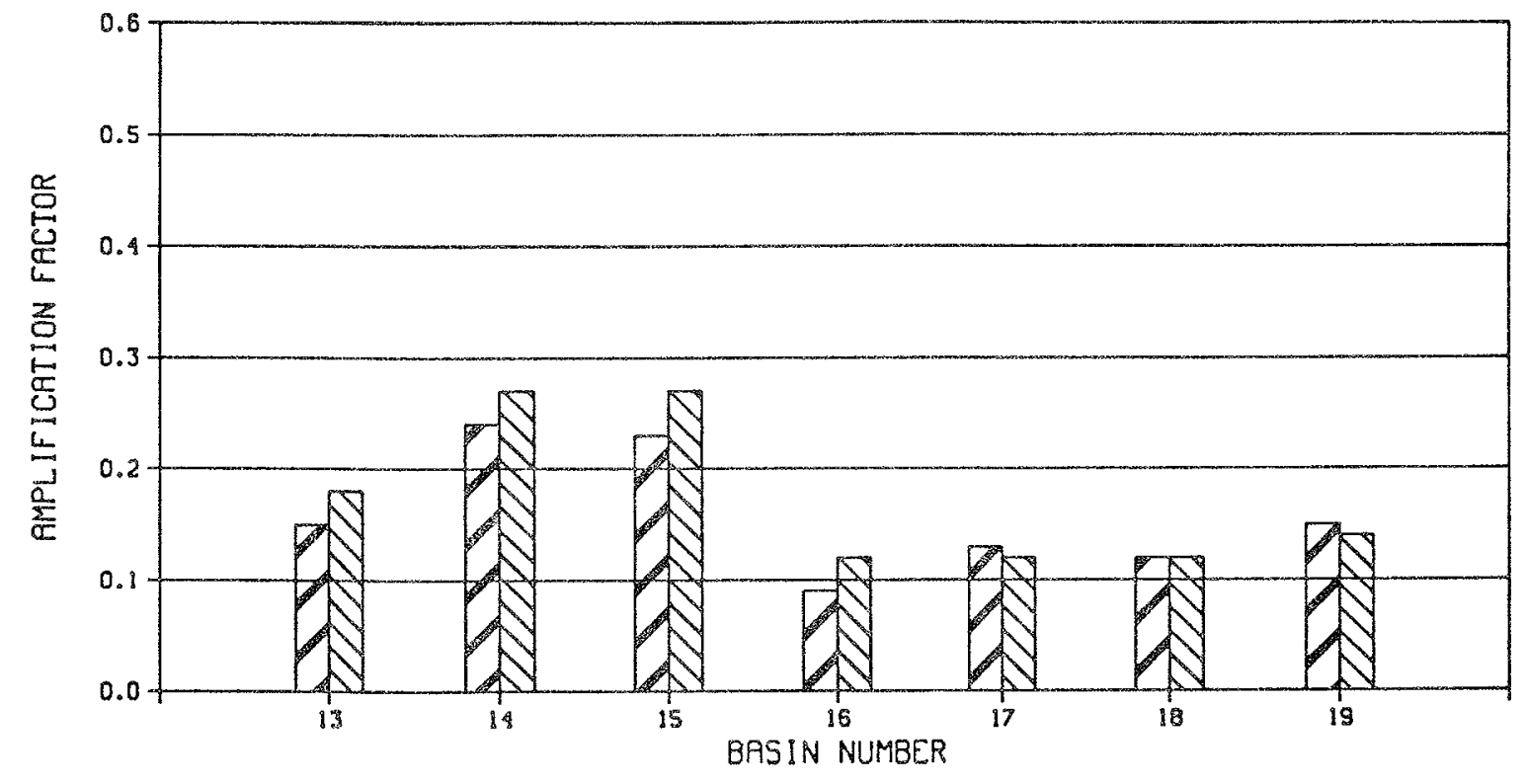

LEGEND

[D PLAN 1

$\triangle \triangle$ PLAN 2
WAVE AMPLIFICATION FACTOR KAWAIHAE SHALLOW-DRRFT HARBOR, HI WRVE PERIOO $=7 \mathrm{sec}$ WAVE DIRECTION $-225 \mathrm{deg}$

PLATE 4 
HARBOR BERTHING RREAS

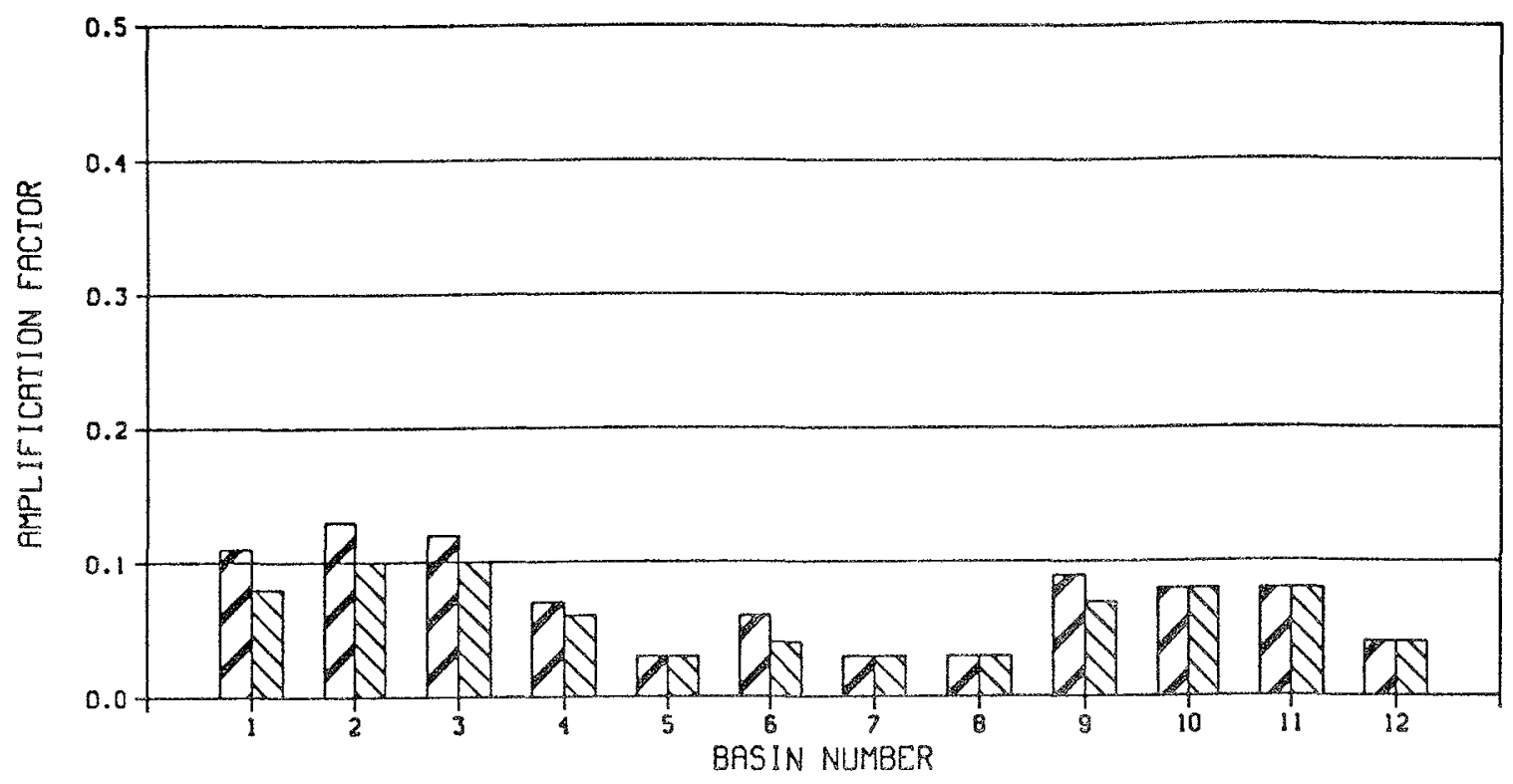

HARBOR ENTRANCE CHANNEL AND TURNING BASIN

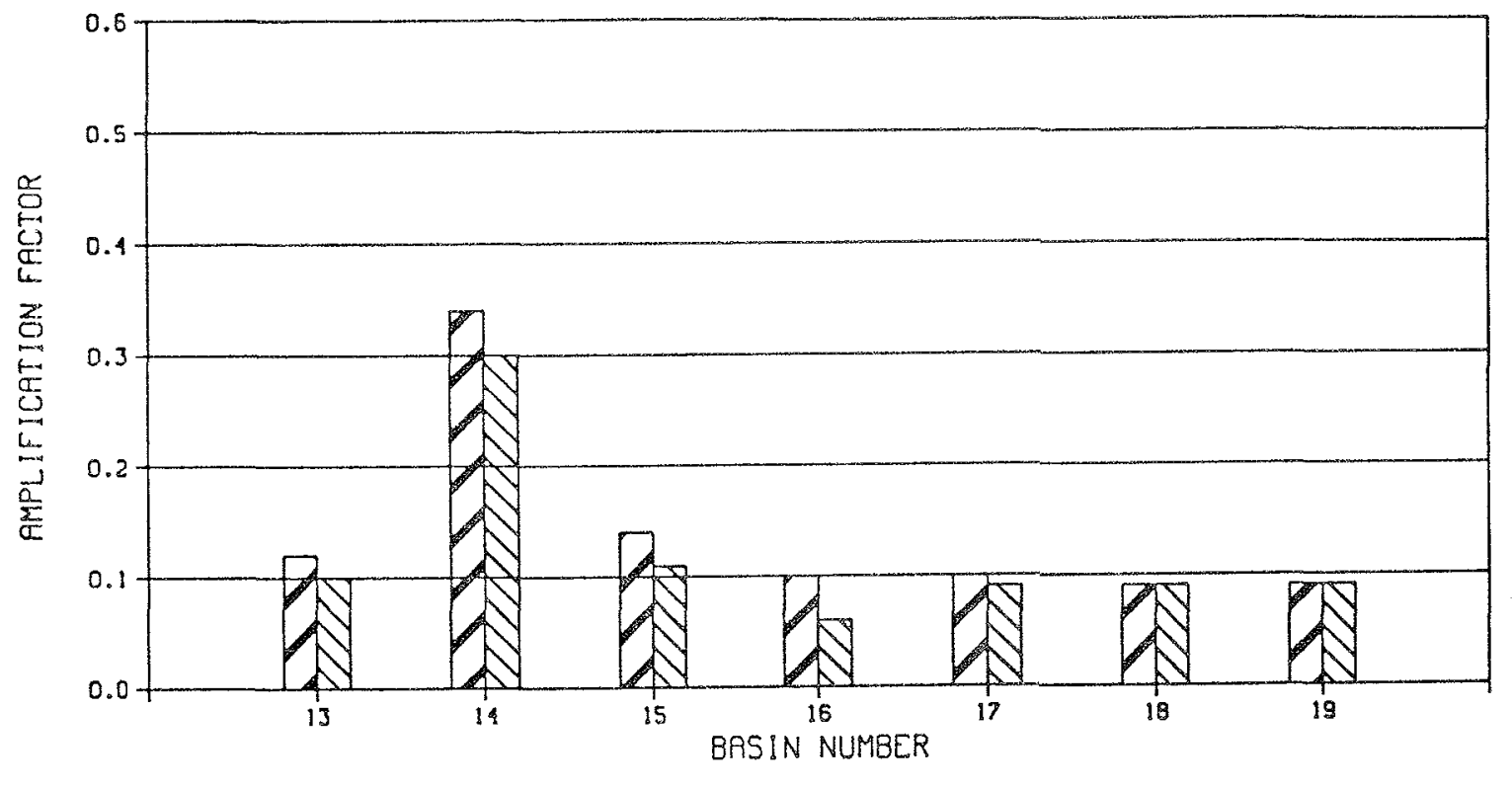

LEGEND

[D PLAN 1

$\triangle$ PLAN 2
WRVE AMPLIFICATION FACTOR KAWRIHAE SHALLOW-DRRFT HARBOR, HI WAVE PERIOD - 9 sec WAVE DIRECTION $=225$ deg 
HARBOR BERTHING AREAS

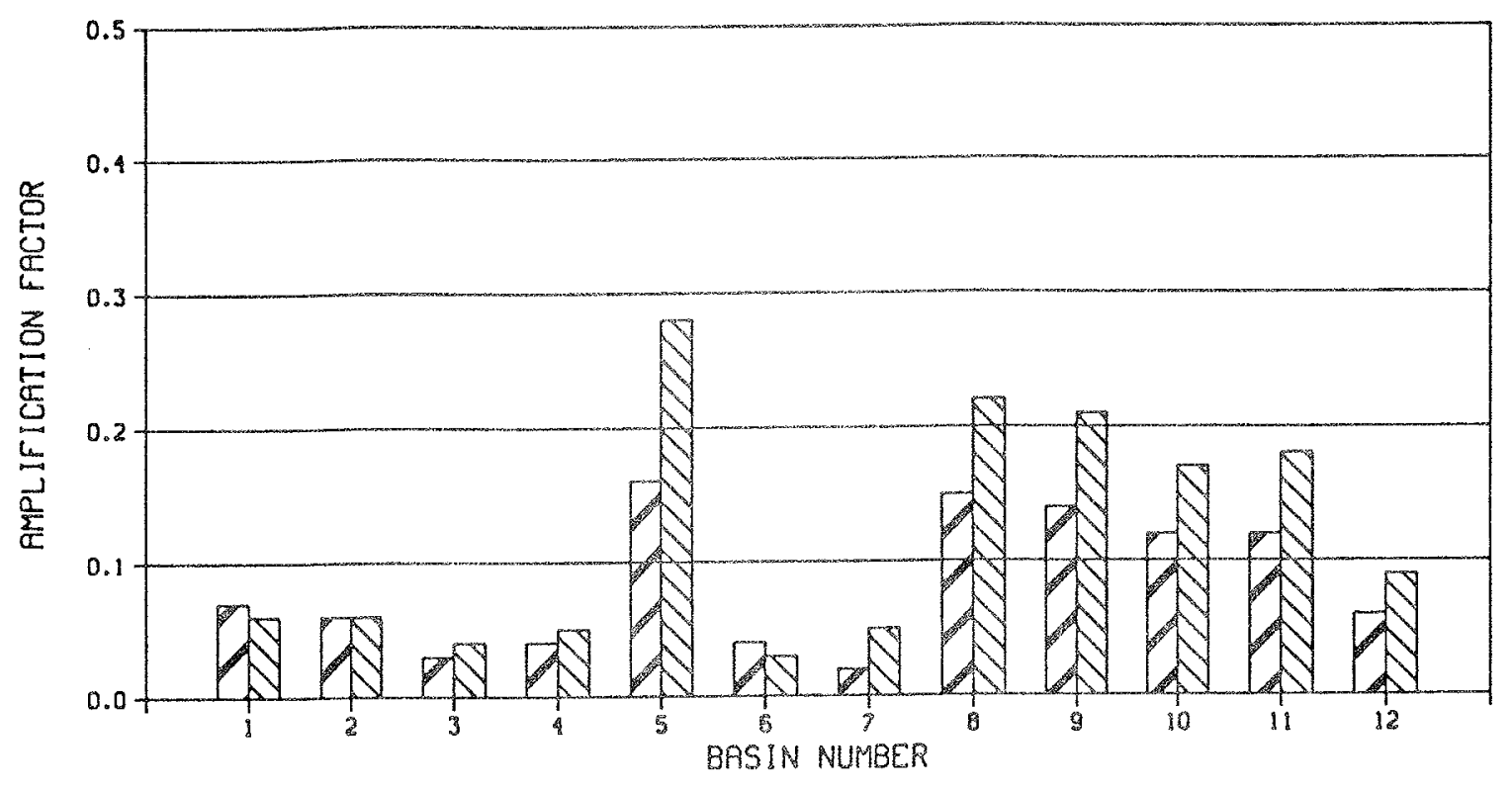

HARBOR ENTRANCE CHANNEL ANO TURNING BASIN

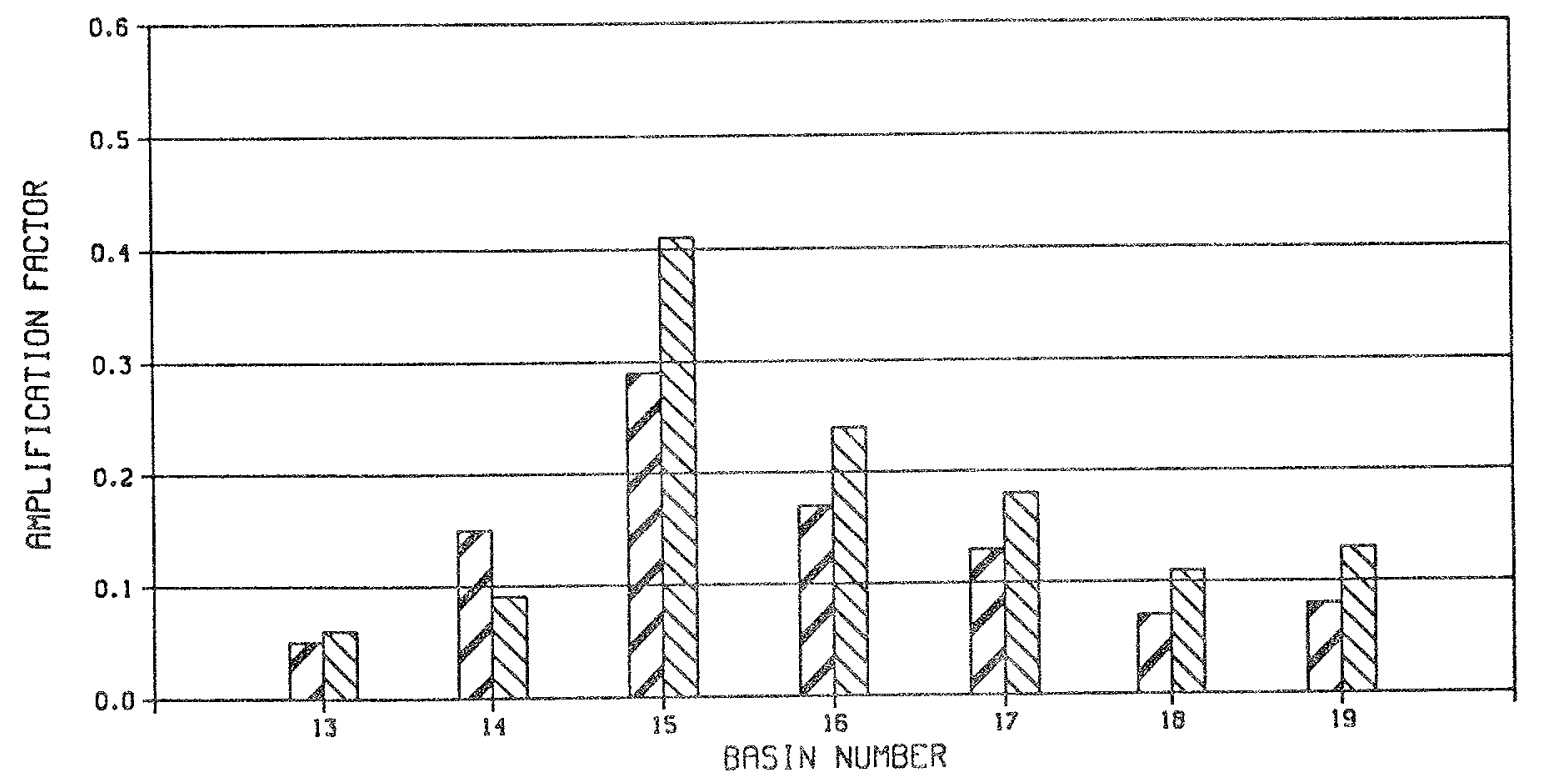

LEGENO

[Z] PLAN !

¿I PLAN 2
WAVE AMPLIFICATION FRCTOR KAWAIHAE SHALLOW-DRAFT HARBOR, HI WAVE PERIOO $~ 31$ sec WRVE DIRECTION $=225 \mathrm{deg}$ 
HARBOR BERTHING AREAS

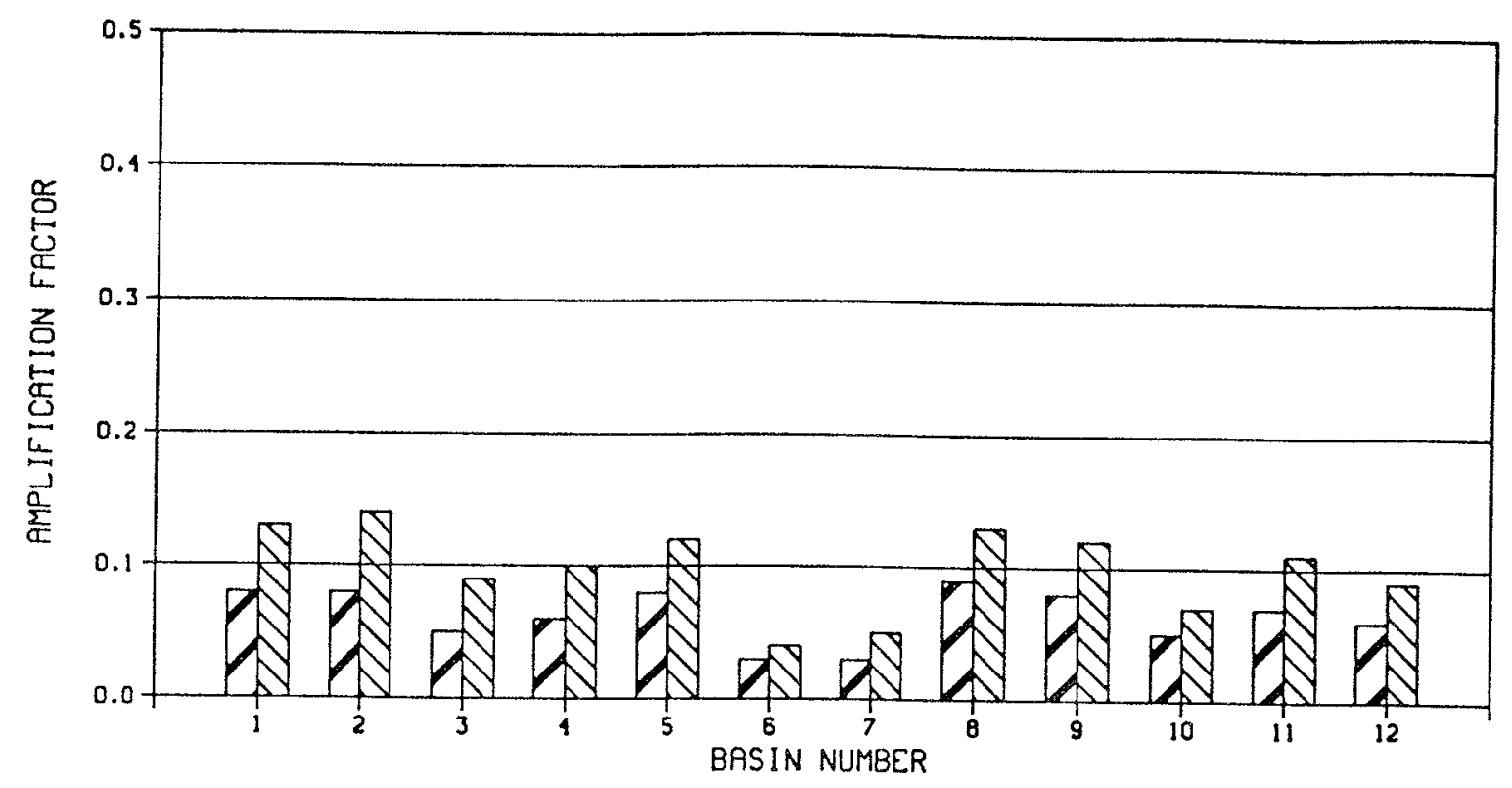

HARBOR ENTRANCE CHANNEL AND TURNING BRSIN

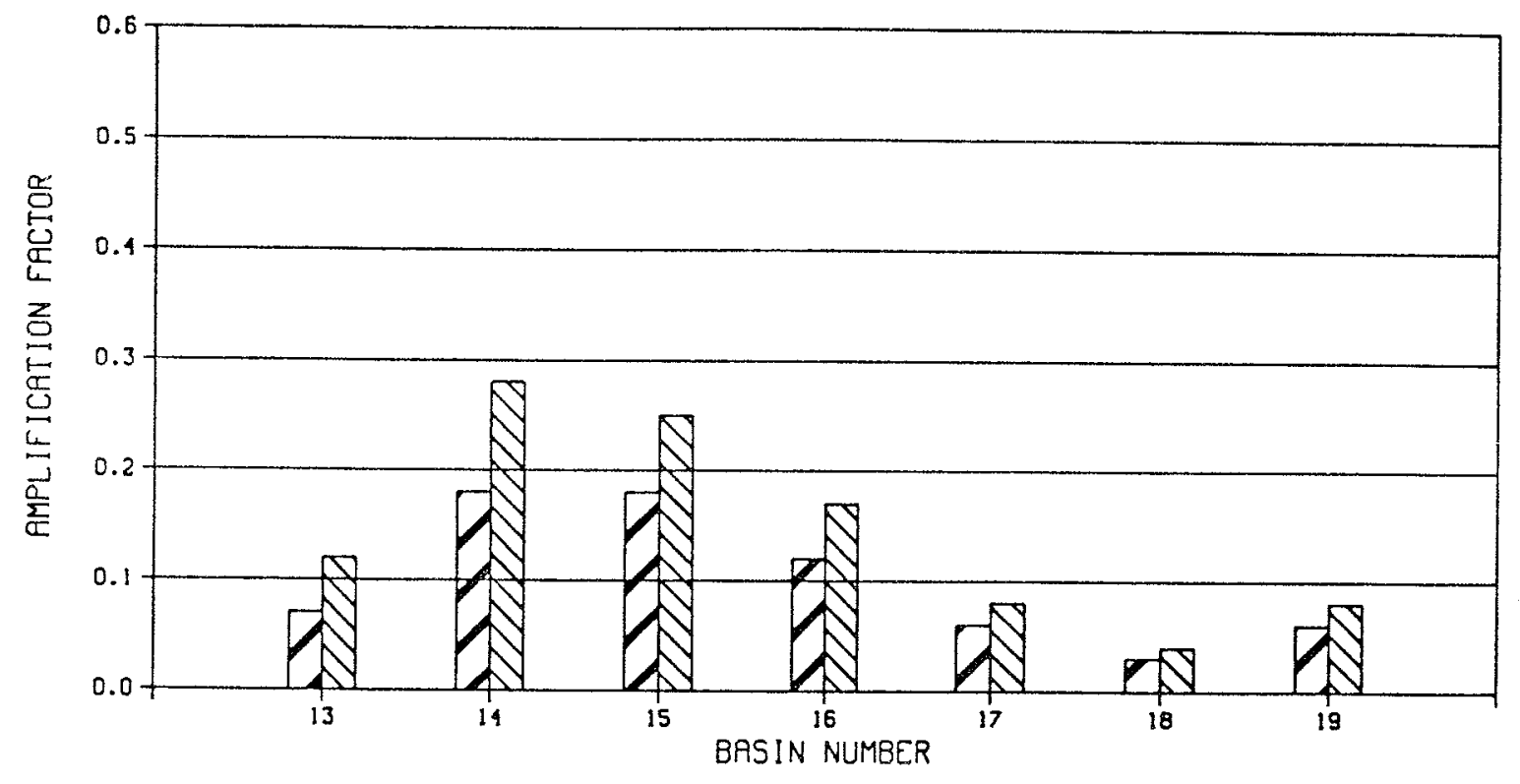

LEGEND

(7) PLAN 1

$\triangle$ PLAN 2
WAVE AMPLIF ICATION FACTOR

KAWAIHAE SHALLOW-DRAFT HARBOR, HI WAVE PERIOD - $13 \mathrm{sec}$ WRVE DIRECTION - 225 deg 
HARBOR BERTHING AREAS

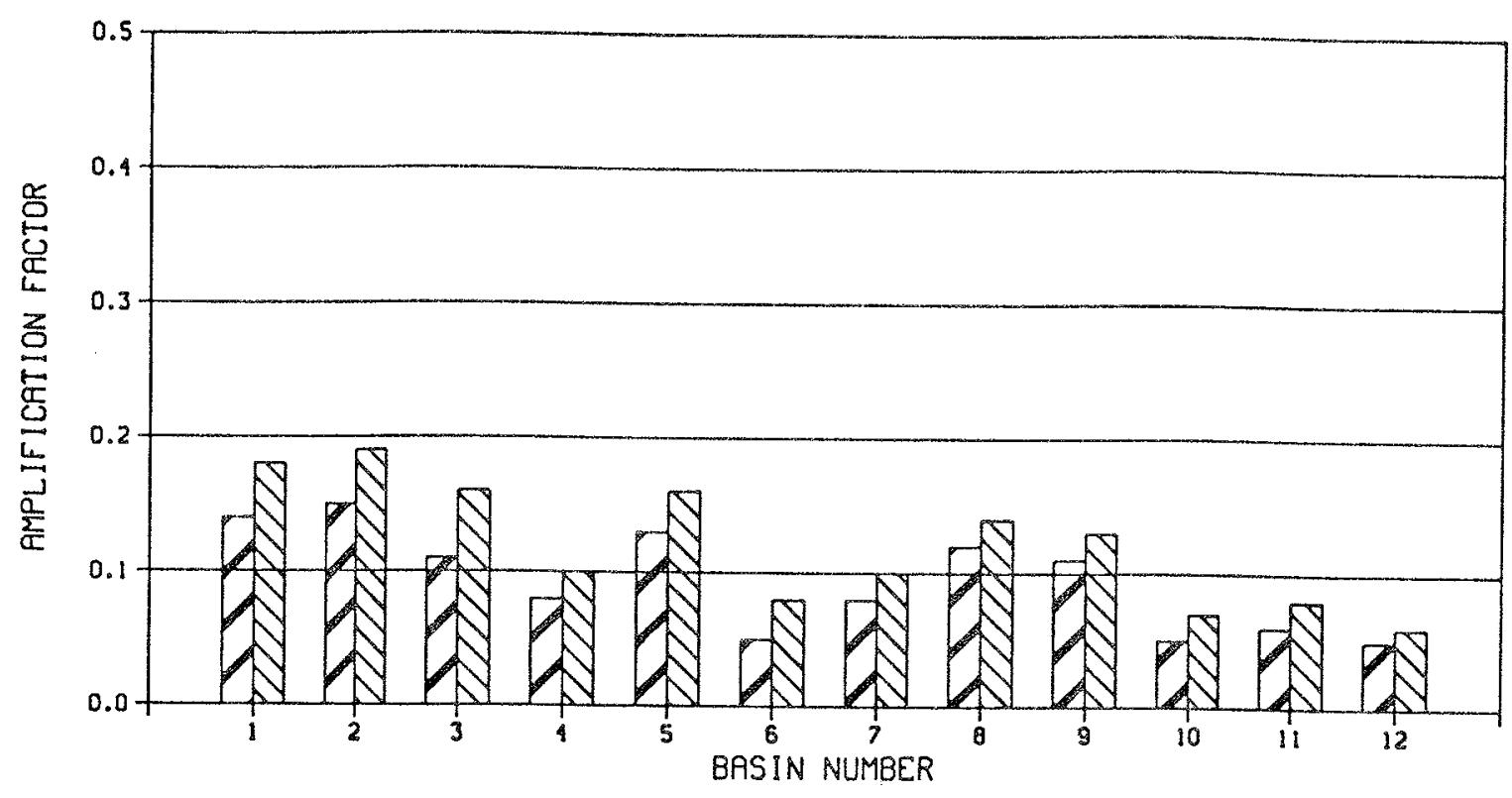

HARBOR ENTRANCE CHANNEL AND TURNING BASIN

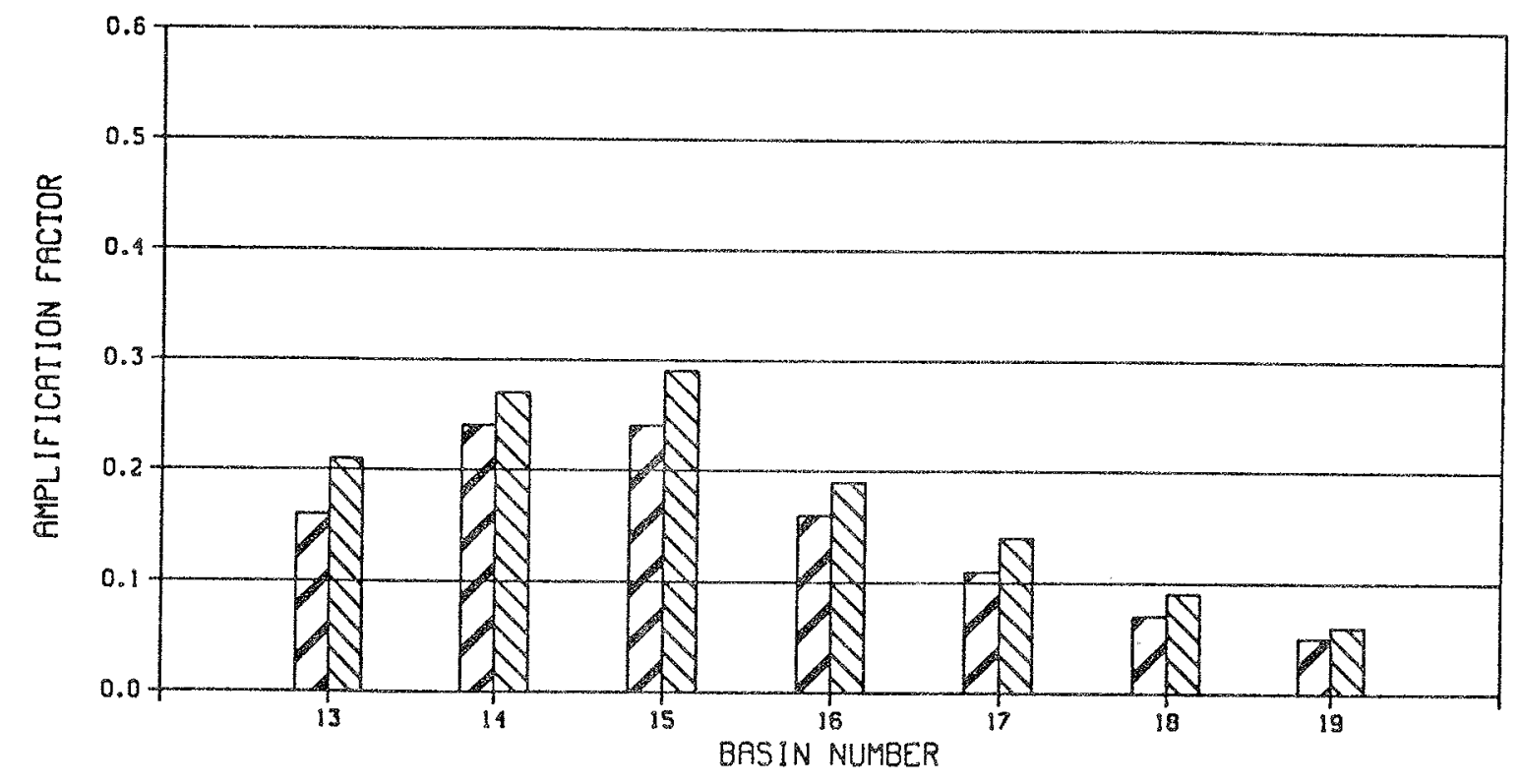

LEGEND

[D PLAN 1

$\triangle \triangle$ PLAN 2
WRVE AMPLIF ICATION FACTOR KAWAIHAE SHALLOW-DRAFT HARBOR, $\mathrm{HI}$ WRVE PERIOO - 15 seC WRVE DIRECTIDN $=225$ deg 
HARBOR BERTHING AREAS

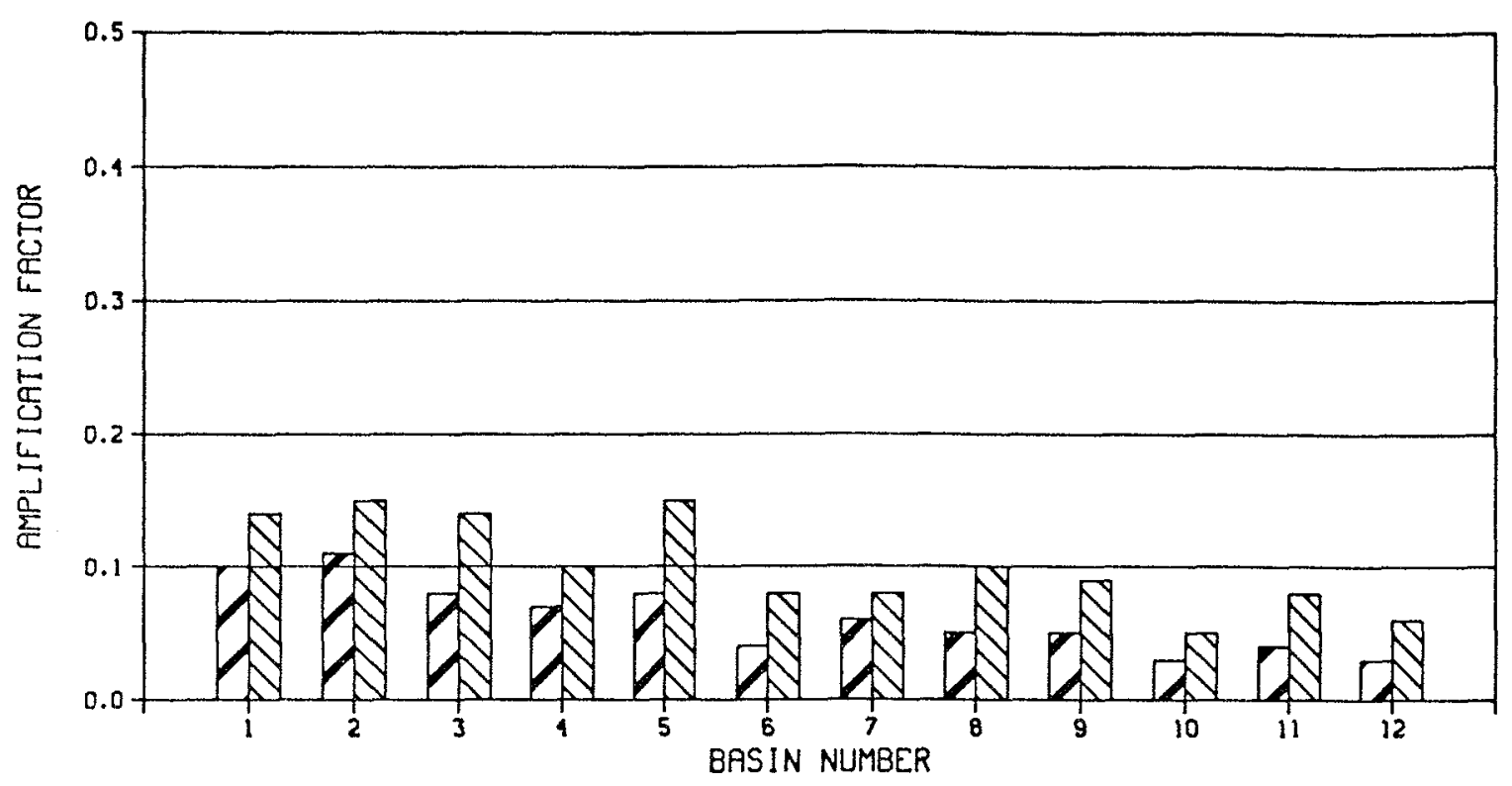

HRRBOR ENTRANCE CHANNEL AND TURNING BASIN

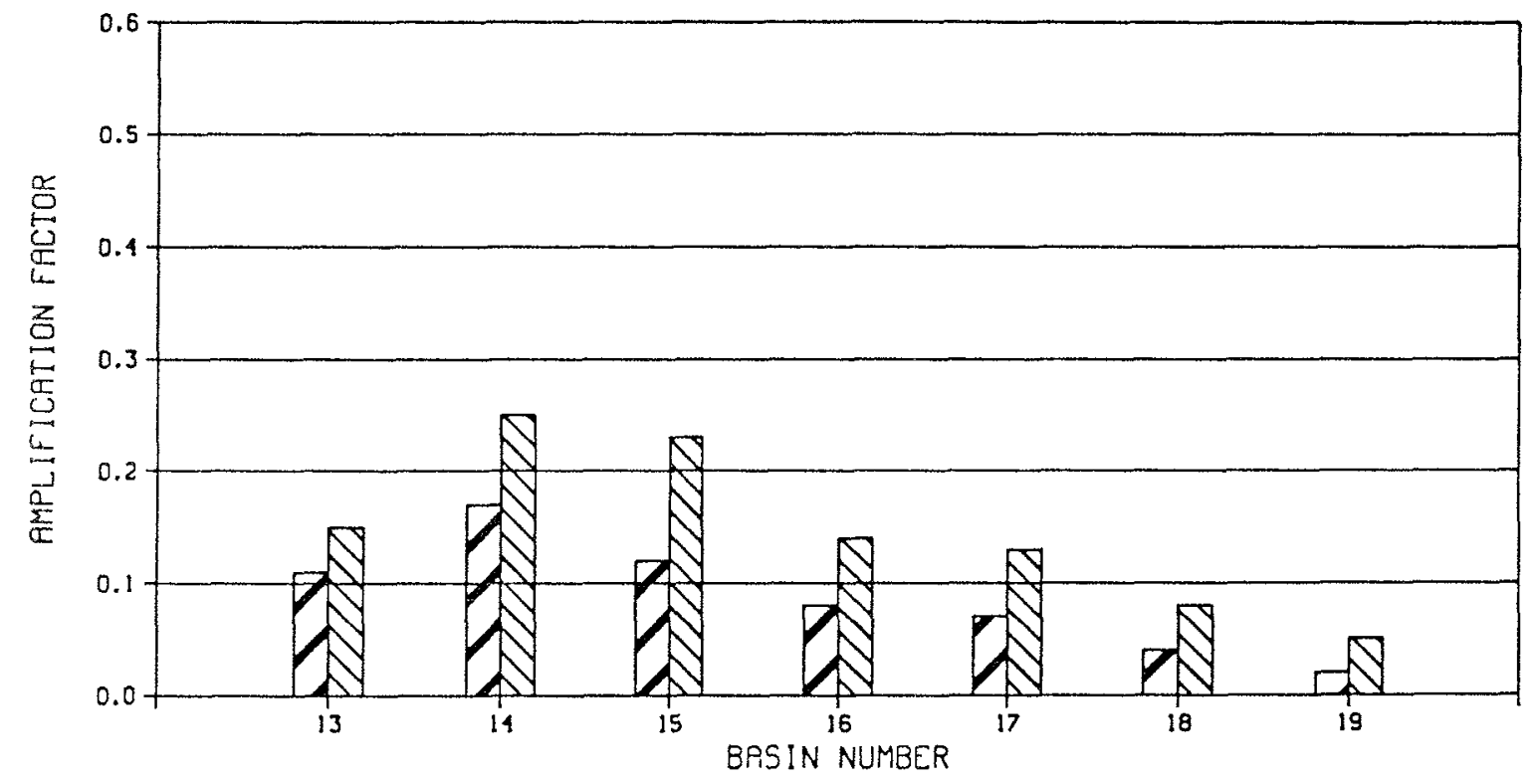

LEGEND

L PLAN I

$\triangle$ PLAN 2
WAVE AMPLIFICATION FACTOR

KAWRIHRE SHALLOW-DRAFT HARBOR, HI

WAVE PERIOO - $17 \mathrm{sec}$

WAVE DIRECTION - 225 deg 
HARBOR BERTHING AREAS

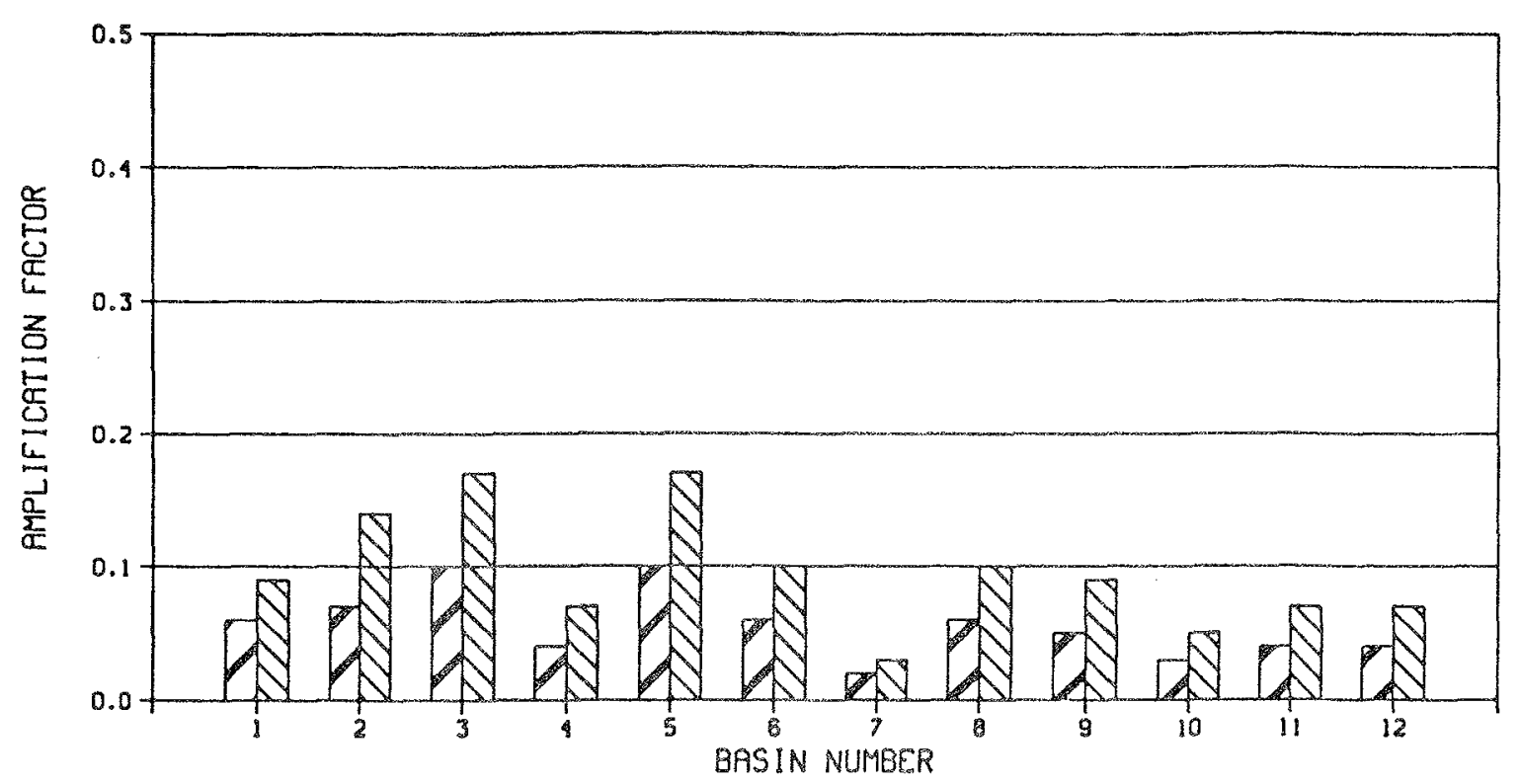

HARBOR ENIRANCE CHANNEL RND IURNING BASIN

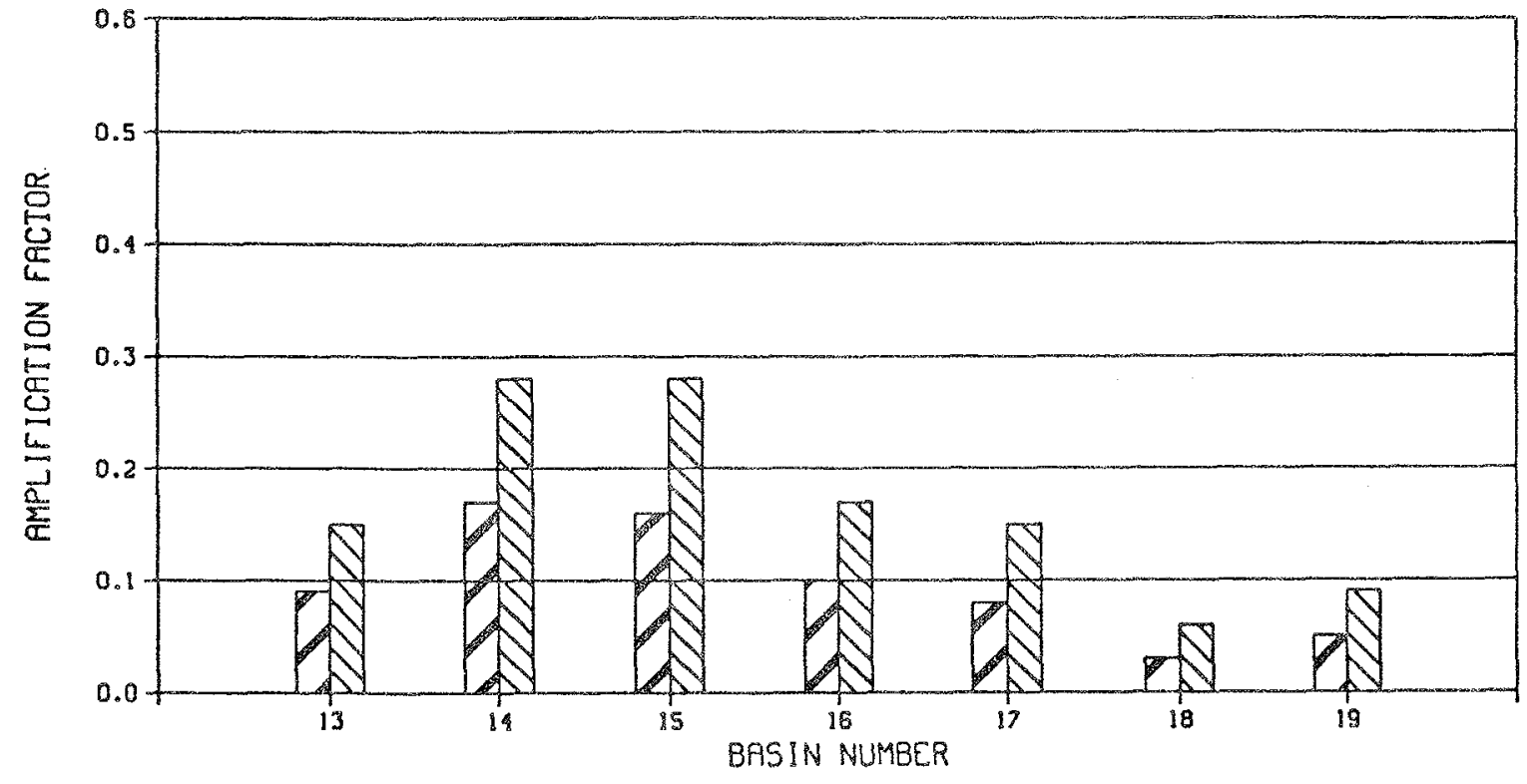

LEGEND

(2) PLAN 1

$\triangle \triangle$ PLAN 2
WAVE AMPLIFICATION FACTOR

KAWAIHAE SHALLOW-DRRFT HRRBOR, HI WAYE: PERIOO $=20 \mathrm{sec}$ WAVE DIRECTION - $225 \mathrm{deg}$ 
HARBOR BERTHING RREAS

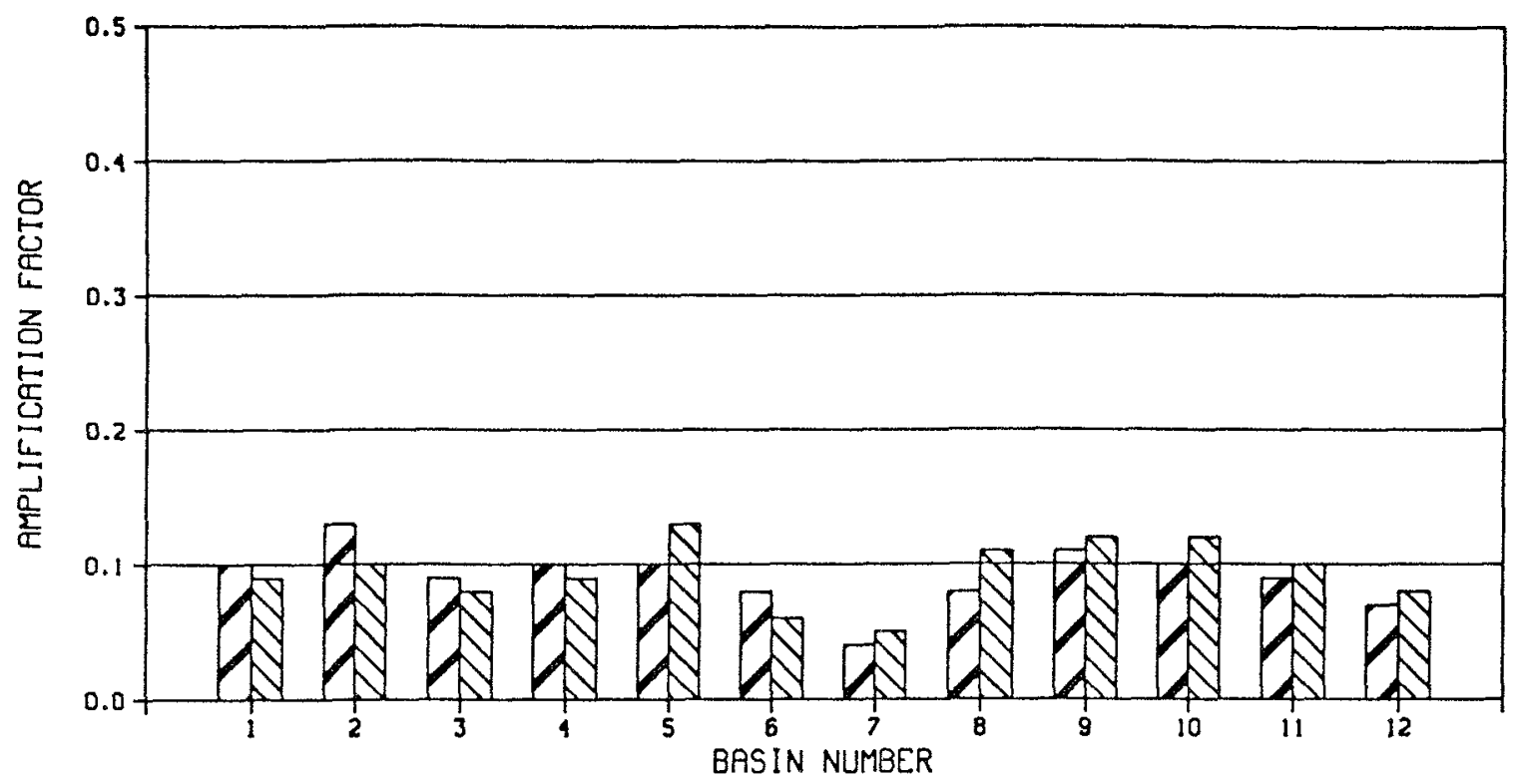

HARBOR ENTRANCE CHANNEL RND TURNING BASIN

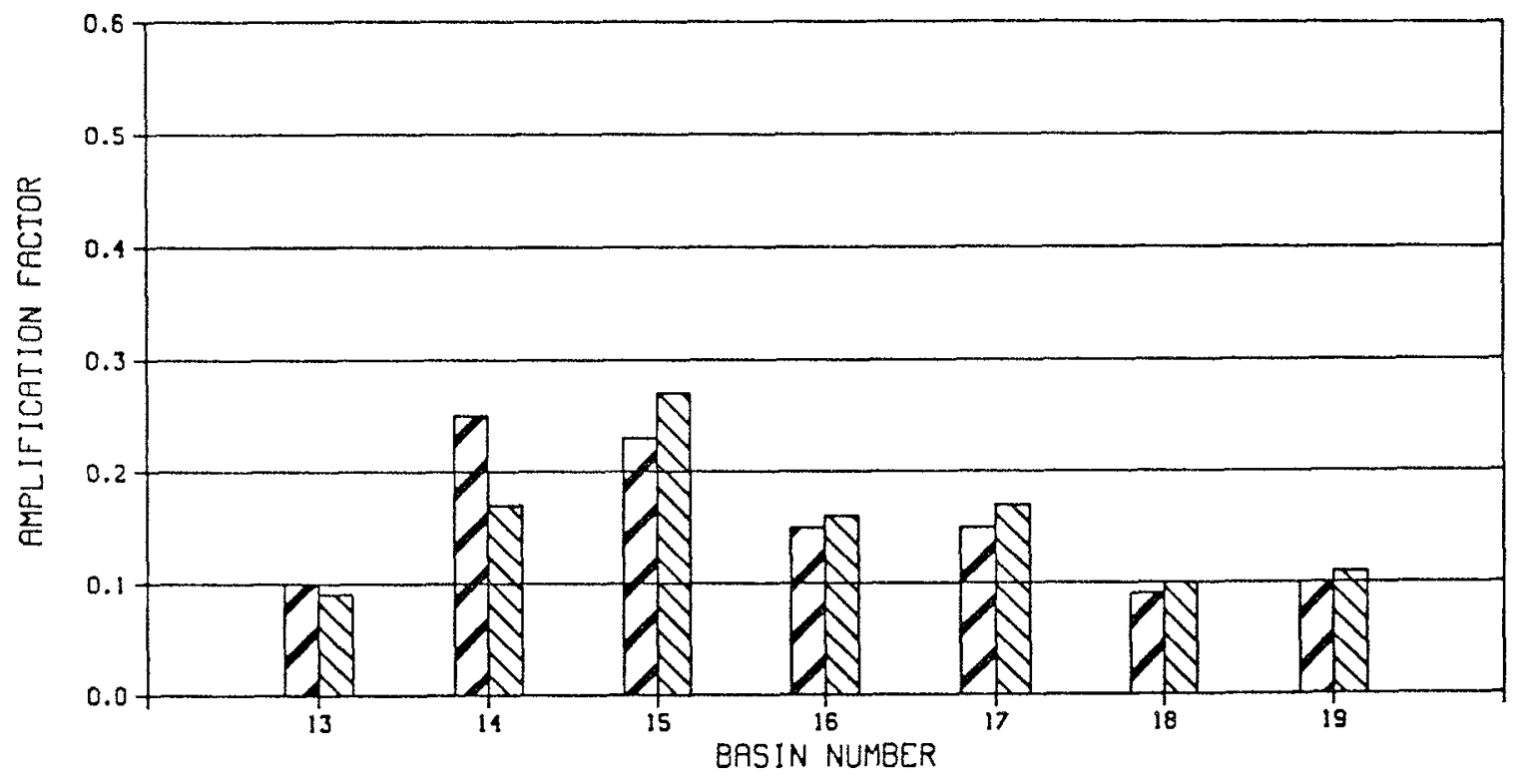

LEGEND

$D$ PLAN 1

$\triangle$ PLFN 2
WAVE AMPLIFICATION FACTOR

KAWAIHRE SHALLOW-DRAFT HRRBOR, $\mathrm{HI}$ WRVE PERIOD - $7 \mathrm{sec}$

WAVE OIRECTION - $247.5 \mathrm{deg}$ 
HARBOR BERTHING AREAS

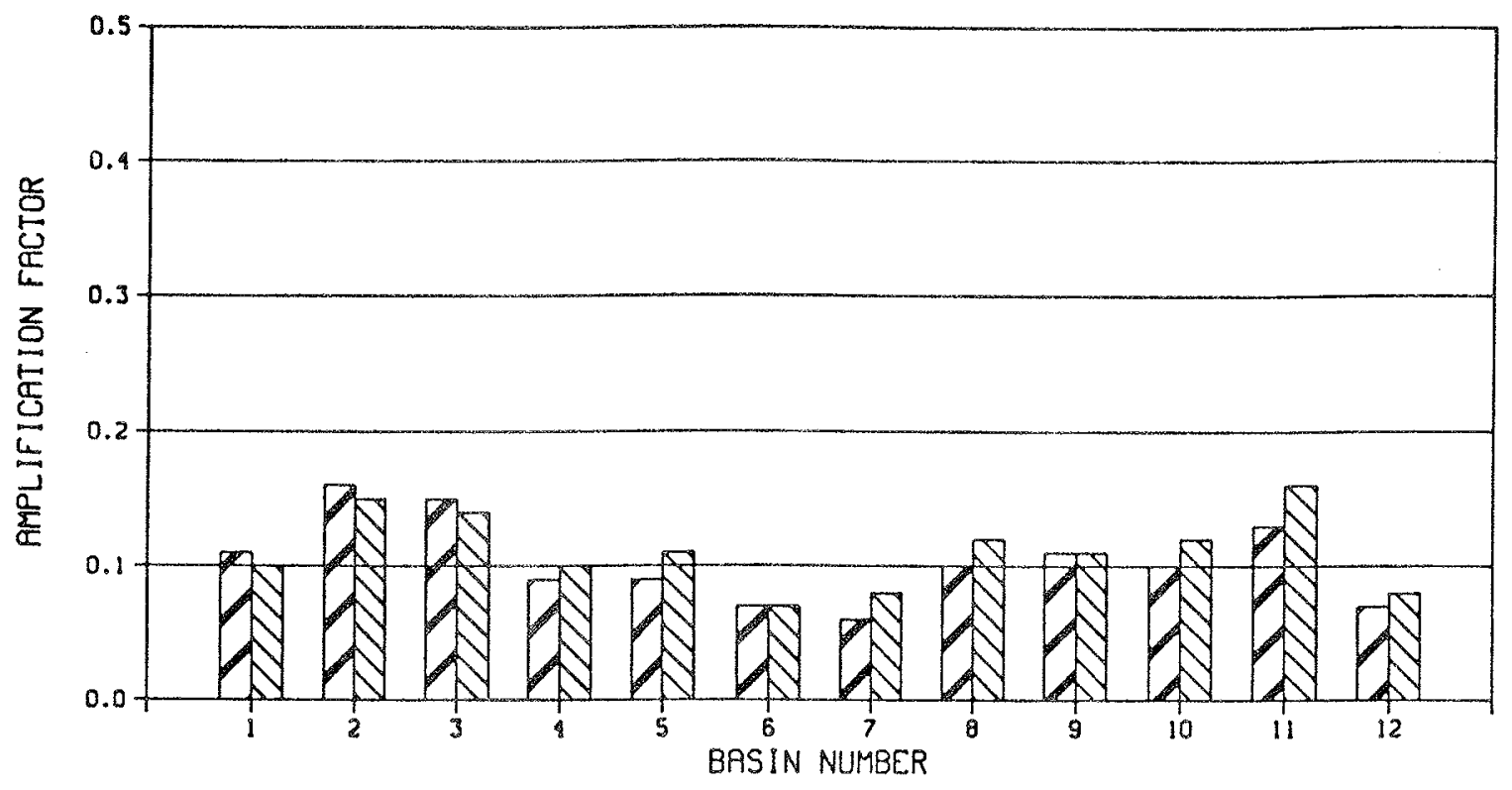

HRRBOR ENTRANCE CHRNNEL AND TURNING BRSIN

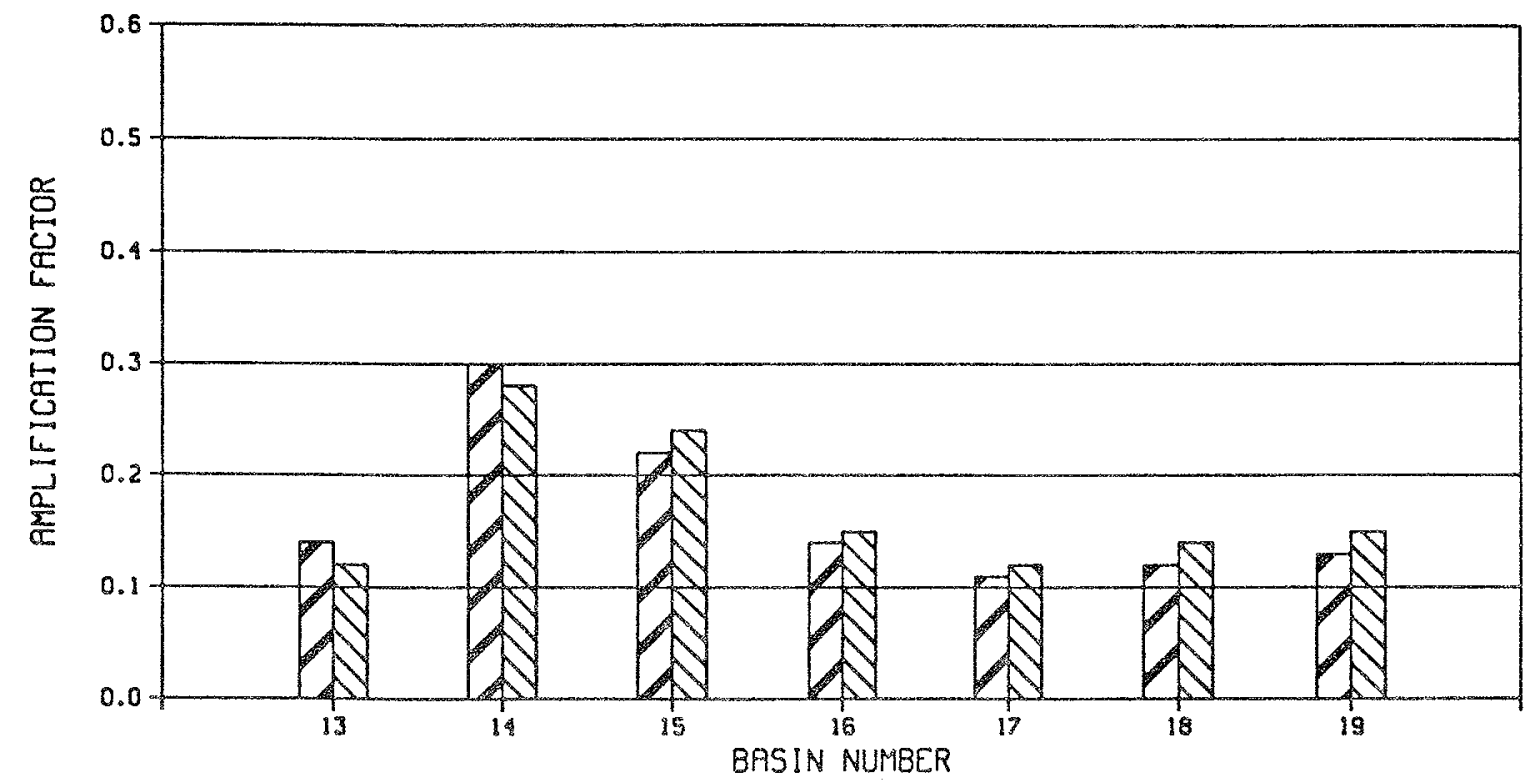

LEGEND

[2] PLAN 1

$\triangle 9$ PLAN 2
WRVE AMPLIFICATION FACTOR

KAWAIHAE SHALLOW-DRAFT HRRBOR, $\mathrm{HI}$ WAVE PERIOO - 9 s\&C WPVE OIRECTION $-247.5 \mathrm{deg}$

PLATE 12 


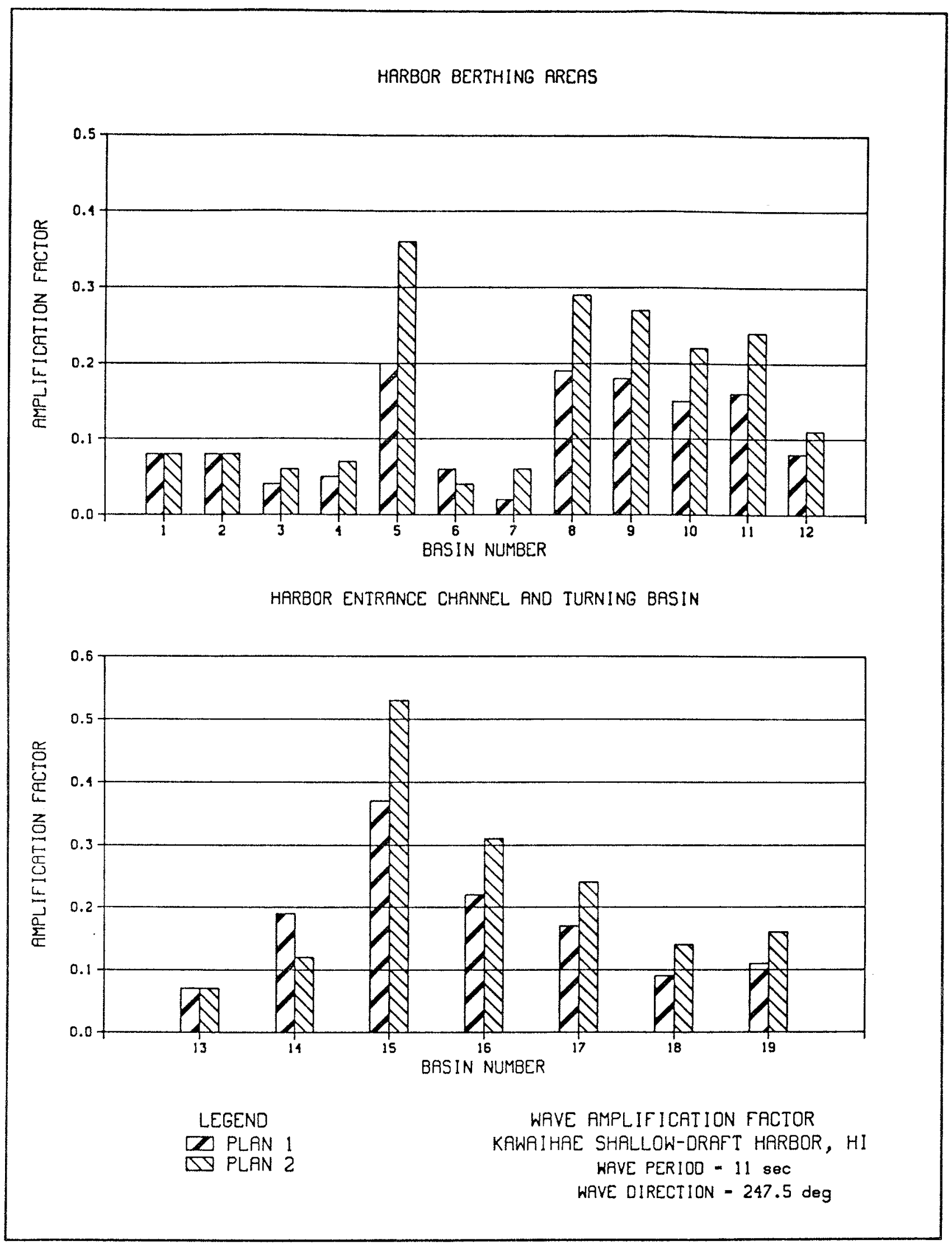


HARBOR BERTHING AREAS

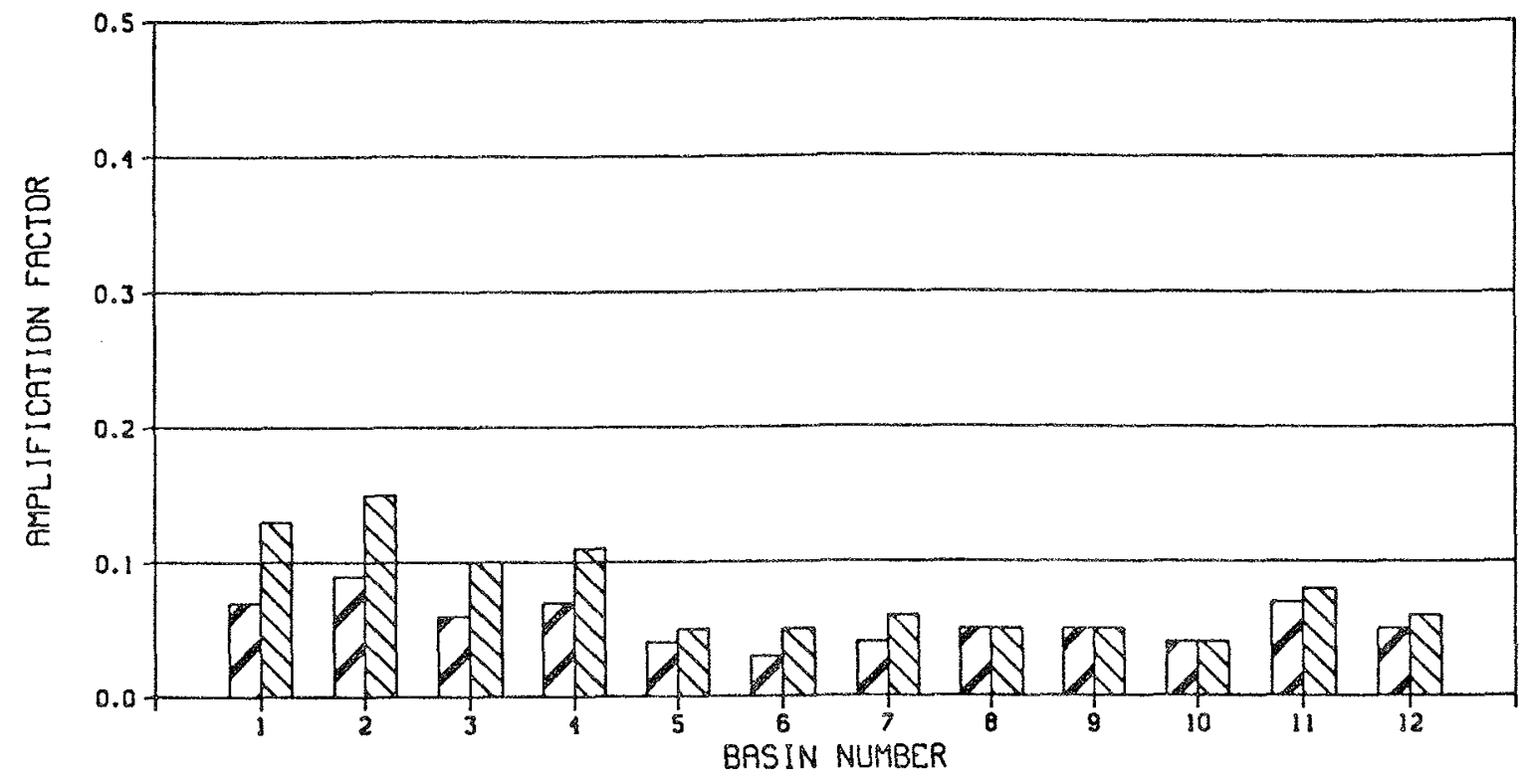

MARBOR ENTRANCE CHRNNEL ANO TURNING BRSIN

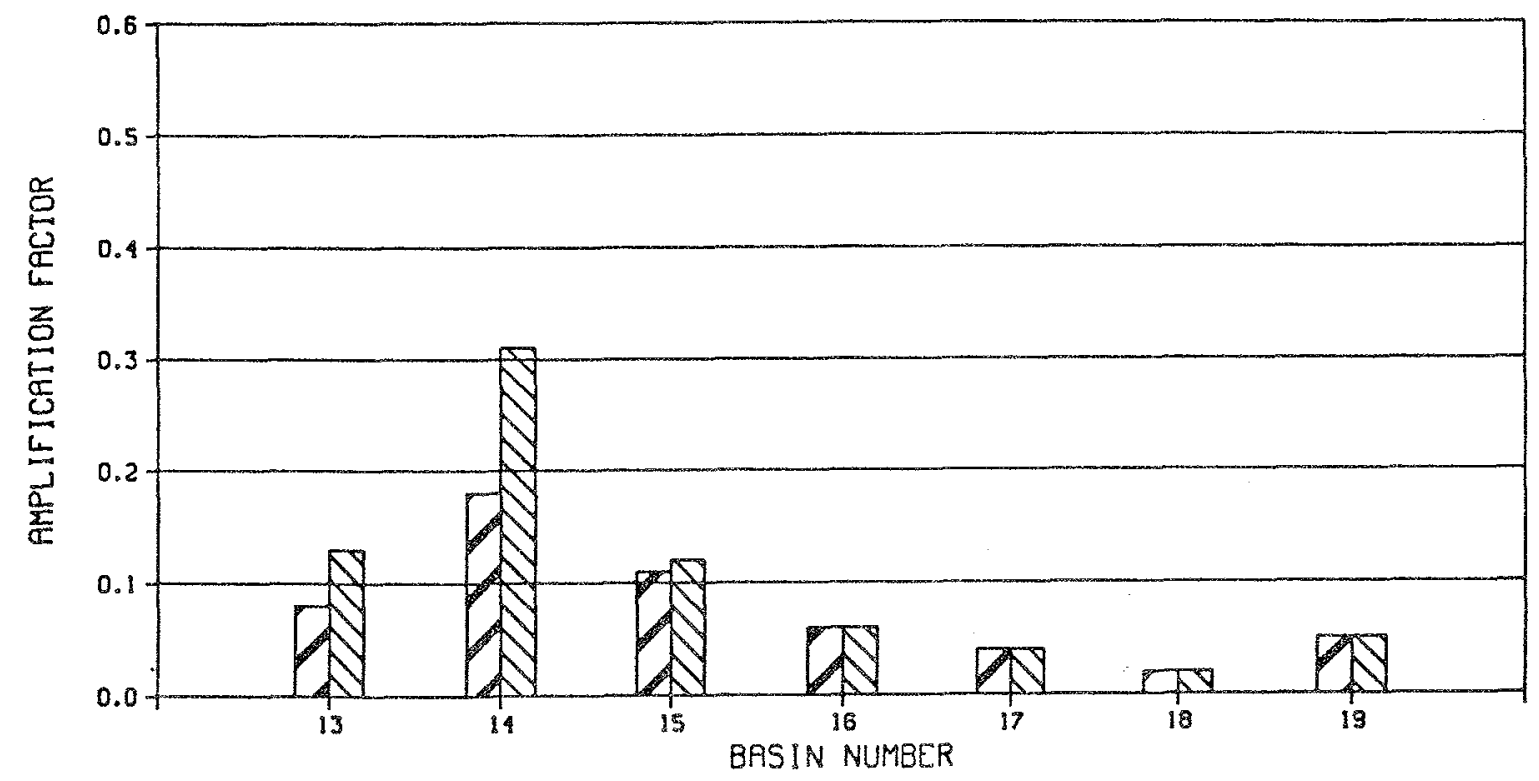

LEGEND

LD PLAN I

$\triangle$ PLAN 2
WAVE AMPLIFICATION FRCTOR KAWAIHAE SHALLOW-DRAFT HRRBOR, HI WAVE PERIOO - 13880 WAVE DIRECTION $=247.5 \mathrm{deg}$ 
HARBOR BERTHING AREAS

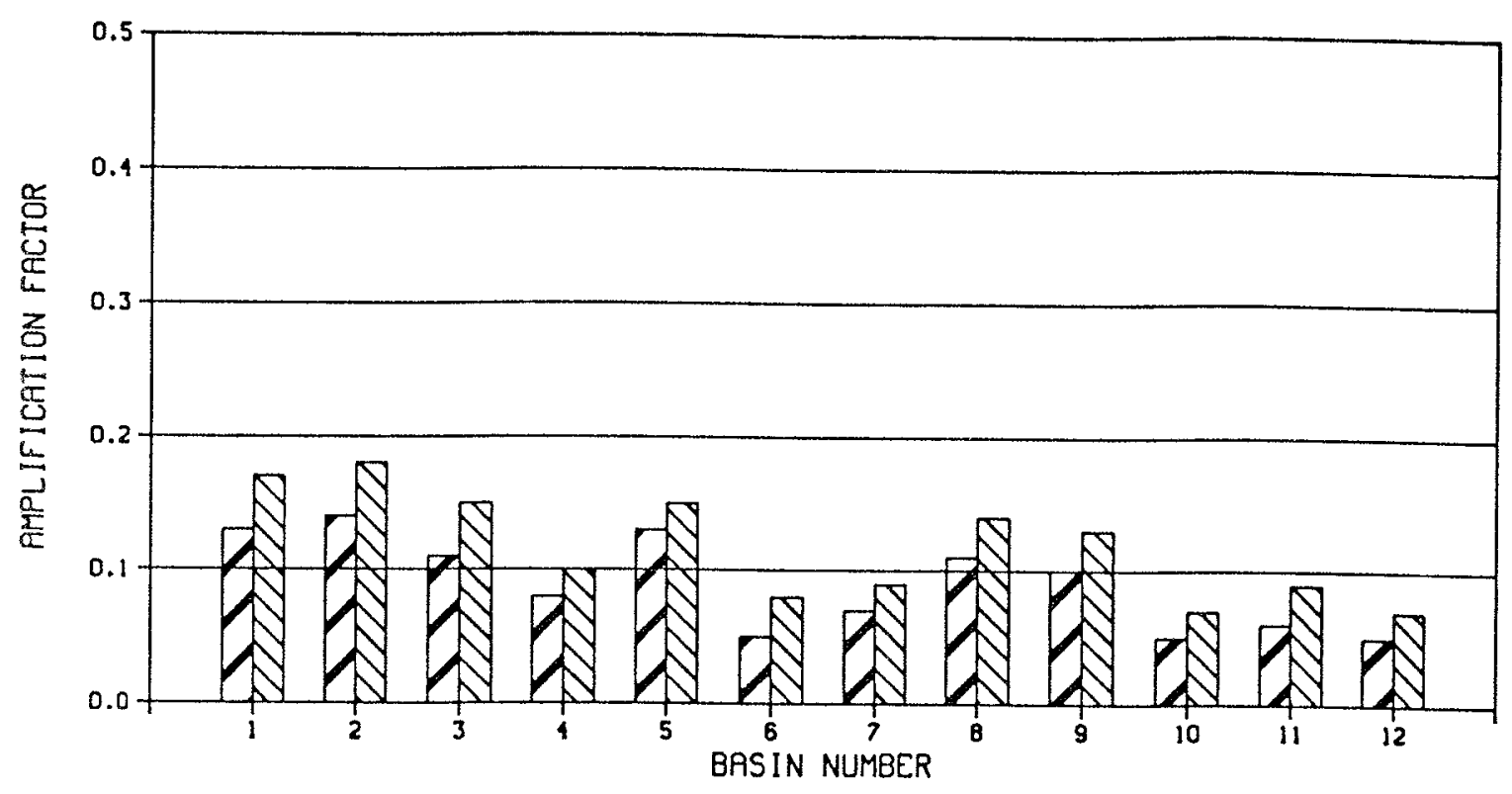

HARBOR ENTRANCE CHANNEL AND TURNING BASIN

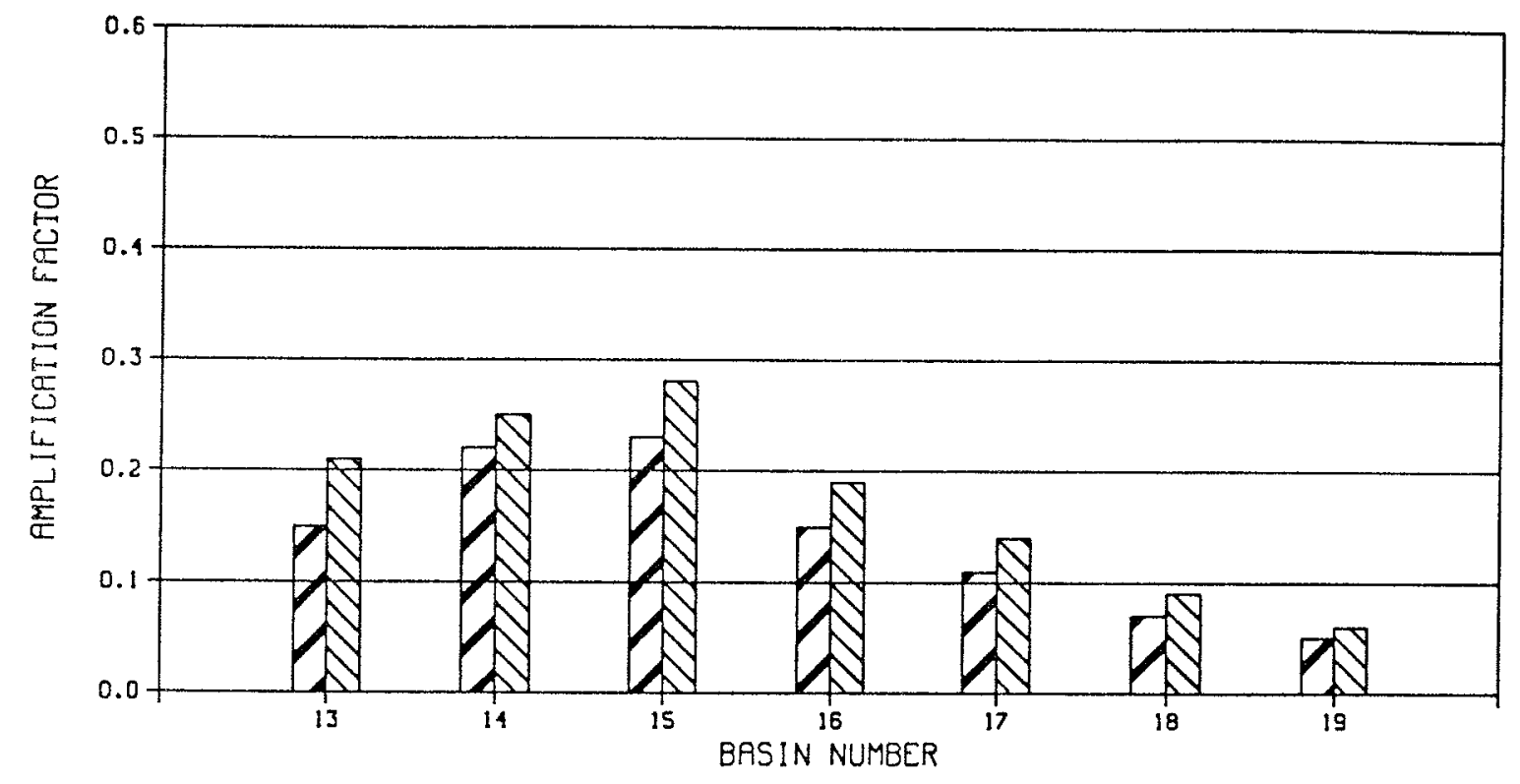

LEGEND

$\square$ PLAN 1

$\triangle$ PLAN 2
WAVE RMPLIFICATION FACTOR

KAWRIHRE SHALLOW-ORAFT HRRBOR, HI WRVE PERIOD - 15 seC WAVE OIRECTION - $247.5 \mathrm{deg}$ 


\section{HARBOR BERTHING AREAS}

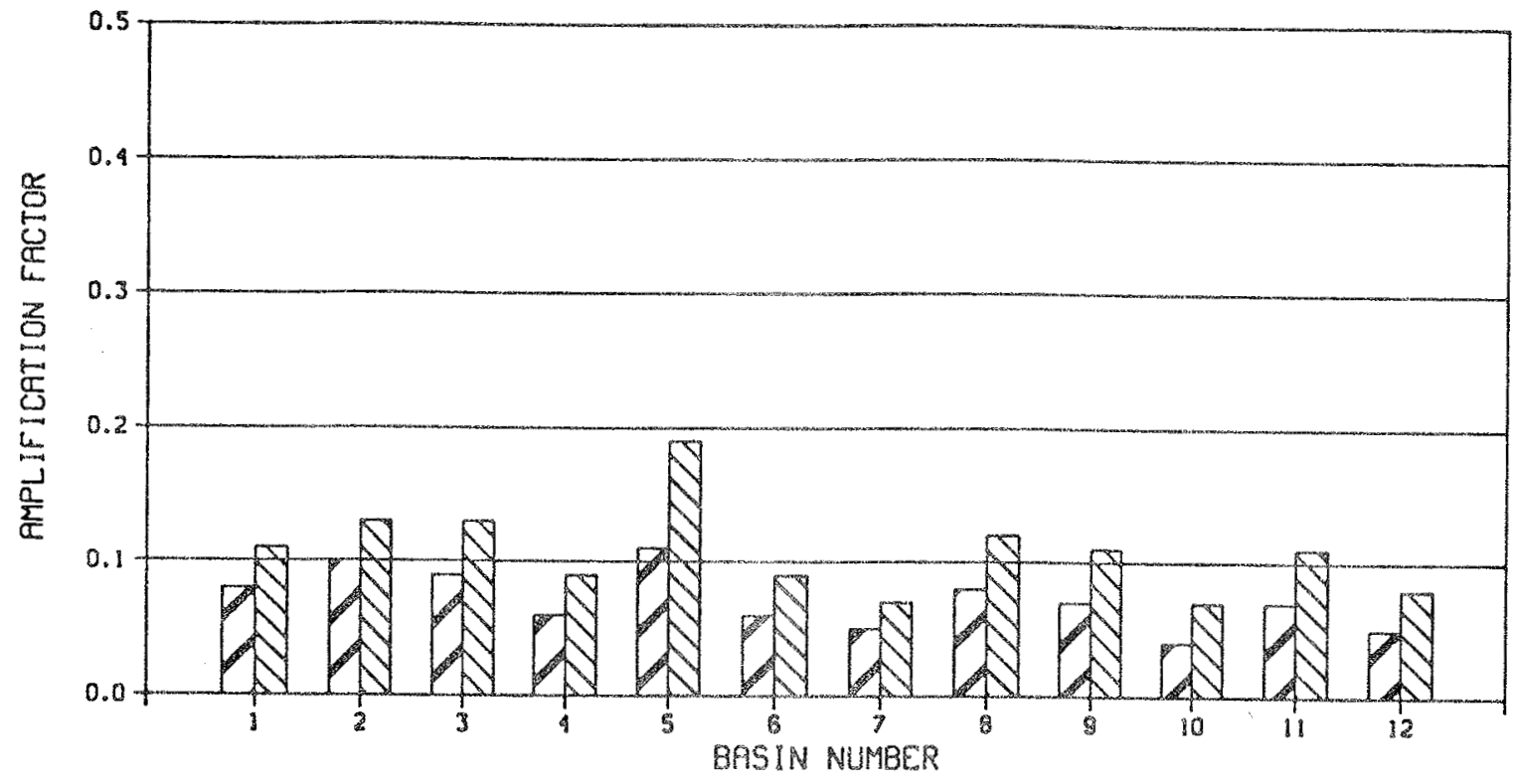

HARBOR ENTRANCE CHANNEL AND TURNING BASIN

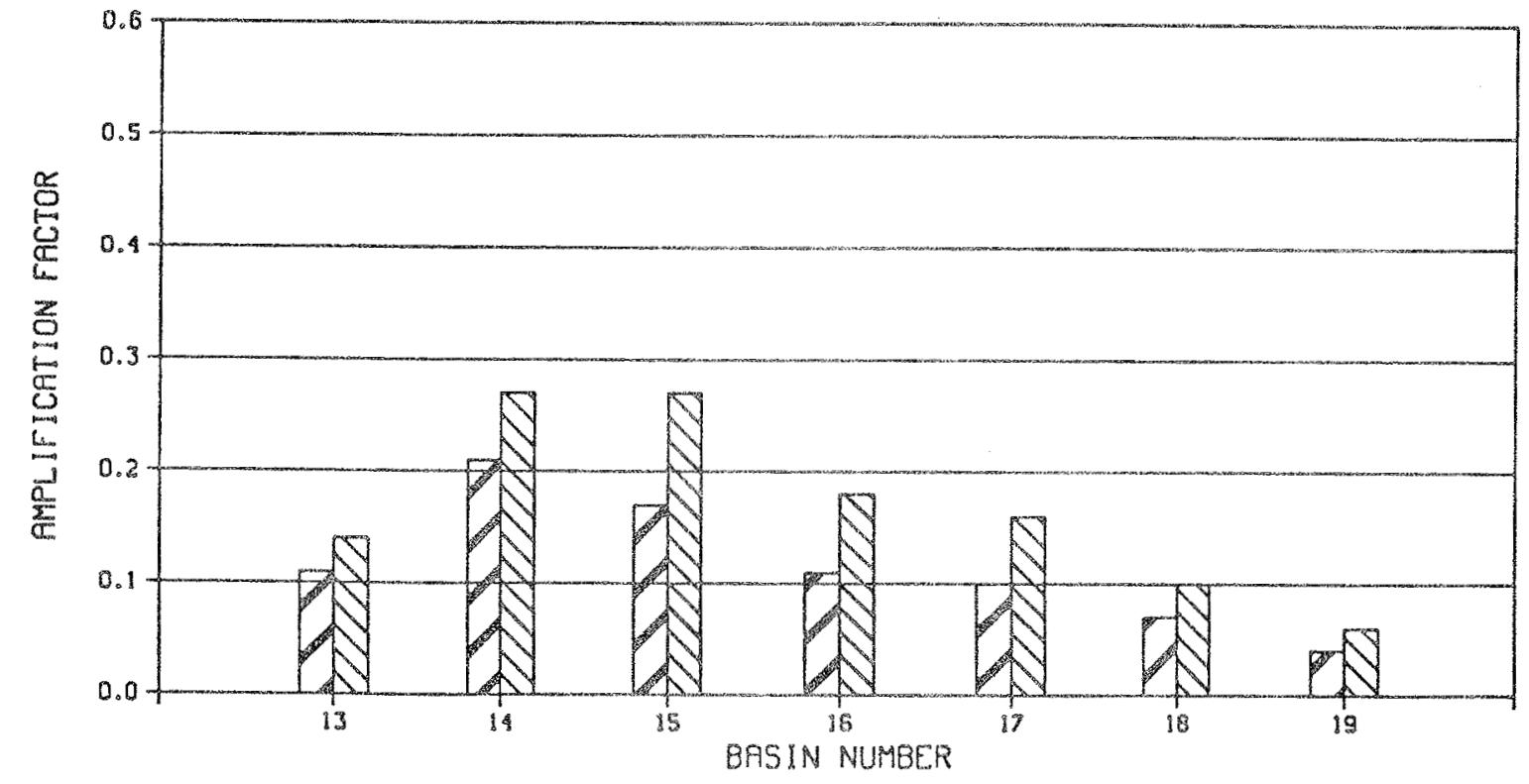

LEGEND

[2] PLAN 1

$\triangle \triangle$ PLAN 2
WAVE AMPLIFICATION FACTOR KAWAIHAE SHRLLOW-DRAFT HARBOR, $\mathrm{HI}$ WAVE PERIOD $=17$ SBC HRVE DIRECTIDN $=247.5 \mathrm{~d} g$ 
HARBOR BERTHING AREAS

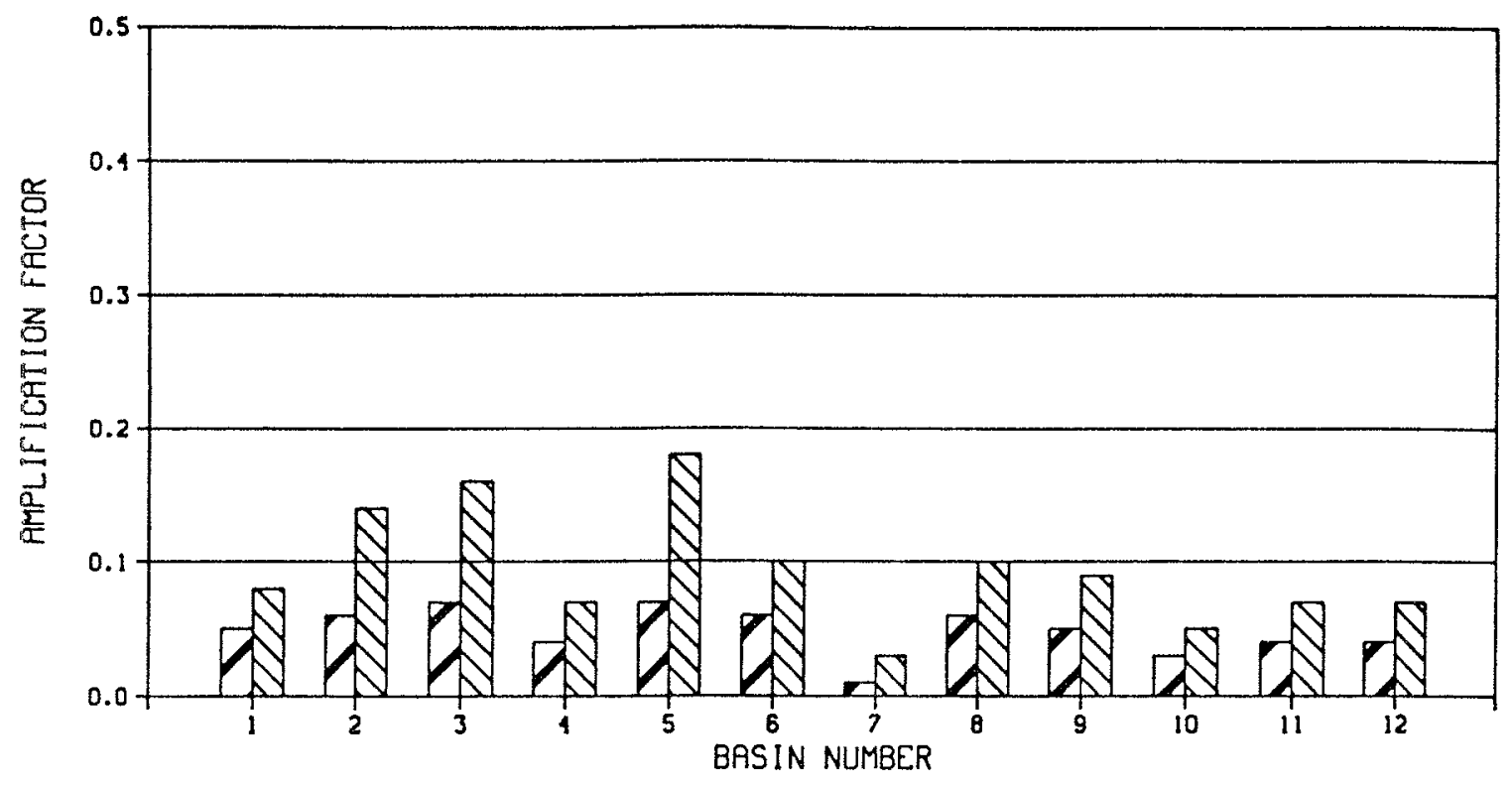

HARBOR ENTRANCE CHRNNEL AND TURNING BASIN

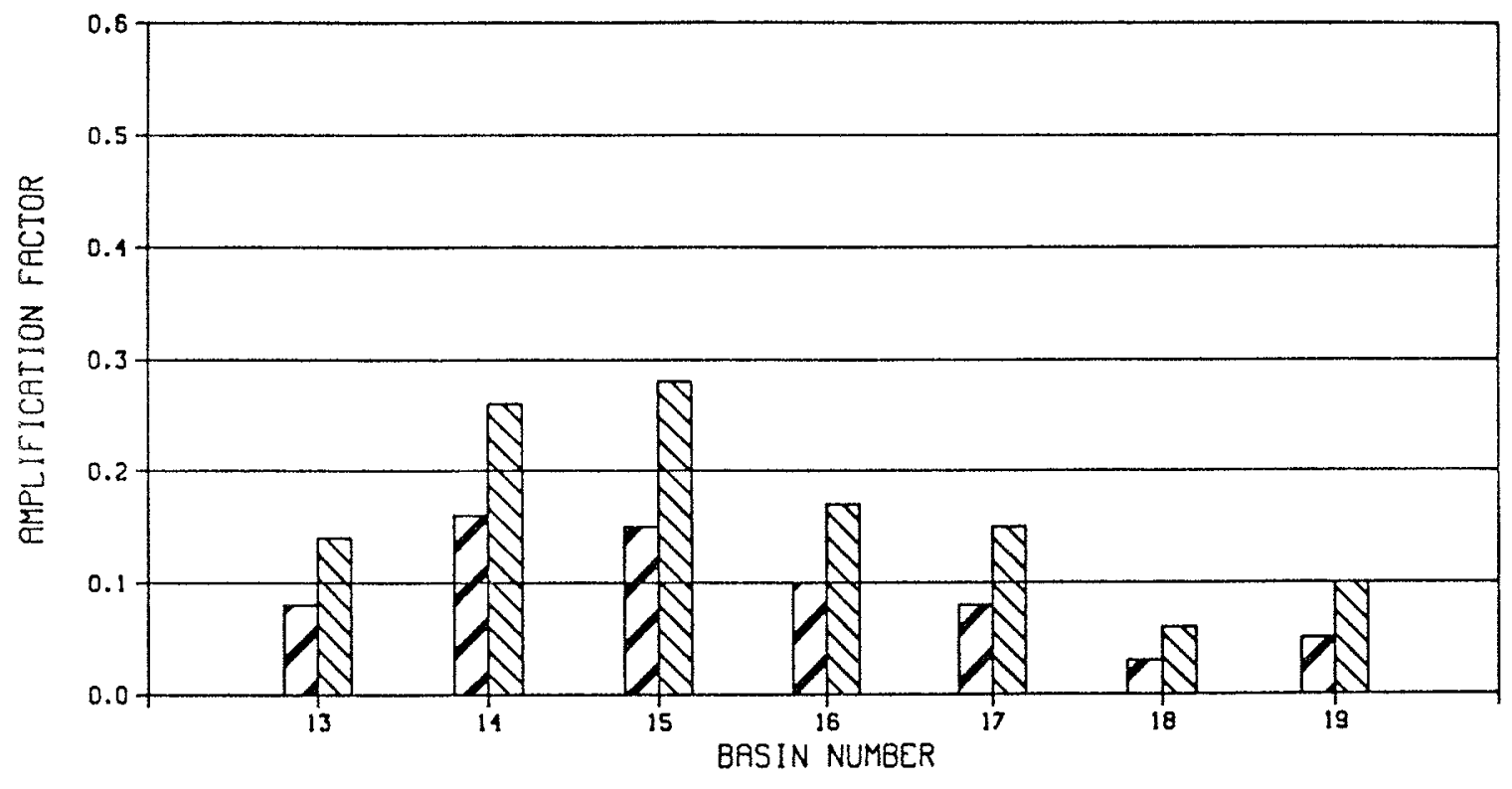

LEGEND

[D PLAN 1

$\triangle$ PLAN 2
WAVE AMPLIFICATION FACTOR

KAWRIHRE SHALLOW-DRRFT HARBOR, HI WAVE PERIDO - $20 \mathrm{sec}$ WAVE DIRECTION $-247.5 \mathrm{deg}$ 
HARBOR BERTHING RREAS

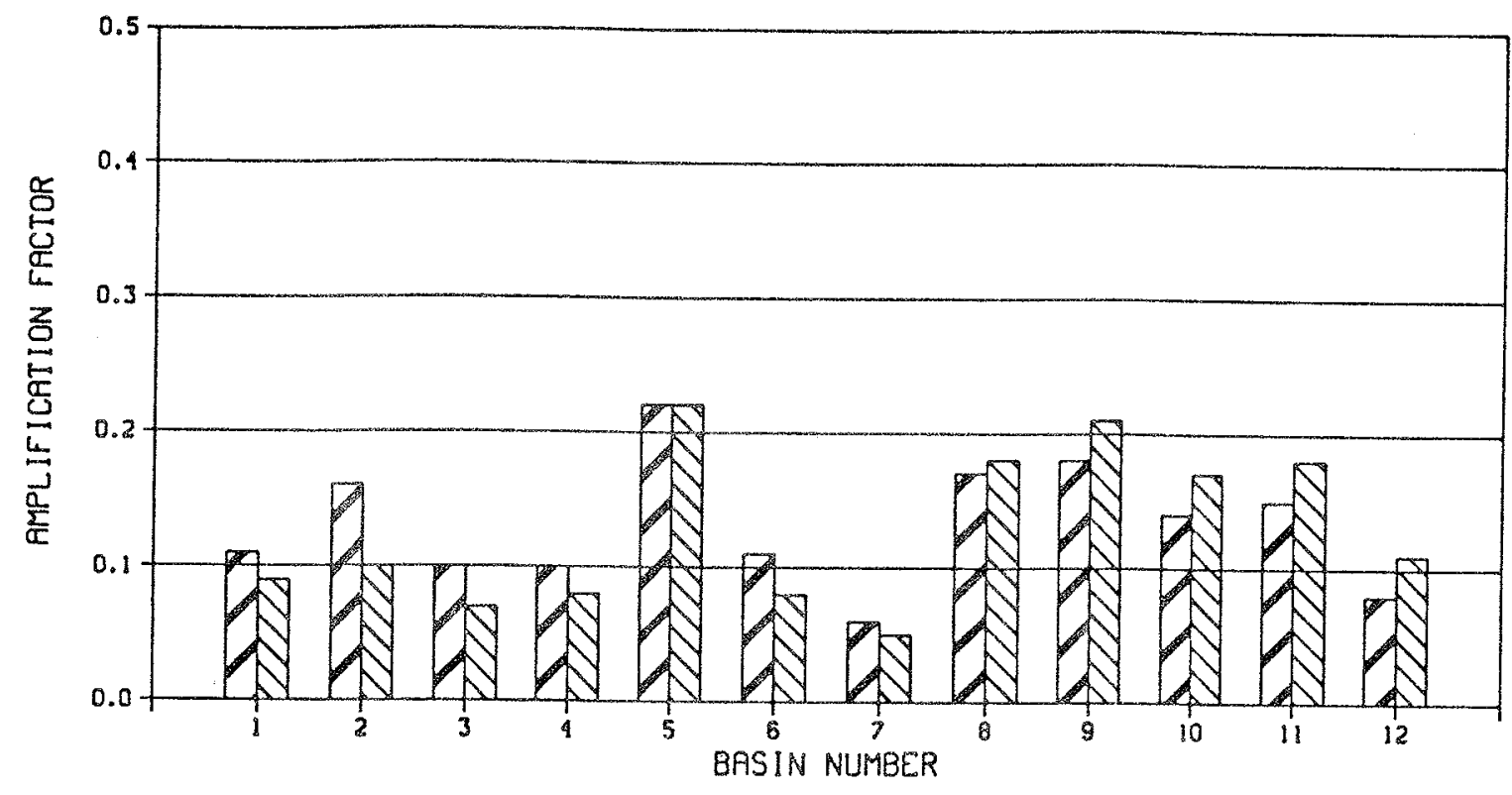

HRRBOR ENTRANCE CHANNEL FND IURNING BASIN

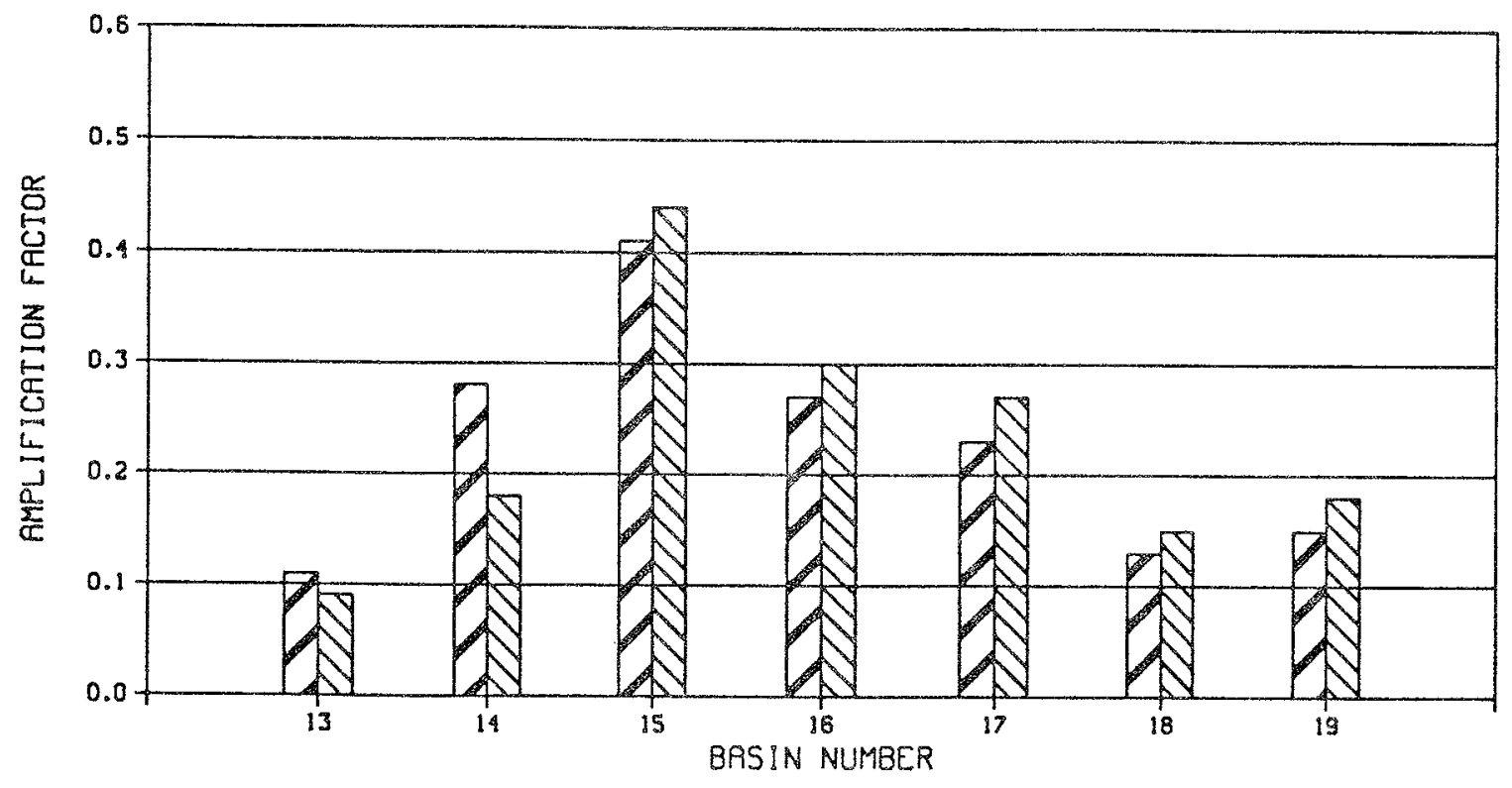

LEGEND

$\square$ PLAN 1
$\triangle \triangle$ PLAN 2
WAVE RMPLIFICATION FACTOR

KAWAIHAE SHRLLOW-DRAFT HRRBOR, $\mathrm{HI}$ WAVE PERIOD * 7 soc WAVE DIRECTION $=270 \mathrm{deg}$

PLRTE 18 
HRRBOR BERTHING AREAS

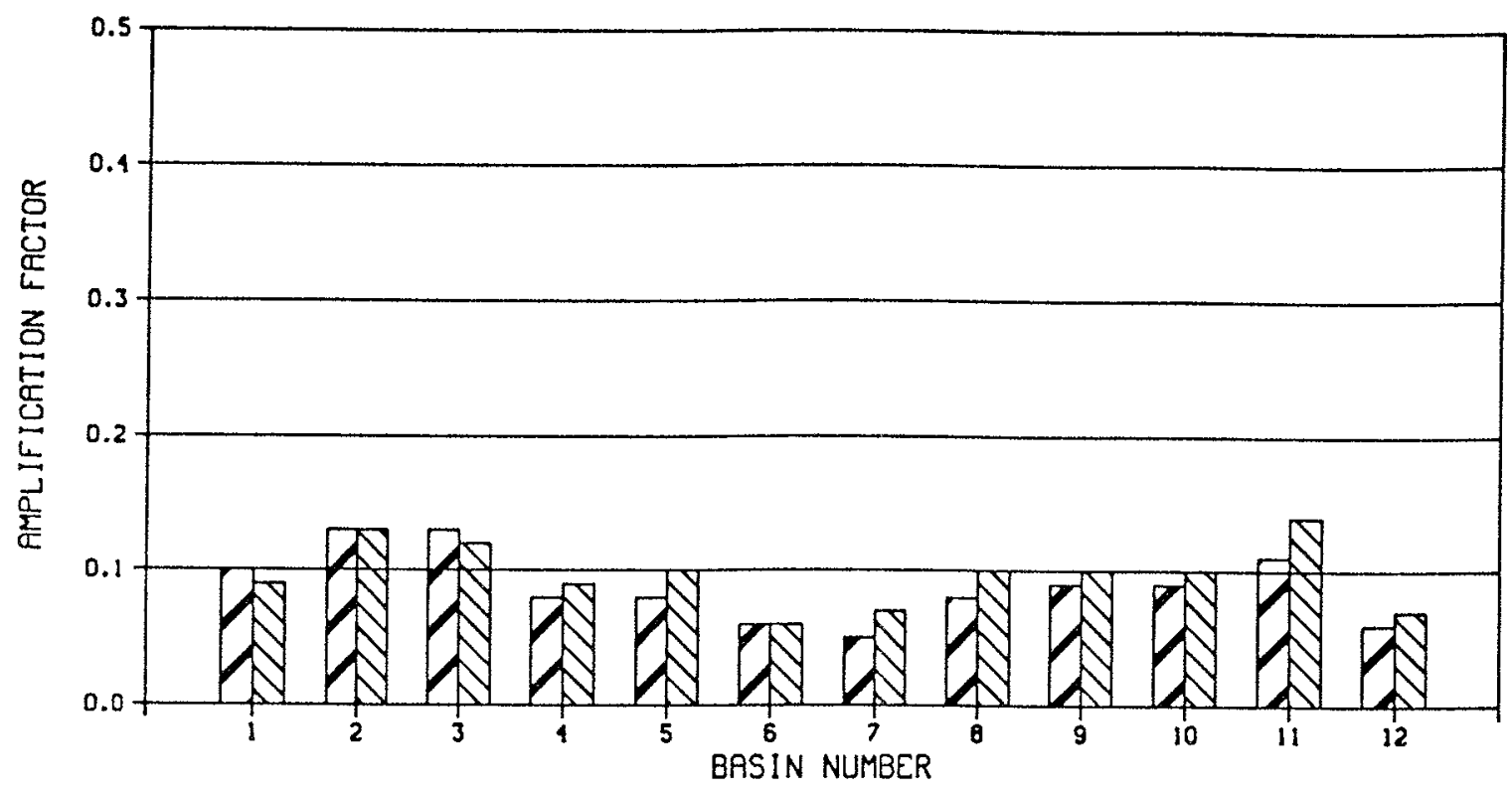

HARBOR ENTRANCE CHANNEL AND TURNING BASIN

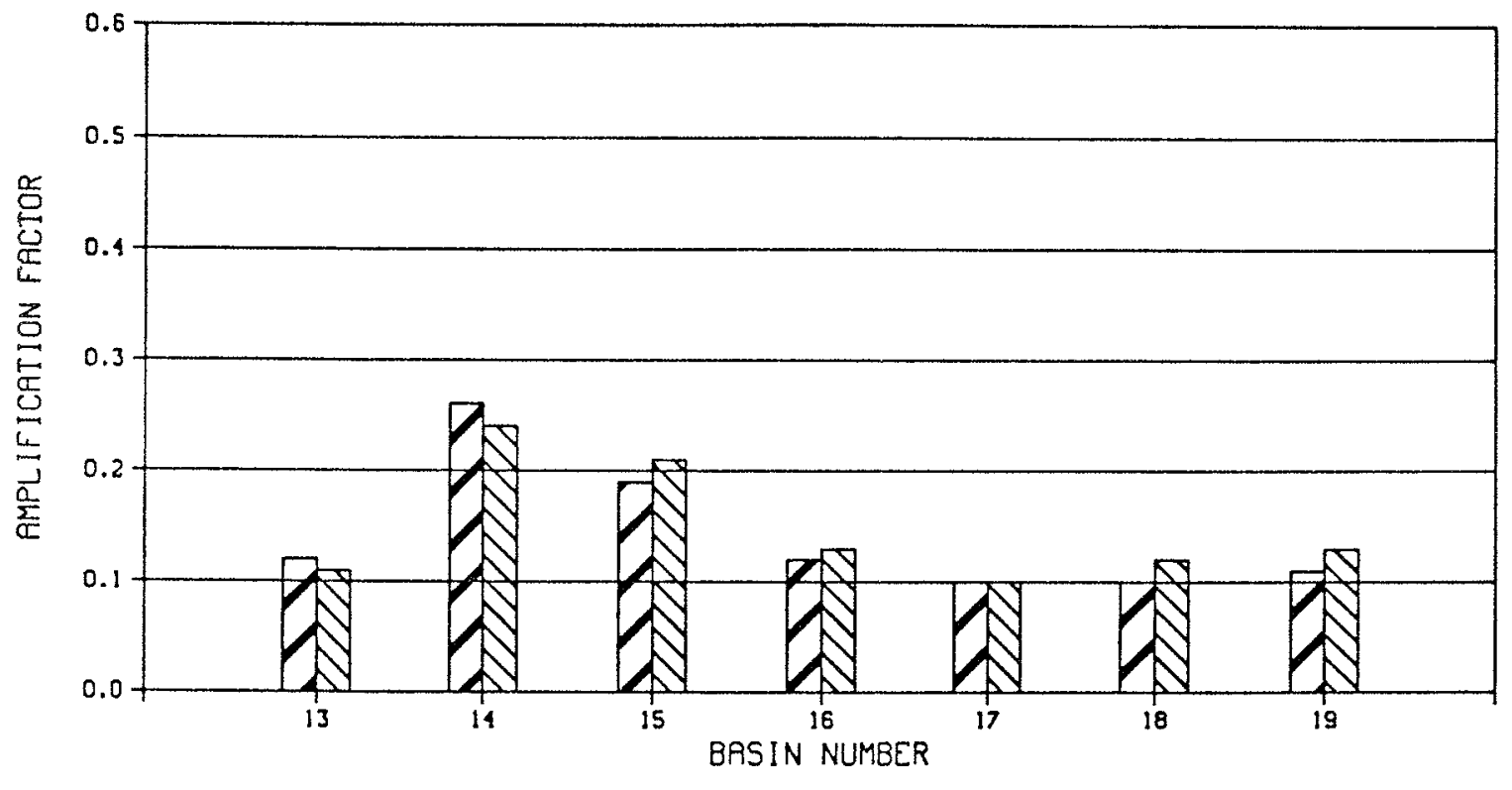

LEGENO

D PLAN 1

$\triangle$ PLAN 2
WAVE AMPLIFICATION FACTOR KAWRIHAE SHALLOW-DRAFT HARBOR, HI WAVE PERIOD - 9 sec WAVE DIRECTION - 270 deg 
HARBOR BERTHING AREAS

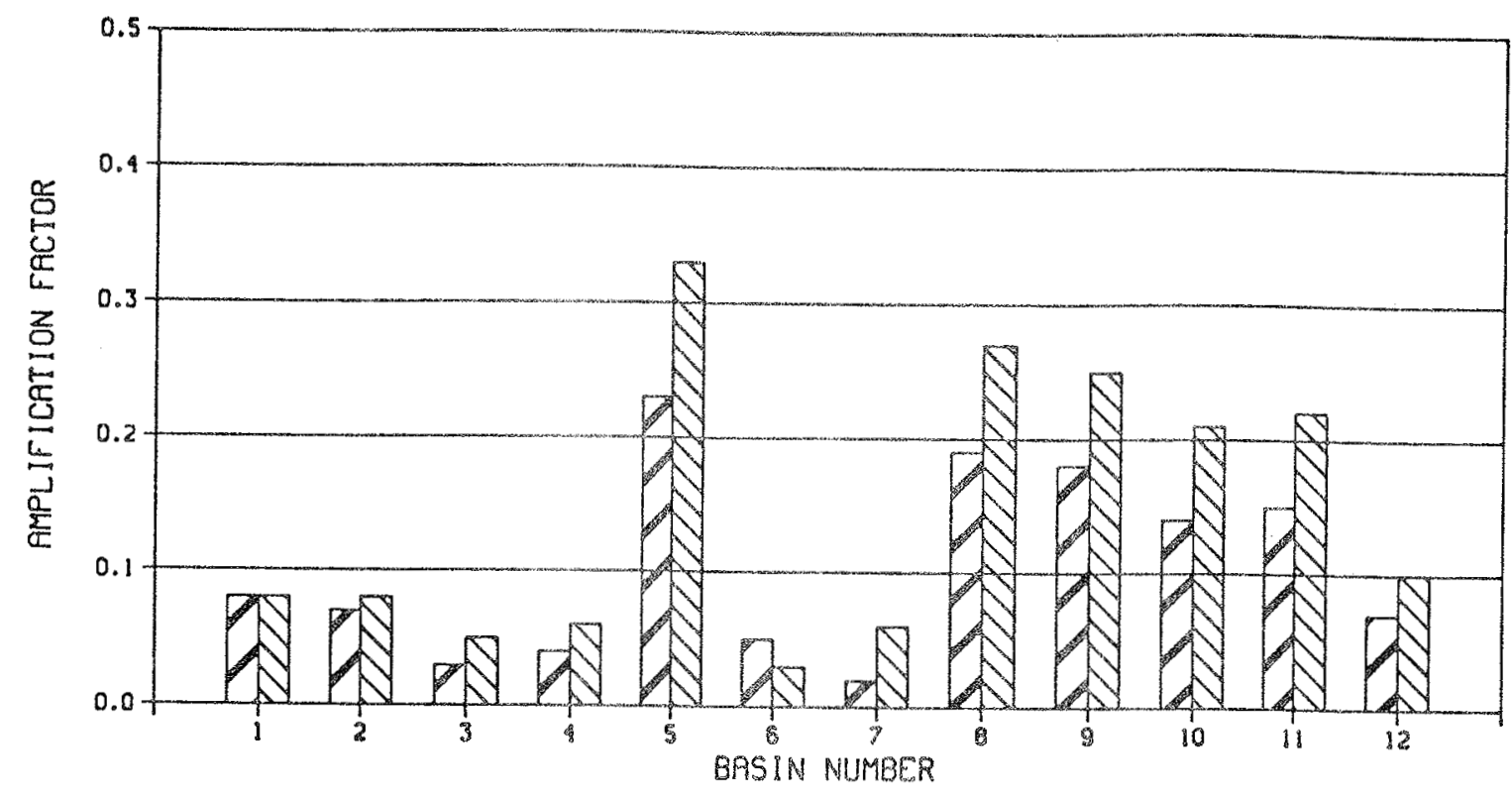

HARBOR ENTRANCE CHANNEL AND TURNING BASIN

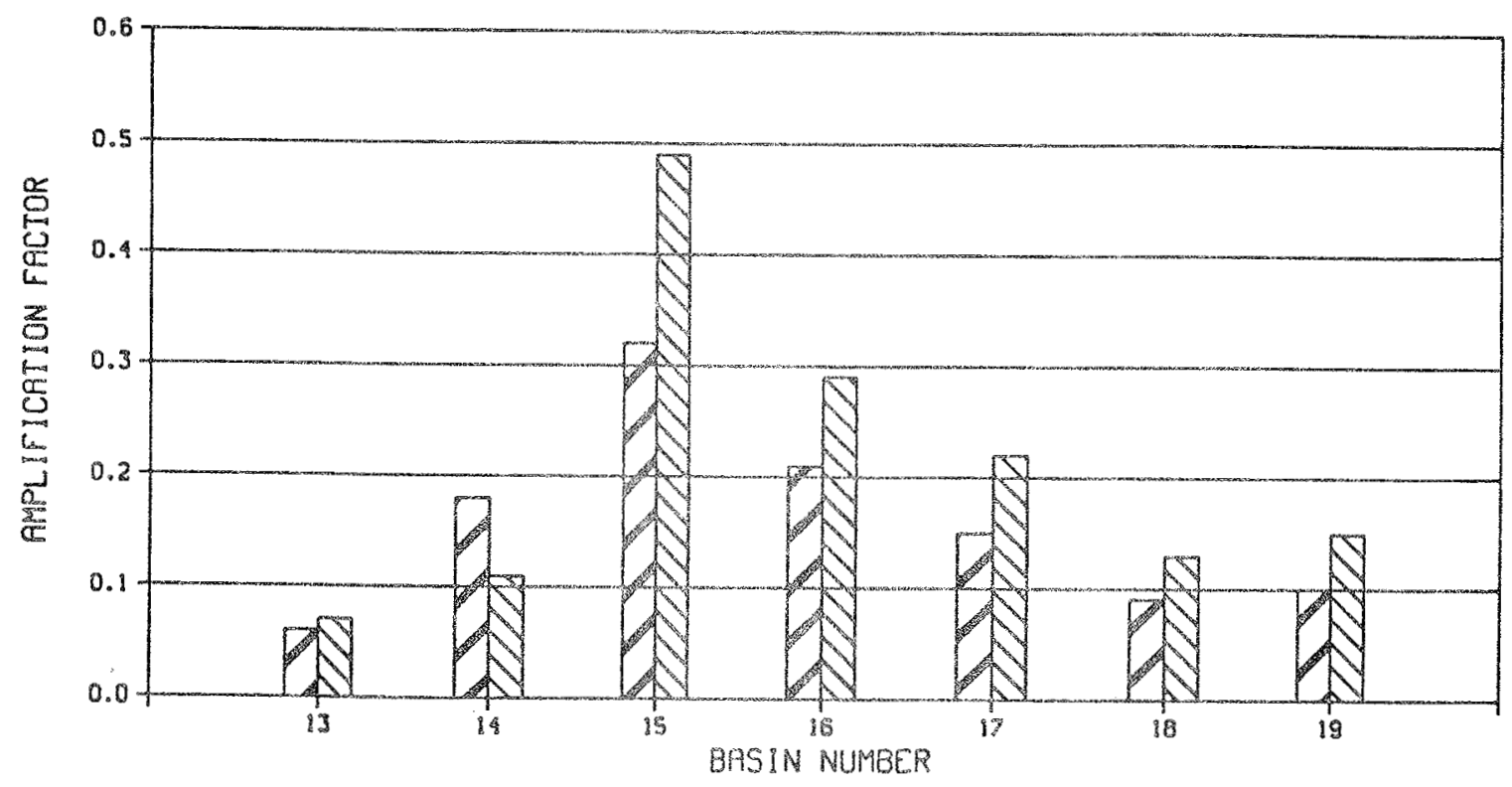

LEGEND

[2] PLAN 1

$\triangle \triangle$ PLAN 2
WAVE AMPLIFICATIDN FRCTOR

KAWAIHAE SHRLLOW-ORAFT HARBOR, HI WAVE PERIOO $=1188 C$ WAYE DIRECTION = 270 deg

PLATE 20 
HRRBOR BERTHING RREAS

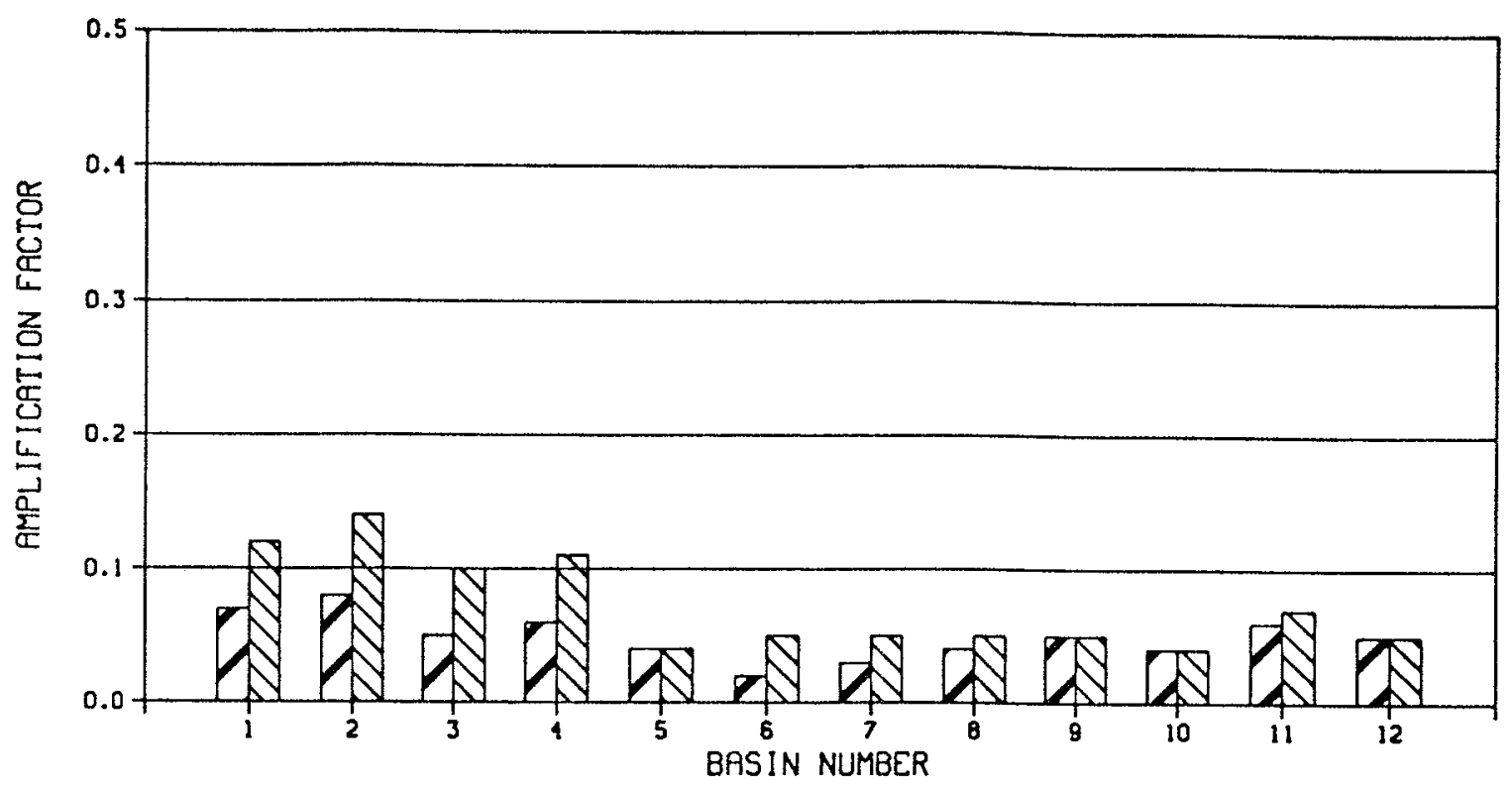

HARBOR ENTRANCE CHANNEL AND IURNING BASIN

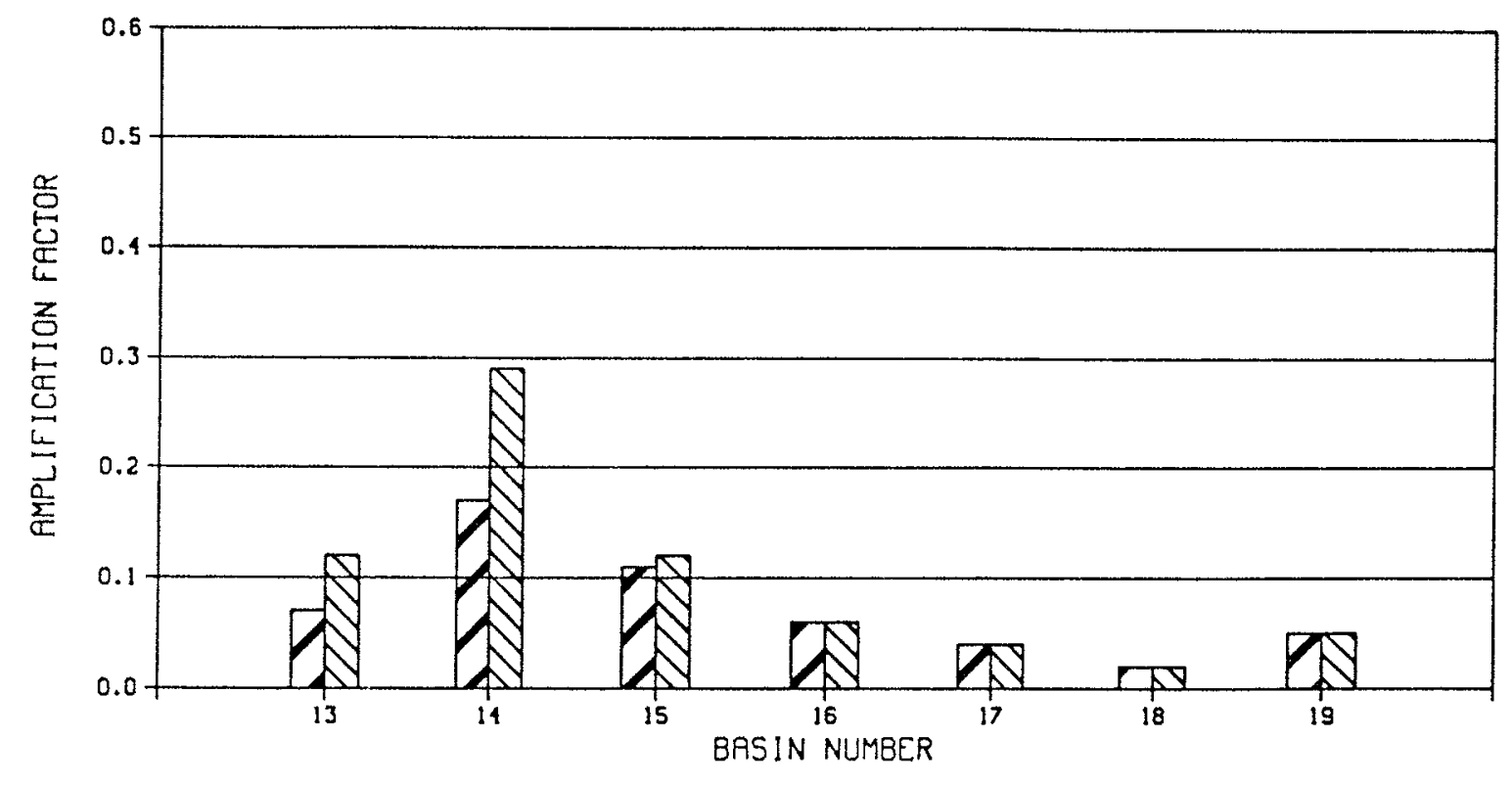

LEGEND

$\square$ PLAN 1

$\triangle$ PLAN 2
WAVE AMPLIFICATION FACTOR

KAWRIHRE SHRLLOW-DRAFT HRRBOR, HI

WAVE PERIOD - $13 \mathrm{sec}$

WRVE OIRECTION - 270 deg 
HARBOR BERTHING AREAS

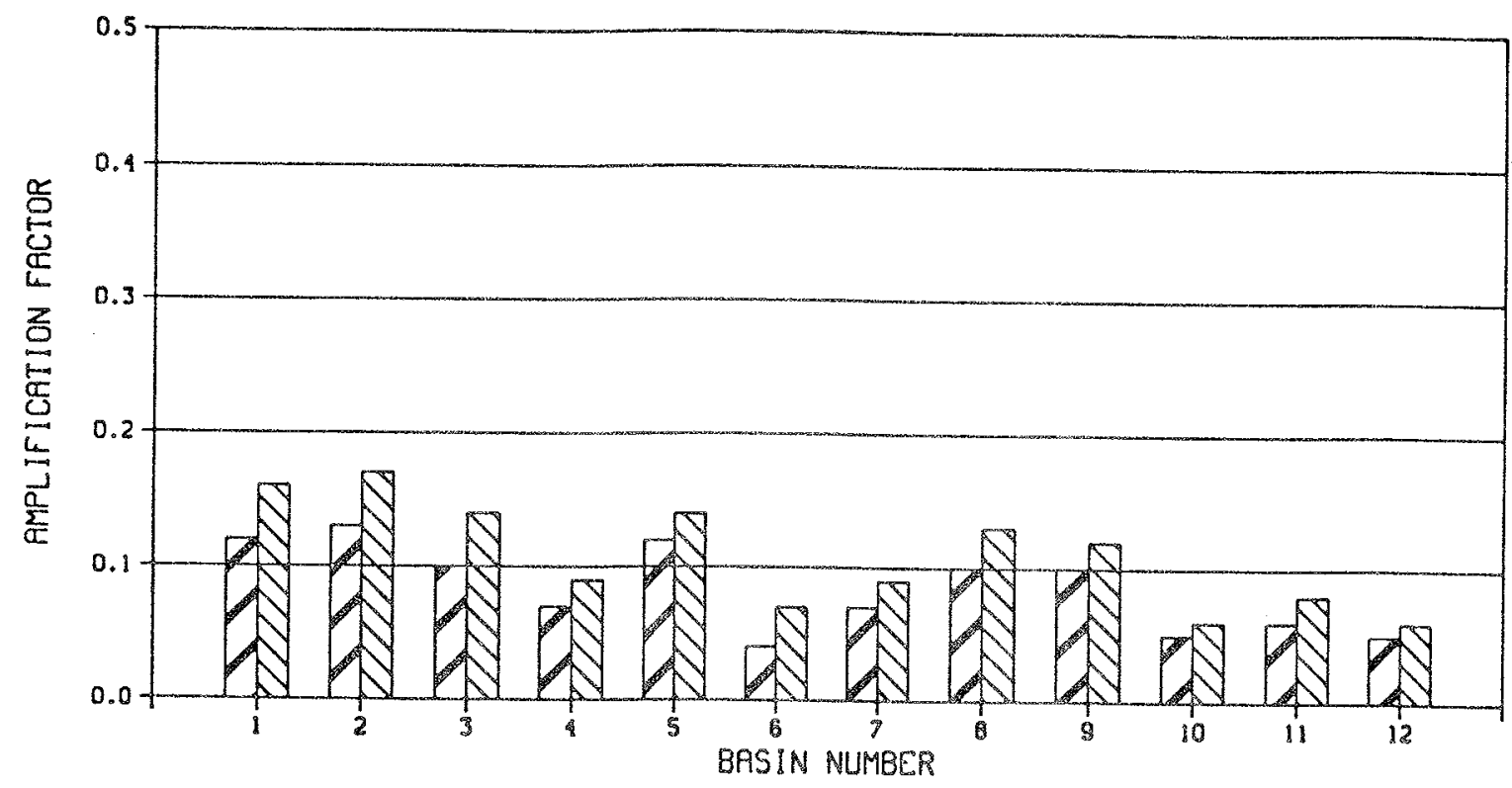

HARBOR ENTRANCE CHANNEL RND TURNING BASIN

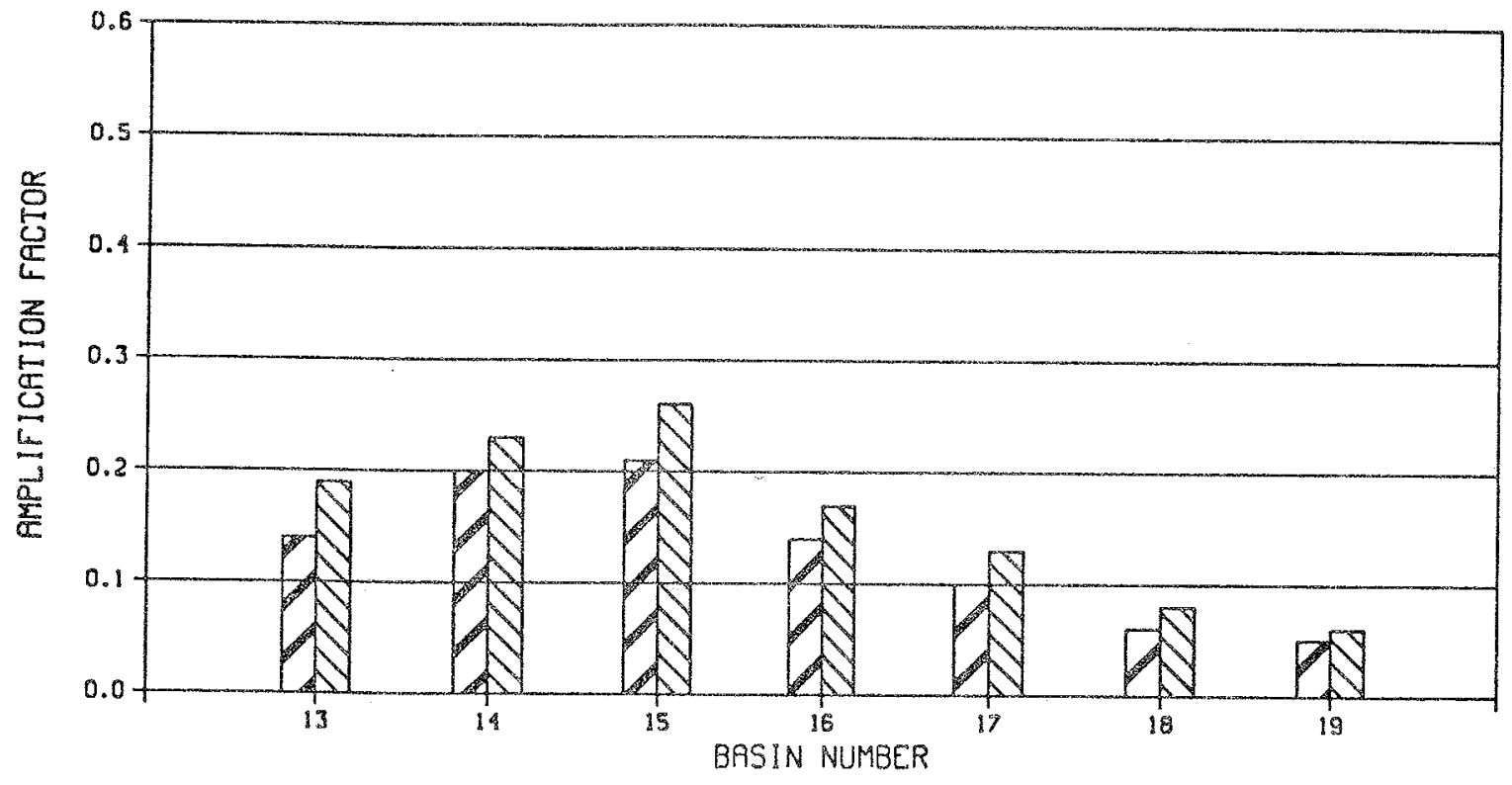

LEGEND

[D PLAN 1

$\triangle \triangle$ PLAN 2
WAVE AMPLIFICATION FACTOR KAWAIHAE SHALLOW-ORAFT HARBOR, HI WAVE PERIOD $=15 \mathrm{sec}$ WRVE OIRECTION - 270 deg 
HARBOR BERTHING ARERS

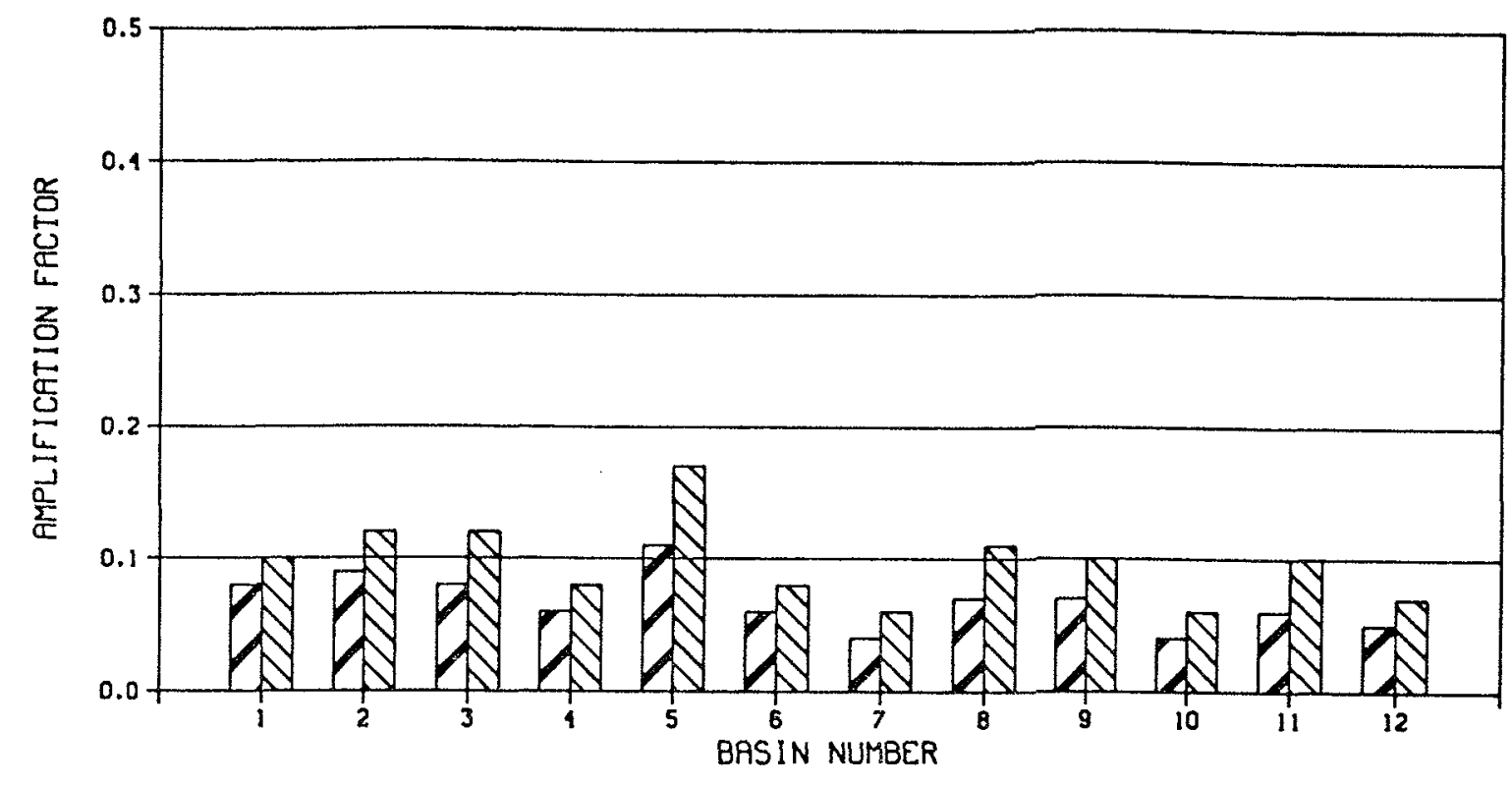

HARBOR ENTRANCE CHANNEL AND TURNING BASIN

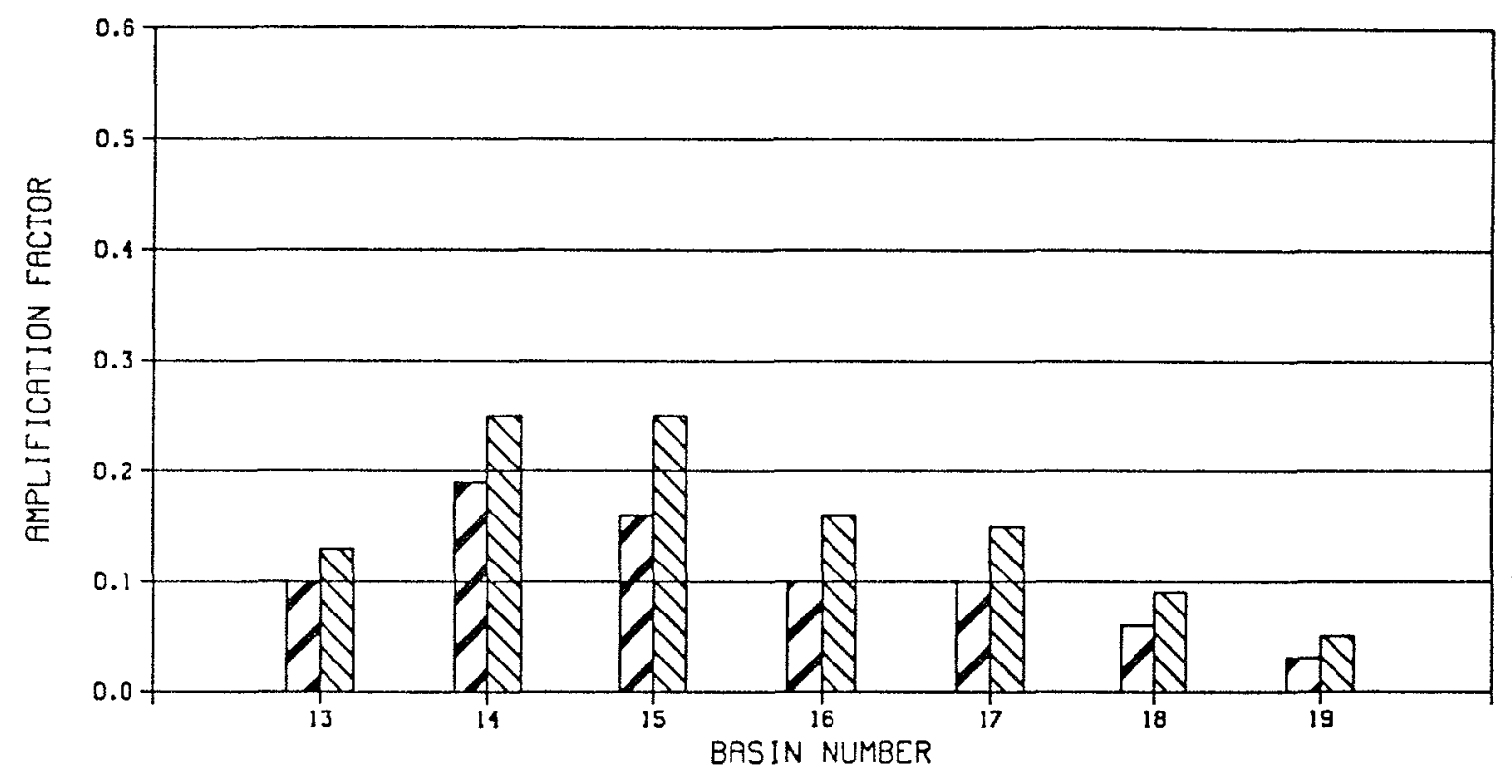

LEGEND

D PLAN 1

$\triangle$ PLAN 2
WAVE RMPLIFICATION FACTOR

KFWAIHAE SHALLOW-DRAFT HRRBOR, HI WAVE PERIOD - $17 \mathrm{sec}$

WAVE DIRECTION - 270 deg 
HARBOR BERTHING AREAS

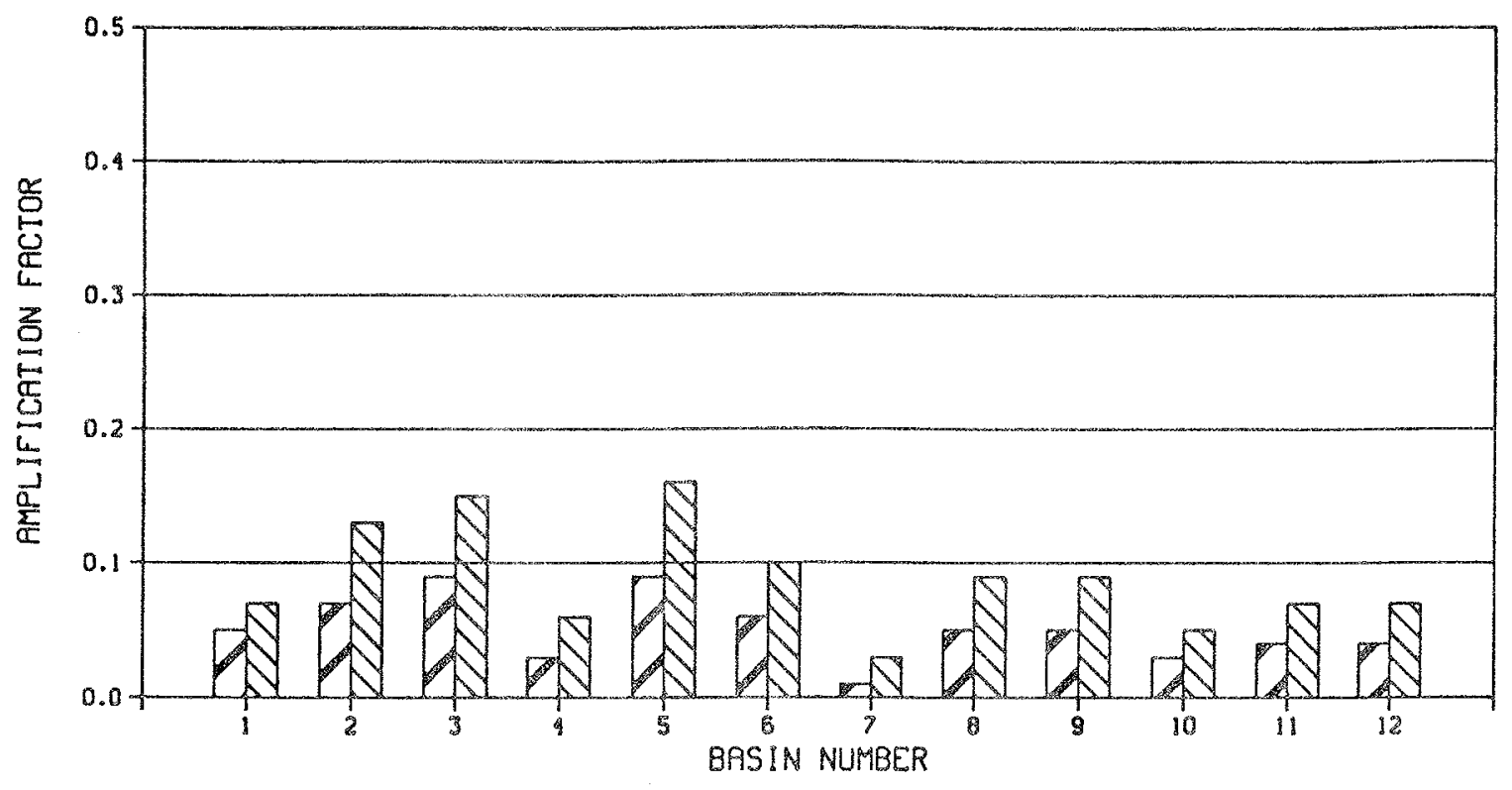

HAREOR ENTRANCE CHANNEL AND TURNING BASIN

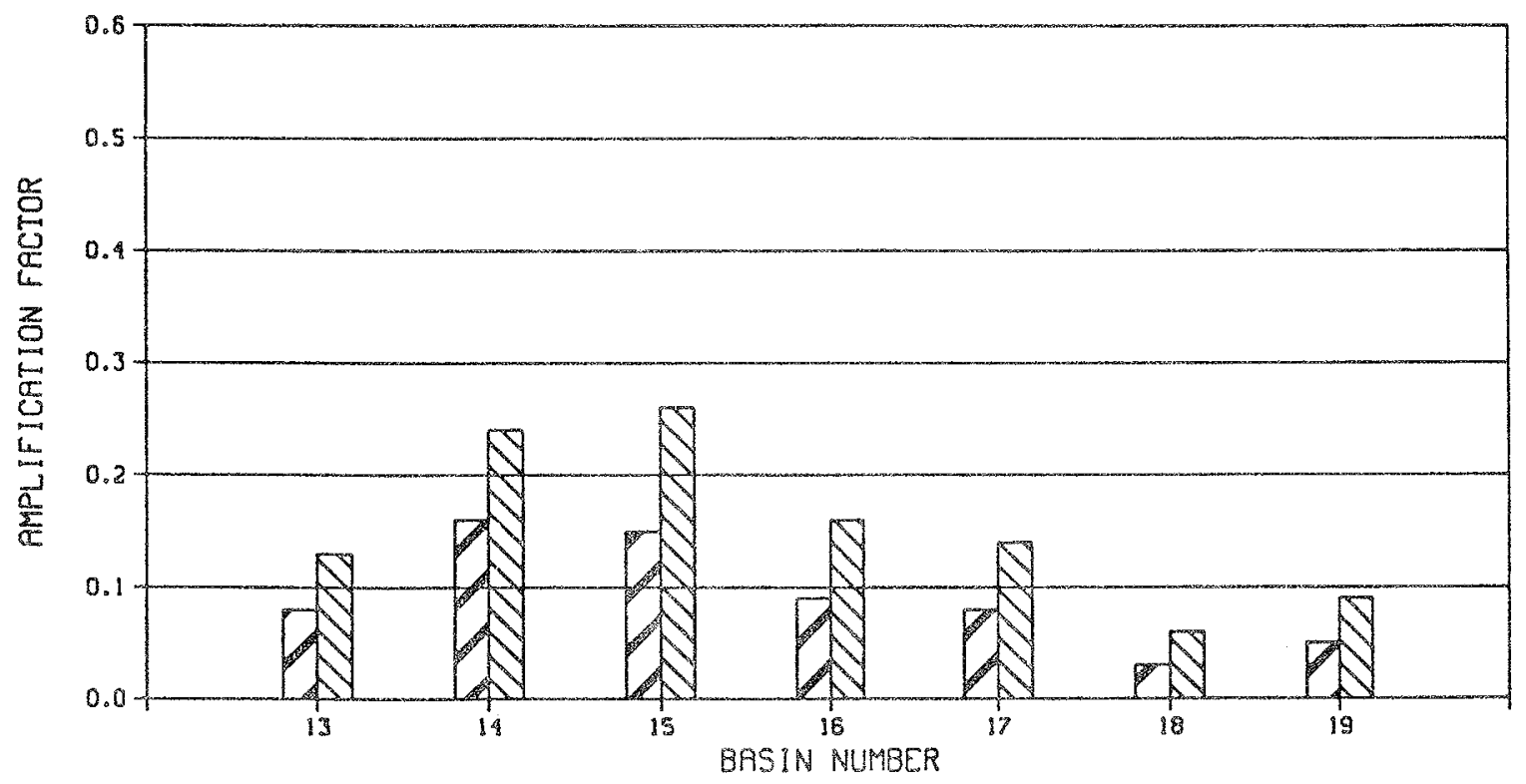

LEGEND

TE PLAN I

$\triangle \triangle$ PLAN 2
WAVE AMPLIFICAT ION FACTOR

KAWAIHAE SHALLOW-DRAFT HARBOR, HI WAVE PERIOO $=20$ S8C WAVE DIRECTION $=270 \mathrm{deg}$ 
HARBOR BERTHING RREAS

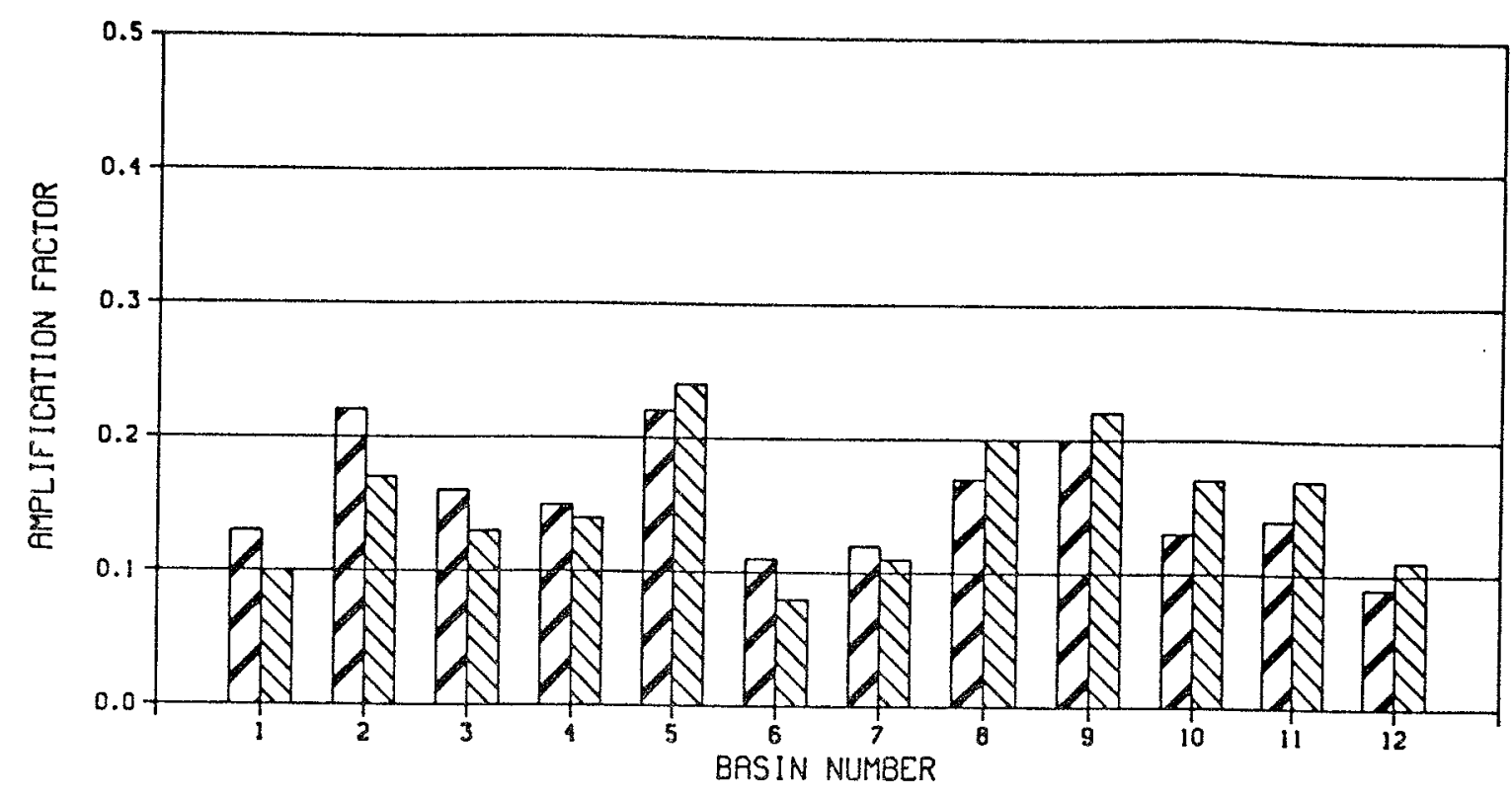

HARBOR ENTRANCE CHANNEL AND IURNING BASIN
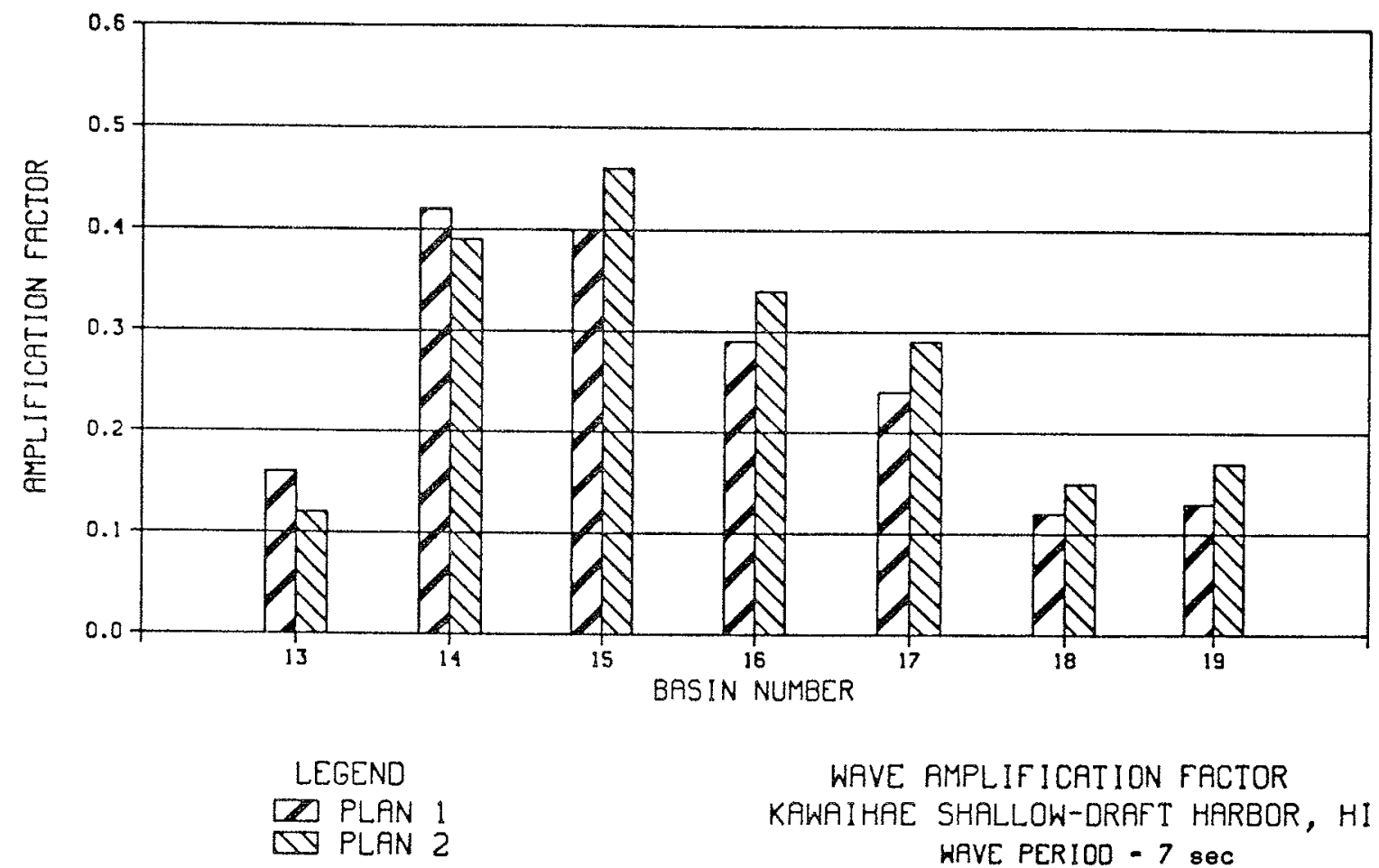

WAVE RMPLIFICATION FACTOR KAWAIHAE SHALLOW-DRAFT HARBOR, $\mathrm{HI}$ WAVE PERIOO - 7 sec

WRVE DIRECTION -292.5 deg 
HARBOR BERTHING AREAS

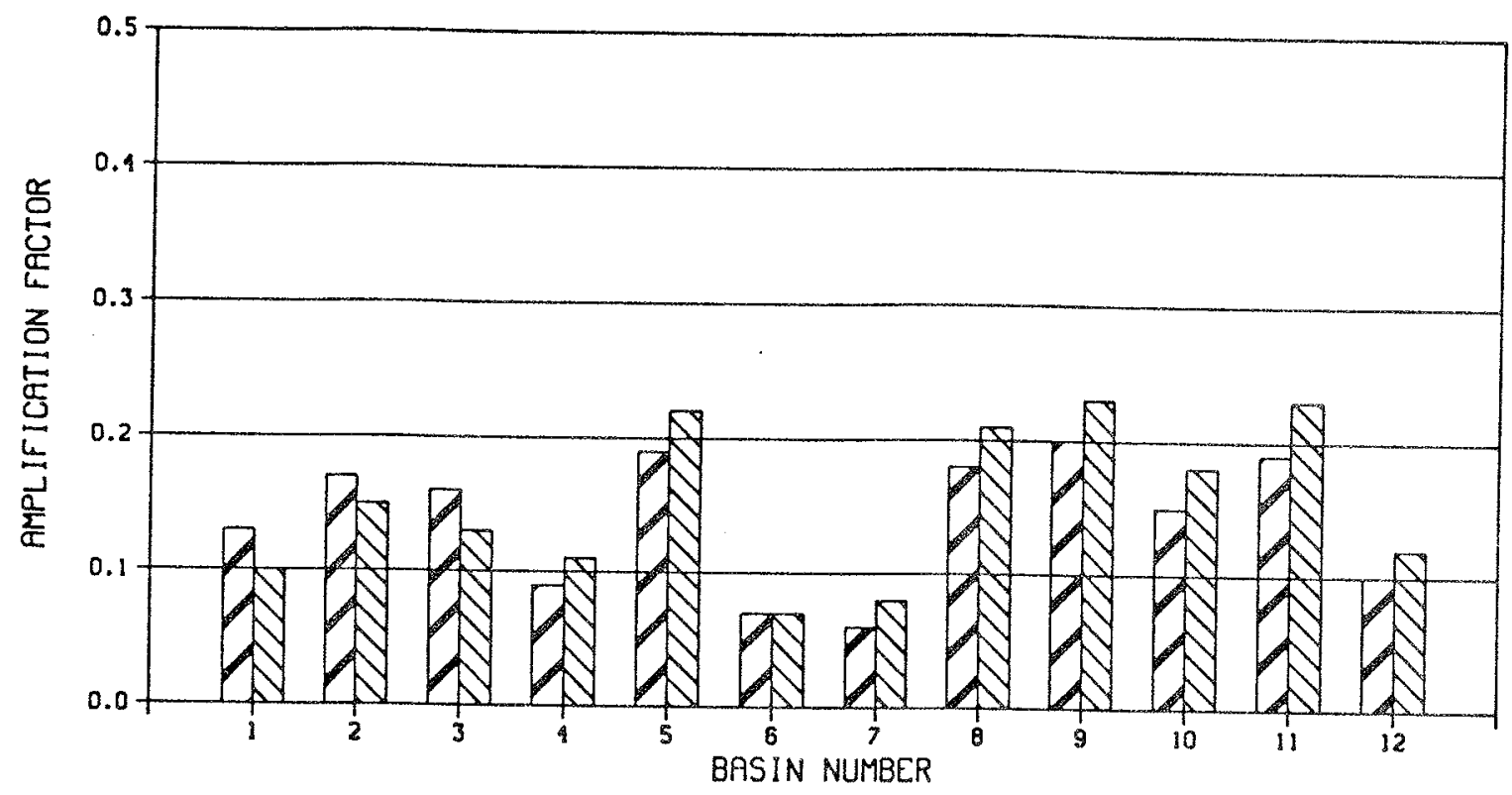

HRRBOR ENTRANCE CHANNEL AND TURNING BRSIN

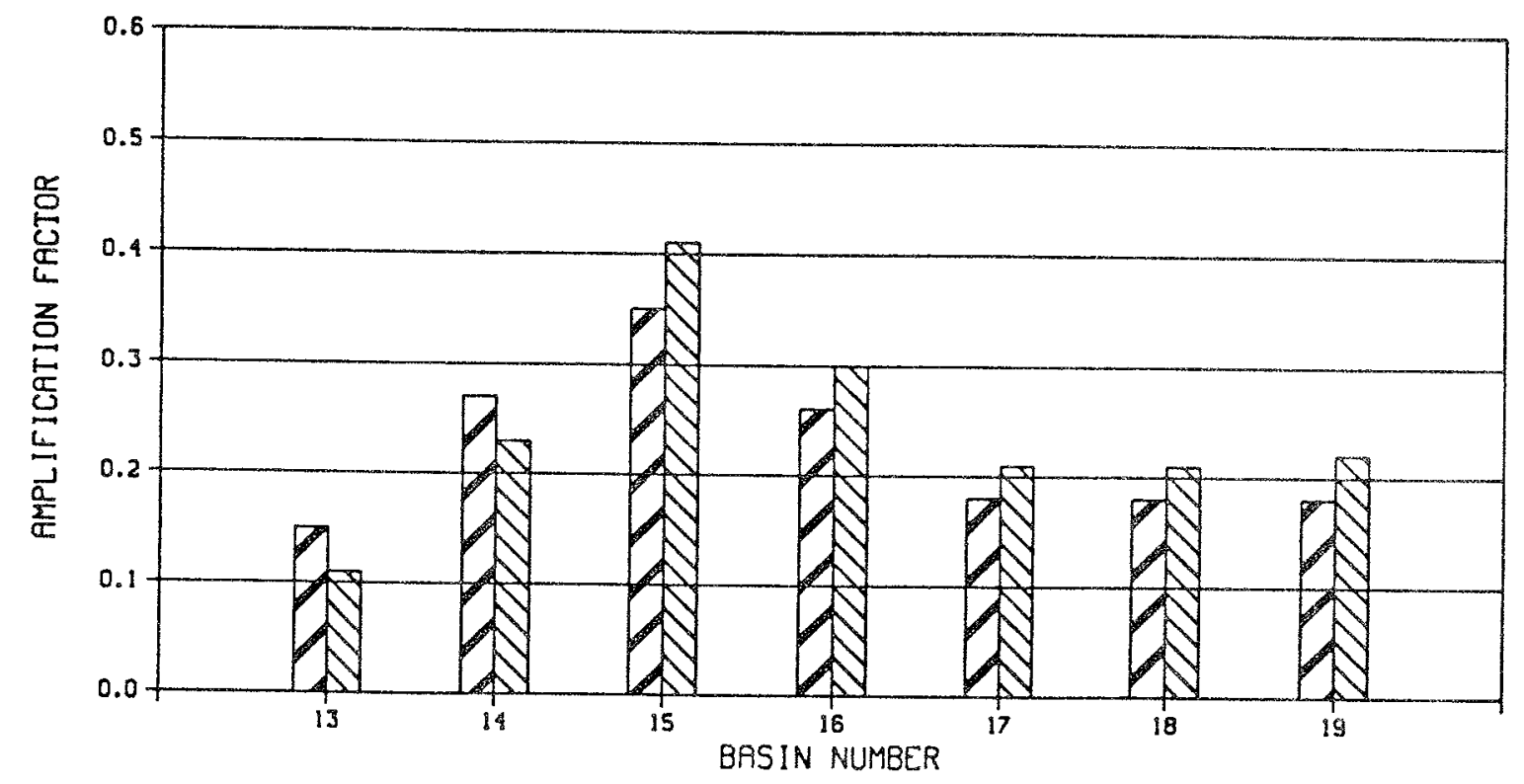

LEGENO

[D PLAN 1

$\triangle$ PLAN 2
WAVE RMPLIF ICATION FACTOR

KAWAIHAE SHRLLOW-DRAFT HRRBOR, HI WAVE PERIOD -9 sec

WAVE DIRECTION - $292.5 \mathrm{deg}$ 
HARBOR BERTHING AREAS

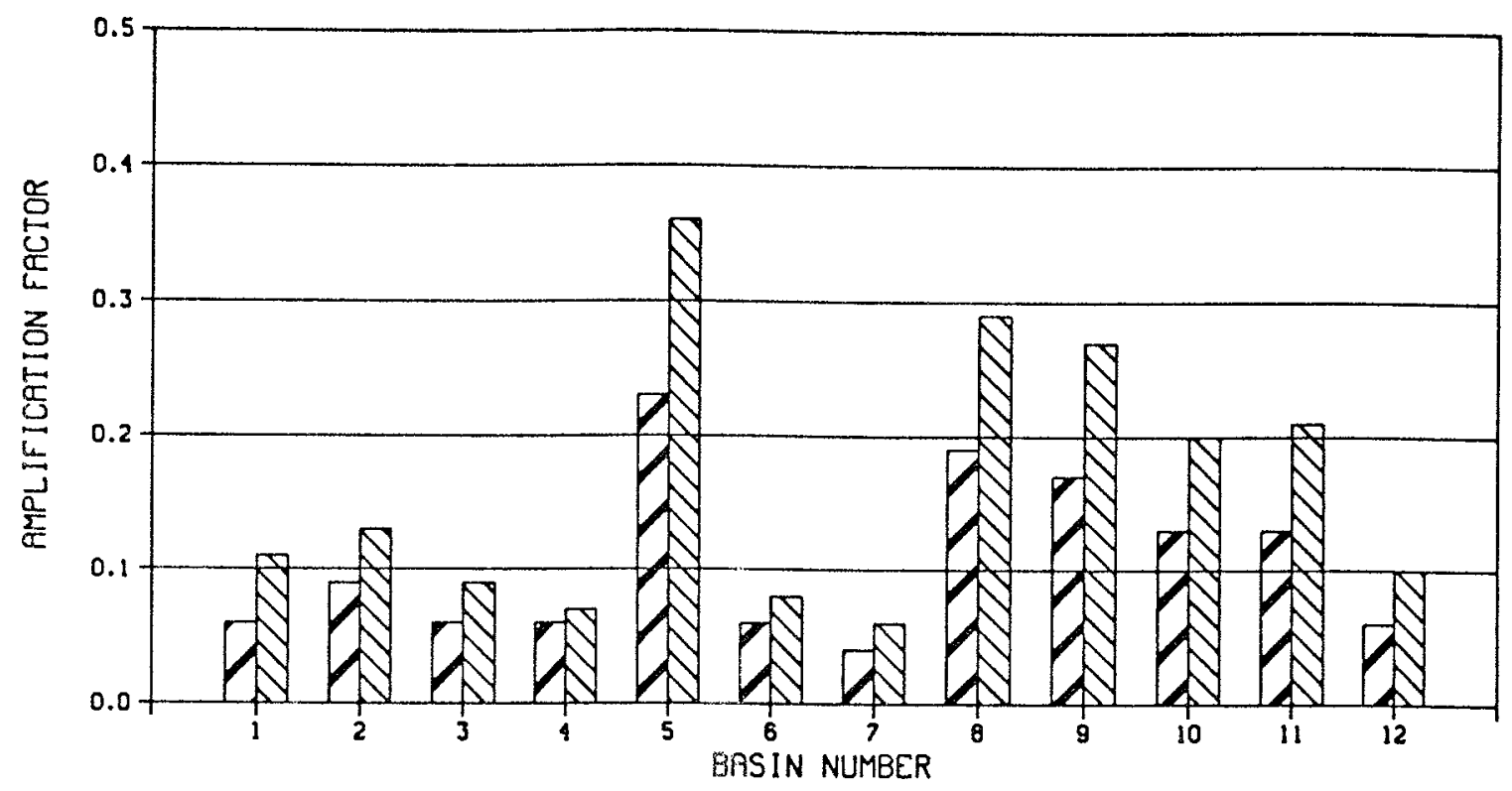

HARBOR ENTRANCE CHRNNEL RND TURNING BASIN

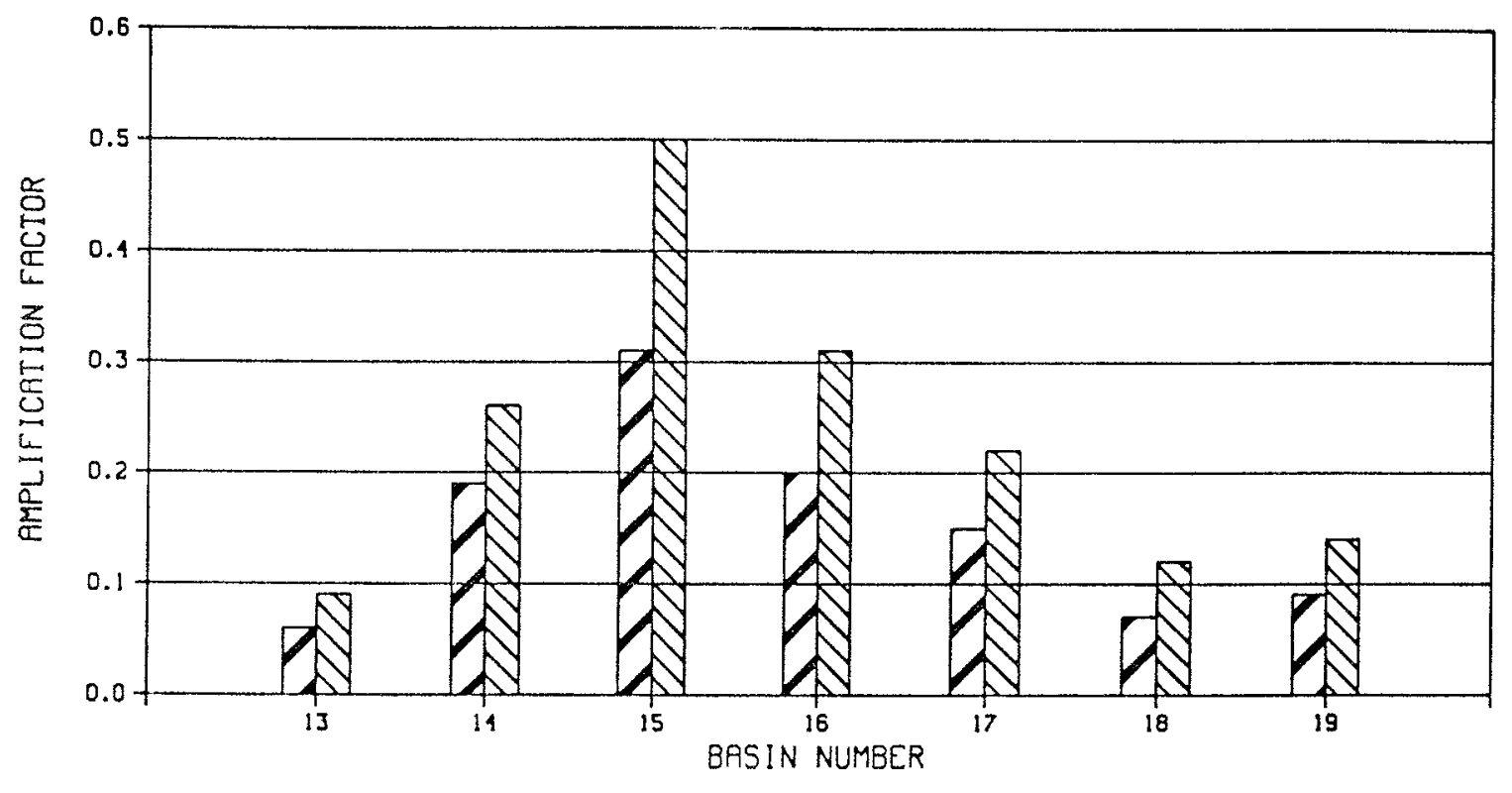

LEGEND

$\square$ PLAN 1

$\triangle$ PLAN 2
WAVE RMPLIFICATION FACTOR

KAWAIHAE SHALLOW-DRAFT HARBOR, HI WAVE PERIOD - 11 sec WRVE OIRECTION $-292.5 \mathrm{deg}$ 
HARBOR BERTHING AREAS

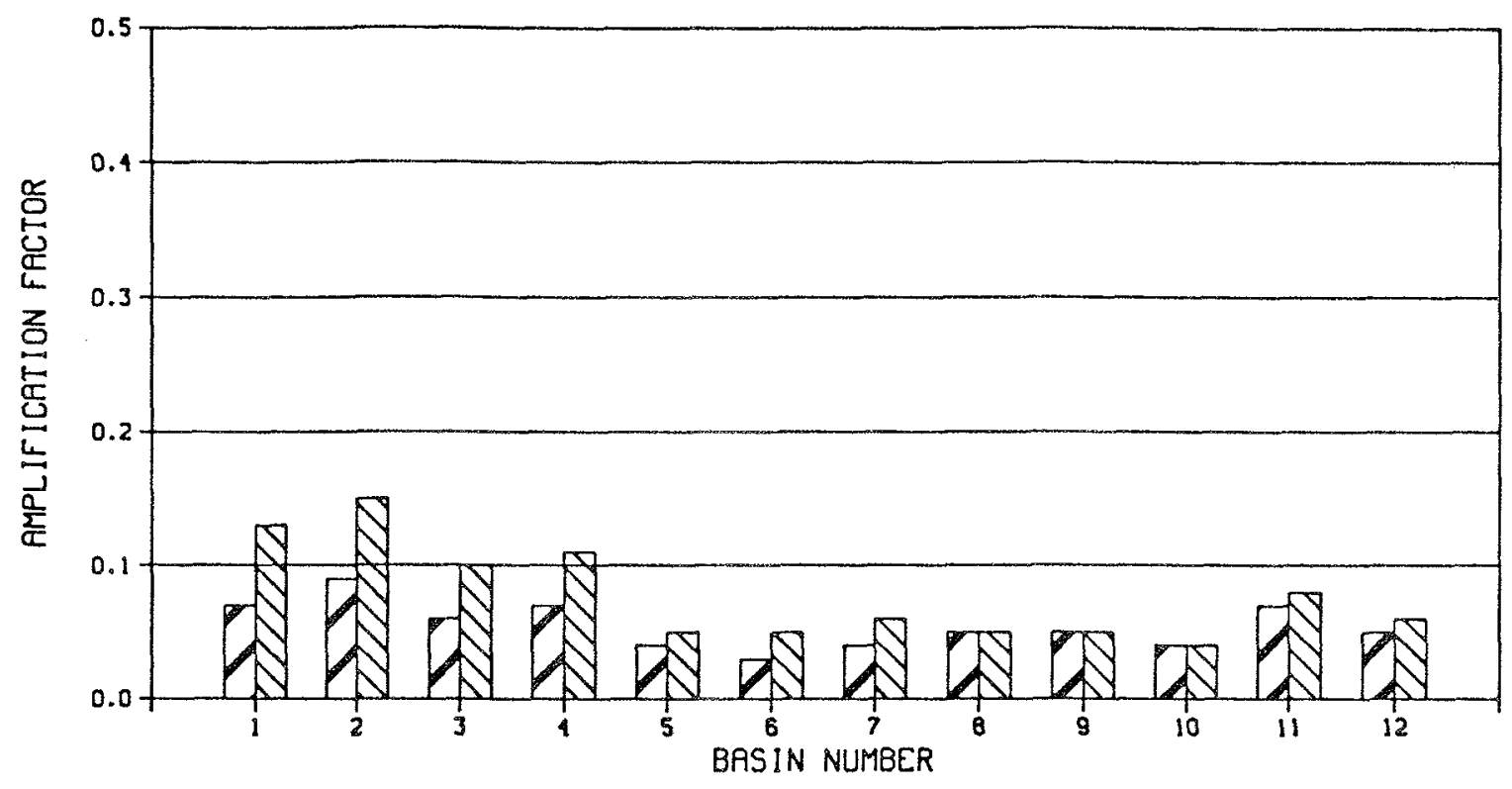

HARBOR ENTRANCE CHANNEL AND TURNING BASIN

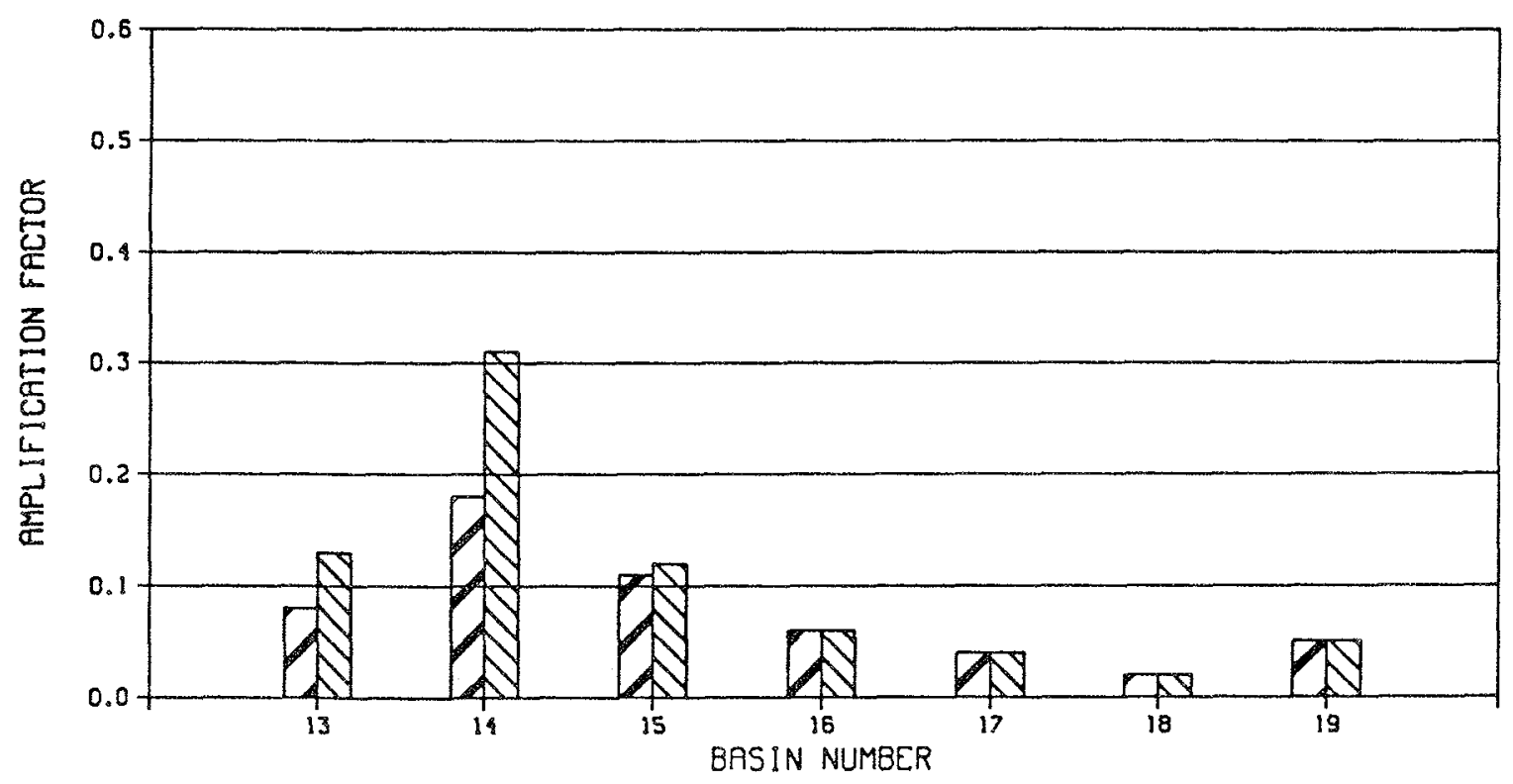

LEGEND

CD PLAN 1

$\triangle$ PLAN 2
WAVE AMPLIFICATION FACTOR KAWAIHAE SHRLLOW-DRRFI HARBOR, $\mathrm{HI}$ WAVE PERIOD - 13 sec WAVE DIRECTION $=292.5 \mathrm{deg}$ 
HARBOR BERTHING AREAS

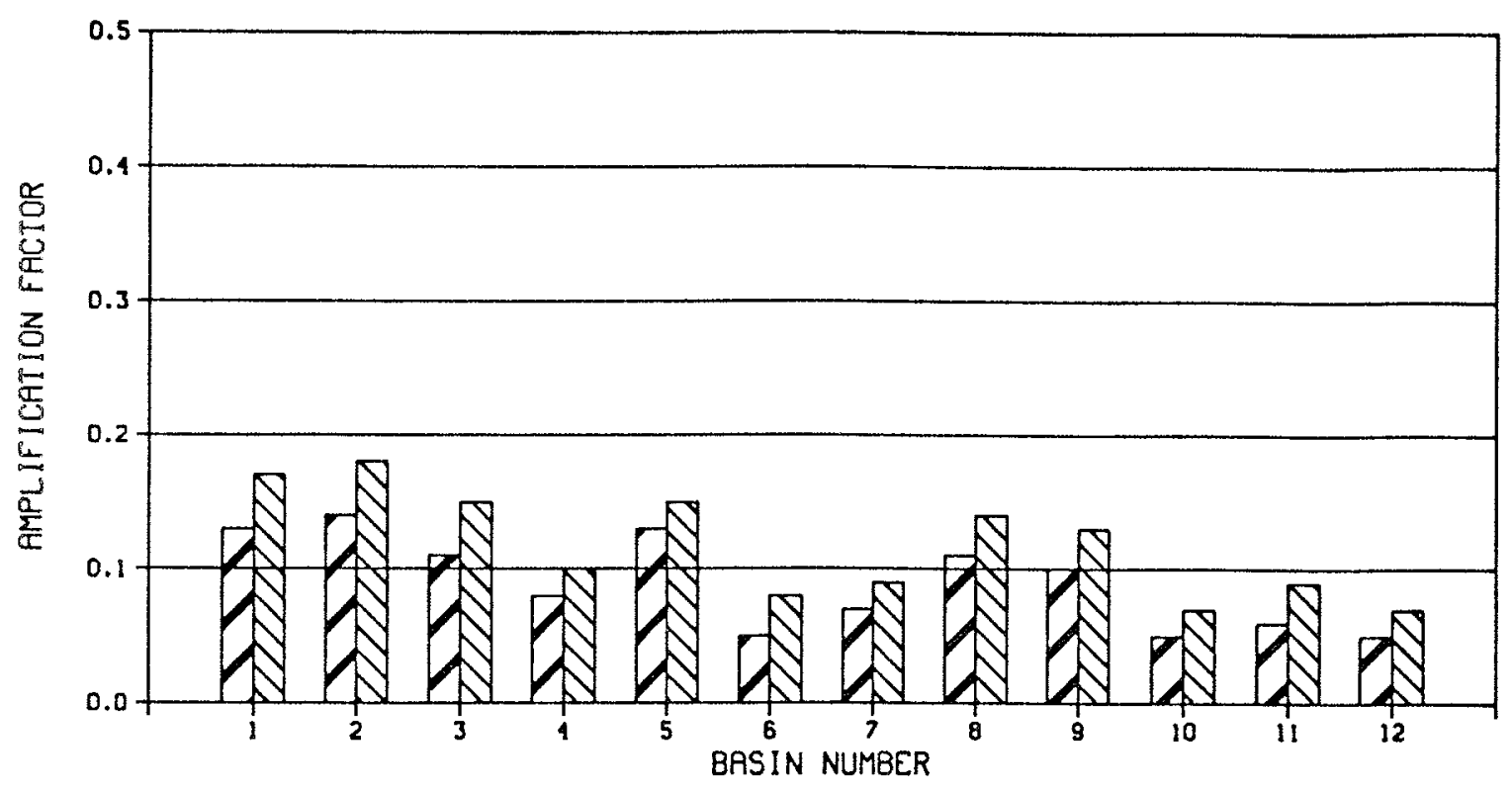

HRRBOR ENTRANCE CHANNEL AND TURNING BASIN

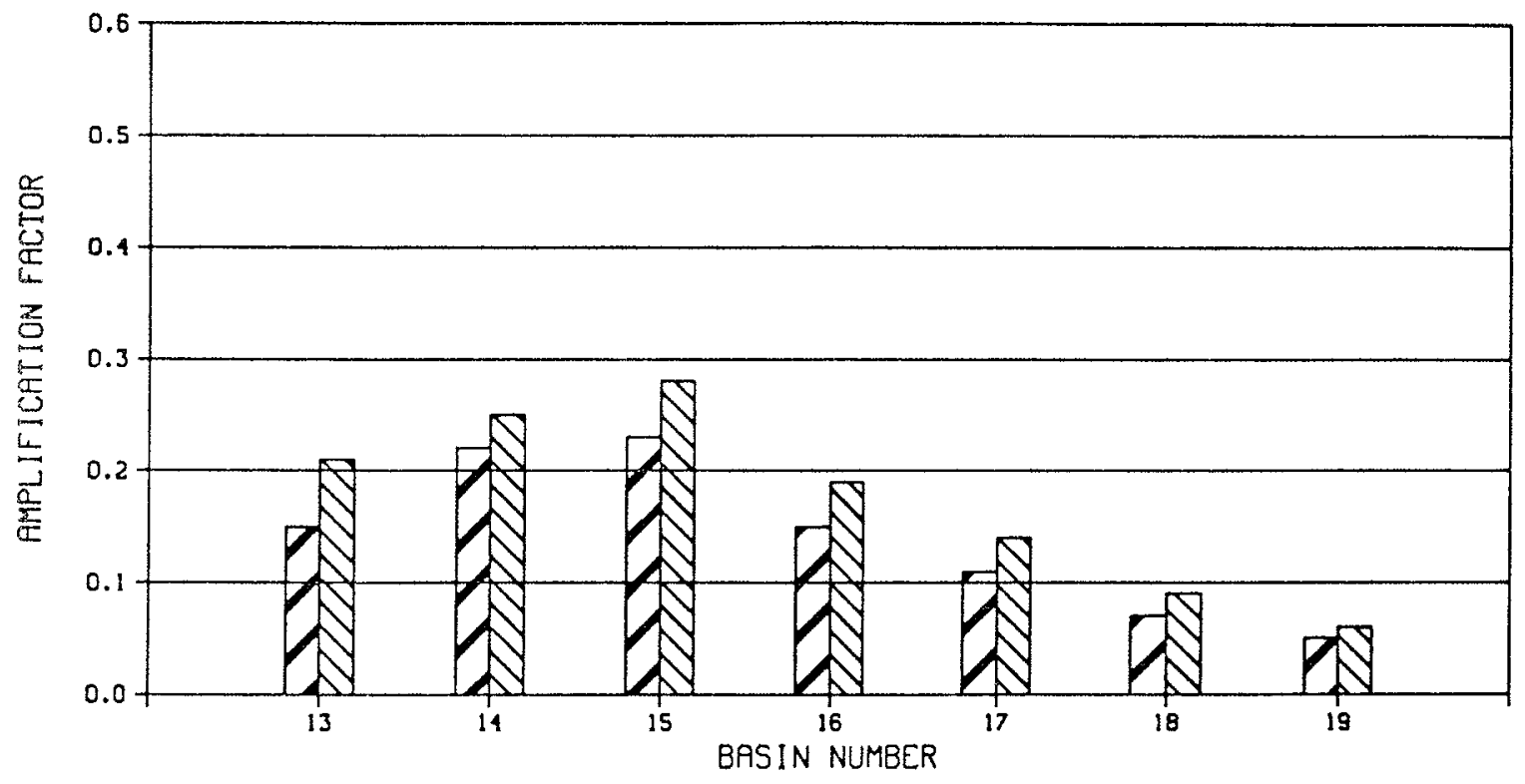

LEGEND

$\square$ PLAN 1

$\triangle$ PLAN 2
WAVE AMPLIFICATION FACTOR

KAWAIHRE SHRLLOW-DRAFT HRRBOR, HI

WRVE PERIOD - 15 sec

WAVE DIRECTION - $292.5 \mathrm{deg}$ 
HARBOR BERTHING AREAS

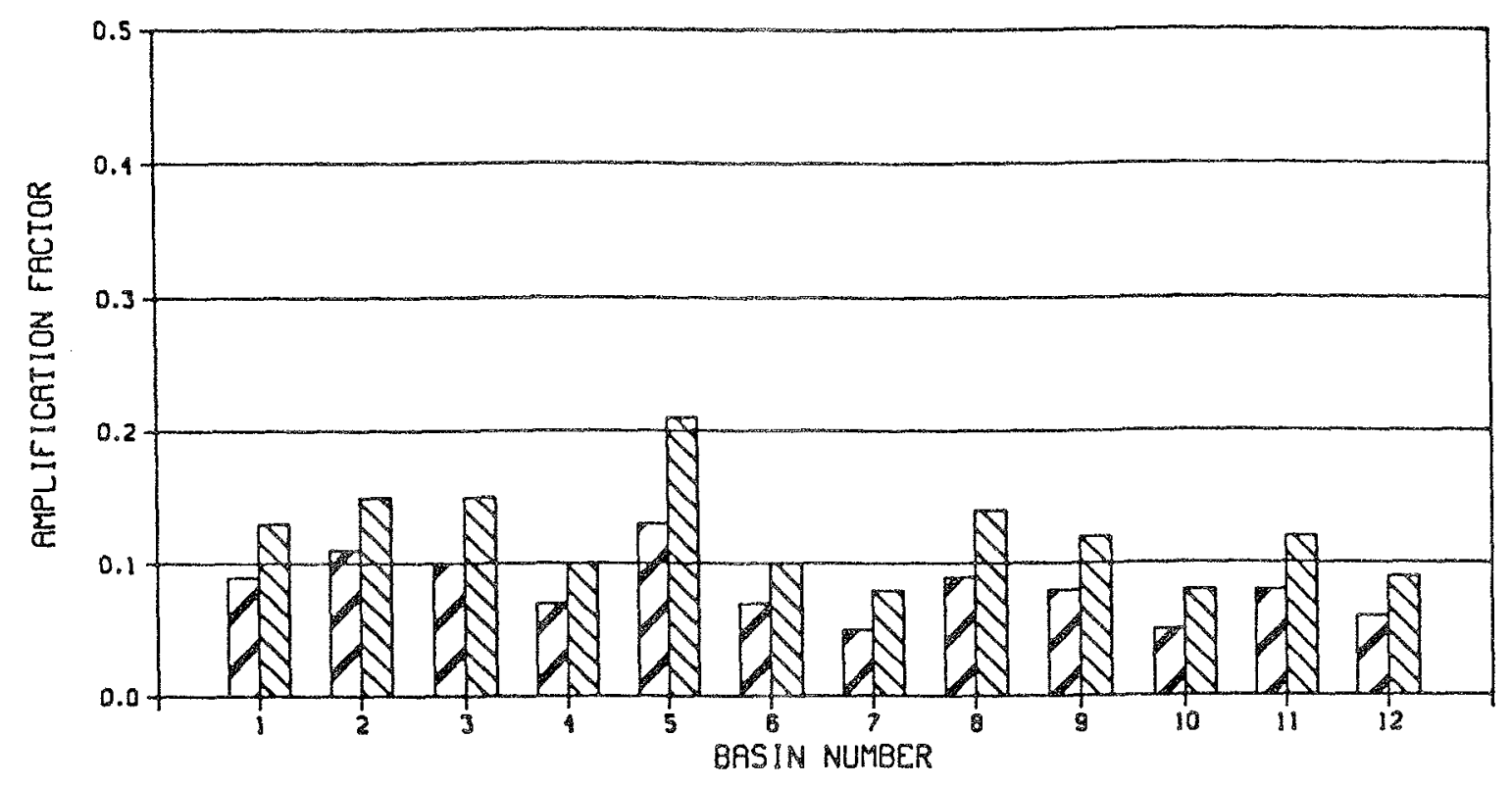

HRRBOR ENTRANCE CHRNNEL AND TURNING BASIN

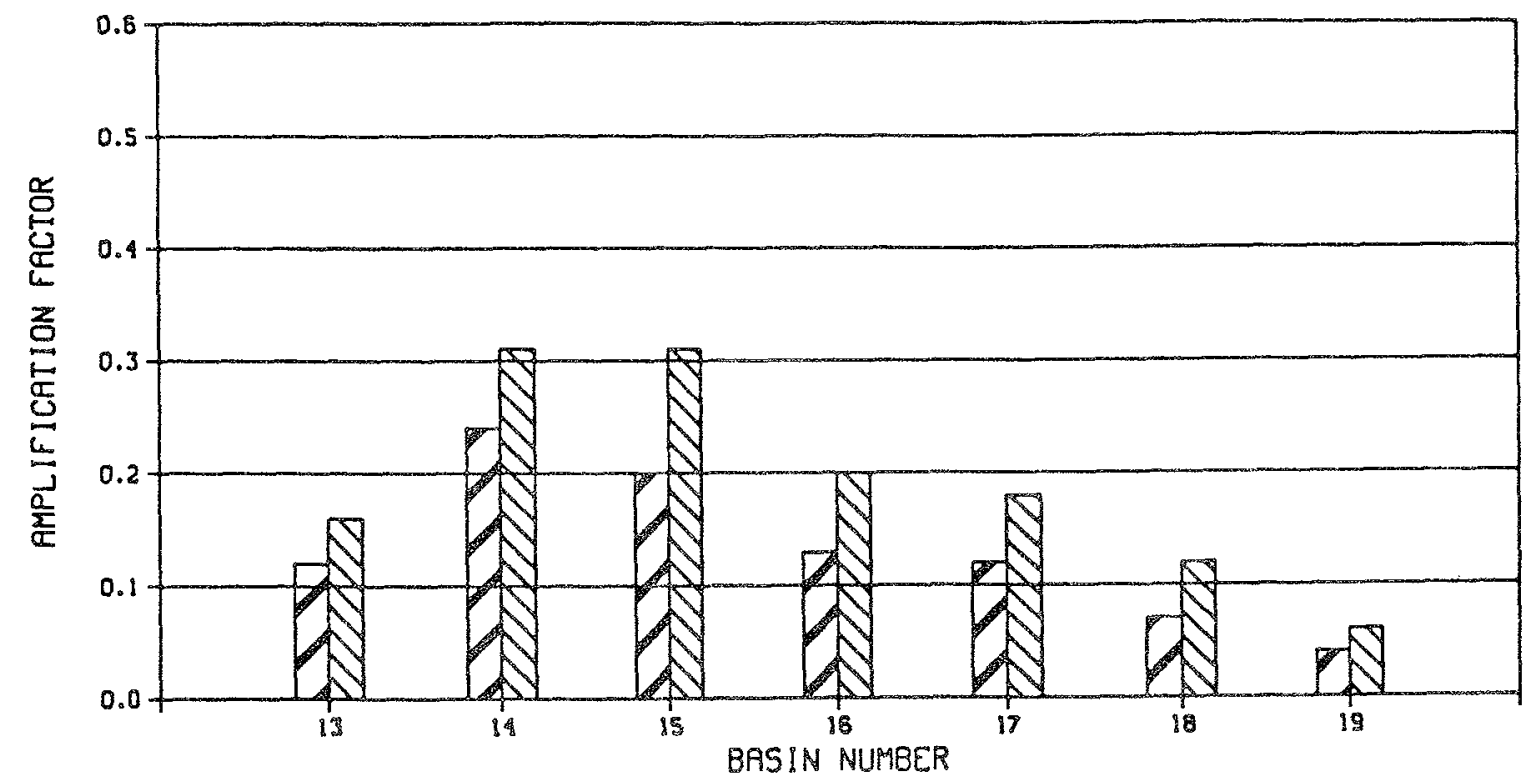

LEGEND

DE PLAN 1

$\triangle$ PLAN 2
WAVE RMPLIF ICRTION FACTOR KAWRIHAE SHALLOW-DRAFT HRRBOR, $\mathrm{HI}$ HAVE PERIOO $=1788 \mathrm{C}$ WAVE DIRECTION $=292.5 \mathrm{dOg}$

PLATE 30 
HARBOR BERTHING AREAS

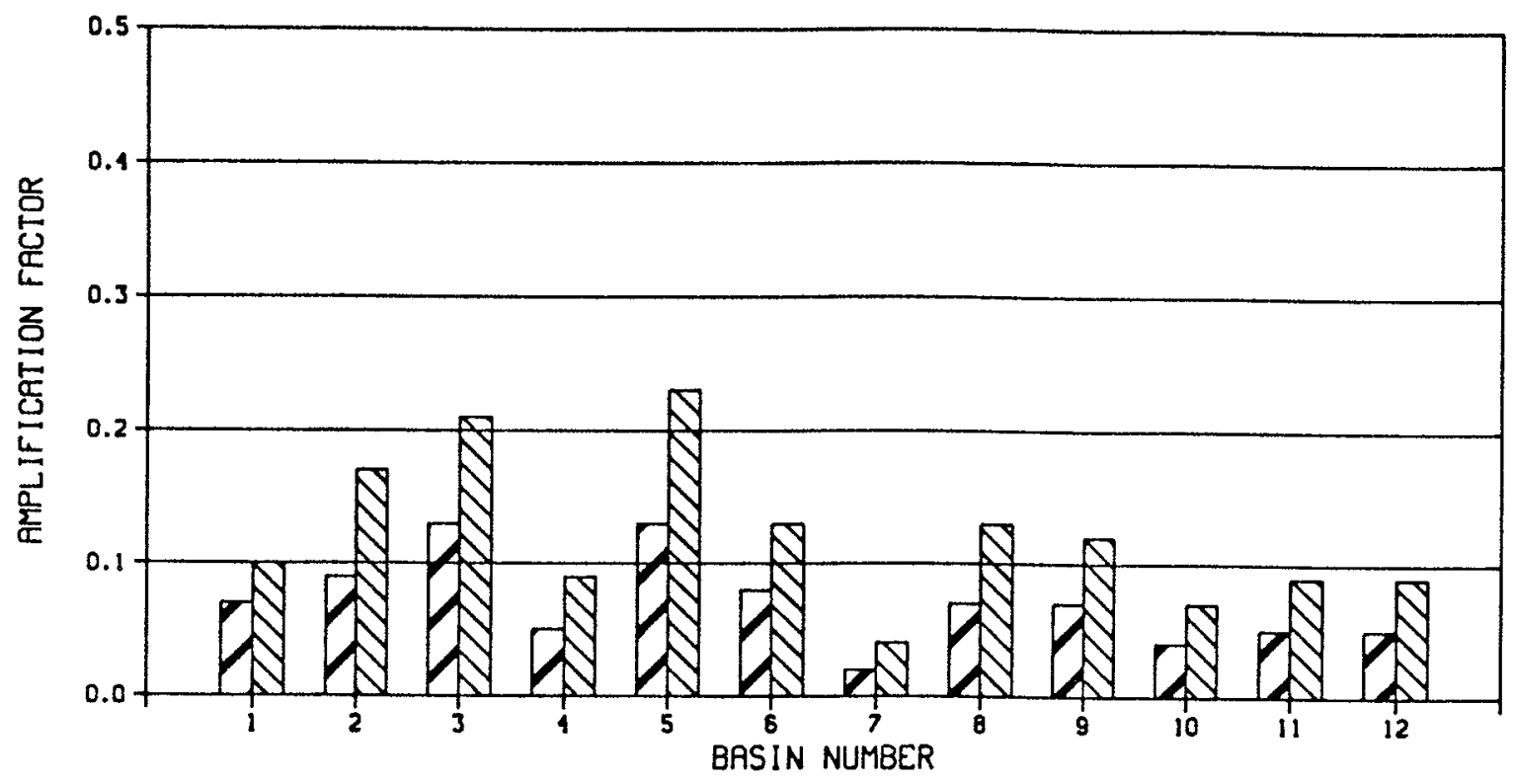

HARBOR ENTRANCE CHRNNEL AND TURNING BASIN

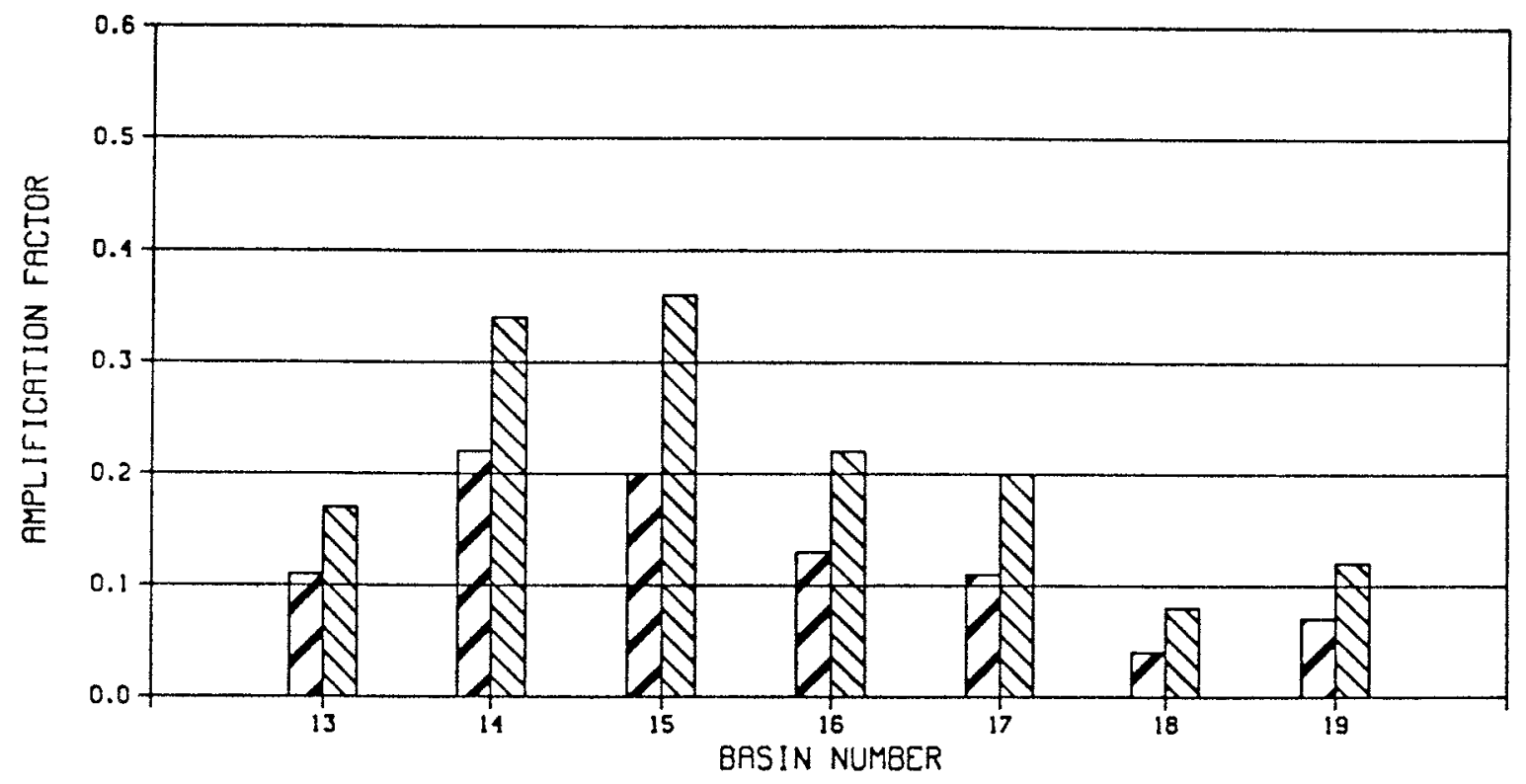

LEGEND

$\square$ PLAN 1

$\triangle$ PLAN 2
WAVE RMPLIFICATION FACTOR

KAWAIHAE SHALLOW-ORAFT HARBOR, HI WAVE PERIOO - 20 sec WAVE OIRECTION - $292.5 \mathrm{deg}$ 
HARBOR BERTHING ARERS

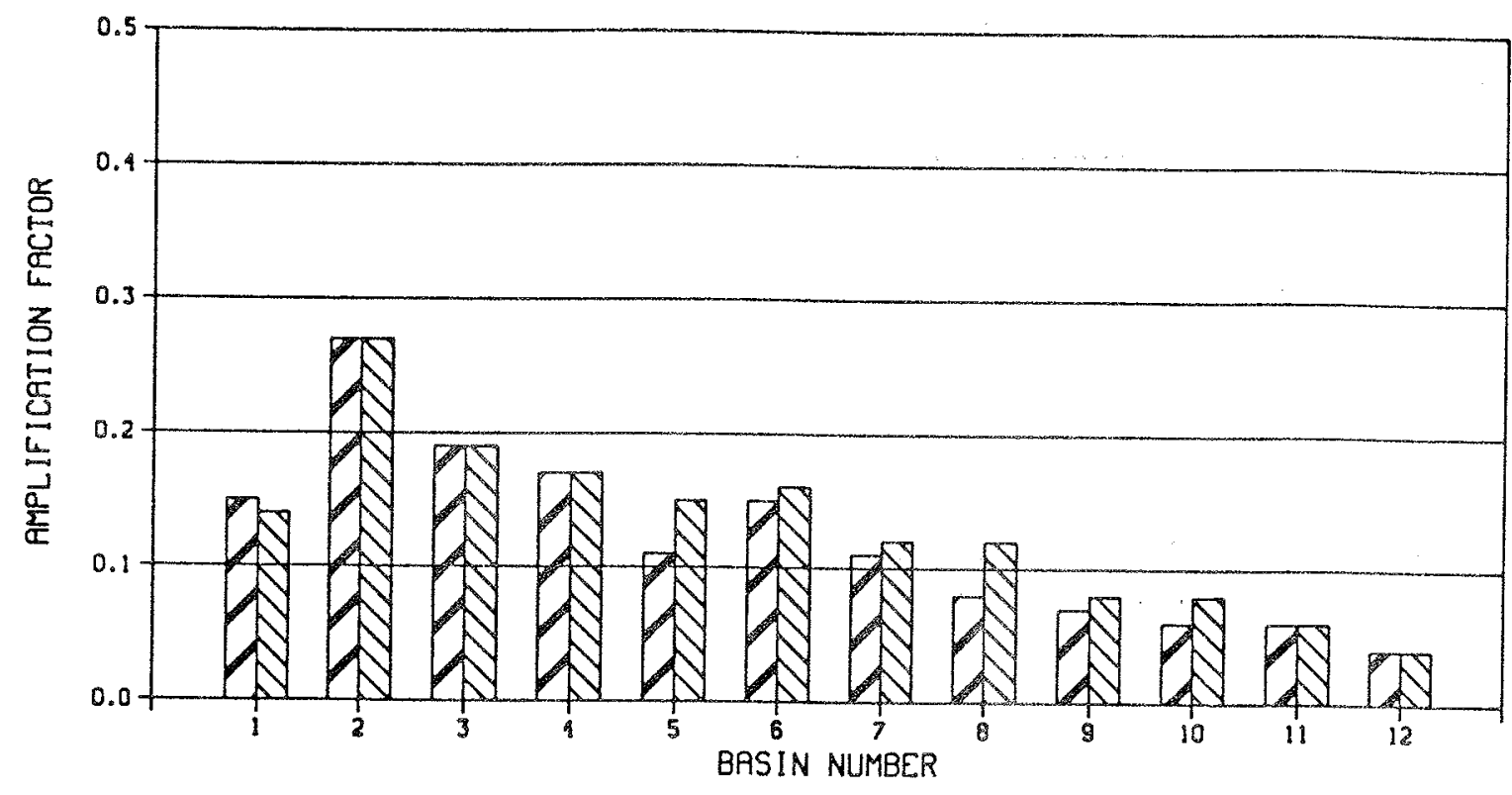

HARBOR ENTRRNCE CHANNEL AND TURNING BRSIN

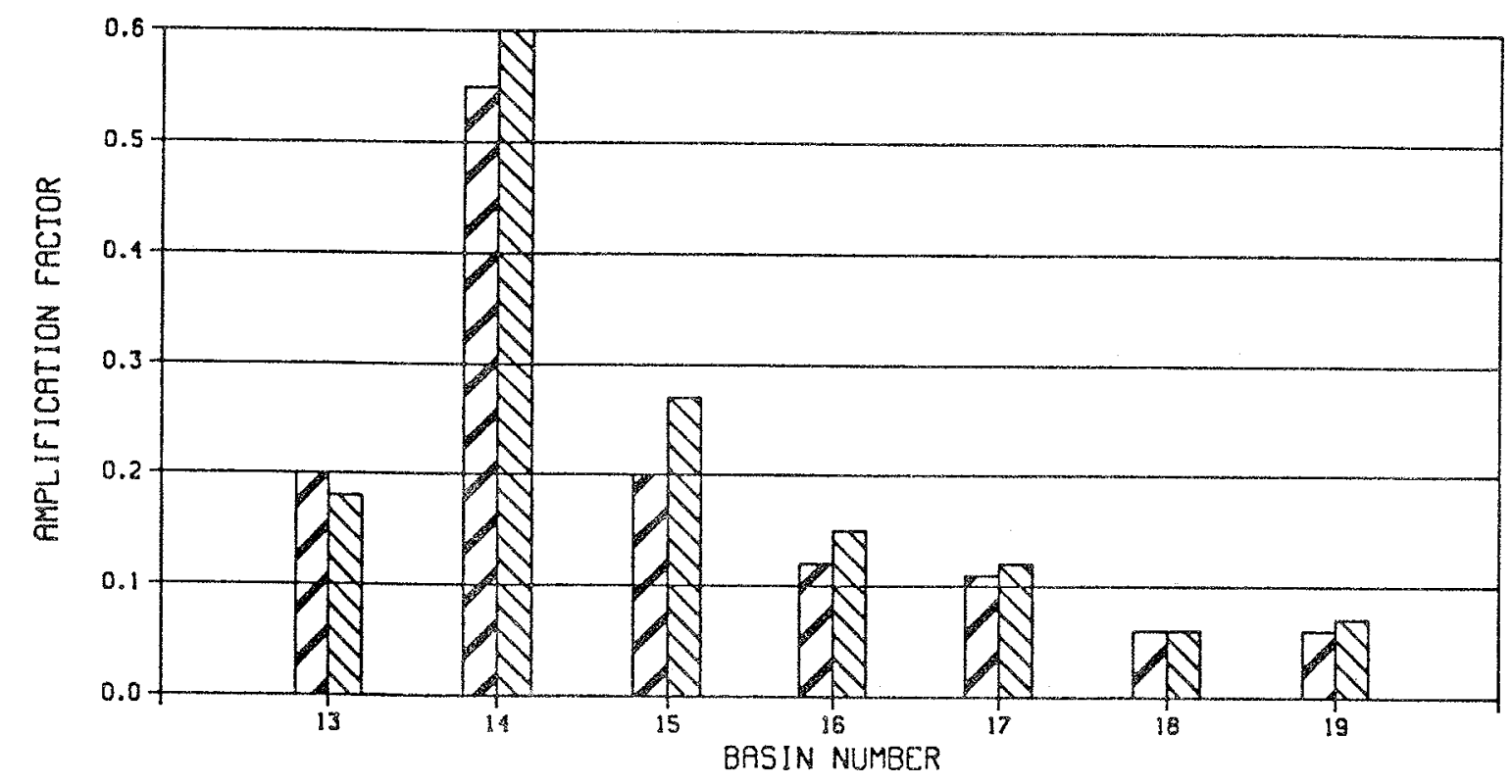

LEGEND

[2] PLAN 1

159 PLAN 2
WAVE AMPLIFICATION FACTOR

KAWAIHAE SHRLLOW-DRAFT HARBOR, HI WAVE PERIOD -7 BQC

WAVE DIRECTION $=315 \mathrm{deg}$ 
HARBOR BERTHING AREAS

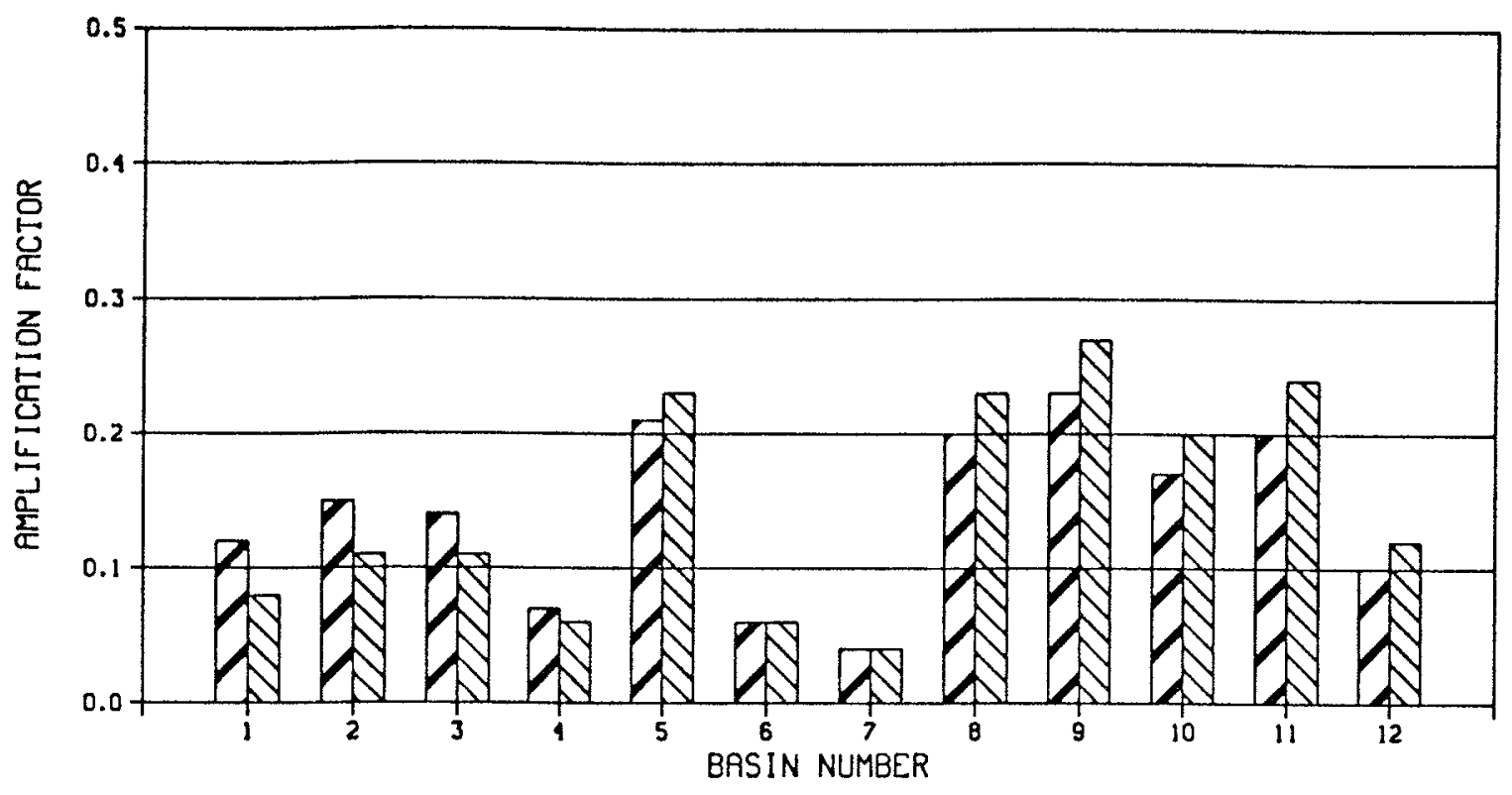

HARBOR ENTRANCE CHANNEL AND TURNING BASIN

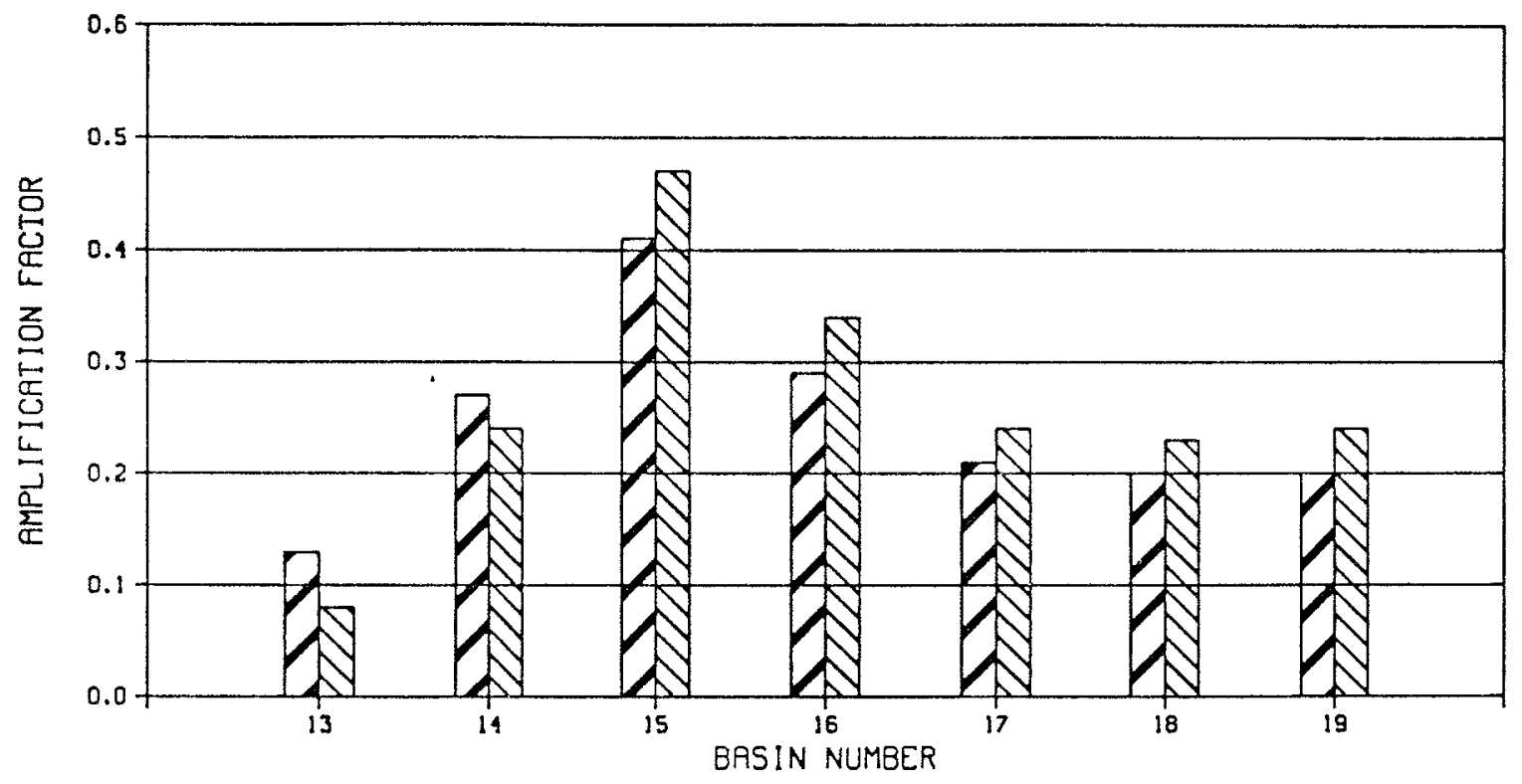

LEGENO

$\square$ PLAN 1

$\triangle$ PLAN 2
WAVE AMPLIF ICATION FACTOR

KRWAIHRE SHRLLOW-DRAFT HARBOR, $\mathrm{HI}$

WAVE PERIOD - 9 sec

WAVE DIRECTION - 315 deg 
HARBOR BERTHING AREAS

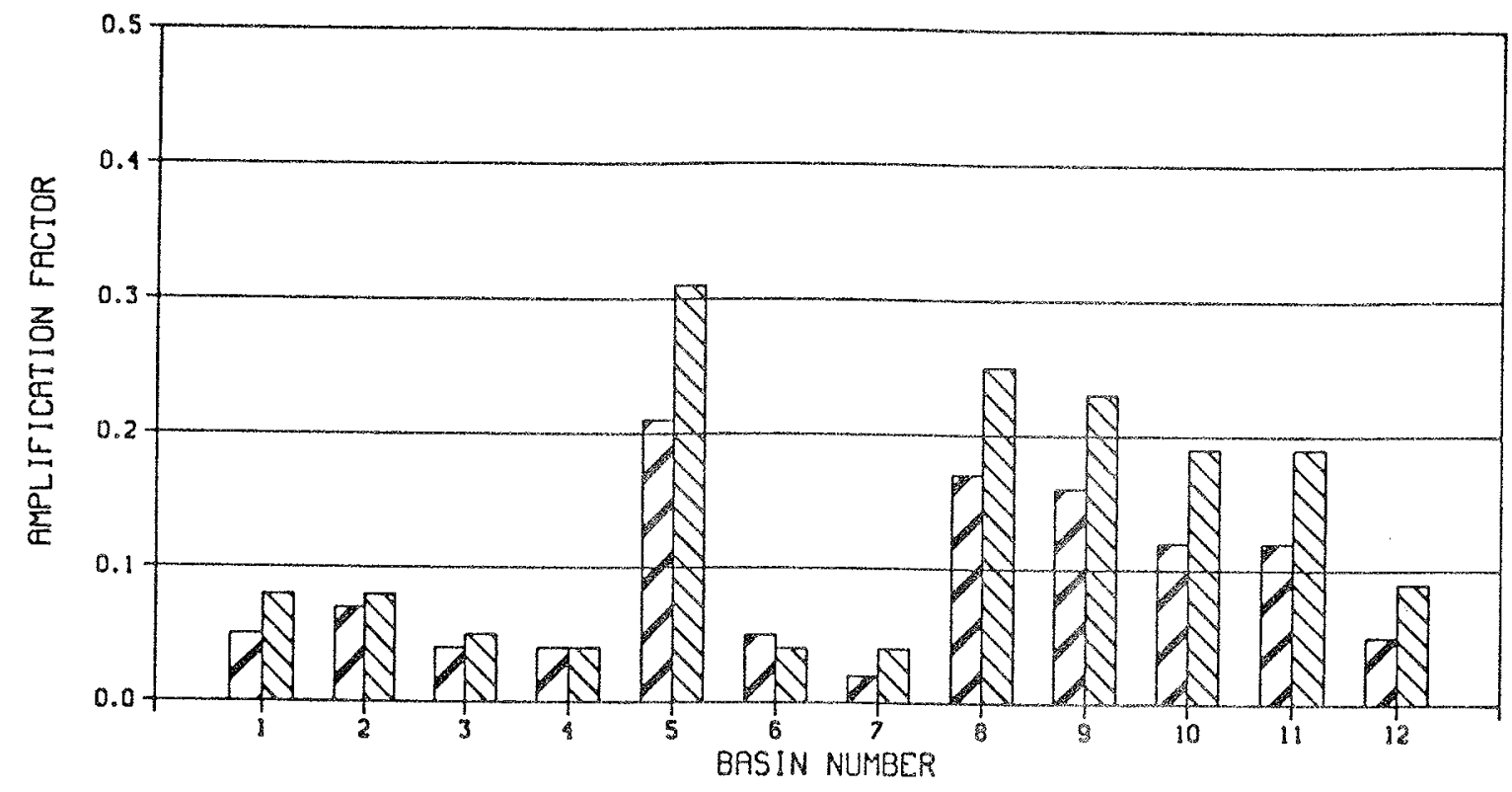

HARBOR ENTRANCE CHANNEL AND TURNING BASIN

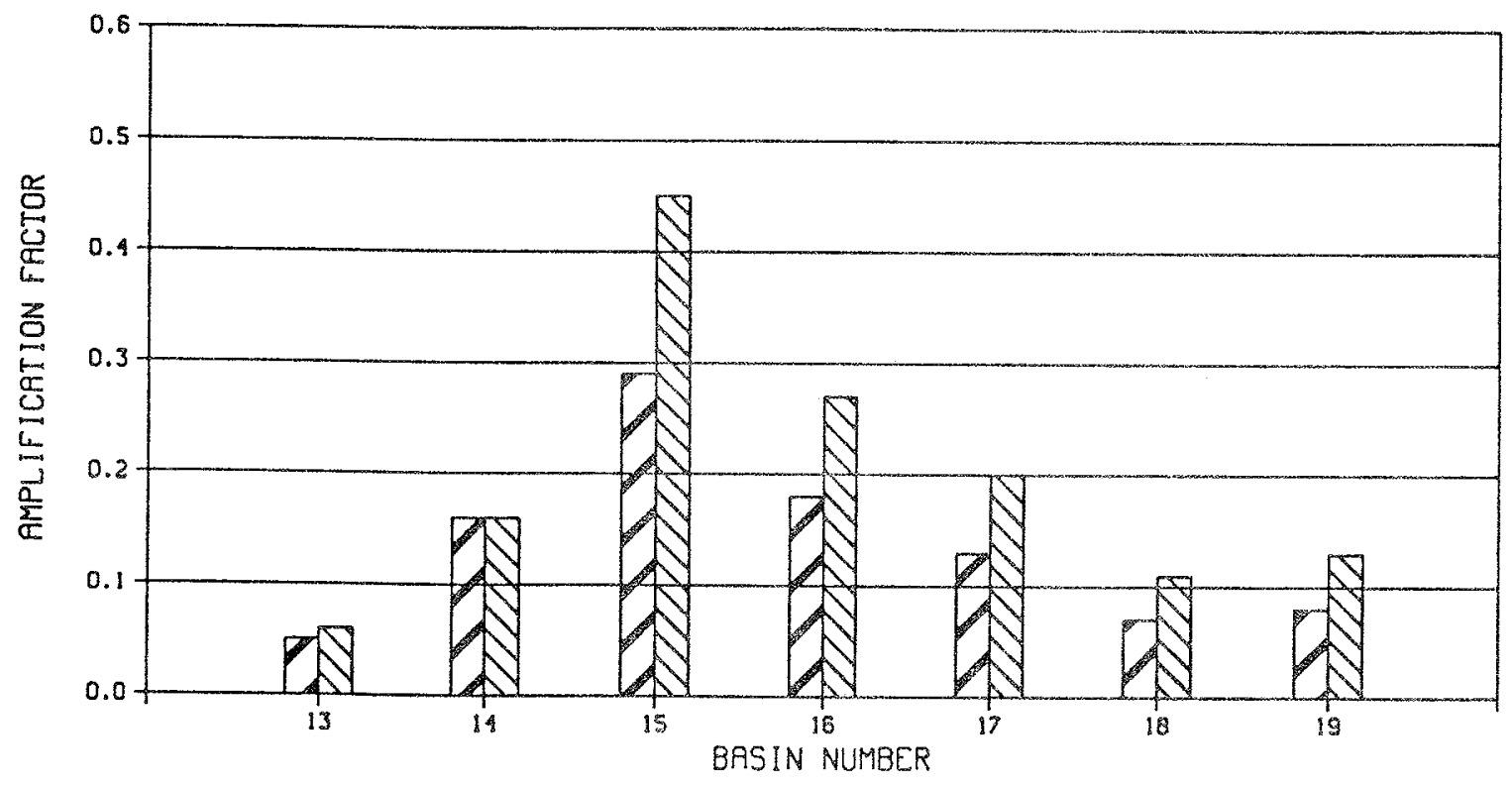

LEGEND

[D PLAN 1

$\triangle \nabla$ PLAN 2
WAVE RMPLIFICATION FACTOR

KAWAIHAE SHALLOW-DRAFT HRRBOR, HI WAVE PERIOO = 11 sEC WRVE DIRECTION - 315 deg 


\section{HARBOR BERTHING AREAS}

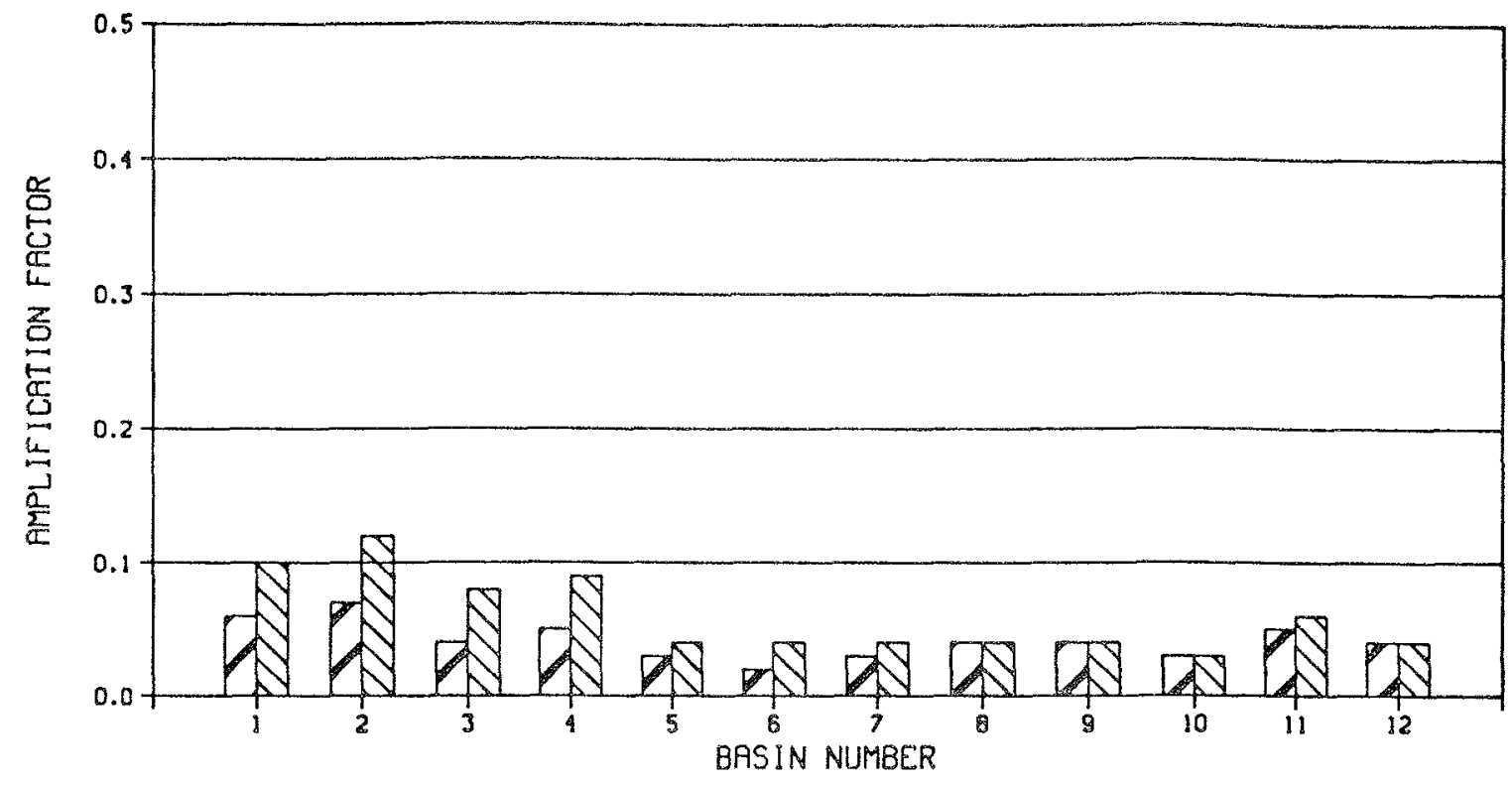

HARBOR ENTRANCE CHANNEL AND TURNING BASIN

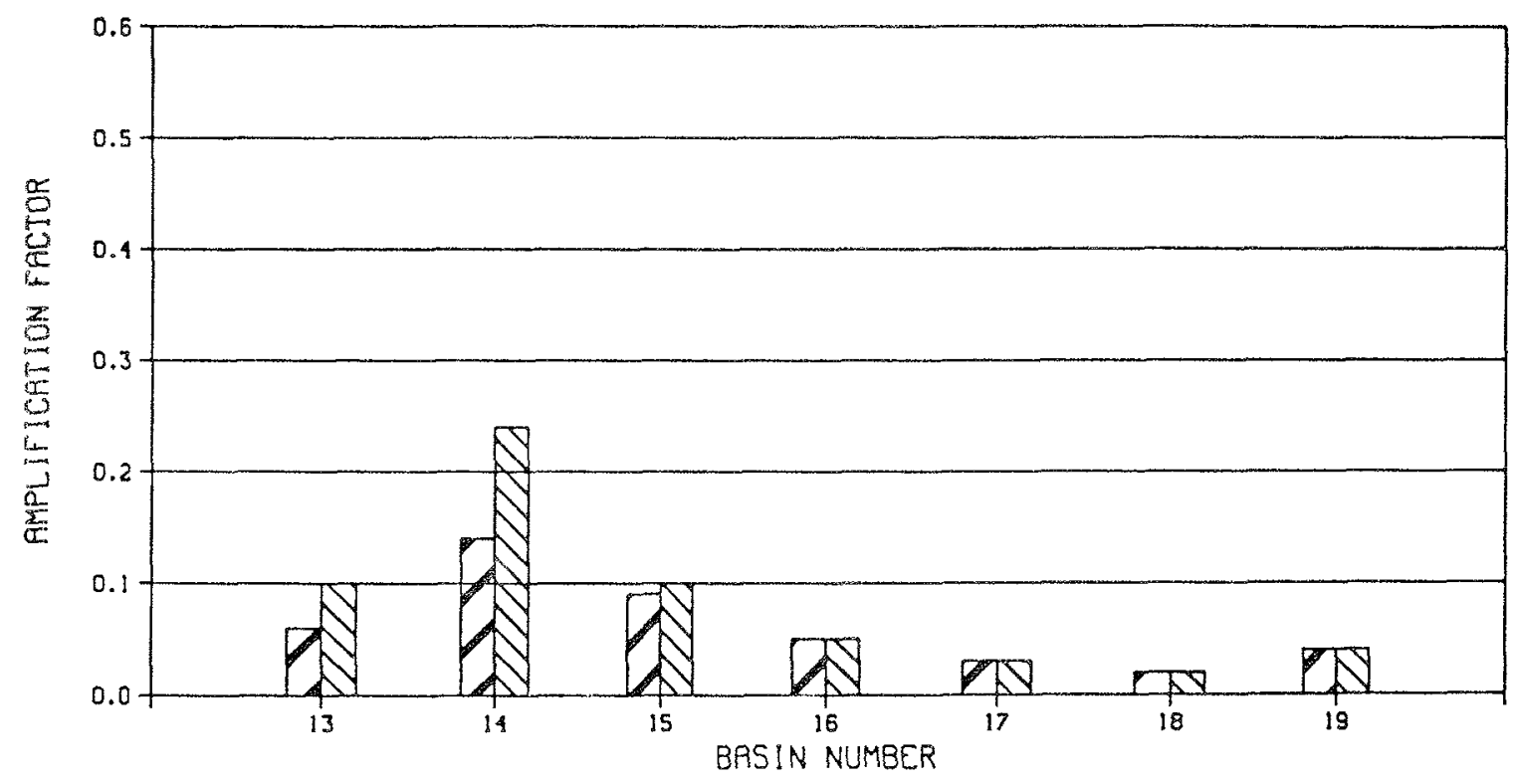

LEGEND

PLAN 1

$\triangle$ PLAN 2
WAVE RMPLIF ICATION FACTOR KAWAIHAE SHALLOW-DRAFT HARBOR, HI WAVE PERIDO - $13 \mathrm{sec}$ WAVE DIRECTION - $315 \mathrm{deg}$ 
HARBOR BERTHING AREAS

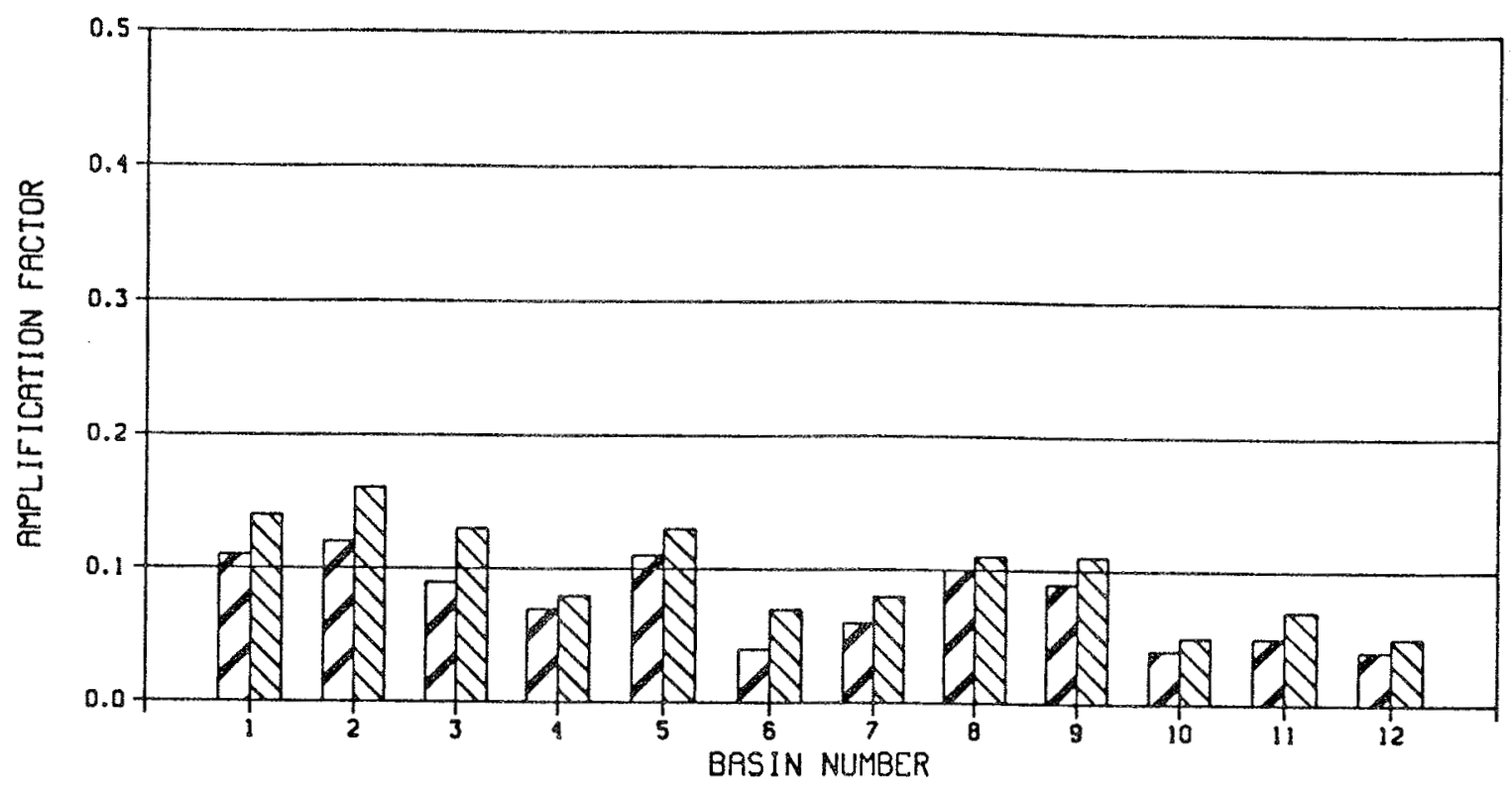

HARBOR ENTRANCE CHANNEL AND IURNING BASIN

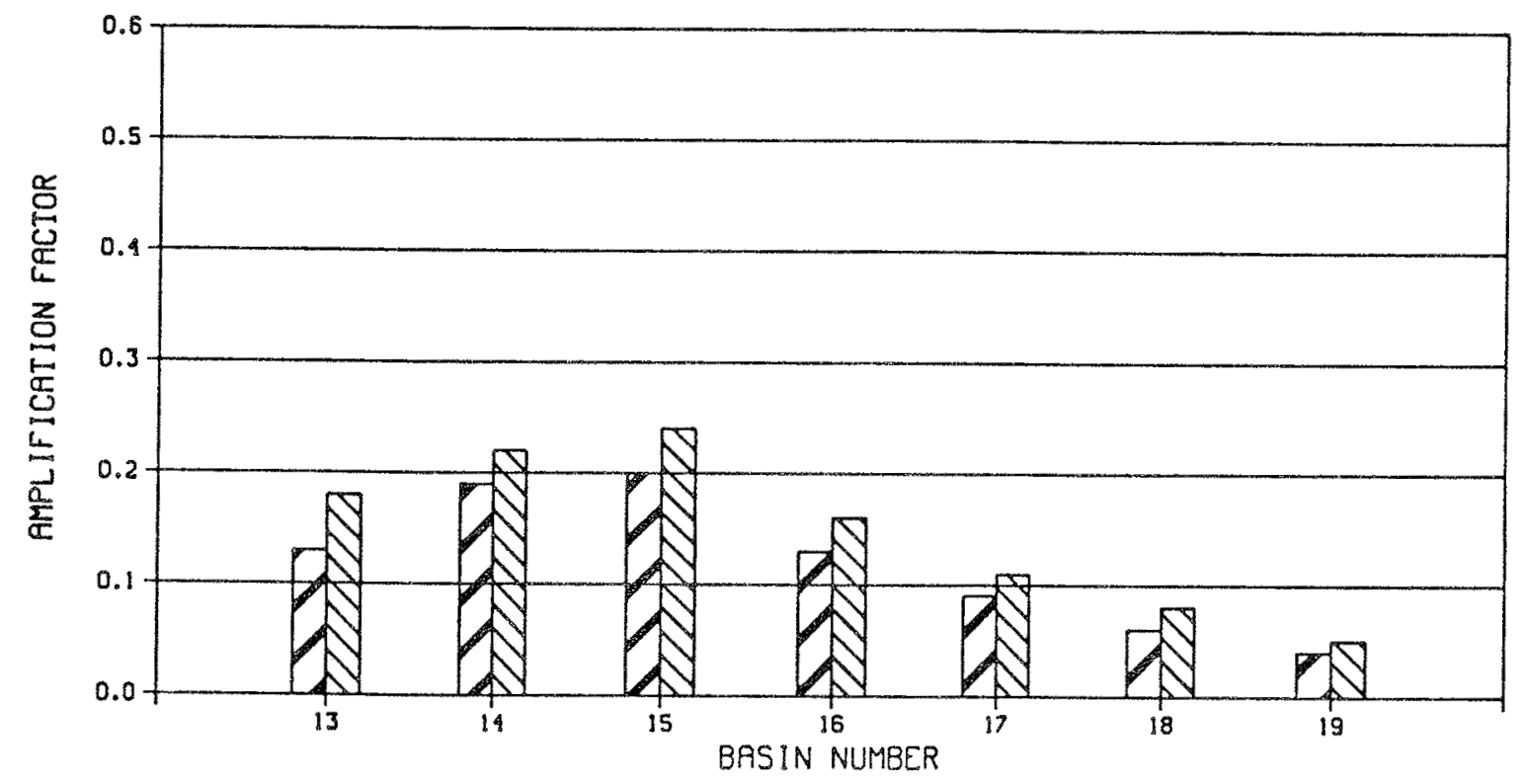

LEGEND

L2 PLAN 1

$\triangle$ PLAN 2
WAVE RMPLIFICATION FACTOR

KAWRIHAE SHFLLOW-DRAFT HRRBOR, $\mathrm{H}$ ! WRVE PERIDD - $15 \mathrm{sec}$

WRVE DIRECTION -315 deg 
HARBOR BERTHING RREAS

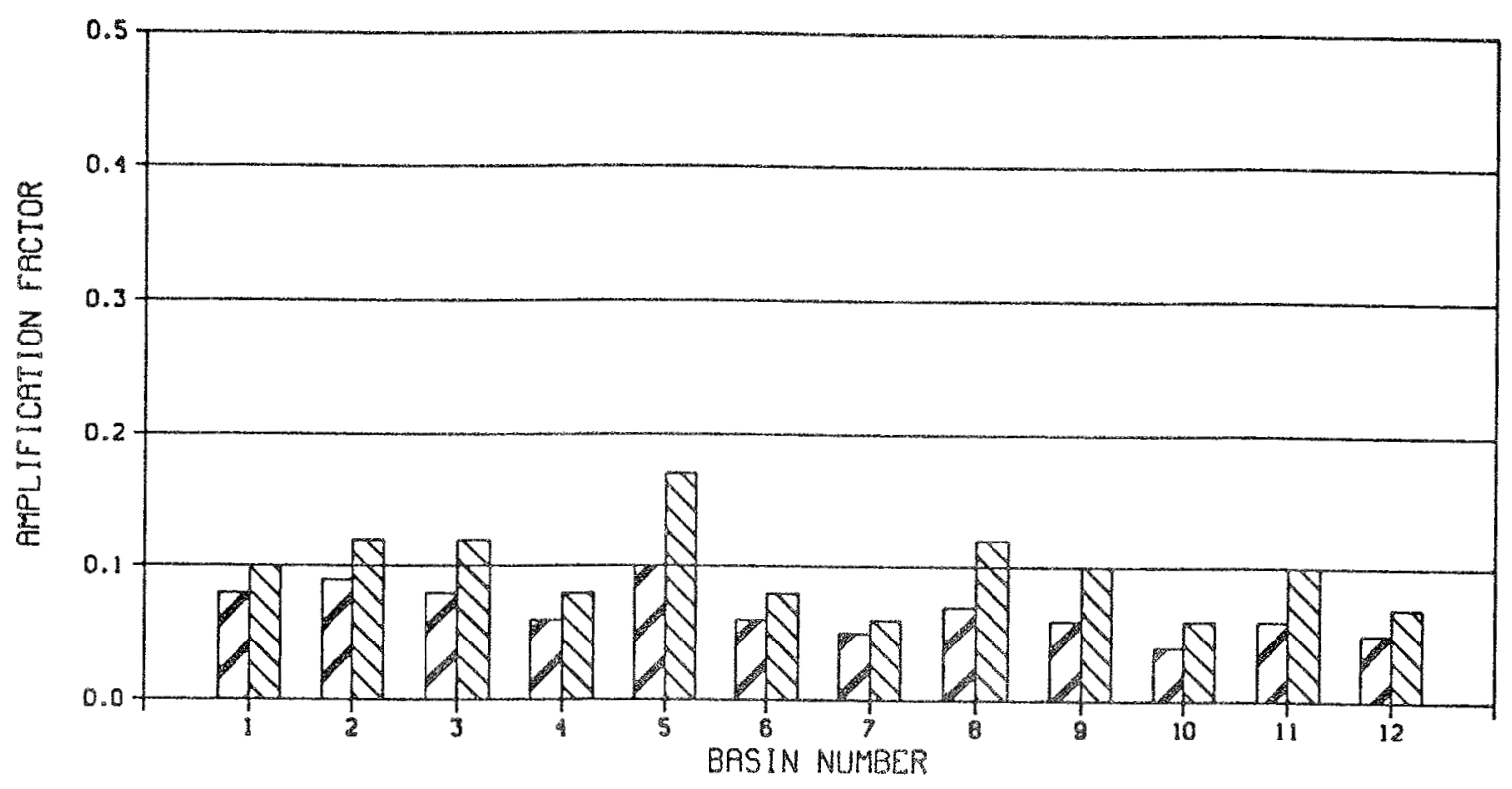

HARBOR ENTRANCE CHANNEL RND TURNING BASIN

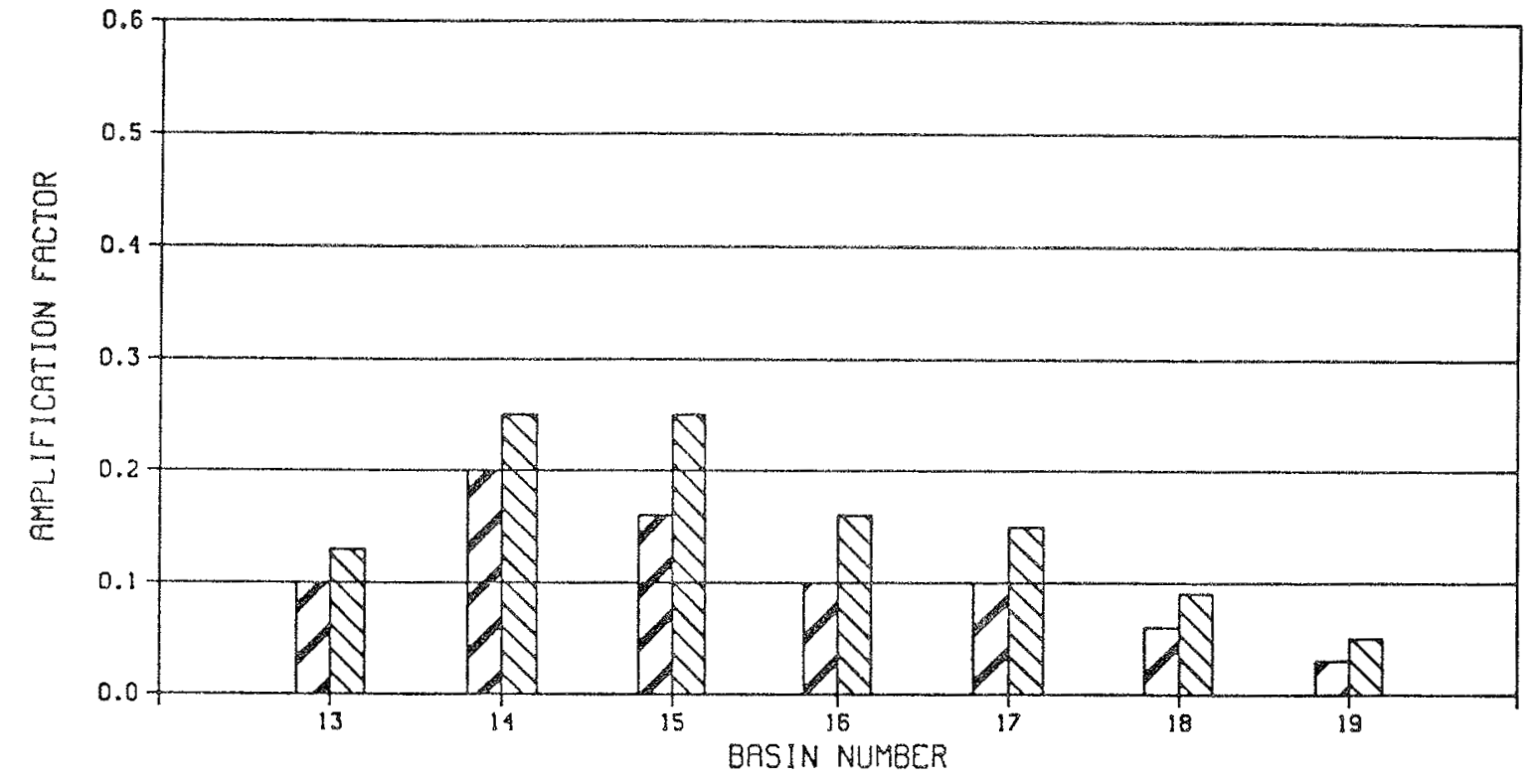

LEGEND

2] PLAN 1

$\triangle 8$ PLAN 2
WAVE RMPLIFICATION FRCTOR

KAWAIHAE SHRLLOW-ORAFT HARBOR, HI WRVE PERIOD $-17 \mathrm{seC}$ WRVE DIRECTION $=315 \mathrm{deg}$ 
HARBOR BERTHING AREAS

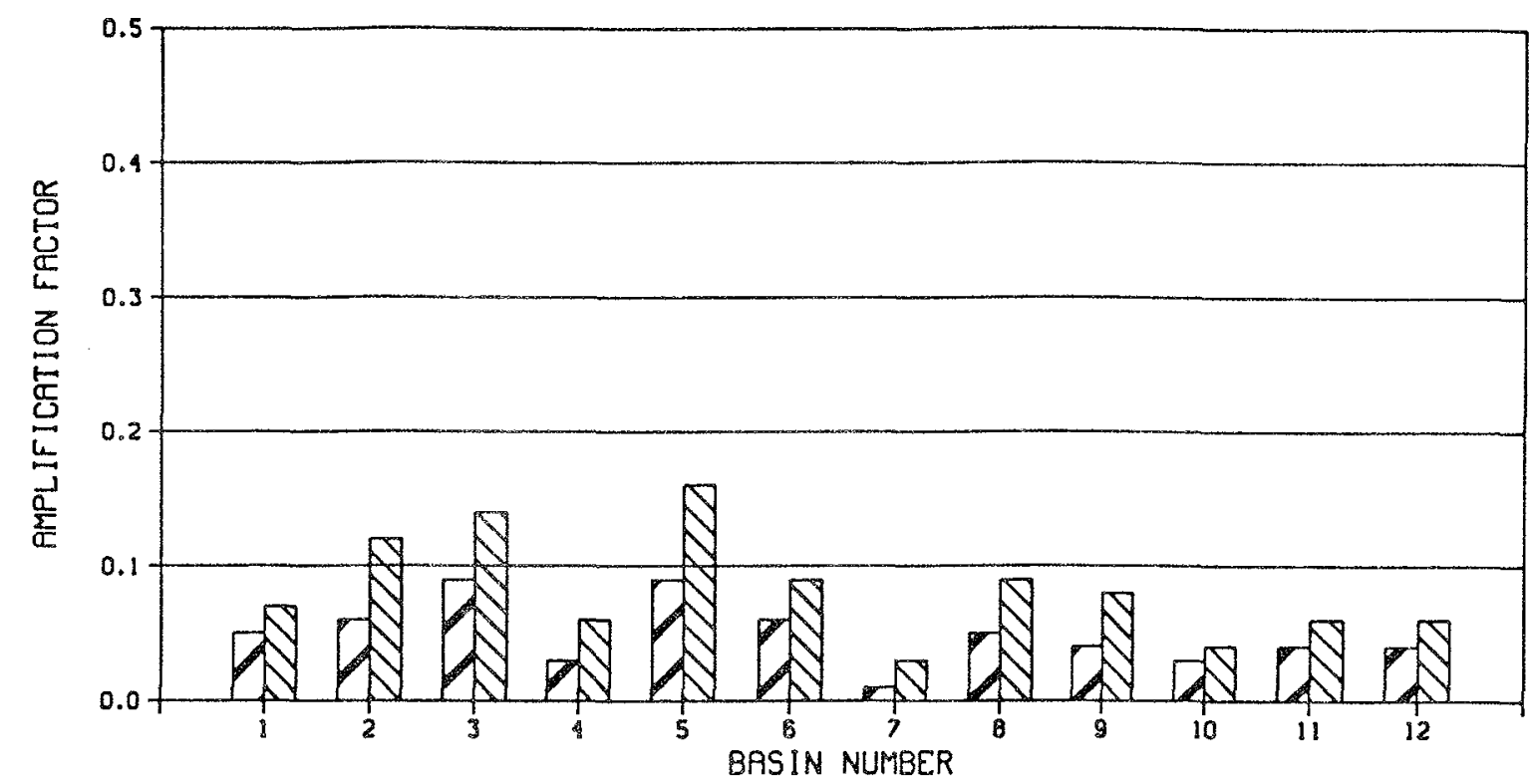

HARBOR ENTRANCE CHRNNEL AND TURNING BRSIN

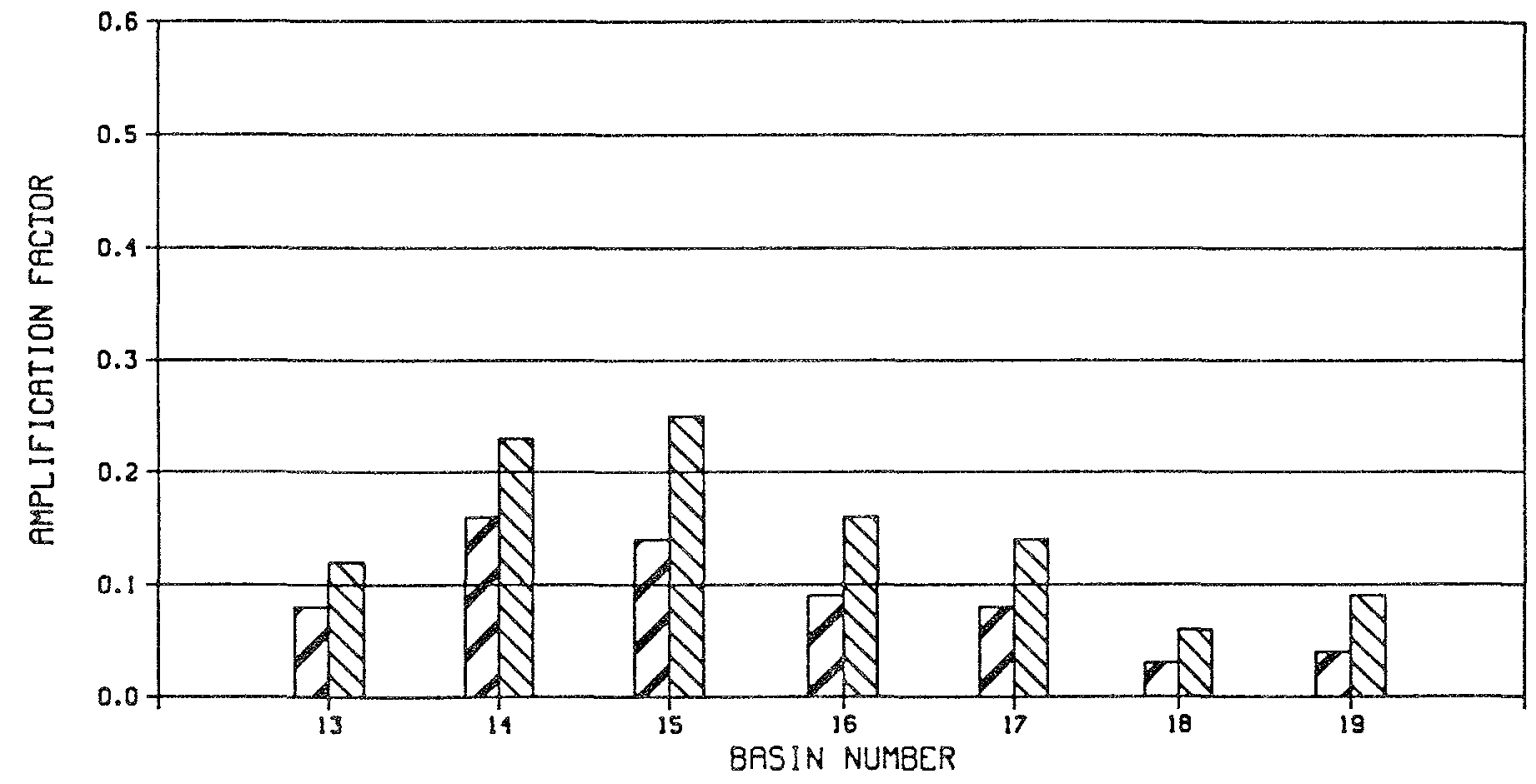

LEGEND

D PLPN 1

$\triangle 8$ PLAN 2
WAVE AMPLIFICATION FACTOR KAWAIHAE SHRLLOW-DRAFT HARBOR, HI HAVE PERIOD $=20 \mathrm{sec}$ WAVE DIRECTION - 315 deg 
HRRBOR BERTHING AREAS

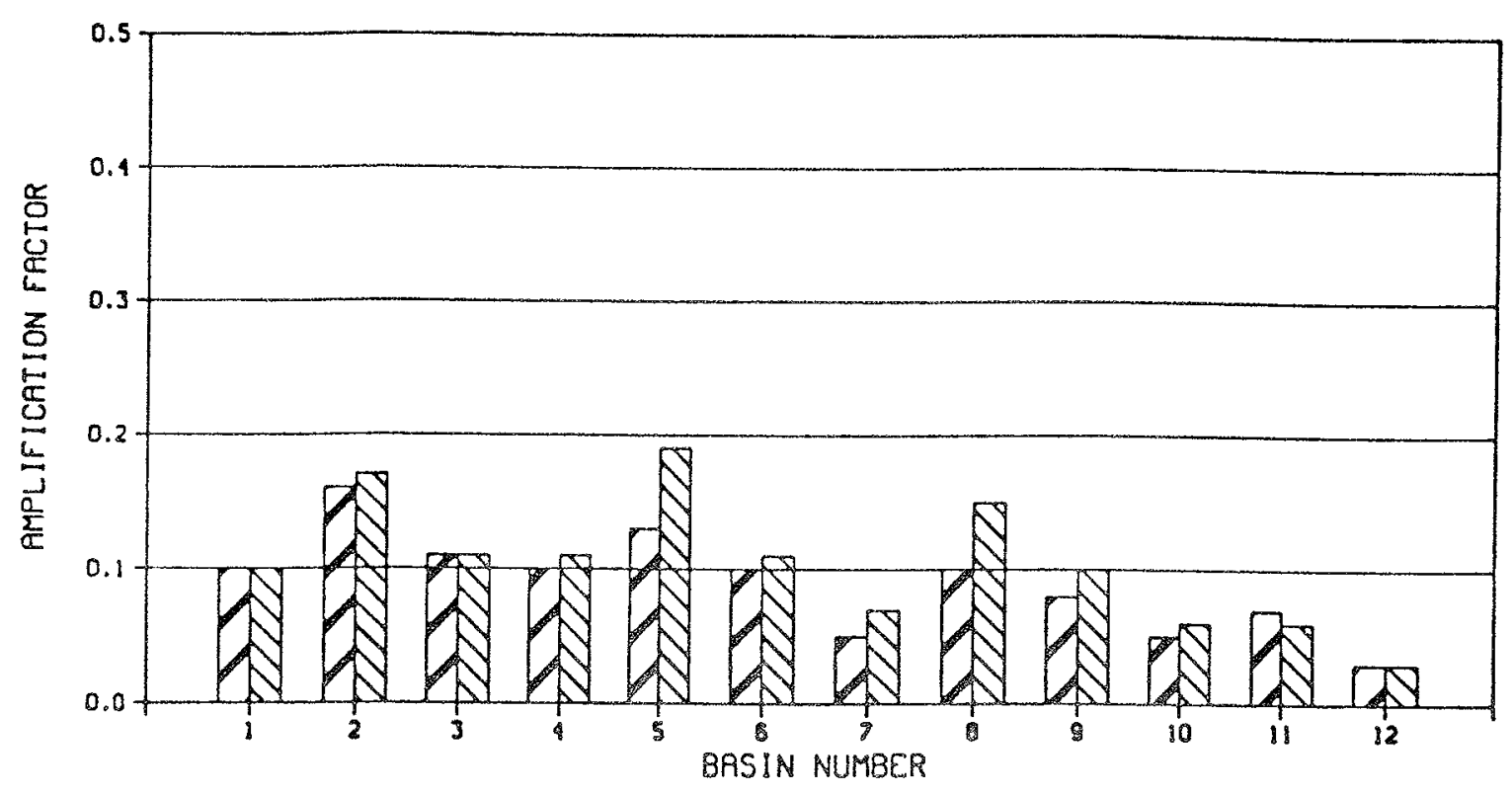

HARBOR ENTRANCE CHRNNEL AND TURNING BASIN

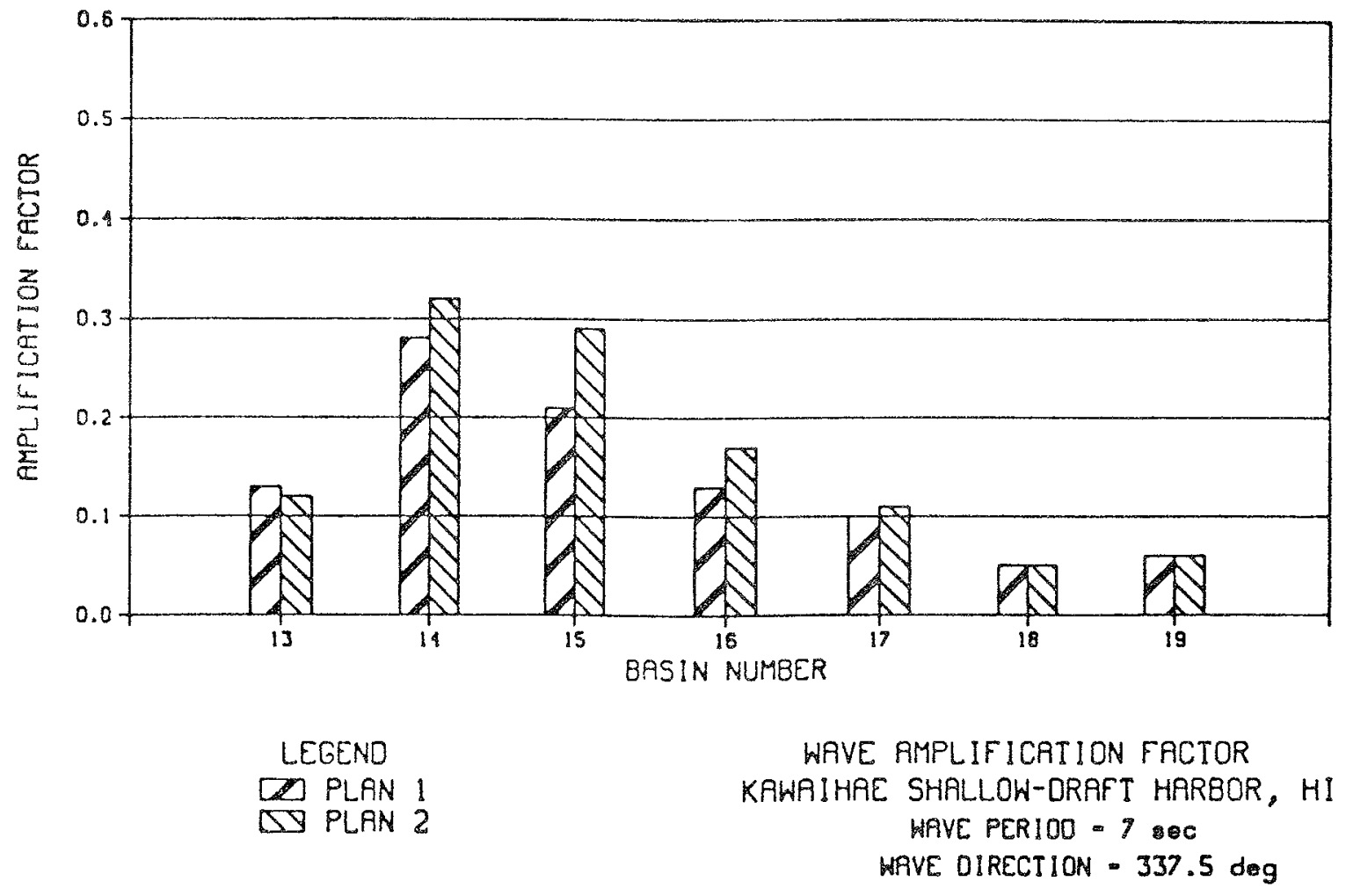


APPENDIX A: OFFSHORE WAVE CLIMATE PERCENT OCCURRENCE TABLES 
Table A-1

Percent Occurence of Height and Period by Direction"

Wave Direction $=202.5 \mathrm{deg}$ (from which waves approach)

\begin{tabular}{|c|c|c|c|c|c|c|c|c|c|}
\hline Wave Height & & & & ak $\mathrm{Pe}$ & od (s & & & & \\
\hline ft & 5 & 7 & 9 & 11 & 13 & 15 & 17 & 20 & Total \\
\hline $0-3$ & $*$ & 0.01 & 0.01 & 0.01 & 0.01 & $*$ & $*$ & * & 0.04 \\
\hline $3-6$ & $*$ & $*$ & * & $*$ & 0.01 & * & * & $*$ & 0.02 \\
\hline $6-9$ & $*$ & 0.01 & * & * & * & * & * & $*$ & 0.02 \\
\hline $9-12$ & . & $*$ & . & . & . & . & . & . & $*$ \\
\hline $12-15$ & . & . & $*$ & . & . & . & . & . & $*$ \\
\hline$>15$ &. &. &. &. &. &. & 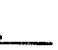 & 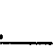 & 0.00 \\
\hline Total & $*$ & 0.03 & 0.01 & 0.01 & 0.02 & 0.01 & $*$ & * & 0.08 \\
\hline
\end{tabular}

Table A-2

Percent Occurence of Height and Period by Direction

Wave Direction $=225.0 \mathrm{deg}$ (from which waves approach)

\begin{tabular}{|c|c|c|c|c|c|c|c|c|c|}
\hline \multirow{2}{*}{$\begin{array}{l}\text { Wave Height } \\
\mathrm{ft}\end{array}$} & \multicolumn{8}{|c|}{ Peak Period (sec) } & \multirow[b]{2}{*}{ Total } \\
\hline & 5 & 7 & 9 & 11 & 13 & 15 & 17 & 20 & \\
\hline $0-3$ & * & 0.02 & 0.02 & 0.02 & 0.03 & 0.01 & * & * & 0.10 \\
\hline $3-6$ & * & 0.01 & 0.01 & 0.01 & 0.01 & 0.02 & 0.01 & $*$ & 0.07 \\
\hline $6-9$ & $*$ & 0.02 & * & * & $*$ & * & * & $*$ & 0.02 \\
\hline $9-12$ & . & 0.02 & . & . & . & . & . & . & 0.02 \\
\hline $12-15$ & . & $*$ & 0.01 & . & . & . & . & . & 0.01 \\
\hline$>15$ &. & . & 0.02 & . & . & .. & $\ldots$ & - & 0.02 \\
\hline Total & * & 0.07 & 0.06 & 0.03 & 0.04 & 0.03 & 0.01 & * & 0.24 \\
\hline
\end{tabular}

* Percent occurrence is below table resolution 
Table A-3

Percent Occurence of Height and Period by Direction ${ }^{*}$

Wave Direction $=247.5 \mathrm{deg}$ (from which waves approach)

\begin{tabular}{|c|c|c|c|c|c|c|c|c|c|}
\hline \multirow{2}{*}{$\begin{array}{c}\text { Wave Height } \\
\mathrm{ft}\end{array}$} & \multicolumn{8}{|c|}{ Peak Period (sec) } & \multirow[b]{2}{*}{ Total } \\
\hline & 5 & 7 & 9 & 11 & 13 & 15 & 17 & 20 & \\
\hline $0-3$ & 0.01 & 0.03 & 0.02 & 0.02 & 0.03 & 0.02 & * & * & 0.13 \\
\hline $3-6$ & $*$ & 0.02 & 0.01 & 0.01 & 0.02 & 0.02 & 0.01 & * & 0.09 \\
\hline $6-9$ & 0.01 & 0.02 & $*$ & 0.02 & $*$ & $*$ & $*$ & * & 0.05 \\
\hline $9-12$ & . & 0.02 & 0.01 & 0.01 & . & . & . & . & 0.04 \\
\hline $12-15$ & . & 0.01 & * & . & $*$ & . & . & . & 0.01 \\
\hline$>15$ & . & $\ldots$ & 0.01 & . & $\cdot$ & $\cdot$ & .. & . & $*$ \\
\hline Total & 0.02 & 0.10 & 0.05 & 0.06 & 0.05 & 0.04 & 0.01 & $*$ & 0.33 \\
\hline
\end{tabular}

Table A-4

Percent Occurence of Height and Period by Direction

Wave Direction $=270.0 \mathrm{deg}$ (from which waves approach)

\begin{tabular}{|c|c|c|c|c|c|c|c|c|c|}
\hline \multirow{2}{*}{$\begin{array}{c}\text { Wave Height } \\
\mathrm{ft}\end{array}$} & \multicolumn{8}{|c|}{ Peak Period (sec) } & \multirow[b]{2}{*}{ Tota1 } \\
\hline & 5 & 7 & 9 & 11 & 13 & 15 & 17 & 20 & \\
\hline $0-3$ & 0.02 & 0.06 & 0.05 & 0.05 & 0.08 & 0.04 & 0.01 & $*$ & 0.31 \\
\hline $3-6$ & 0.01 & 0.04 & 0.02 & 0.03 & 0.05 & 0.04 & 0.01 & $*$ & 0.20 \\
\hline $6-9$ & 0.01 & 0.03 & 0.03 & 0.03 & 0.01 & $*$ & $*$ & $*$ & 0.11 \\
\hline $9-12$ & . & 0.03 & $*$ & 0.03 & 0.03 & . & . & . & 0.09 \\
\hline $12-15$ & . & $*$ & $*$ & . & 0.01 & . & . & . & 0.01 \\
\hline$>15$ & . & . & 0.01 & $*$ & 0.01 &. &. & . & 0.02 \\
\hline Total & 0.04 & 0.16 & 0.11 & 0.14 & 0.19 & 0.08 & 0.02 & $*$ & 0.74 \\
\hline
\end{tabular}

* Percent occurrence is below table resolution 
Table A-5

Percent Occurence of Height and Period by Direction ${ }^{*}$ Wave Direction $=292.5 \mathrm{deg}$ (from which waves approach)

\begin{tabular}{|c|c|c|c|c|c|c|c|c|c|}
\hline \multicolumn{2}{|c|}{ Wave Height } & \multicolumn{7}{|c|}{ Peak Period (sec) } & \multirow[b]{2}{*}{ Total } \\
\hline $\mathrm{ft}$ & 5 & 7 & 9 & 11 & 13 & 15 & 17 & 20 & \\
\hline $0-3$ & 0.12 & 0.55 & 0.45 & 0.47 & 0.71 & 0.34 & 0.09 & 0.02 & 2.75 \\
\hline $3-6$ & 0.04 & 0.34 & 0.23 & 0.28 & 0.41 & 0.37 & 0.13 & 0.02 & 1.82 \\
\hline $6-9$ & $*$ & 0.04 & 0.05 & 0.07 & 0.12 & 0.04 & 0.01 & 0.01 & 0.34 \\
\hline $9-12$ & . & 0.01 & 0.02 & 0.28 & 0.69 & 0.02 & $x$ & . & 1.02 \\
\hline $12-15$ & . & 0.01 & 0.01 & 0.03 & 0.34 & 0.08 & $*$ & . & 0.47 \\
\hline$>15$ &. & . &. & $*$ & 0.03 & 0.03 & - & . & 0.06 \\
\hline Total & 0.16 & 0.95 & 0.76 & 1.13 & 2.30 & 0.88 & 0.23 & 0.05 & 6.46 \\
\hline
\end{tabular}

Table A-6

Percent Occurence of Height and Period by Direction

Wave Direction $=315.0 \mathrm{deg}$ (from which waves approach)

\begin{tabular}{|c|c|c|c|c|c|c|c|c|c|}
\hline \multirow{2}{*}{$\begin{array}{c}\text { Wave Height } \\
\mathrm{ft}\end{array}$} & \multicolumn{8}{|c|}{ Peak Period (sec) } & \multirow[b]{2}{*}{ Total } \\
\hline & 5 & 7 & 9 & 11 & 13 & 15 & 17 & 20 & \\
\hline $0-3$ & 0.72 & 3.37 & 2.79 & 2.85 & 4.34 & 2.10 & 0.58 & 0.12 & 16.86 \\
\hline $3-6$ & 0.28 & 2.06 & 1.74 & 1.96 & 2.51 & 2.26 & 0.81 & 0.15 & 11.74 \\
\hline $6-9$ & 0.02 & 0.17 & 0.37 & 2.13 & 1.59 & 0.27 & 0.05 & 0.05 & 4.61 \\
\hline $9-12$ & . & 0.01 & 0.03 & 0.80 & 3.98 & 0.71 & 0.03 & . & 5.56 \\
\hline $12-15$ & . & . & $*$ & 0.08 & 1.13 & 0.74 & 0.07 & . & 2.02 \\
\hline$>15$ &. & . & . &. & 0.11 & 0.22 & 0.12 &. & 0.45 \\
\hline Total & 1.02 & 5.61 & 4.92 & 7.82 & 13.66 & 6.30 & 1.66 & 0.32 & 41.31 \\
\hline
\end{tabular}

* Percent occurrence is below table resolution 
Table A-7

Percent Occurence of Height and Period by Direction ${ }^{*}$

Wave Direction $=337.5 \mathrm{deg}$ (from which waves approach)

\begin{tabular}{|c|c|c|c|c|c|c|c|c|c|}
\hline \multicolumn{2}{|c|}{ Wave Height } & \multicolumn{7}{|c|}{ Peak Period (sec) } & \multirow[b]{2}{*}{ Tota] } \\
\hline $\mathrm{ft}$ & 5 & 7 & 9 & 11 & 13 & 15 & 17 & 20 & \\
\hline $0-3$ & 0.89 & 4.22 & 3.44 & 3.53 & 5.36 & 2.58 & 0.72 & 0.14 & 20.88 \\
\hline $3-6$ & 0.39 & 2.67 & 2.99 & 2.89 & 3.15 & 2.79 & 1.00 & 0.17 & 16.05 \\
\hline $6-9$ & 0.04 & 0.22 & 1.24 & 3.59 & 1.93 & 0.39 & 0.06 & 0.05 & 7.52 \\
\hline $9-12$ & . & 0.03 & 0.06 & 1.09 & 3.48 & 0.57 & 0.07 & . & 5.30 \\
\hline $12-15$ & . & . & $*$ & 0.08 & 0.53 & 0.42 & 0.07 & . & 1.10 \\
\hline$>15$ &. &. & $\ldots$ &. &. & . & . & $\ldots$ & $*$ \\
\hline Total & 1.32 & 7.14 & 7.73 & 11.18 & 14.45 & 6.75 & 1.92 & 0.36 & 50.85 \\
\hline
\end{tabular}

$*$ Percent occurrence is below table resolution 
APPENDIX B: NOTATION 


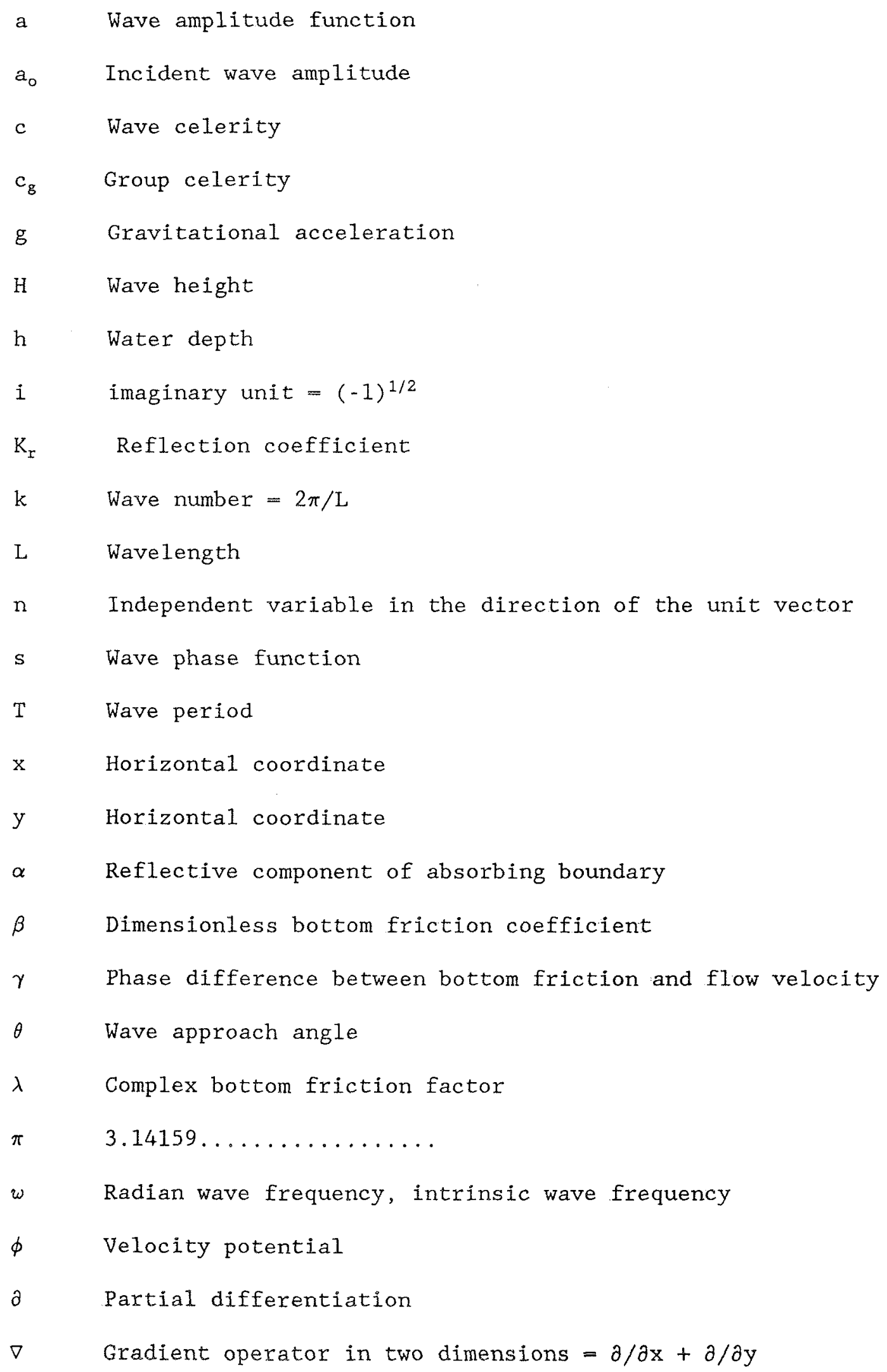

